\title{
PONTES PROTENDIDAS DE MADEIRA
}

Eng. DENER GONÇALVES PRATA

Tese apresentada à Escola de Engenharia de São Carlos, da Universidade de São Paulo, como parte dos requisitos para obtenção do Título de Doutor em Engenharia Estrutural.

ORIENTADOR: Prof. Titular Carlito Calil Junior 


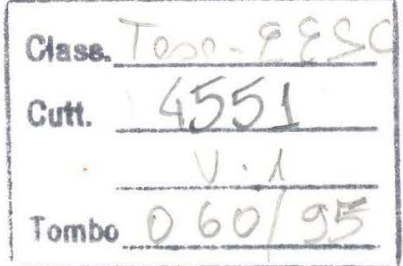

1t 0742550

Prata, Dener Gonçalves

P912p Pontes protendidas de madeira / Dener Gonçalves Prata.São Carlos, 1995.

$2 v$.

Tese (Doutorado) - Escola de Engenharia de São Carlos Universidade de São Paulo, 1995

Orientador: Prof. Dr. Carlito Calil Junior

1. Pontes de madeira. 2. Estruturas protendidas. I. Título 
à Miwako

companheira e amiga. 


\section{AGRADECIMENTOS}

O autor agradece a colaboração dada pelas empresas:

PREMA SIA, de RIO CLARO - SP, pelo fornecimento da madeira utilizada na experimentação aqui desenvolvida.

PROTENDIDOS DYWIDAG DO BRASIL LTDA, de SÃO PAULO SP, pela cessão dos materiais empregados na experimentação: cilindro hidráulico, barras roscadas com passo tratado, porcas e placas de ancoragem.

O autor agradece a aportunidade oferecida pelo Departamento de Estruturas, da Escola de Engenharia de São Carlos, de ver este trabalho desenvolvido em suas dependências, no Laboratório de Madeiras e de Estruturas de Madeira (LaMEM).

O autor agradece também a colaboração intensa, dedicada e amiga, do Prof. Titular Carlito Calil Júnior, que foi luz nos dificeis momentos vivenciados na confecção desta tese, particularmente neste ano que passou.

O autor deixa registrado o carinho dedicado pelos funcionários do LaMEM, técnicos e administrativos, que foram decisivos à realização desta Tese.

O autor agradece também o trabalho de apoio dado pela arquiteta Cristina M. Perissinoto Baron e pelos engenheirandos Giani M. Pfister e Fernando Sérgio Okimoto na edição de mais este trabalho. 


\section{SUMÁRIO}

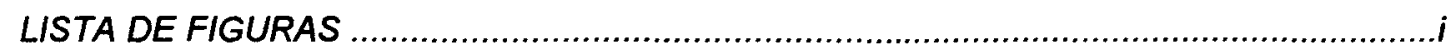

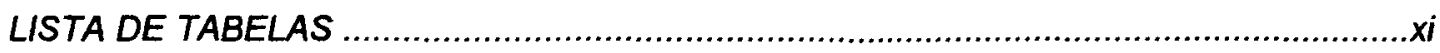

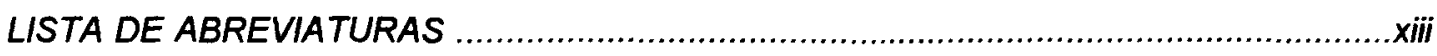

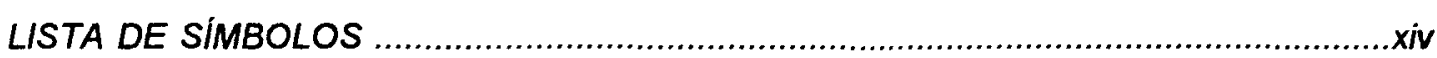

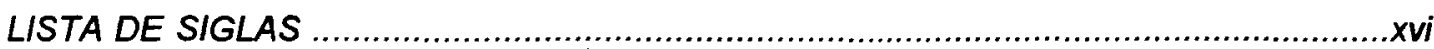

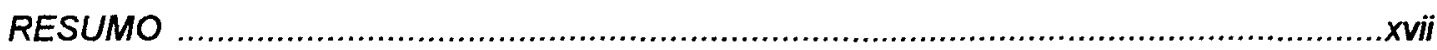

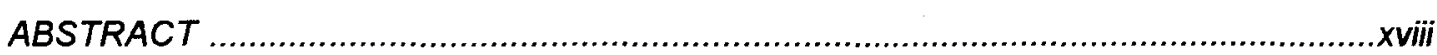

1. SISTEMAS ESTRUTURAIS DE PONTES DE MADEIRA ......................................

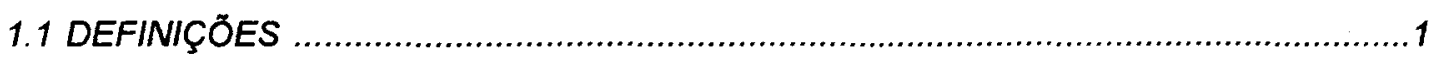

1.2 FORMAS ESTRUTURAIS DE PONTES ........................................................

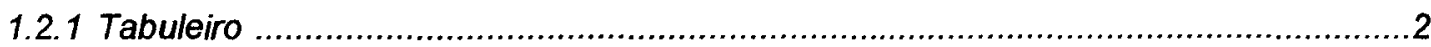

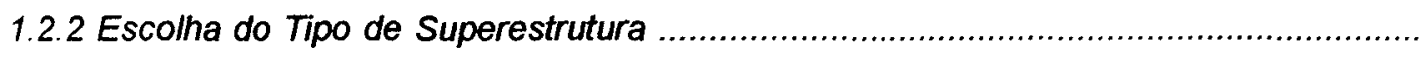

1.3 VARIEDADE DE FORMAS

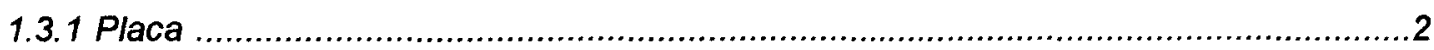

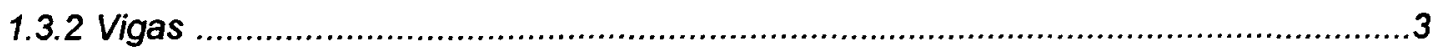

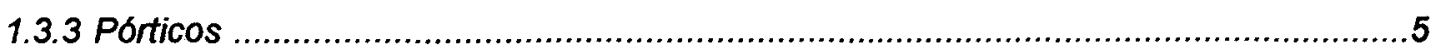

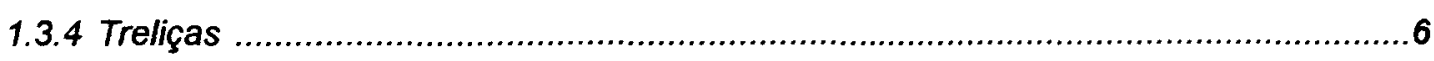

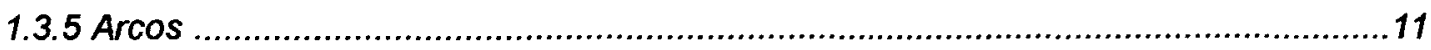

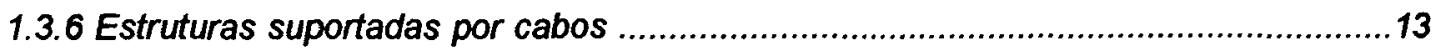

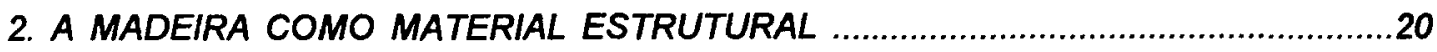

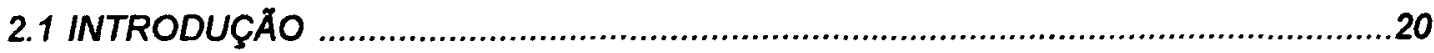

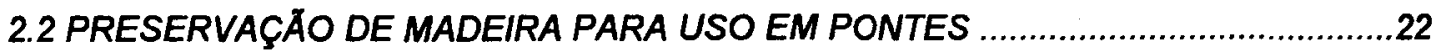

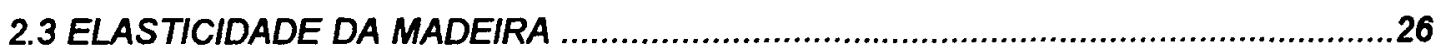

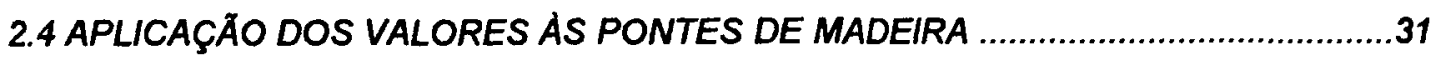

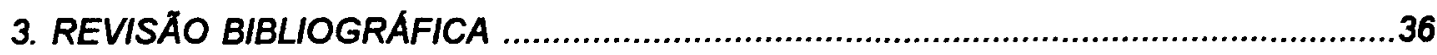

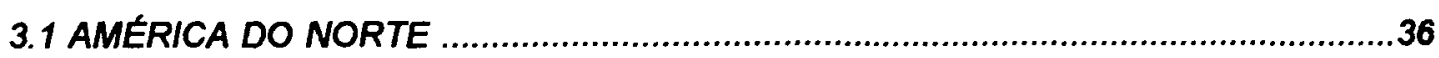

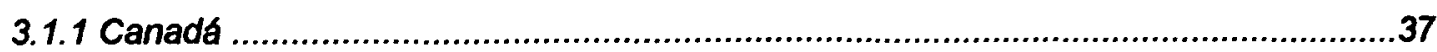

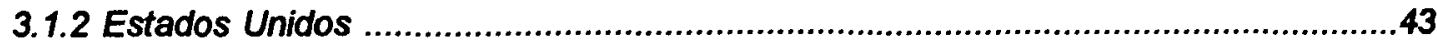

3.1.2.1 American Institute of Timber Construction .......................................................43

3.1.2.2 American Association of State Higways and Transportation Officials (AASHTO)....44 3.1.2.3 Federal Highway Administration(FHWA) e o Transportation Reseach Board(TRB). 44

3.1.2.4 American Raiway Engineering Association (AREA). 


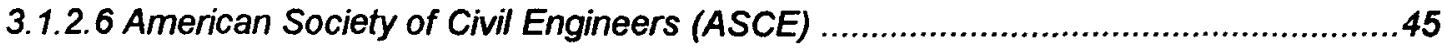

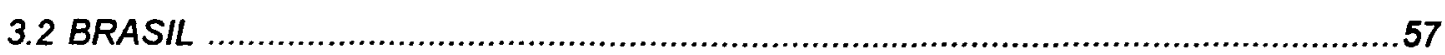

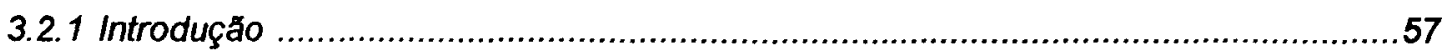

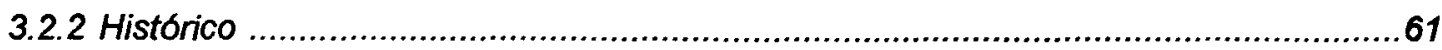

3.2.3 O Laboratorio de Madeiras e de Estruturas de Madeira (LaMEM) ...........................74

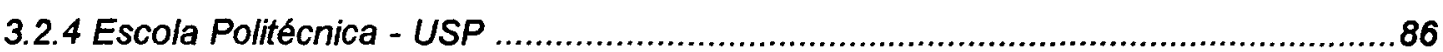

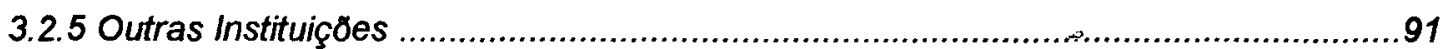

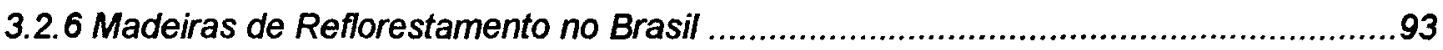

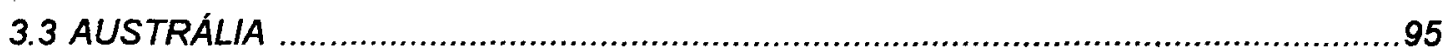

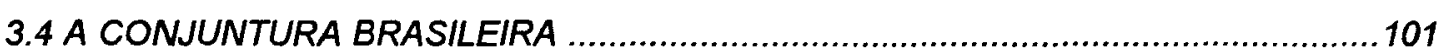

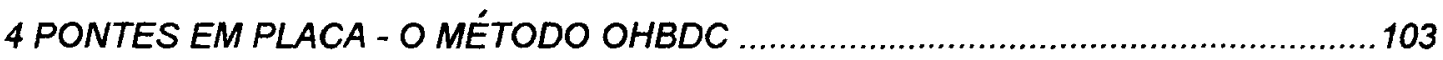

4.1 MÉTODO SIMPLIFICADO PARA DETERMINAÇÃO DE MOMENTOS

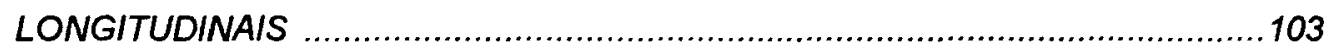

4.1.1 Limitaçסes na Geometria das Pontes ..............................................................106

4.1.2 O Método de Carregamento Ontário ............................................................110

4.1.3 Consideração da Carga Dinâmica ........................................................................115

4.1.4 Base de desenvolvimento do Método Ontário ....................................................117

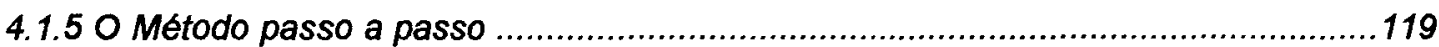

4.1.6 Método Simplificado - Estado Limite de Utilizaçăo Tipo I (SLS I) .............................124

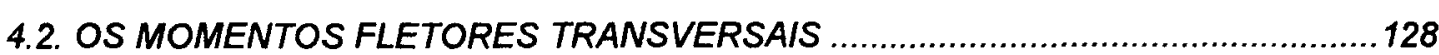

4.2.1 Método Analíticos para Pontes em Placas Sobre Vigas .....................................131

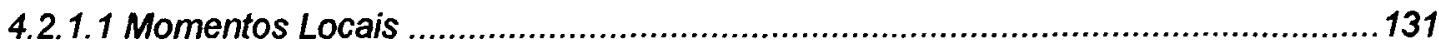

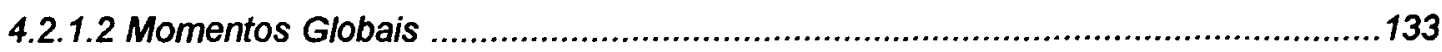

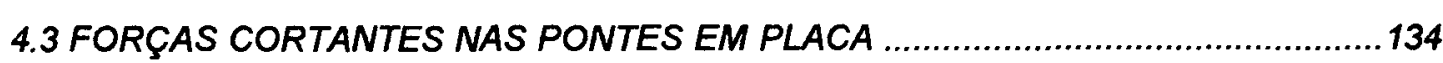

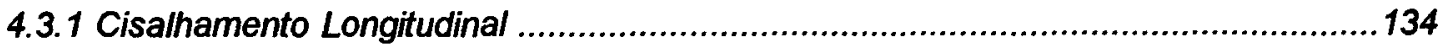

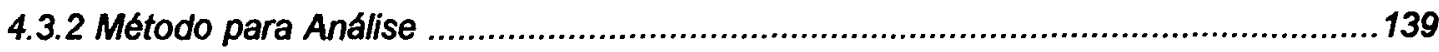

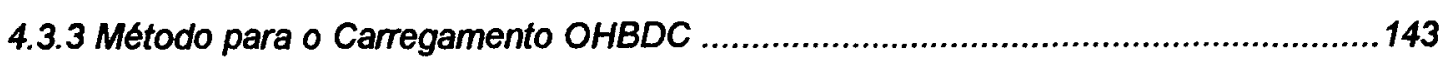

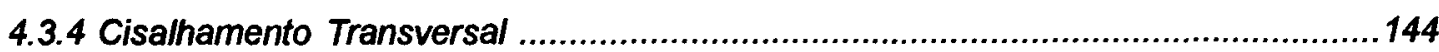

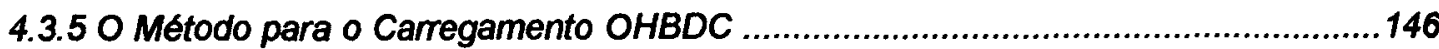

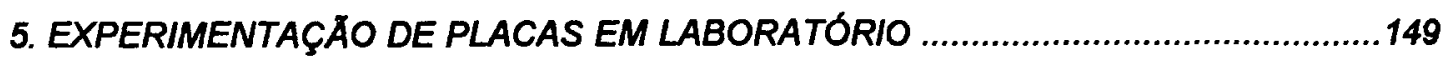

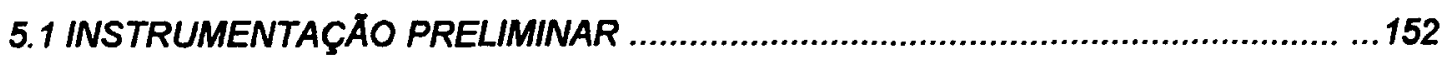

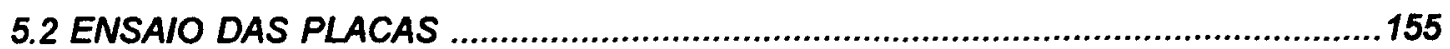

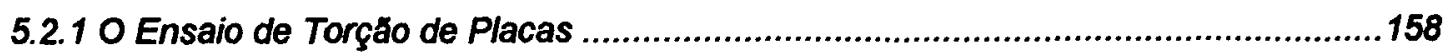

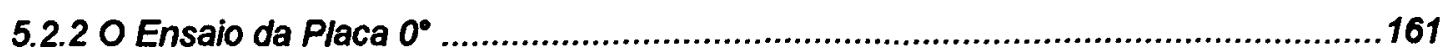

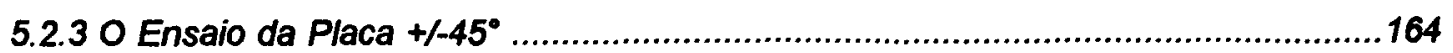

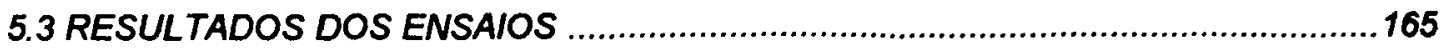


6. CONCLUSÕES

ANEXO A 171

ANEXO B .229

ANEXO C .263

ANEXO D .284

REFERÊNCIAS BIBLIOGRÁFICAS .301 


\section{LISTA DE FIGURAS}

FIGURA 1.1 - Placas de madeira maciça

(a) madeira laminada colada.

(b) madeira laminada atirantada (passiva) e colada.

(c) madeira laminada pregada; há pregos de topo e lateralmente, interconectando as vigas.

(d) madeira atirantada (ativa), nåo colada. 3

FIGURA 1.2 - Vigas de madeira maciça:

(a) Madeira serrada em bruto.

(b) Madeira laminada colada.

(c) Madeira serrada, solidarizada por tarugos ou anéis metálicos e parafusos.

(d) Postes.

(e) Postes combinados, solidarizados por anéis metalicos ou tarugos e parafusos.

FIGURA 1.3 - Vigas de seção composta:

(a) Vigotas de madeira serrada, coladas a uma placa de compensado ou laminado.

(b) Vigas de madeira serrada, coladas ou pregadas a duas placas (caixăo).

(c) Vigas intertravadas por chapas duras de fibra ou laminado.

(d) Vigas de madeira laminada colada fechadas por placas de compensado (caixåo).

.4

FIGURA 1.4 - Grelhas Ortogonais : (a) Planta ortogonal

(b) Planta com esconsidade ( $\phi$ ) .5

FIGURA 1.5 - Porticos longitudinais:

(a) Pórtico acrescentado às vigas

(b) Portico escorado 6

FIGURA 1.6 - Configuraçðes das pontes em treliça:

(a) Treliça ou Arco Treliçado apbiam o piso no plano inferior.

(b) Viga Treliçada, Treliça ou Arco Treliçado apbiam o piso no plano superior. 
FIGURA 1.7 - Componentes das pontes em treliça:

(a) tabuleiro continuo, longitudinal, apoiado em vigas de piso transversais

(b) tabuleiro contínuo, transversal, apoiado em vigas longitudinais que se apóiam em treliças

ou vigas transversais. .8

FIGURA 1.8 - Formas mais comuns de treliças para pontes:
(a) PRATT.
(b) HOWE.
(c) WARREN.
(d) K-Contraventado.
(e) Sistema Contraventado em Losangos.

FIGURA 1.9 - Enrijecimentos dos painéis de treliças para apoio do tabuleiro.

(a) Tabuleiro superior;

(b) Tabuleiro inferior. 10

FIGURA 1.10 - Vigas de seção composta, pregadas:

(a) Disposiçăo construtiva.

(b) Idealizaçăo como treliça. .10

FIGURA 1.11 - Nomenclatura dos elementos da ponte em arco. 11

FIGURA 1.12 - Tipos de ponte em arco. 12

FIGURA 1.13 - Componentes da ponte suportada por cabos:

1. Viga ou treliça de rigidez longitudinal.

2. Sistema de cabos que suporta a base.

3. Torre, que apoia os cabos.

4. Ancoragem para suporte vertical e/ou horizontal dos cabos. 14

FIGURA 1.14 - Ponte Pensil_: (a) Pendurais verticais.

(b) Pendurais inclinados.

(c) Suspensăo combinada. $14 / 15$ 
FIGURA 1.15 - Ponte Estaiada:

(a) Sistema em leque, puro;

(b) Sistema em harpa;

(c) Sistema em leque, modificado. 15

FIGURA 1.16 - Sistemas de ancoragem:

(a) auto-ancorado;

(b) aterrado. .16

FIGURA 1.17 - Sistema com dois planos verticais contendo cabos paralelos longitudinais. 17

FIGURA 1.18 - Sistemas de dois cabos planos: (a) posicionados entre vias de tráfego;

(b) posicionados externamente às vigas. .17

FIGURA 1.19 - Sistemas de quatro cabos em planos paralelos. .18

FIGURA 1.20 - Sistema com um único plano de cabos, central. 18

FIGURA 1.21 - Sistema com dois planos inclinados de cabos. 19

FIGURA 2.1 - Corte esquemático do tronco da árvore mostrando as posiçбes de anisotropia e eixos de referéncia : $L$, longitudinal; $R$, radial; $T$, tangencial, em vigas resultantes do desdobro do tronco. .21

FIGURA 2.2 - Comparaçăo dos processos de preservaçăo d̀ pressăo para a madeira. 24

FIGURA 2.3 - Valor do coeficiente de Torçăo $k$. 34

FIGURA 3.1 - Ponte Ferroviária Moderna .36

FIGURA 3.2 - Ponte ferroviária em madeira com tabuleiro lastrado. 37

FIGURA 3.3 - Ponte ferroviária em tabuleiro aberto. 37 
FIGURA 3.5 - Aspecto estrutural das placas que compoem o pórtico protendido da Ponte em Fox Lake, Ontário.

FIGURA 3.6 - Sistema com tabuleiro celular de madeira. 42

FIGURA 3.7 - Pontes de Madeira Laminada Tensionada, West Virginia University, da TBI.
a) Placa;
b) Placas com Vigas de madeira laminada colada $(\mathrm{m} / \mathrm{c})$;
c) Celular com nervuras de $\mathrm{m} / \mathrm{c}$.

FIGURA 3.8 - Tabuleiro de mit de dupla camada. .51

FIGURA 3.9 - Aspectos principais da Hiroshima Bridge : Vistas das vigas laminadas.
(a) lateral;
(b) seção transversal;
(c) aspecto das torres da ponte;
(d) módulo do sistema de banzos paralelos $.53 / 54$

FIGURA 3.10 - Estrutura Geológica do Territorio Brasileiro. .58

FIGURA 3.11 - Relevo do Temitório Brasileiro, Planicies e Planaltos. 58

FIGURA 3.12 - Bacias hidrográficas no Brasil. 59

FIGURA 3.13 - Mapa com a localizaçåo dos rios Sul-Americanos citados. 60

FIGURA 3.14 - Primeira Ponte Pensil de Chavantes, dois văos treliçados e um văo pênsil de $75 \mathrm{~m}$ (extensăo : $120 \mathrm{~m}$ ).

FIGURA 3.15 (a) Vista Lateral da Terceira Ponte Pensil de Chavantes;

(b) Aspecto dos cabos e das contençoes das transversinas. .63

FIGURA 3.16 - Ponte Grande. .64

FIGURA 3.17 - Ponte da Rua Såo Felipe. .65 
FIGURA 3.19 - Ponte de madeira com aterro - até 4.50m de văo.

FIGURA 3.26 - Ponte de S. PAULO - CIA.NITROQUÍMICA.

FIGURA 3.28 - Vista de meia ponte proposta por HORTEGAL. .78

FIGURA 3.29 - Modelo de ponte com viga armada instrumentado por LOGRADO. .79

FIGURA 3.30 - Ponte de Eucalipto Citriodora usada no estudo de DIAS (1987). $.80 / 81$

FIGURA 3.31 - Grelha idealizada para a análise (DIAS, 1987). .82

FIGURA 3.32 - Modelo de Tabuleiro, de Peroba Rosa :

(a) Posicionamento de sete barras de aço;

(b) Posicionamento de onze barras de aço;

(c) Seçăo Transversal [MATTHIESEN, 1987]. .84

FIGURA 3.33 - Modelo com onze linhas de barras de aço e anéis metálicos. .85 
FIGURA 3.35 - Ponte Estaiada proposta:[ALMEIDA, 1989]
(a) Elevaçăo;
(b) Planta
(c) Ponte esquemática;
(d) Seçåo transversal. $.87 / 88$

FIGURA 3.36 - Ponte de Ipero. $.89 / 90$

FIGURA 3.37- Aspecto de montagem da viga bicircular com tarugos de aço. .91

FIGURA 3.38 - Estrutura montada. .92

FIGURA 3.39 - Ponte Rodoviária Típica Existente na Austrália até a década passada. .97

FIGURA 4.1 - Modelo de distribuiçăo transversal para momentos longitudinais. 104

FIGURA 4.2 - Distribuição Transversal do Momento Longitudinal $M_{x}$. 105

FIGURA 4.3 - Pontes que nåo podem ser analisadas por métodos simplificados :

(a) planta de uma ponte com largura variável;

(b) planta de uma ponte em placa com poucos apoios isolados;

(c) planta de uma ponte esconsa com ângulo de esconsidade maior que $20^{\circ}$;

(d) ponte curva em planta, com $L^{2} / 0 R$ maior que 1.00;

(e) ponte com seçăo transversal não uniforme;

(f) elevaçăo lateral de ponte com seçăo năo uniforme na porçăo central (50\% do văo);

(g) seçăo de ponte em placa sobre vigas com menos que quatro vigas;

(h) ponte de seçáo celular com menos que trés células. $108 / 109$

FIGURA 4.4 - Demarcaçăo das porçס̃es externas e interna nas seçסes transversais das pontes :
(a) em placa;
(c) placa sobre vigas de madeira serrada;
(b) em placa sobre vigas;
(d) estrutura celular. 110

FIGURA 4.5 - Carregamento Ontário:
(a) Nivel 3;
(b) Nivel 2;
(c) Nivel 1. .112/113 
FIGURA 4.6 - Momentos fletores gerados por meio caminhăo ou meia faixa carregada. .114

FIGURA 4.7 - Fator de aceitaçăo de carga dinámica conforme o Ontario Highway Bridge Design Code (OHBDC). 116

FIGURA 4.8 - Casos determinantes de carregamento correspontes ao OHBDC, trés e quatro faixas de tráfego (para uma e duas faixas os carregamentos em uma e duas faixas såo os determinantes, respectivamente). 118

FIGURA 4.9 - Diagramas de $D$ e $C_{f}$ :
a) pontes de uma faixa de tráfego;
b)pontes de duas faixas de tráfego;
c) pontes de trés faixas de tráfego;
d) pontes de quatro faixas de trafego. $122 / 123$

FIGURA 4.10 - Diagrama de procedimentos descritos, OHBDC, estado limite de utilização de tipo II e estado limite último.

FIGURA 4.11 - Diagramas de $D$ e $C_{f}$, estado limite de utilização tipo 1, uma faixa de tráfego carregada:

a)pontus: de duas faixas de tráfego;

b) porisis de trés faixas de tráfego;

c) poina de quatro faixas de tráfego, (SLSI, OHBDC). $.126 / 127$

FIGURA 4.12 - Seçăo parcial da placa deformada sob açăo de $M_{y}$ gerado por um eixo carregado do veículo; a linha tracejada indica a superfície indeformada. 128

FIGURA 4.13 - Distribuiçăo de $M_{y}$ : transversal, valor máximo; longitudinal, envoltória das distribuiçōes possiveis. 129

FIGURA 4.14 - Dispersăo da carga de rodas no tabuleiro :
a) transversal;
b) longitudinal;
c) planta (eixo duplo, OHBDC). .132

FIGURA 4.15 - Momentos Locais, carregamento OHBDC. 132

FIGURA 4.16 - Momentos Transversais Globais em pontes em placas sobre vigas, gerados pelo carregamento OHBDC. 
FIGURA 4.17 - Definiçăo de $V_{x}$ em seçōes contíguas, em uma faixa da ponte. 135

FIGURA 4.18 - Distribuiçåo Transversal de Momentos e Cortantes Longitudinais. 136

FIGURA 4.19 - Posiçào relativa à carga móvel das seçðes analisadas. 137

FIGURA 4.20 - (a) Ponte real

(b) Placa ortotropica

(c) Grelha equivalente. 139

FIGURA 4.21 - Forças cortantes, carregamento em meia-pista. 143

FIGURA 4.22 - Força cortante transversal máxima nas pontes :

(a) rigidez maior

(b) rigidez torcional menor. $146 / 147$

FIGURA 5.1 - Placa protendida para ensaio de torção. .151

FIGURA 5.2 - Placa protendida para ensaio de torção. 151

FIGURA 5.3 - Instrumentação Preliminar, Primeira fase. 152

FIGURA 5.4 - Primeiros resultados de laboratório. 153

FIGURA 5.5 - Resultados experimentais; protensăo de 150 kN. 154

FIGURA 5.6 - Placa E montada. 155

FIGURA 5.7 - Placa ABCD montada. 156

FIGURA 5.8 - Placa ortotrópica, quadrada, ensaio de torçăo:

(a) Placa $0^{\circ}$

(b) Placa $+45^{\circ}$ 158

FIGURA 5.9 - Disposiçăo de Carregamento na Placa $0^{\circ}$. 162

FIGURA 5.10 - Amanjo de Ensaio, placa $0^{\circ}$. 163 
FIGURA B.1: Configuraçסes das Molas Belleville :

(a) disco simples.

(b) discos em paralelo.

(c) discos em série.

FIGURA B.2 - Carga por Deslocamento das molas simples.

FIGURA B. 3 - Carga por Deslocamento das molas em séries.

FIGURA B.5 - Detalhes de ancoragem das barras de protensão:

$\begin{array}{ll}\text { a) Detalhe Padrăo } & \text { b) Detalhe com os feixes de Mola Belleville. }\end{array}$

FIGURA B. 6 - Planta de Instrumentação para a Merrills Bridge.

FIGURA B.7 - Detalhes da célula de carga.

FIGURA B.8 - Instalação da célula de carga nas ancoragens :

a) sem os conjuntos de molas

b) com os conjuntos de Molas Belleville.

FIGURA B.9 - Programaçăo do Sistema de Monitoração à Distância.

FIGURA C.1 - Tabuleiro FPL e suas configuraçסes de ensaio (sem e com perfis "C"). ....271

FIGURA C.2 - Gráfico comparativo dos valores encontrados em estudos anteriores, $\boldsymbol{E}_{\boldsymbol{T}}$.

FIGURA C.3 - Gráfico comparativo dos valores encontrados em estudos anteriores, $G_{L T}$. 
FIGURA C.4 - Esquema de carregamento para o estudo de torçăo de placa para

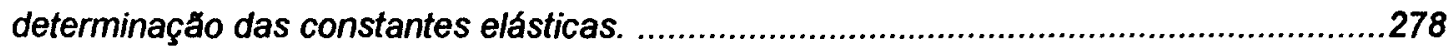

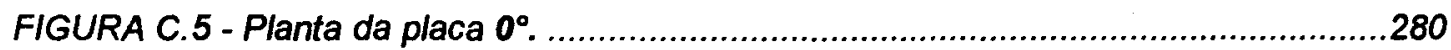

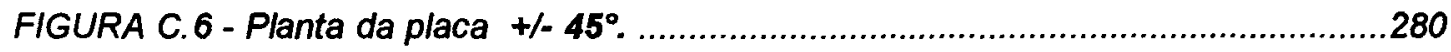

FIGURA C.7 - Resultados de ensaio da placa $0^{\circ}$, deslocamento no centro, carga no canto.

FIGURA C. 8 - Resultados de ensaio da placa $+45^{\circ}$, deslocamento no centro, carga no canto.

FIGURA C. 9 - Resultados de ensaio da placa $-45^{\circ}$, deslocamento no centro, carga no canto.

FIGURA C.10 - ET como função da tensão de protensăo no tabuleiro. 283

FIGURA C.11 - $G_{L T}$ como função da tensão de protensão no tabuleiro. 283 


\section{LISTA DE TABELAS}

TABELA 2.1 - Valores dos índices de Poisson.

TABELA 2.2 - Valores Comparativos.

TABELA 2.3 - Valores obtidos.

TABELA 2.4 - Valores Comparados.

TABELA 2.5 - Resumo de Valores para Cálculo.

QUADRO 4.1 : Classificaçăo das rodovias.

QUADRO 4.2 : Fatores de Reduçåo de Cargas.

QUADRO 4.3 : Númiero de faixas de Cálculo, OHBDC.

QUADRO 4.4 : Momento Longitudinal Inicial, $D_{d}(m)$.

TABELA 4.1 - Analise de Grelha de uma ponte, momentos e cortantes longitudinais. 138

TABELA 4.2 - Valores de D para Força Cortante Longitudinal, em metros, OHBDC. 141

TABELA 4.3 - Número Determinante de Faixas Carregadas, Esforço Cortante, OHBDC. 142 TABELA 4.4 - Rigidezes a Computar para análise de placa articulada. 145

TABELA 5.1 - Resultados da Classificaçăo por Flexăo. 157

TABELA 5.2 - Larguras medidas da Placa $0^{\circ}$. 
TABELA 5.4 - Resultados de Ensaios - Placa $0^{\circ}$

TABELA 5.5 - Resultados de Ensaios - Placa $-45^{\circ}$ 165

TABELA 5.6 - Resultados de Ensaios - Placa +45․

TABELA B.1 : Perda de altura em uma mola Belleville a partir da situação sem carregamento. 241

TABELA B.2 - Perda de altura para séries de molas Belleville. 243

TABELA C.1 - Resultados dos Ensaios de Torção. .282 


\section{LISTA DE ABREVIATURAS}

$\begin{array}{ll}\text { ACA } & \text { - Arseniato de Cobre em soluçăo Amoniacal. } \\ C C A & \text { - Arseniato de Cobre Cromatado. } \\ C C B & \text { - Borato de Cobre Cromatado. } \\ D L A & \text { - Dynamic Load Allowance, Aceitaçăo de Cărga Dinâmica. } \\ E L U & \text { - Estado Limite Último. } \\ E L U t & \text { - Estado Limite de Utilizaçăo. } \\ \text { LVL } & \text { - Laminated Veneer Lumber, placa laminada longitudinal. } \\ M L C & \text { - Madeira Laminada Colada. } \\ M L P & \text { - Madeira Laminada Pregada. } \\ M L T & \text { - Madeira Laminada Tensionada. }\end{array}$




\section{LISTA DE SÍMBOLOS}

a

b

$t$

$f$

$r$

$\boldsymbol{R}$

$T$

E

G

$D$

- coeficiente da matriz de constantes elásticas.

- meja largura da placa ortotrópica; espessura de laminaçס̋es.

- altura de peças de madeira.

- frequiência de flexăo da estrutura.

- eixo radial para a madeira, coordenadas cilíndricas.

- eixo logitudinal para a madeira, coordenadas cilindricas; eixo transversal da placa, coordenadas cartesianas.

- eixo de tráfego, longitudinal da placa; coordenadas cartesianas.

- eixo transversal da placa; coordenadas cartesianas.

- deslocamento da placa (funçăo $w(x, y)$ ).

- carregamento genérico da placa (função $p(x, y)$ ).

- desvio padrăo.

- espessura da placa.

- eixo de referéncia anisotrópico para a madeira, longitudinal (na direçăo das fibras).

- eixo de referéncia anisotrópico para a madeira, radial (na direçăo dos raios).

- eixo de referéncia anisotropico para a madeira, tangencial (perpendicular aos raios); número de caminhóes-tipo diários.

- módulo de elasticidade longitudinal em um eixo.

- modulo de elasticidade transversal.

- rigidez de placa; fator de distribuiçăo transversal de cargas.

- momento de inércia à flexâo.

- momento de inércia d torçăo.

- metade da rigidez total torcional da placa.

- espaçamento entre vigas; coeficiente da matriz de constantes elásticas.

- momento fletor.

- força cortante.

- área; classe de via.

- número de veículos por dia; quantidade de vigas.

- classe de via.

- classe de via.

- peso do veículo-tipo; largura da faixa de tráfego.

- fator de ajuste para o parametro $D$. 


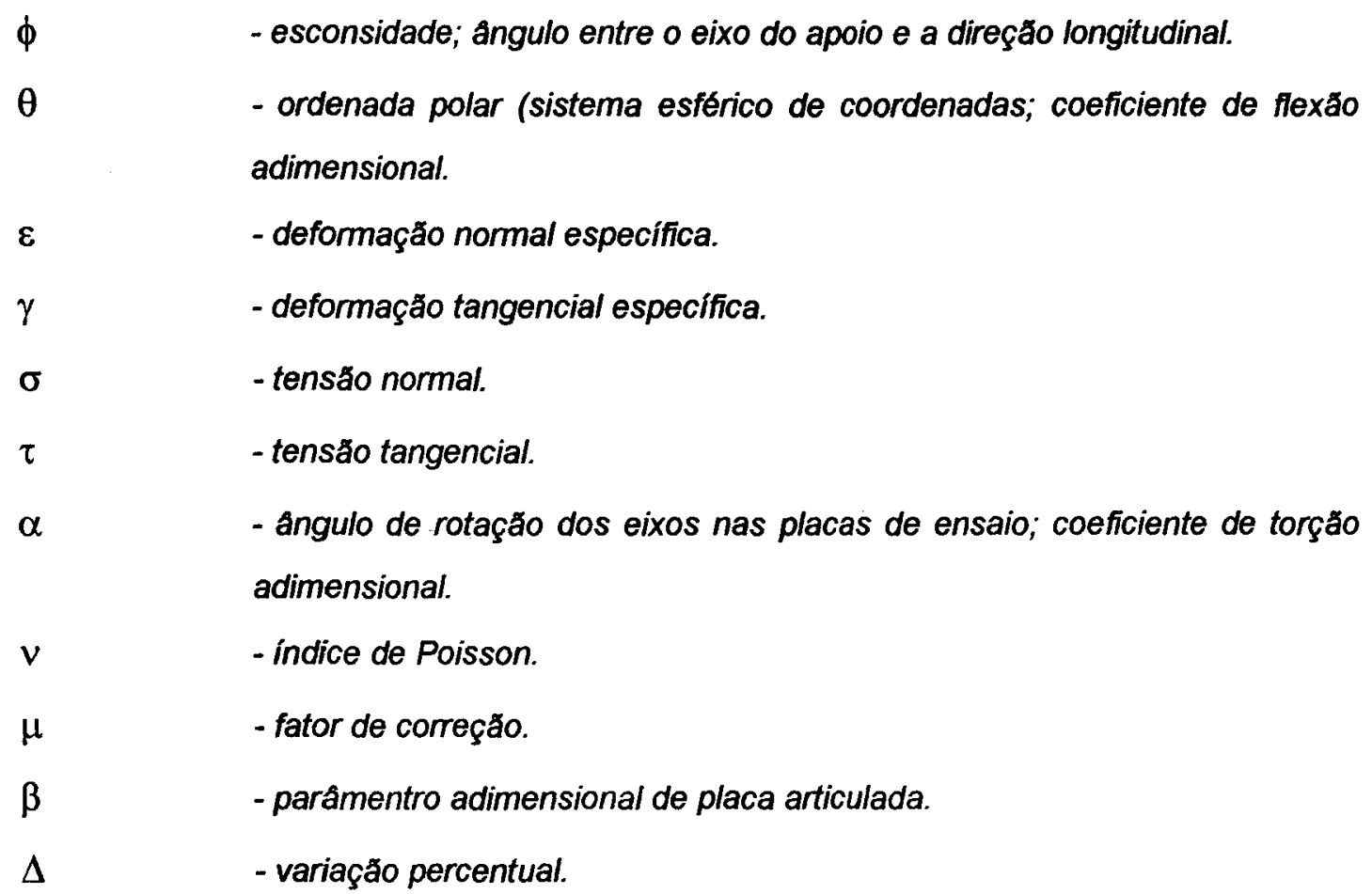




\section{LISTA DE SIGLAS}

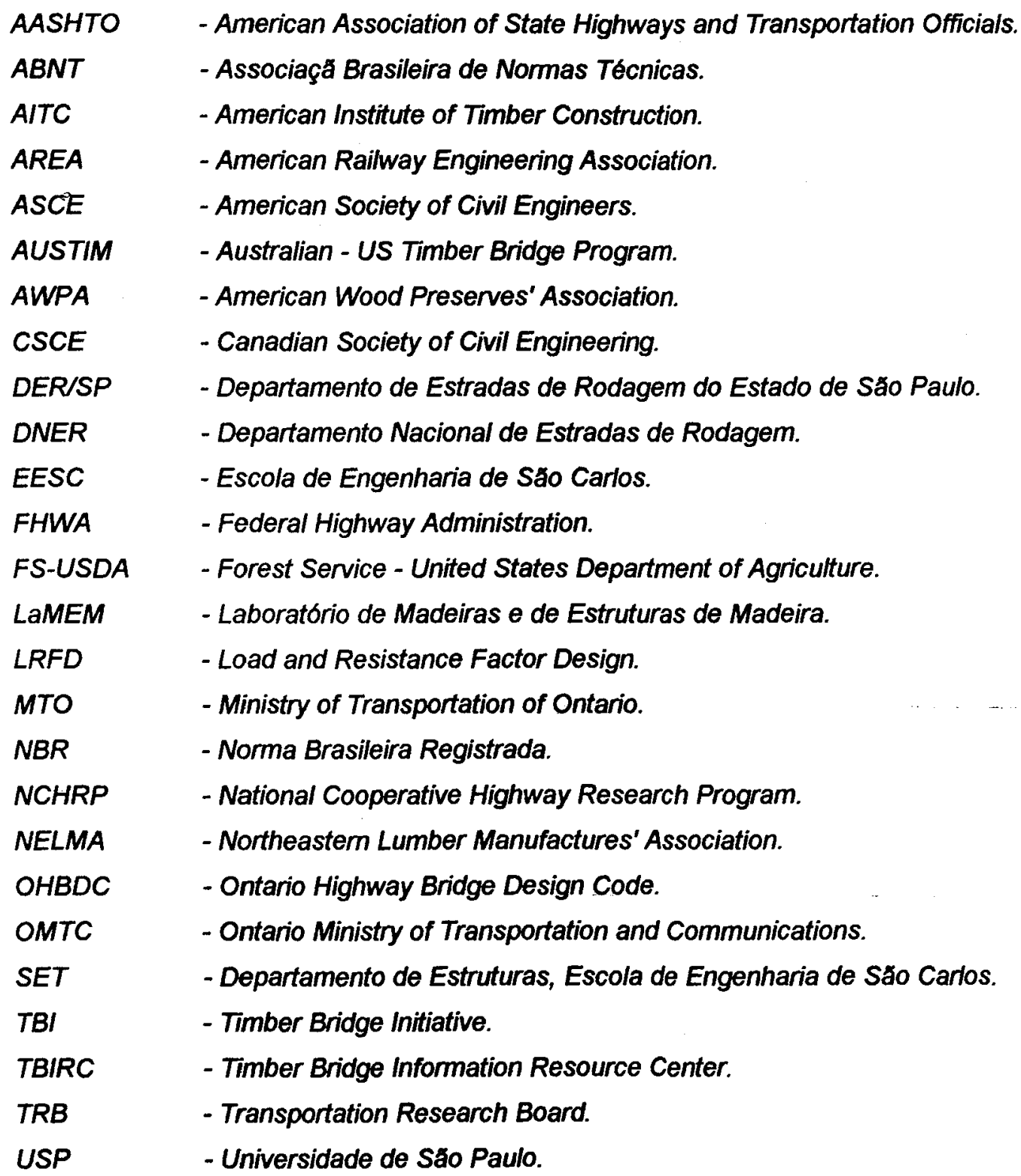




\section{RESUMO}

Esta tese apresenta o estudo dos sistemas construtivos, métodos de análise e cálculo de pontes de madeira com ênfase no estudo teórico e experimental de pontes de madeira protendidas, com a determinação de parâmetros elásticos para a utilização da espécie de madeira de reflorestamento eucalipto citriodora fornecendo as diretrizes de projeto a serem seguidas. 


\section{ABSTRACT}

This thesis present the study on many constructive and structural systems, methods of analysis and design of timber bridges with emphasis in the teorethical and experimental studies of prestressed timber bridges with the determination of elastic parameters to the utilization of reforestation specie Eucalyptus Citriodora, grown in Brazil and giving the guidelines for their design and construction. 


\section{1. - SISTEMAS ESTRUTURAIS DE PONTES DE MADEIRA}

\subsection{DEFINIÇÕES}

As pontes são soluções estruturais para a transposição de obstáculos nas vias de transporte. Há exemplos de pontes para solução de gargalos em canais com cruzamento em desnivel para as embarcações e de vias rápidas de acesso urbano sob aeroportos.

As pontes são mais comuns em rodovias e ferrovias e, por esta razão, atendem com mais freqüencia aos carregamentos destas vias. Outras interferências são diferenciadas como viadutos - as obras de transposição de obstáculos que não sejam cursos d'água - e neste os casos são mais abundantes, tanto para os carregamentos de rodovias e ferrovias quanto para pedestres e dutovias.

São definidas: ${ }^{1}$

- ponte : Construção destinada a ligar margens opostas de uma superfície líquida qualquer.

- viaduto : Construção destinada a transpor uma depressão de terreno ou servir de passagem superior.

As diretrizes para projeto de estruturas para transposição de tais obstáculos são as mesmas e gerais, razão pela qual estas estruturas serão aqui denominadas pontes.

\footnotetext{
${ }^{1}$ Ferreira, Aurélio B. de H. - Novo Dicionário da Lingua Portuguesa - 1a. Edição (14a. reimp.)
} 


\subsection{FORMAS ESTRUTURAIS DE PONTES}

\subsubsection{Tabuleiro.}

Sistema plano que recebe as solicitações do tráfego, transferindo-as ao resto da superestrutura. Em um bom projeto, o tabuleiro deve atuar como parte da superestrutura, absorvendo tensões resultantes da transferência de cargas na direção longitudinal; por exemplo, o tabuleiro pode atuar como mesa superior de uma viga principal; como parte do banzo superior de uma treliça; como tirante de um arco; como escora de equilibrio do esforço no cabo de uma ponte pênsil auto-atirantada. Pode-se, porém, ter a necessidade de isolar o tabuleiro da estrutura principal, para se evitar deformações incompativeis entre materiais diferentes que conduzam a concentração de tensões, levando o projeto a detalhes especiais de articulação.

\subsubsection{Escolha do tipo de superestrutura}

A escolha do material e da forma estrutural para a superestrutura principal é um problema complexo e só pode ser resolvido considerando-se todos os fatores que afetam o projeto de cada ponte. A escolha é função do vão, sendo influenciada diretamente pela qualidade e custo dos materiais, condições e exeqüibilidade das fundações, geometria do tabuleiro (altura da superfície, traçado da via) e limitações impostas pelo local na execução da superestrutura.

\subsection{VARIEDADE DAS FORMAS}

\subsubsection{Placa}

O sistema de piso do tabuleiro é o elemento estrutural principal, responsável pela resistência global da superestrutura às solicitações de todos os tipos, transferindo-as à mesoestrutura. 
Há placas de diversas concepções. São seções transversais características:

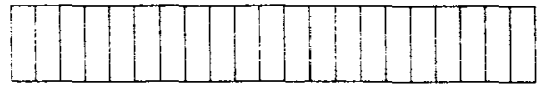

(a)

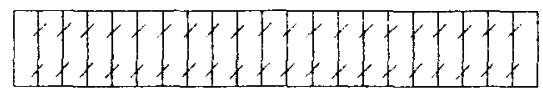

(c)

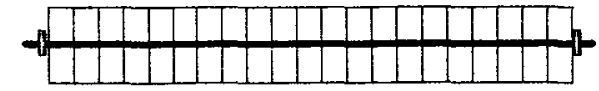

(b)

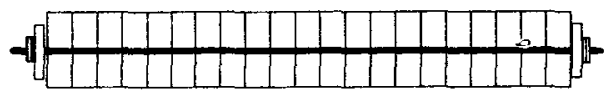

(d)

FIGURA 1.1 - Placas de madeira maciça

(a) madeira laminada colada.

(b) madeira laminada atirantada (passiva) e colada.

(c) madeira laminada pregada; há pregos de topo e lateralmente, interconectando as vigas.

(d) madeira atirantada (ativa), năo colada.

Destas formas básicas podem ser feitas muitas variações e combinações.

\subsubsection{Vigas}

O sistema de piso do tabuleiro arranja os travamentos superiores sem, efetivamente, resistir às solicitações globais da superestrutura. As vigas podem ser unicamente longitudinais ou estarem dispostas longitudinal e transversalmente. São seções transversais tipicas:

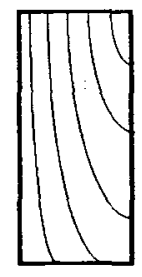

(a)

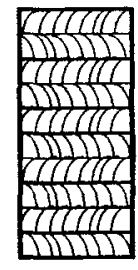

(b)

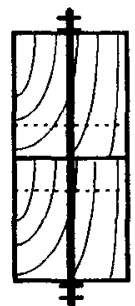

(c)

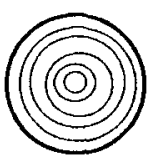

(d)

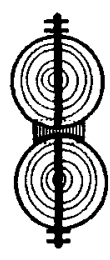

(e)

FIGURA 1.2 - Vigas de madeira maciça:

(a) Madeira serrada em bruto.

(b) Madeira laminada colada.

(c) Madeira serrada, solidarizada por tarugos ou anéis metálicos e parafusos.

(d) Postes.

(e) Postes combinados, solidarizados por aneis metálicos ou tarugos e parafusos. 
Arranjos adicionais podem ser feitos para aumentar a altura das seções utilizando-se chapas de compensado, de laminado ou de fibras :

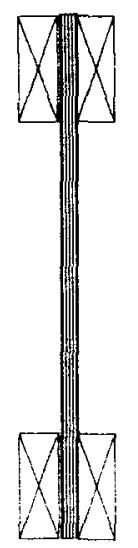

(a)

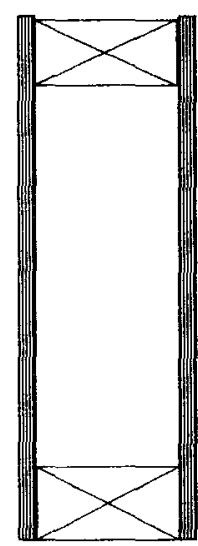

(b)

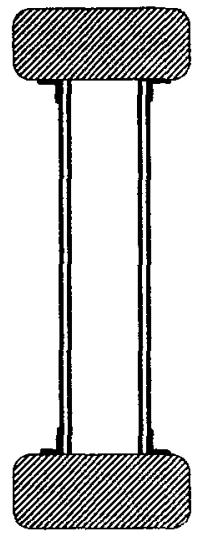

(c)

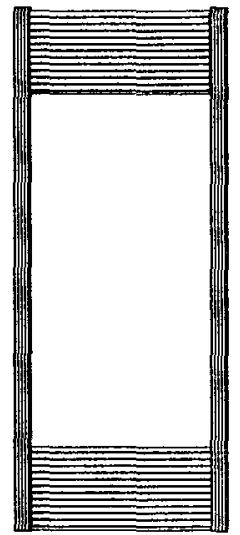

(d)

FIGURA 1.3 - Vigas de seçăo composta:

(a) Vigotas de madeira serrada, coladas a uma placa de compensado ou laminado.

(b) Vigas de madeira serrada, coladas ou pregadas a duas placas (caixăo).

(c) Vigas intertravadas por chapas duras de fibra ou laminado, e coladas.

(d) Vigas de madeira laminada colada fechadas por placas de compensado (caixão).

Um sistema combinado implica em se distribuir o carregamento, responsabilizando-se o tabuleiro pela rigidez transversal da placa e as vigas longitudinais mais o tabuleiro pela rigidez longitudinal. É denominado placa sobre vigas, comportando-se de modo bastante semelhante às grelhas ortogonais.

Um sistema de grelha composto de vigas de madeira é aplicado com sucesso em pisos de pontes com dois arcos ou treliças longitudinais principais, onde vigas longitudinais apoiam-se sobre as vigas transversais : é a grelha simples, sem a compensação pelas vigas dos esforços de torção.

A grelha propriamente dita, com as vigas no mesmo plano de trabalho (longitudinais e transversais), com resistência à torção e tabuleiro com vigas longitudinais, transversais, ou misto, em madeira, é bastante aplicada 
quando se dispõe de madeira laminada colada, e adaptam-se muito bem quando há esconsidade (não perpendicularidade entre apoios e vigas longitudinais) na geometria da planta da ponte. Também é possível o uso de travessas de postes roliços e/ou com vigas de seção composta (como mostrado nas figuras acima) de modo a enrijecer o conjunto; as transversinas funcionam como diafragmas na contenção lateral das almas das vigas e servem para o apoio do tabuleiro entre as vigas longitudinais.

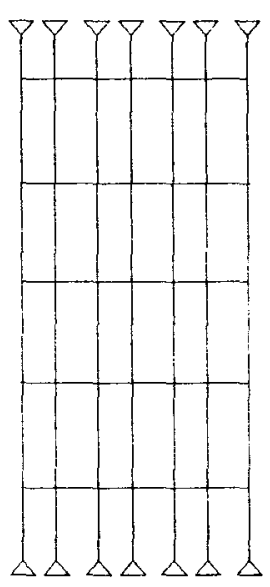

FIGURA 1.4 - Grelhas Ortogonais :

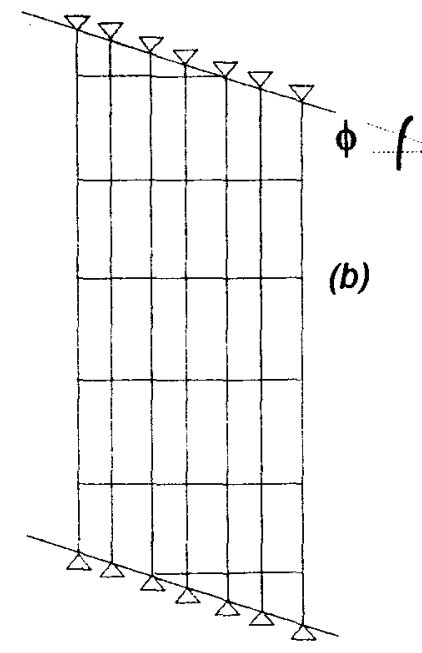

(a) Planta ortogonal.

(b) Planta com esconsidade ( $\phi)$.

Um outro sistema combinado implica em utilizar-se duas placas unidas por vigas, formando uma placa vazada, se de pequena altura, ou em viga de seção celular, de várias células, se de altura maior.

Vigas de grande altura, vazadas e longitudinais também são encontradas em pontes de madeira (Viga Vierendeel), mais citadas como pórticos ou casos especiais de treliça.

\subsubsection{Pórticos}

Sistemas com aplicação de pórticos (cavaletes, escoras) são restritos a médios vãos, como reforços às vigas. Såo estruturas típicas : 


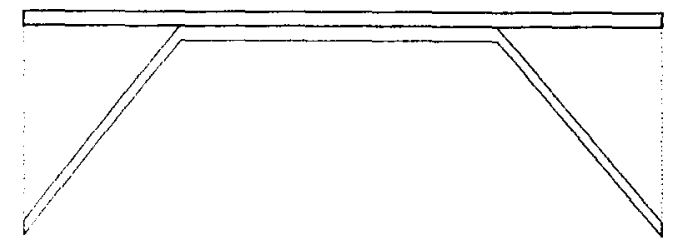

(a)

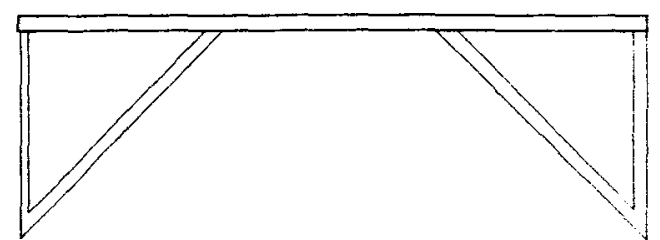

(b)

FIGURA 1.5 - Porticos longitudinais: _(a) Portico acrescentado ds vigas.

(b) Pórtico escorado.

\subsubsection{Treliças}

Uma treliça é um conjunto de barras retas compondo triângulos e articuladas entre si. Uma treliça tem as seguintes características :

(a) OS EIXOS de todos os elementos são retos e concorrentes nos nós ou juntas;

(b) A TRELIÇA propriamente dita é carregada somente nos nós.

São as forças axiais, nos elementos de treliça, que resistem principalmente às cargas aplicadas. Os momentos fletores são pequenos e têm efeito muito reduzido nas forças axiais necessárias ao equilíbrio, embora teoricamente os momentos fletores em todos os elementos devessem ser nulos, pois os elementos seriam articulados sem atrito em todos os nós. Na prática, a maioria dos elementos são conectados rigidamente nas juntas. Porém, o valor dos momentos fletores nos elementos é pequeno, sendo controlado pelas dimensões da treliça, por técnicas de fabricação, pré- montagem e montagem final.

Uma treliça plana pode ser considerada como uma viga de grande altura, onde as mesas de uma seção I "jumbo" fossem substituidas por um sistema aberto de elementos de alma. Em certos casos, deve-se empregar treliças em lugar de vigas de alma cheia: 
- uma viga reta simplesmente apoiada ou contínua no tabuleiro de uma ponte pênsil enrijecida;

- uma ponte com viga atirantada;

- um arco (mesmo em combinação : arco treliçado).

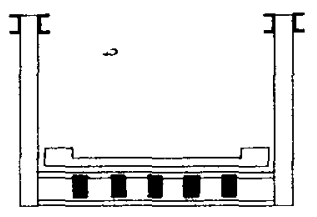

Seção AA

Ponte Treliçada com

Tabuleiro inferior

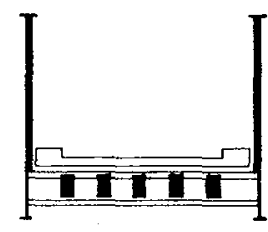

ov Seção $A A$ Ponte em Placa sobre vigas

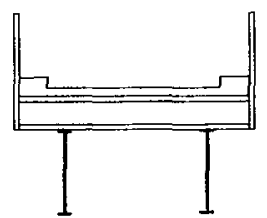

Seçăo BB

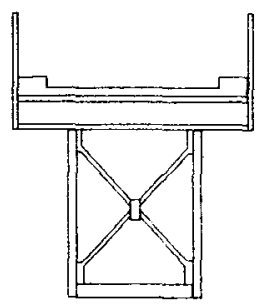

Ponte em vigas Duplas

a Seçăo $B B$

Ponte Treliçada

Viga de Piso

Arco, Viga

Viga de Piso

Viga ou Treliça

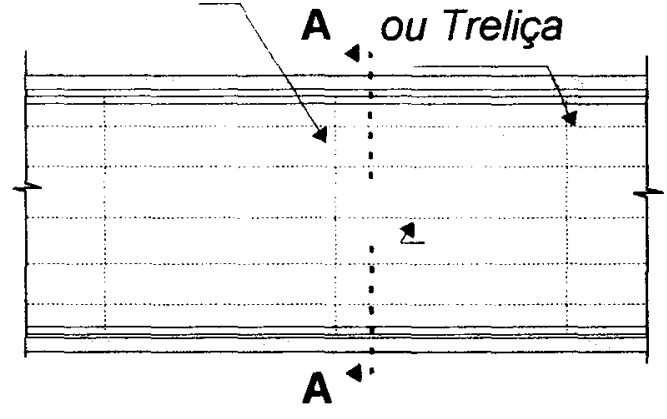

Planta

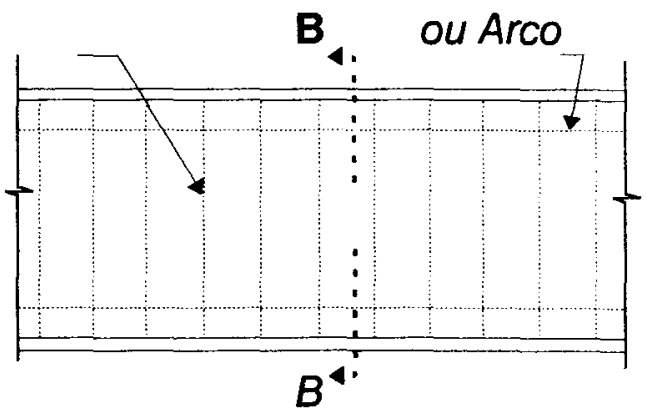

Planta

FIGURA 1.6 - Configuraçðes das pontes em treliça:

(a) Treliça ou Arco Treliçado apoiam o piso no plano inferior.

(b) Viga Treliçada, Treliça ou Arco Treliçado apoiam o piso no plano superior.

Uma ponte completa em treliça tem os seguintes componentes :

l. Uma laje de tabuleiro, apoiada em

II. longarinas, que por sua vez se estendem entre as

III. transversais nos pontos de nós das

IV. duas treliças longitudinais principais. 
V. Há o contraventamento horizontal nos planos dos banzos, transmitindo cargas horizontais transversais aos

VI. contraventamentos verticais extremos e dai aos

VII. pilares.

VIII. Além disso deve existir contraventamentos verticais intermediários.

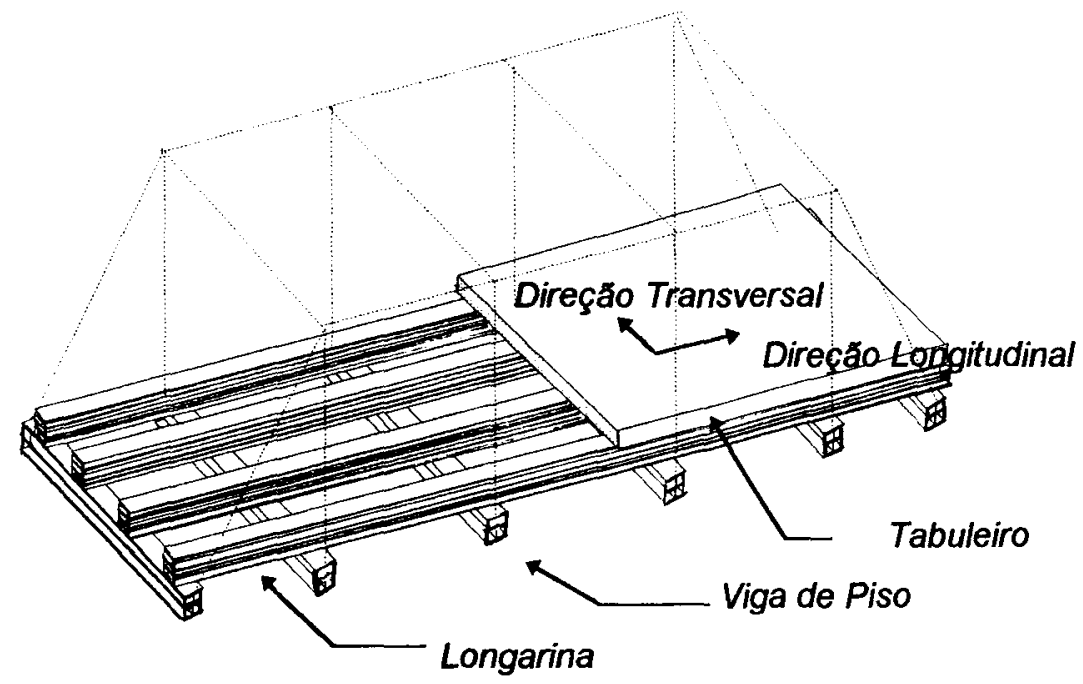

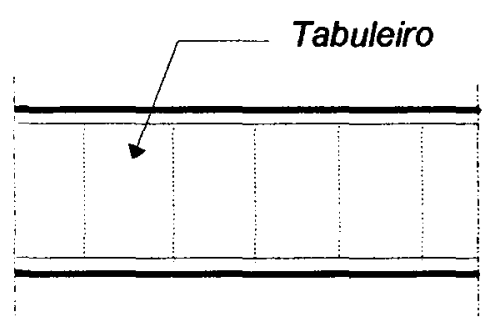

(a)

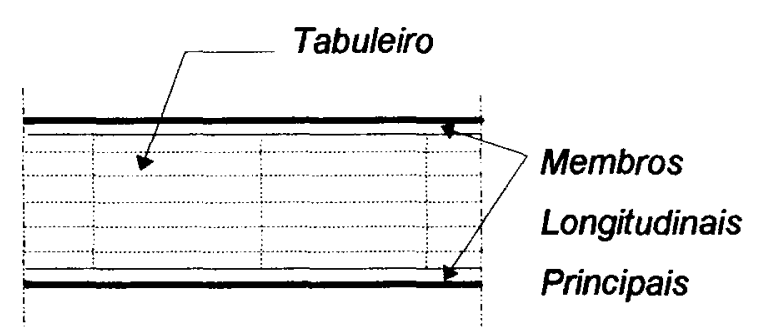

(b)

FIGURA 1.7 - Componentes das pontes em treliça:

(a) tabuleiro contínuo, longitudinal, apoiado em vigas de piso transversais;

(b) tabuleiro contínuo, transversal, apoiado em vigas longitudinais que se apóiam em treliças ou vigas transversais.

Os contraventamentos verticais intermediários auxiliam na distribuição das cargas transversais ao sistema lateral e são úteis durante a construção, mantendo em esquadro a estrutura principal enquanto incompleta. 
(a)

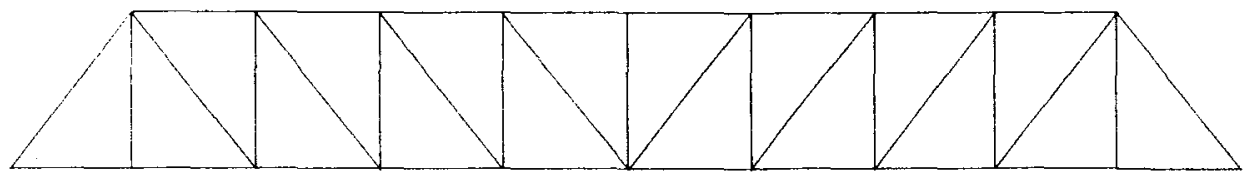

(b)

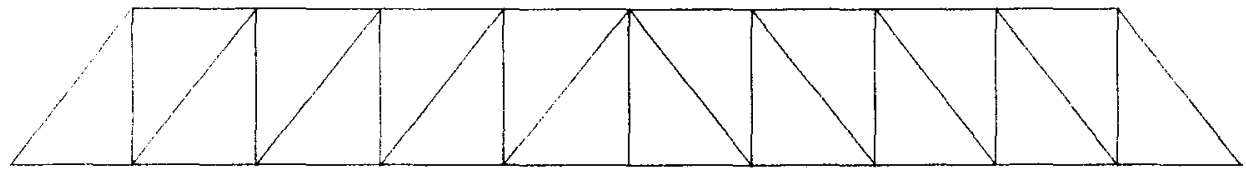

(c)

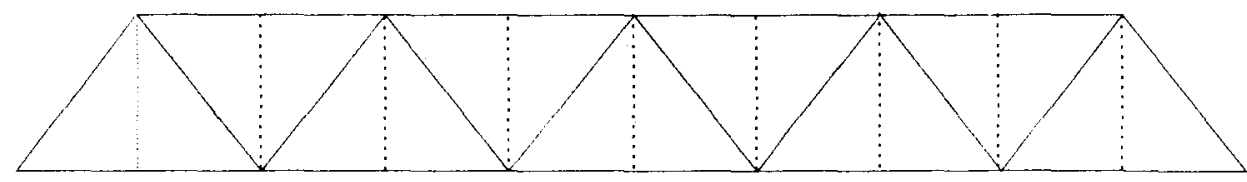

(d)

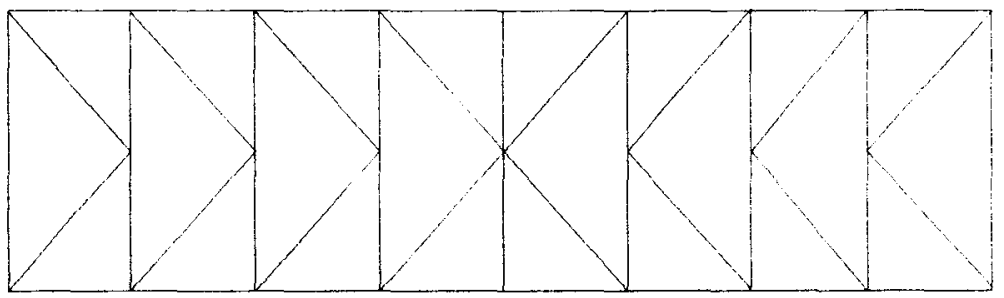

(e)

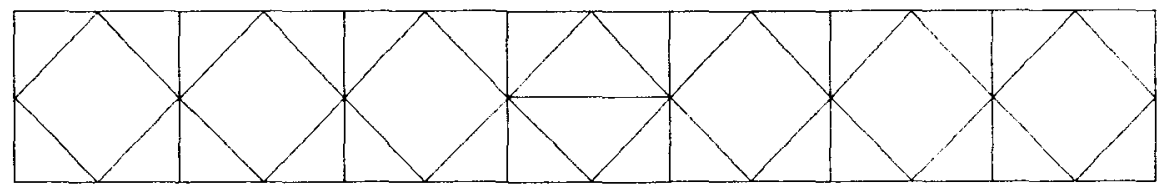

FIGURA 1.8 - Formas mais comuns de treliças para pontes:
(a) PRATT.
(b) HOWE.
(c) WARREN.
(d) K-Contraventado.
(e) Sistema Contraventado em Losangos.

Uma variável importante no projeto das treliças é sua altura, determinante no fator economia. Usualmente a altura da treliça é fixada como uma fração do vão, fazendo variar proporcionalmente a altura à medida em que o vão cresce. Para que o tabuleiro se apóie adequadamente, pode ser necessário subdividir os painéis, de acordo com a posição do tabuleiro : 

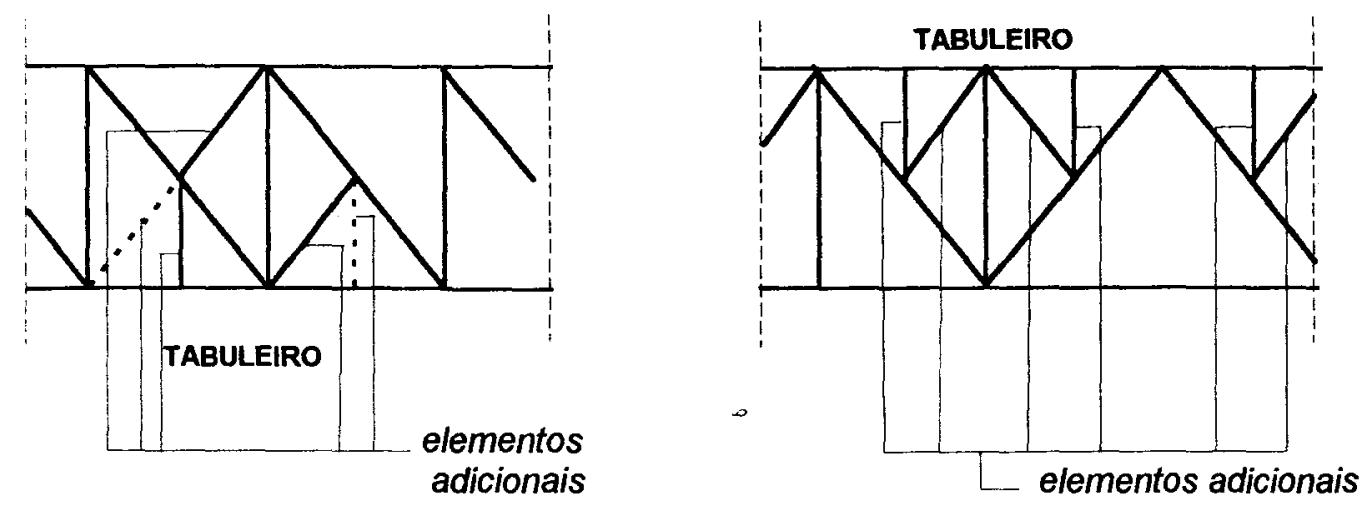

FIGURA 1.9 - Ennijecimentos dos painéis de treliças para apoio do tabuleiro:

(a) Tabuleiro superior;

(b) Tabuleiro inferior.

Certos arranjos de vigas de alma cheia comportam-se como treliças, que podem ser idealizadas como uma treliça reticulada:
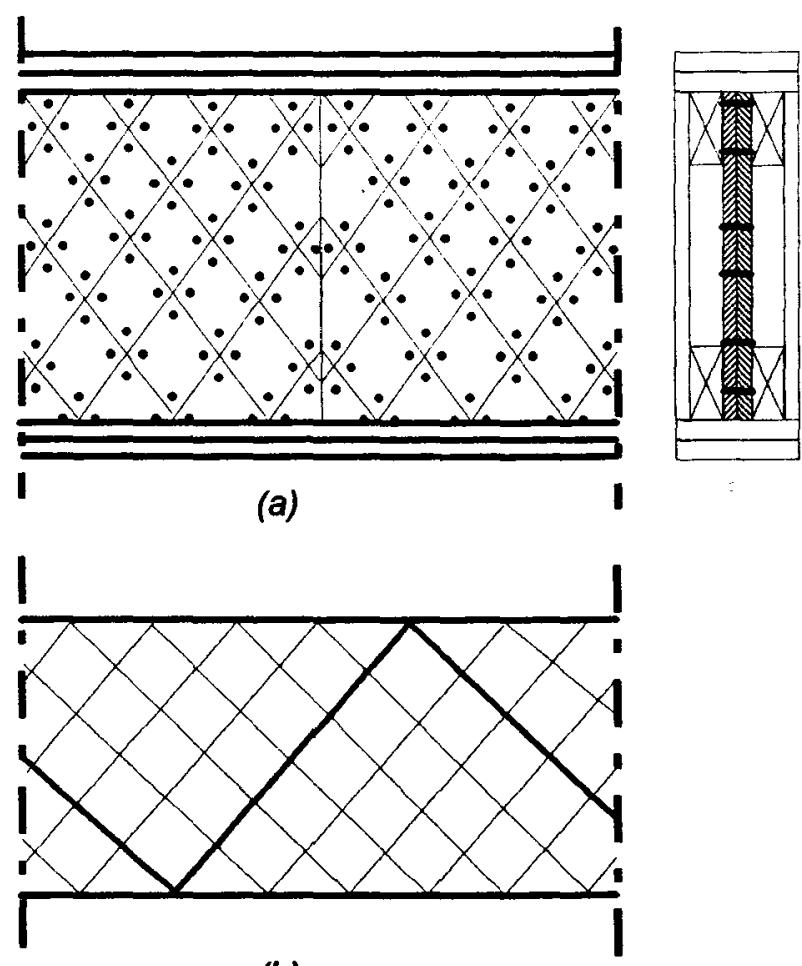

(b)

FIGURA 1.10 - Vigas de seçăo composta, pregadas:

(a) Disposiçăo construtiva - Elevaçăo e Seçăo transversal;

(b) Idealizaçăo como treliça generalizada. 


\subsubsection{Arcos}

Um arco é uma barra de eixo curvo onde as cargas são posicionadas entre os seus apoios e são transmitidas para eles principalmente pelas forças axiais que o comprimem.

Para um determinado carregamento, a forma do arco pode ser escolhida de modo a evitar qualquer momento fletor. Para as cargas verticais, para baixo, esta forma será côncava para baixo. Se as cargas forem concentradas, 0 arco ideal toma um aspecto poligonal. Se as cargas forem distribuídas, 0 arco toma a forma curva. A forma clássica do arco é a constituída pela nervura curva, que vai de encontro a encontro, que fornecem as reações de apoio cujas componentes horizontais são fundamentais para a ação do arco.

Tabuleiro

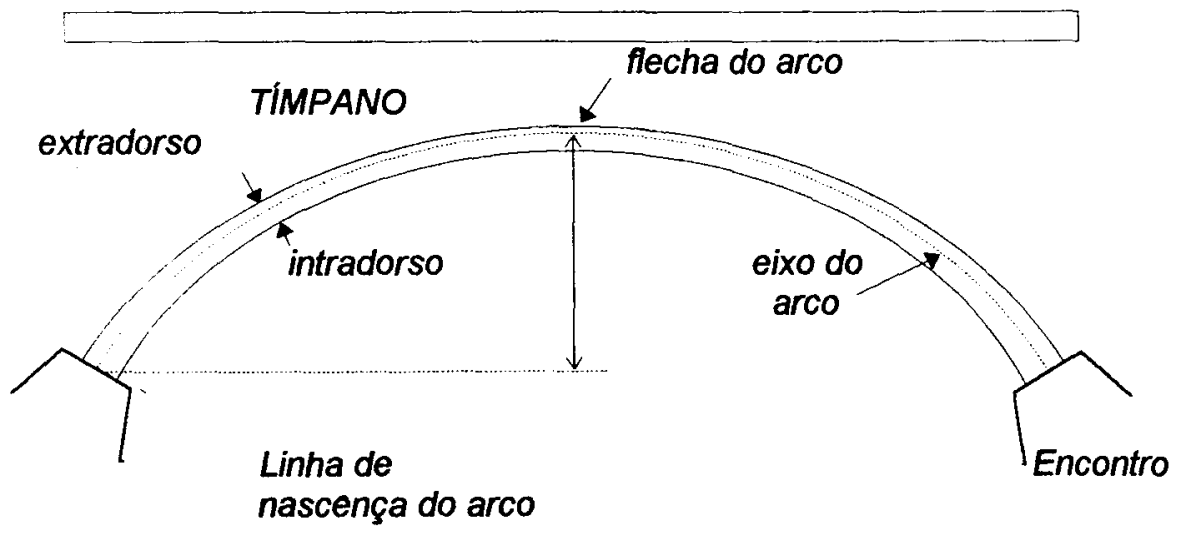

FIGURA 1.11 - Nomenclatura dos elementos da ponte em arco. 


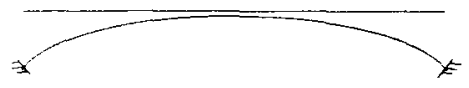

(a) Arco bi-engastado, tabuleiro superior

(c) Arco c/ uma articulaçăo

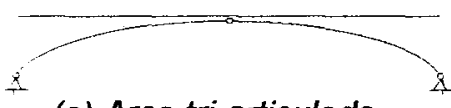

(e) Arco tri-articulado

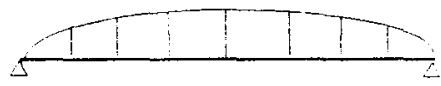

(g) Arco atirantado

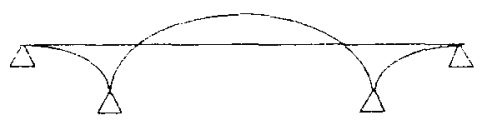

(i) Arco atirantado

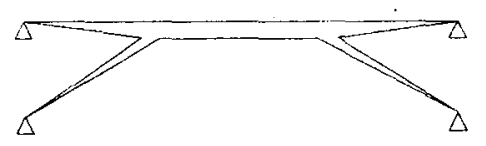

(k) Quadro c/ montantes inclinados

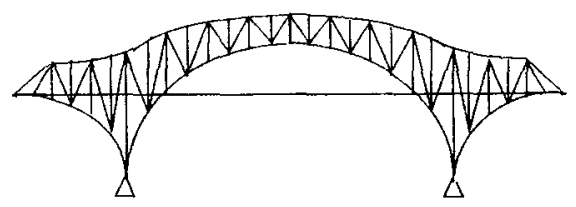

(m) Arco em balanço

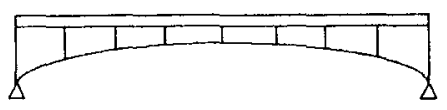

(o) Arco c/ tabuleiro enrijecido

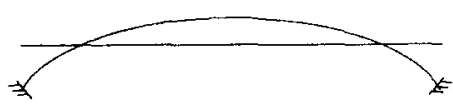

(b) Arco bi-engast., tab. intermediário.

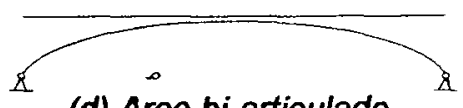

(d) Arco bi-articulado.

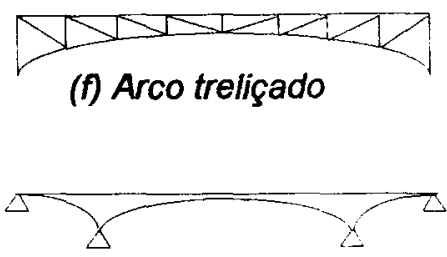

(h) Arco contínuo.

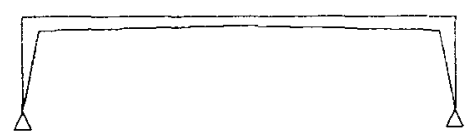

(j) Quadro rígido (Biarticulado)

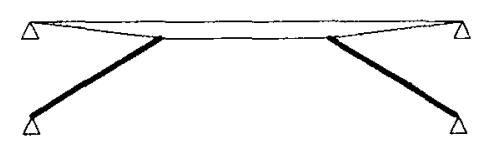

(I) Quadro c/ montantes inclinados

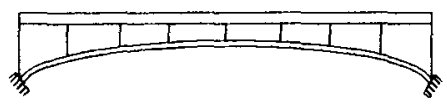

(n) Arco convencional

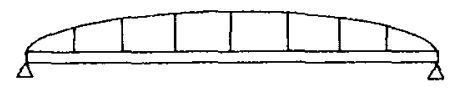

(p) Arco c/ tabuleiro enrijecido 
A linha do arco é geralmente conformada para receber a carga permanente sem momentos fletores. Esta carga é então chamada de carga de forma. Se a carga de forma for grande, a carga móvel se torna, essencialmente, uma pertubação aplicada a um elemento comprimido. Deve-se, pois, obrigatoriamente usar a teoria da deformação no cálculo. Imperfeições iniciais da forma do arco podem ter efeitos muito importantes.

A forma do arco visa reduzir os momentos fletores na superestrutura, devendo apresentar economia de material quando comparada com a equivalente viga reta ou treliça simplesmente apoiada.

Esteticamente, o arco pode ser o tipo de ponte de maior sucesso. O homem parece considerar a forma em arco harmoniosa e expressiva. A forma curva é quase sempre agradável.

\subsubsection{Estruturas suportadas por cabos}

São distinguidas pela capacidade de suplantar grandes vãos; são competitivas para vãos no intervalo de $50 \mathrm{~m}$ a $1500 \mathrm{~m}$.

A imensa maioria de todas as pontes suportadas por cabos pode ser dividida em quatro componentes principais :

1. Viga ou Treliça de Rigidez, com o tabuleiro.

2. Sistema de cabos que suporta a base rígida.

3. Torre ou pilastra suportando o sistema de cabos.

4. Bloco ou pilar de ancoragem, suportando vertical e/ou horizontalmente os cabos. 


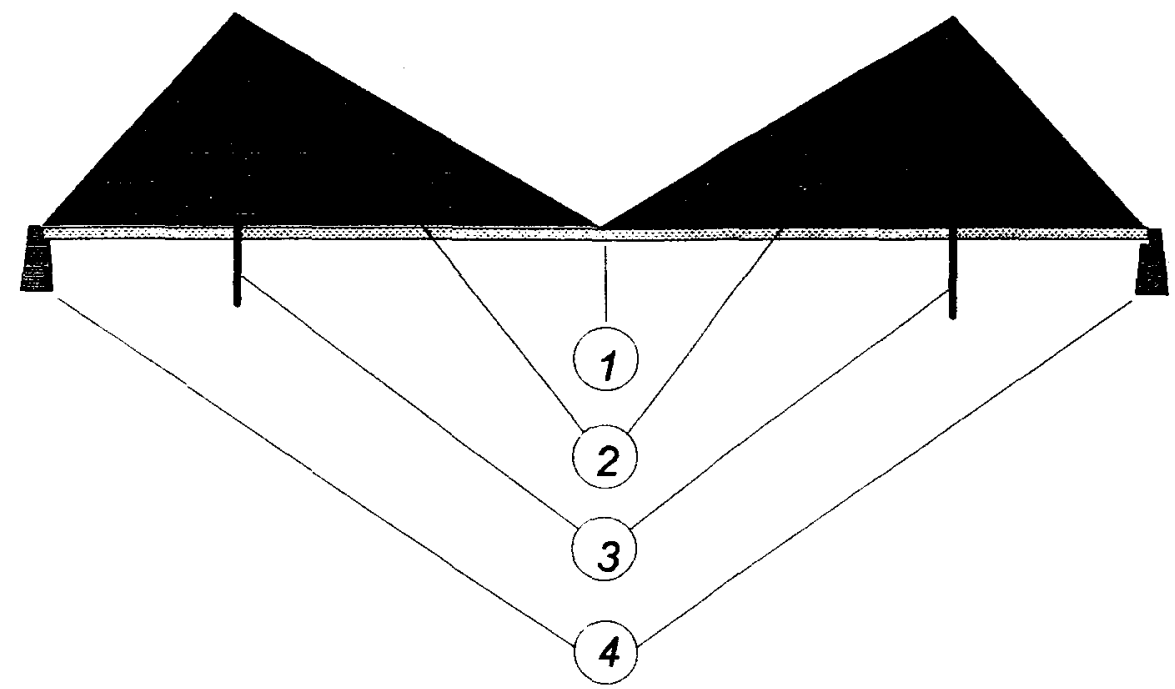

FIGURA 1.13 - Componentes da ponte suportada por cabos:

1. Viga ou treliça de rigidez longitudinal

2. Sistema de cabos que suporta a base

3. Torre, que apoia os cabos

4. Ancoragem para suporte vertical e/ou horizontal dos cabos

Os diferentes tipos destas pontes se caracterizam pela configuração do sistema de cabos. O sistema pênsil compreende um cabo principal parabólico e cabos pendurais verticais ou ligeiramente inclinados, conectando a viga de rigidez ao cabo principal; geralmente há dois cabos principais paralelos. O sistema de cabos estaiados contém cabos retos conectando a viga de rigidez à torre; no sistema em leque, todos os cabos irradiam do topo da torre; no sistema em harpa os cabos são paralelos. Podem-se usar sistemas intermediários.

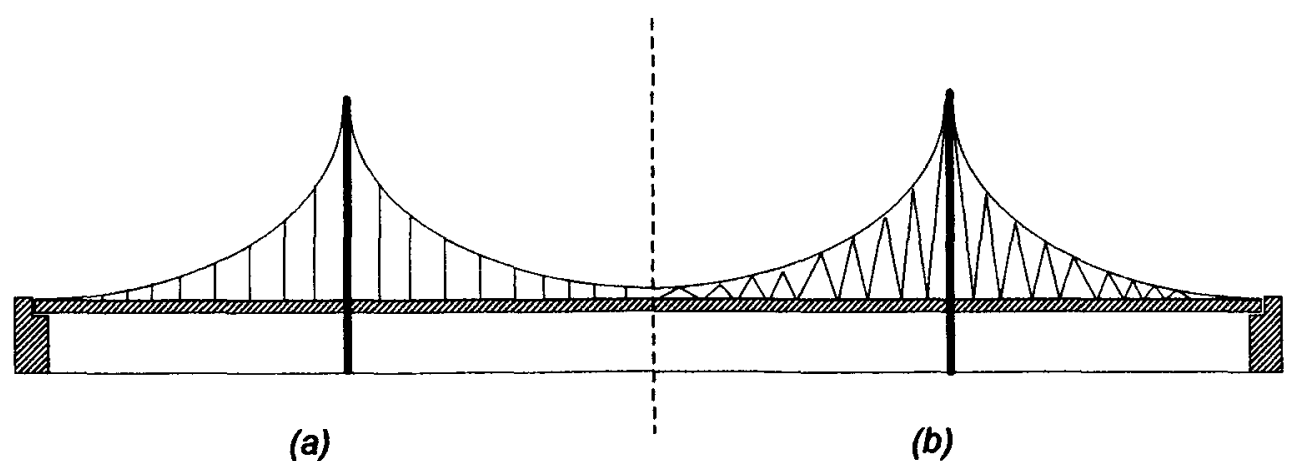

(a)

(b) 


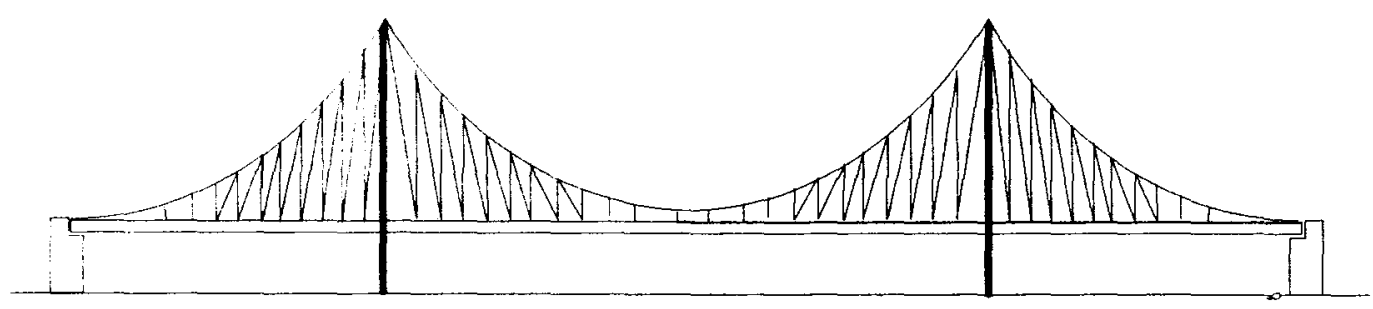

(c)

FIGURA 1.14 - Ponte Pensil_: (a) Pendurais verticais.

(b) Pendurais inclinados.

(c) Suspensão combinada.

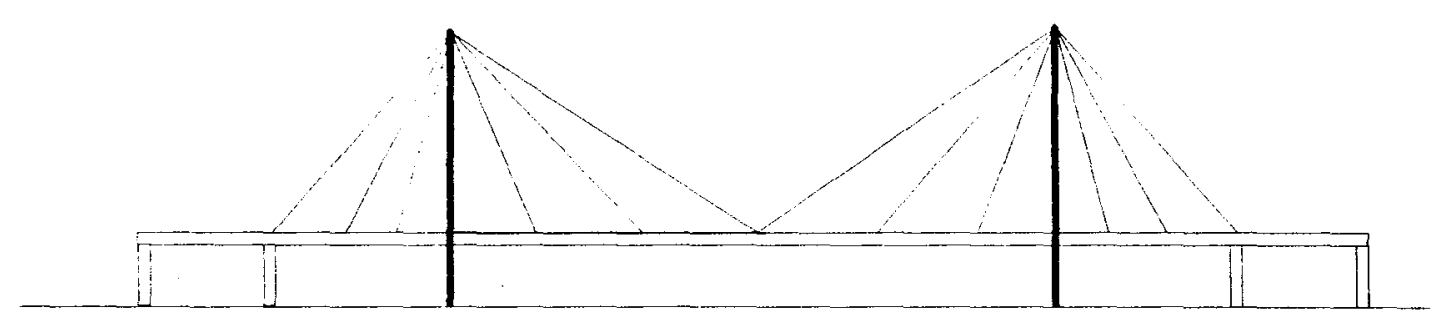

(a)

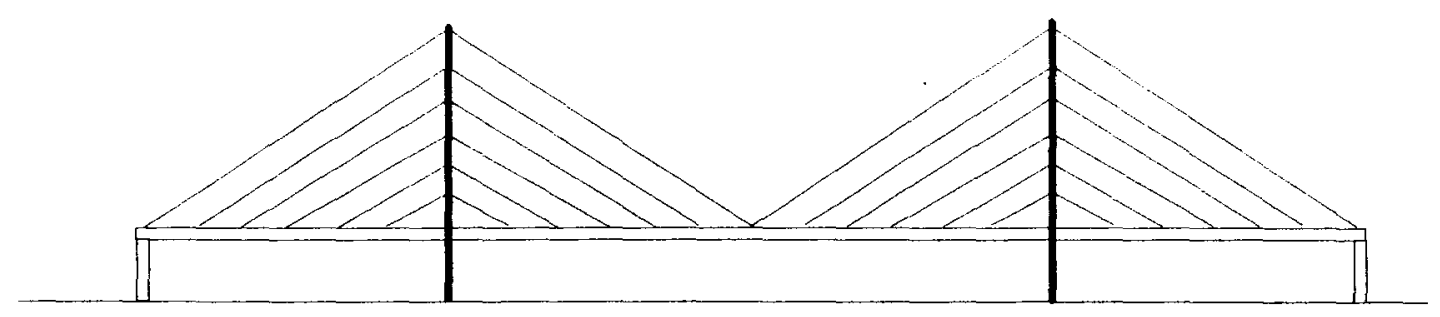

(b)

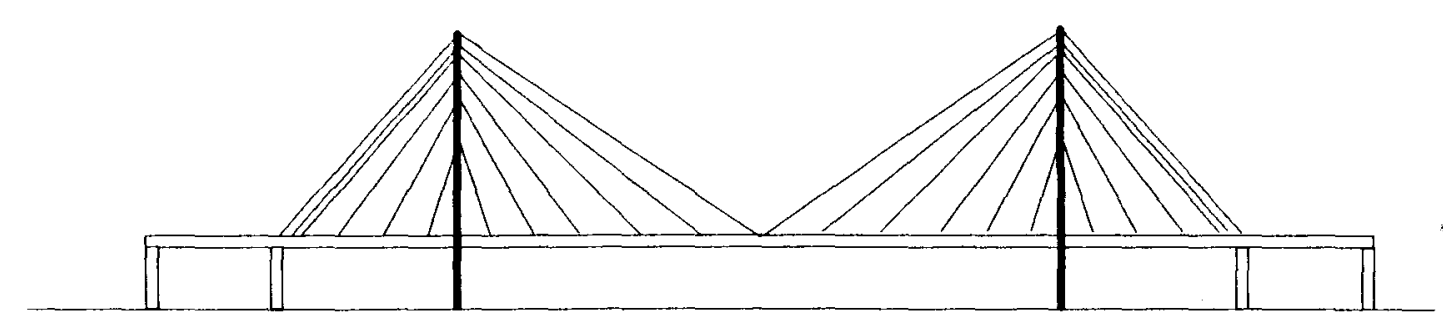

(c)

FIGURA 1.15 - Ponte Estaiada:

(a) Sistema em leque, puro;

(b) Sistema em harpa;

(c) Sistema em leque, modificado. 
As pontes suportadas por cabos mais comuns são as que apresentam três vãos sendo um vão central maior ladeado por dois vãos menores. Em certos casos, porém têm sido empregadas pontes estaiadas com dois vãos, assimétricos; em outros casos, a suspensão ocorre em um vão e os cabos são ancorados sem compartilhar a resistência em vãos adjacentes, tornando a estrutura uma viga de rigidez contínua parcialmente suspensa ou somente pênsil de um vão.

Pontes com vãos múltiplos têm sido construidas em poucos casos. A ponte Seto Ohashi, no Japão, é uma estrutura alternadamente disposta estaiada e pênsil, com cabos auto-ancorados e aterrados parcialmente, para dificultar a propagação de ondas elásticas através da estrutura, e tem cerca de $9400 \mathrm{~m}$ no total. No sistema auto-ancorado, a componente horizontal da força realizada nos cabos é transferida para a viga (ou treliça) de rigidez enquanto a componente vertical é transferida para ao pilar de ancoragem. Já no sistema aterrado, as forças horizontal e vertical são ambas descarregadas no bloco de ancoragem.

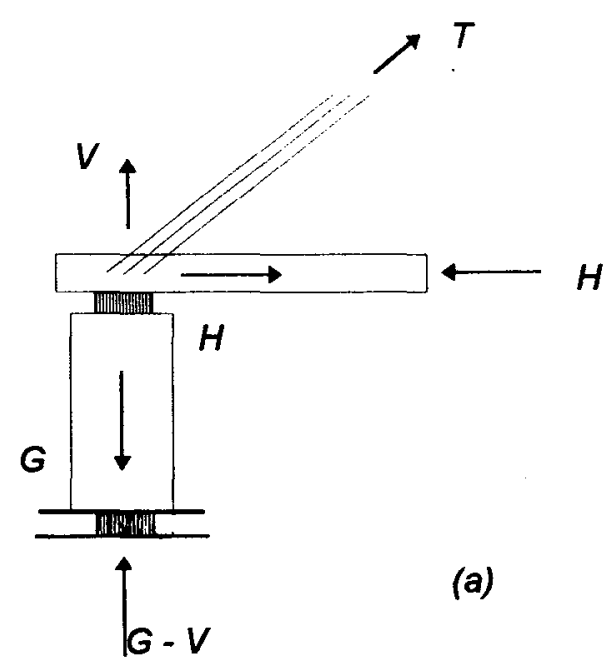

FIGURA 1.16 - Sistemas de ancoragem:

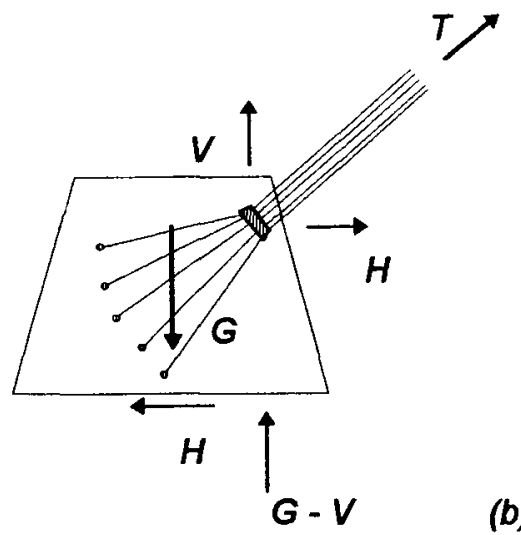

(a) auto-ancorado;

(b) aterrado.

A prática atual consagra o sistema auto-ancorado em pontes estaiadas e 0 sistema aterrado em pontes pénseis, mas ambos os sistemas de ancoragem aplicam-se às pontes pênseis e estaiadas. 
Na direção transversal destas pontes varia bastante a disposição dos cabos. O arranjo mais generalizado é o de dois planos paralelos de cabos suportando a viga de rigidez ao longo das bordas livres da ponte. Este arranjo é encontrado tanto nas pontes pênseis como estaiadas e a armação de enrijecimento é suportada verticalmente e torcionalmente pelos cabos.

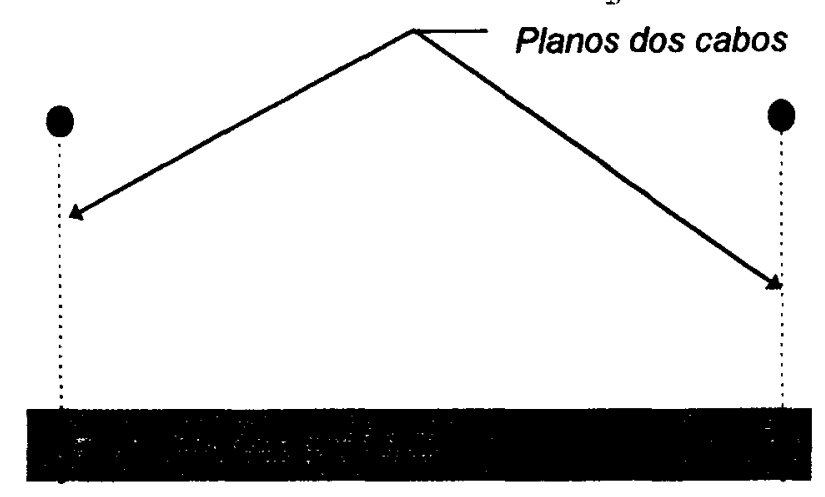

FIGURA 1.17 - Sistema com dois planos verticais contendo cabos paralelos longitudinais.

Nos casos em que houver balanços laterais a intensidade das cargas é preponderante na determinação da resposta da estrutura. Por exemplo, pontes com ferrovias na parte central e rodovias nas faixas externas podem requerer que os cabos fiquem na área mais central, pois do contrário os esforços de flexão da viga seriam bastantes elevados; em contrapartida, a resistência torcional oferecida pelo sistema de cabos se reduz drasticamente. A disposição mais moderada dos planos dos cabos transversalmente é encontrada em pontes com passagens protegidas nas laterais, especialmente para pedestres:
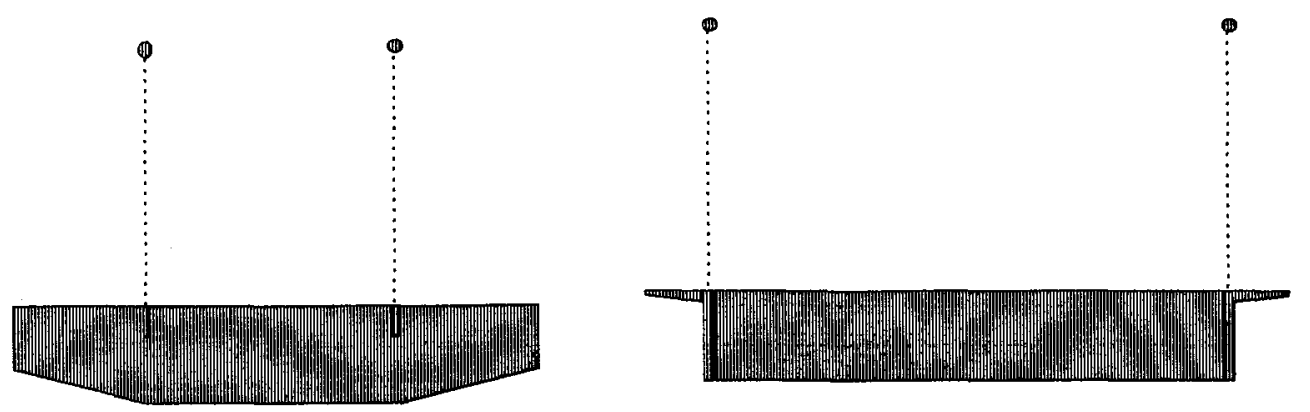

FIGURA 1.18 - Sistemas de dois cabos planos: (a) posicionados entre vias de tráfego; (b) posicionados extemamente ds vigas. 
A colocação de mais de dois planos paralelos de cabos é viável ainda hoje pois reduzirá substancialmente a quantidade de material exigido para transmissão transversal das cargas na estrutura. Já foi executado em algumas grandes pontes pênseis deste século.

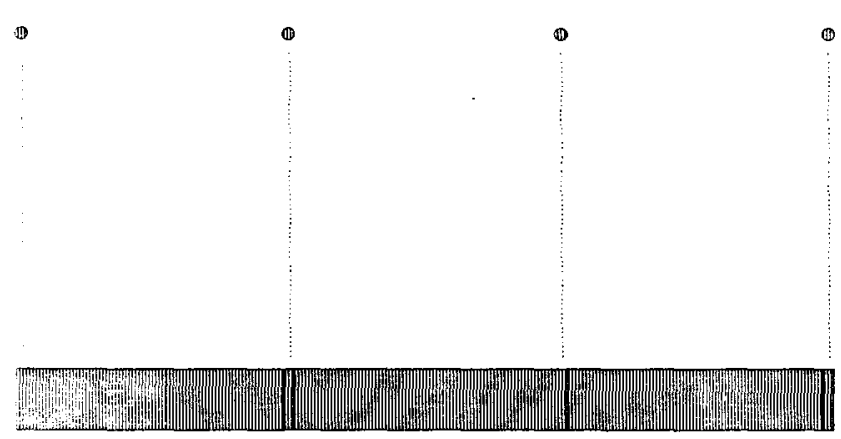

FIGURA 1.19 - Sistemas de quatro cabos em planos paralelos.

Um único plano de cabos pode ser visto em certas pontes estaiadas e este arranjo é tal que a viga de rigidez é suportada apenas verticalmente ao longo do vão entre torres, cabendo à viga efetivamente transmitir os momentos de torção através de uma caixa rígida, de considerável rigidez torcional.

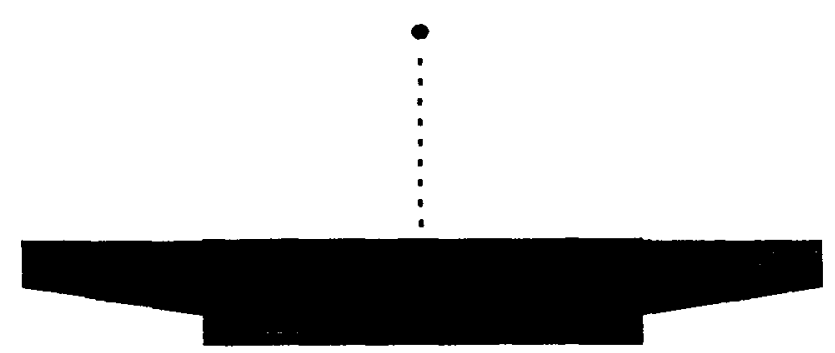

FIGURA 1.20 - Sistema com um único plano de cabos, central.

Cabos planos inclinados fixados nas bordas do assoalho da ponte, convergindo no alto são encontrados em pontes estaiadas com torres em forma de "A". Nesta disposição, a viga de enrijecimento é suportada vertical e torcionalmente pelo sistema de cabos. 


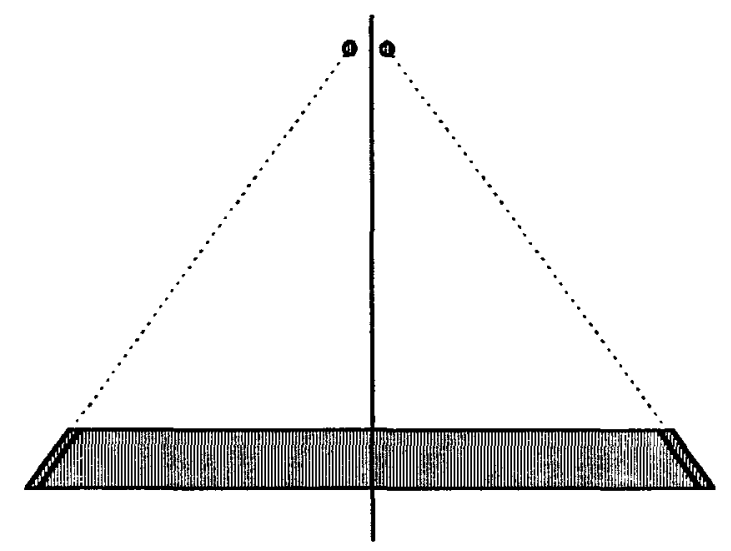

FIGURA 1.21 - Sistema com dois planos inclinados de cabos.

Como observação geral, a mais alta eficiência da sustentação por cabos é obtida quando eles têm função resistente vertical e torcional. Por esta razão é que se deve projetar uma ponte pênsil ou estaiada com dois ou mais planos de cabos fixados nas bordas livres do tabuleiro da ponte na armação de rigidez (viga ou treliça). 


\section{2. - A MADEIRA COMO MATERIAL ESTRUTURAL}

\subsection{INTRODUÇÃO}

A aplicação estrutural da madeira, para ser bem realizada, requer conhecimento da gênese, constituição e arranjo do material. A madeira é um polímero natural, polissacarídeo, produzido pelas árvores vivas através da fotossintese.

Este áçucar especial se dispõe em fibras com enorme variedade de arranjos, transpondo a grande diversidade da natureza em combinações microestruturais únicas, fazendo a impressão digital da espécie, que é recurso de grande valor para a identificação. Desta forma, em gênero e espécies diferentes há características de microestrutura intensamente diferentes, mas as características se mantêm entre indivíduos da mesma espécie vegetal. Os elementos principais componentes da madeira são vasos, traqueídes, poros resiníferos em espécies de coníferas, e vasos, fibras, raios medulares e parênquima em espécies de dicotiledôneas.

No aspecto macroestrutural há intensas variações, mesmo em individuos da mesma espécie. As causas destas variações são diversas : clima, solo, disponibilidade de água, velocidades de crescimento. As propriedades da madeira, resultantes de um processo de polimerização descontínuo na árvore, são não-homogenéas e apresentam valor mais significativo na direção correspondente ao eixo de crescimento da árvore. 
Pode-se analisar uma árvore através da representação de seu tronco em um sistema cilíndrico de eixos de referência. Comos as fibras dispõem-se longitudinalmente ao tronco, pode-se dizer que elas se dispõem transversalmente ao longo de anéis anuais de crescimento da árvore, direções radial e tangencial. Considerando-se que o tronco se alarga, a fronteira viva do material lenhoso tem circunferência cada vez maior, deixando o círculo interno para preenchimento com reservas de energia e aumentando a resistência mecânica do tronco.

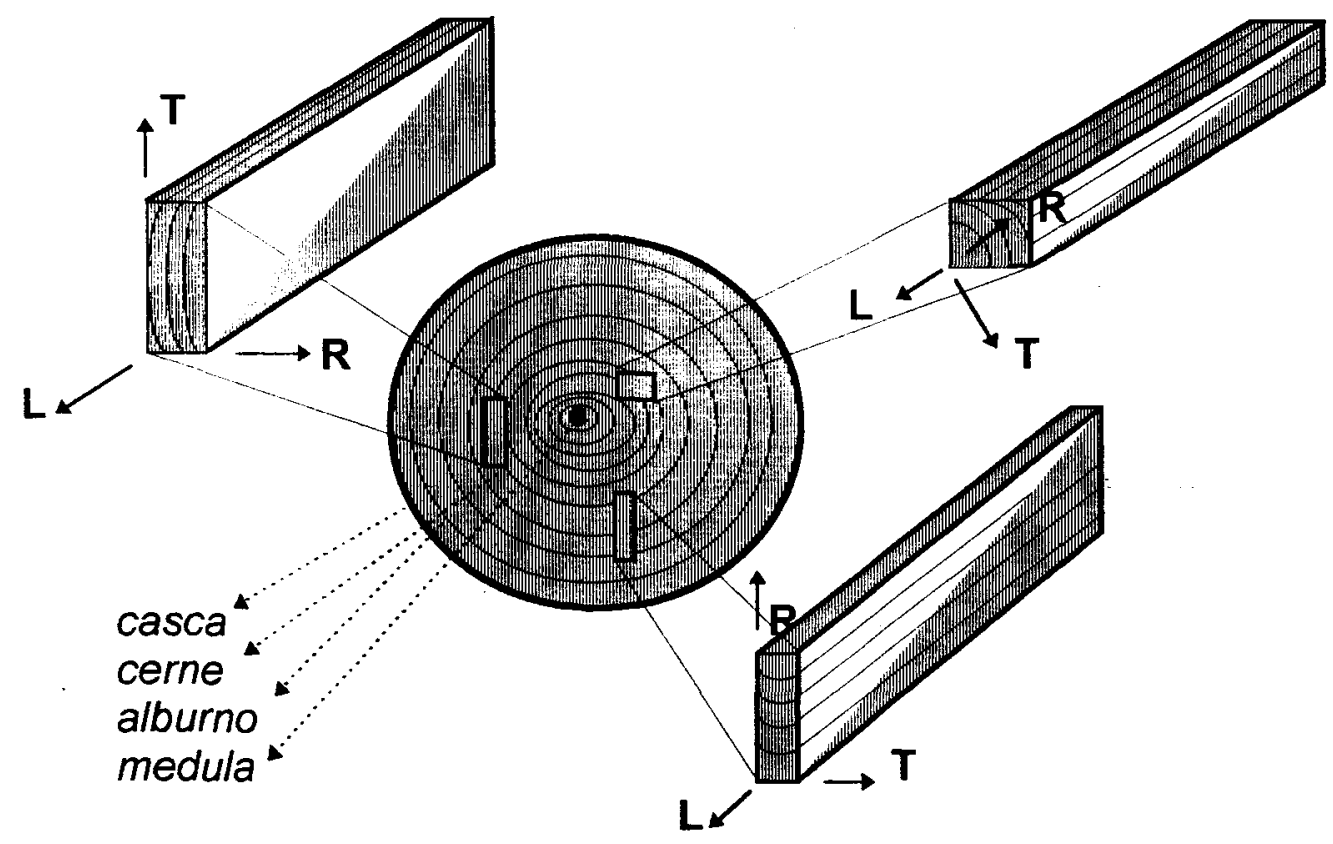

FIGURA 2.1 - Corte esquemático do tronco da árvore mostrando as posiçסes de anisotropia e eixos de referencia : $L$, longitudinal; $R$, radial; $T$, tangencial, em vigas resultantes do desdobro do tronco.

Durante o crescimento da árvore as fibras se desenvolvem com fototropismo positivo, portanto, preferencialmente no sentido de $L$, e à medida que a altura aumenta, alarga-se diametralmente, preenchendo os poros do alburno na região mais interna, adensando-o.

Após o corte da árvore o cerne é a regiăo aproveitável em desdobro da madeira. Deixando de ser um organismo vivo, a ciclagem natural de nutrientes entra em ação, tentando biodegradar a madeira. Por este motivo, 
quando se aplicar estruturalmente a madeira deve-se pensar sempre em "madeira tratada".

\subsection{PRESERVAÇÃO DA MADEIRA PARA USO EM PONTES}

- A aplicação das madeiras em pontes, de maneira geral, requer:

- Permanência da estrutura em serviço com baixa manutenção;

- estabilidade construtiva;

- resistência às variações do tempo, do tráfego e do ambiente.

Desta forma é essencial o tratamento preservativo da madeira para que a estrutura seja durável, esteticamente agradável, funcional e ofereça rigidez às condições de uso

O tratamento preservativo em base oleosa deve ser recomendado em primeiro lugar pois não induz a madeira a fendilhar-se. 0 auxílio à estabilidade dimensional da madeira é extremamente eficaz, fazendo com que a estrutura não apresente movimentos gerados pela flutuação do teor de umidade do ambiente - e, consequentemente, do teor de umidade de equilibrio da madeira. Tais movimentos podem ser não uniformes, causando distorções diferenciais na estrutura, mais prejudiciais do que a variação das propriedades de resistência e elasticidade da madeira na estrutura.

Os tratamentos preservativos principais em base oleosa são: creosoto, pentaclorofenol e naftenato de cobre. Podem ser aplicados em autoclave e em processos de difusão. Apesar de apresentarem instabilidade inicial devido à lenta estabilização do material tratado com o ambiente (exsudação), têm grande fixação às paredes mas não as alteram.

Os tratamentos em base aquosa podem ser adotados em segundo lugar. Os principais tratamentos são: CCA (cobre, cromo, arsênio), CCB (cobre, cromo, boro), ACA (amónia, cobre, arsênio). 
No caso de adoção de tratamentos hidrossolúveis, a exequibilidade das pontes protendidas foi motivo de pesquisa desenvolvida por CACCESE et al (1991) no Maine (EUA), recomendando a utilização de feixes de molas em série com as barras de tensionamento para compensar as variações na força de protensão devidas à flutuação do teor de umidade do tabuleiro. Este trabalho constitui o ANEXO B desta tese.

O processo de fixação dos presenvativos hidrossolúveis à parede celular é bastante rápido, razão pela qual recomenda-se sempre que o tratamento seja feito à pressão e em unidades industriais. Por reagir com a parede celular com grande poder inseticida (devido ao arsênio) e fungicida (devido ao cobre), a diferença entre os agentes de difusão se deve à maior facilidade que se pode encontrar para preencher os poros da madeira. De um modo geral, o boro é o elemento que apresenta maior compatibilidade com as fibras tornando a madeira mais permeável ao tratamento, auxilia a migração do preservativo ao longo de um gradiente de umidade dentro da madeira, é tóxico à maioria dos agentes de biodeterioração, porém pouco tóxico a mamíferos, sem causar problemas à usinagem, corrosão de metais, alteração do odor e da cor. Isoladamente, os boratos devem ser um tratamento prévio para as madeiras a usar em estruturas de pontes, que deve ser seguido de um tratamento adicional e complementar. Para aplicação em águas salinas, requer-se 0 tratamento com CCA preferencialmente aos oleossolúveis devido à toxicidade especial do tratamento aos perfuradores marinhos (limnoria e teredo); as estruturas de madeira tratadas com pentaclorofenol e creosoto apresentaram desempenho inferior frente aos cupins do mar mencionados.

Os tratamentos realizados à pressão em autoclaves têm tipos distintos, referidos aos ciclos de alta e baixa pressões aplicados. O Processo Bethell (ou célula cheia) deixa as células, vasos e poros da madeira cheios de solução. Os Processos Lowry e Rueping não se iniciam com um vácuo inicial, mas com pressão, terminando ambos com um ciclo final de vácuo. 
Estes processos deixam as células, poros e vasos mais vazios, evitando-se o fenômeno de exsudação muito intensa.

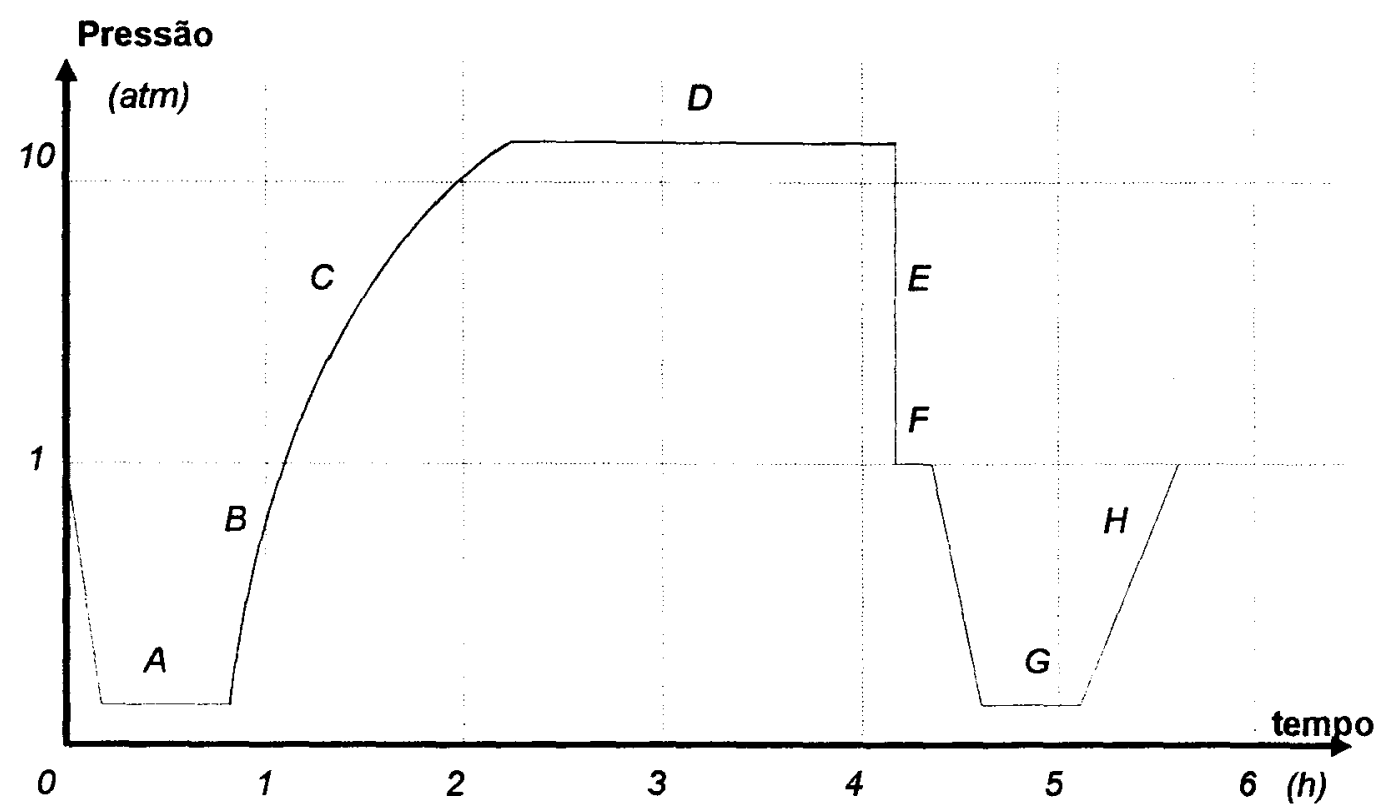

Processo de Célula Cheia

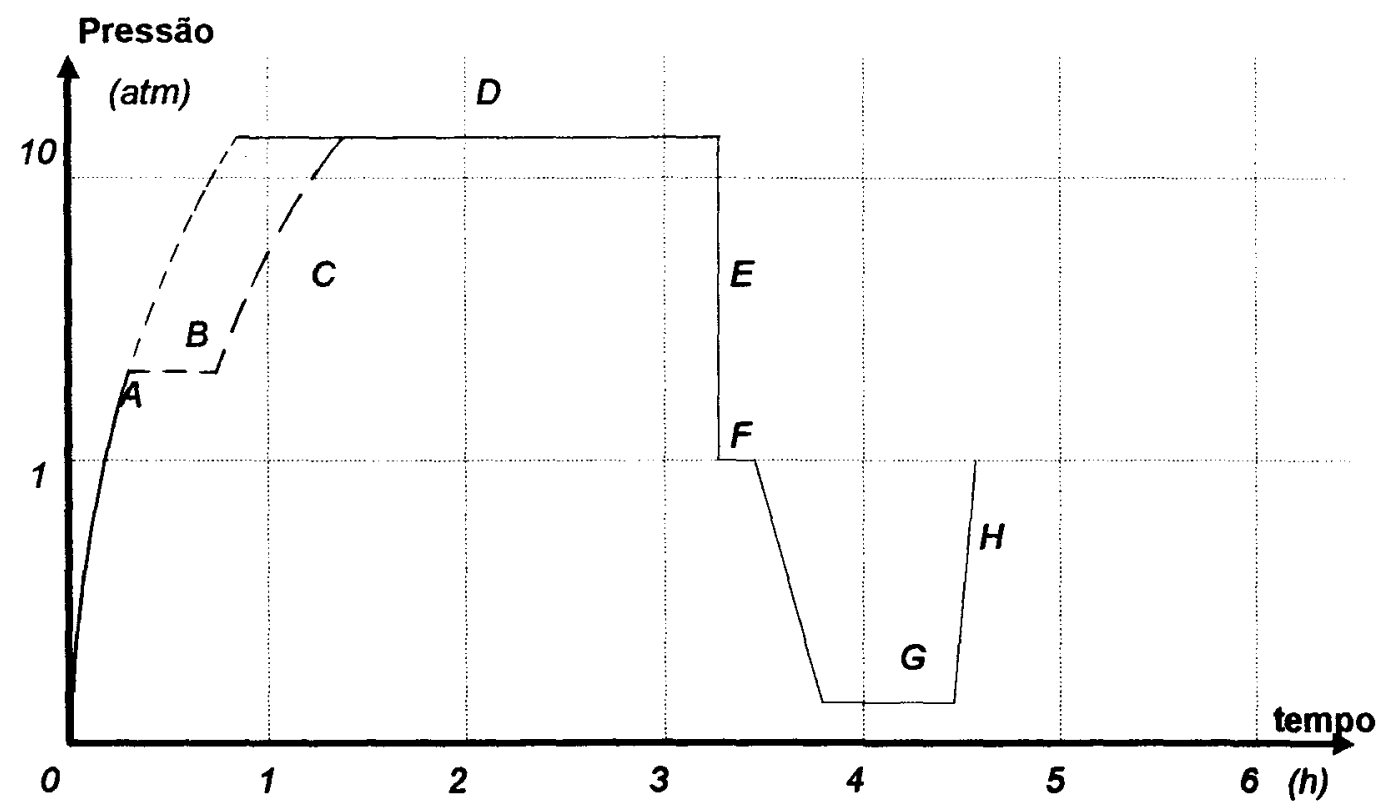

Processo de Célula Vazia

FIGURA 2.2 - Comparaçăo dos processos de preservaçăo à pressăo para a madeira. 
Resumindo, a aplicação de madeira preservada pode seguir as diretrizes:

(1) As madeiras a serem utilizadas em pontes de madeira serão necessariamente tratadas sob pressão. Requer-se unidades industriais licenciadas.

(2) Furos, ranhuras e danos eventuais, realizados em campo, no envelope de preservativo exigirão aplicação de pincelamento ous aspersão adicional antes de se fechar o orifico com conectores.

(3) Excepcionalmente o tratamento local poderá ser feito com um profissional treinado e com creosoto ou naftenato de cobre, se for base oleosa.

(4) Não se exige que o construtor que aplica madeira tratada seja licenciado pelas agências de proteção ambiental.

(5) O tratamento preservativo deve ser tal que os riscos ao ambiente sejam minimizados - isto se consegue utilizando a madeira estrutural somente após a estabilização da madeira

(6) Devem ser seguidas as normas que estabelecem as condições e balanceamento das soluções químicas e as retenções necessárias para o uso final são editadas anualmente pela American Wood Preservers' Association. As normas para análise e certificação/ controle de qualidade, manuseio e manutenção completam o livro de normas.

(7) O uso da madeira tratada amplia a durabilidade da madeira até o limite de duração do tratamento ou do fucionamento estrutural. Projetos de estruturas com tecnologia compatível e a aplicação correta dos preservativos estende a vida útil do projeto em aplicação final, proporcionando a perenização das pontes de madeira como parte da paisagem das vias de transporte.

FONTE:CROSSINGS - Newsletter of The National Timber Bridge Initiative - Vol. 8, Maio 1992 - TIMBER BRIDGE INFORMATION RESOURCE CENTER, Morgantown, WW. 


\subsection{ELASTICIDADE DA MADEIRA}

No aspecto de análise da elasticidade do material, considera-se L o eixo de anisotropia da madeira, pois seções transversais do tronco apresentam simetria radial e semelhança tangencial (simetria rômbica). A equação completa da Lei de Hooke é escrita matricialmente, em um sistema referido aos eixos cilíndricos $(r, \theta, z)$ :

$$
\begin{aligned}
& \varepsilon_{r}=a_{11} \sigma_{r}+a_{12} \sigma_{\theta}+a_{13} \sigma_{z}+a_{14} \tau_{\theta z}+a_{15} \tau_{r z}+a_{16} \tau_{r \theta} \\
& \varepsilon_{\theta}=a_{21} \sigma_{r}+a_{22} \sigma_{\theta}+a_{23} \sigma_{z}+a_{24} \tau_{\theta z}+a_{25} \tau_{r z}+a_{26} \tau_{r \theta} \\
& \varepsilon_{z}=a_{31} \sigma_{r}+a_{32} \sigma_{\theta}+a_{33} \sigma_{z}+a_{34} \tau_{\theta z}+a_{35} \tau_{r z}+a_{36} \tau_{r \theta} \\
& \gamma_{\theta z}=a_{41} \sigma_{r}+a_{42} \sigma_{\theta}+a_{43} \sigma_{z}+a_{44} \tau_{\theta z}+a_{45} \tau_{r z}+a_{46} \tau_{r \theta} \\
& \gamma_{r z}=a_{51} \sigma_{r}+a_{52} \sigma_{\theta}+a_{53} \sigma_{z}+a_{54} \tau_{\theta z}+a_{55} \tau_{r z}+a_{56} \tau_{r \theta} \\
& \gamma_{r \theta}=a_{61} \sigma_{r}+a_{62} \sigma_{\theta}+a_{63} \sigma_{z}+a_{64} \tau_{\theta z}+a_{65} \tau_{r z}+a_{66} \tau_{r \theta}
\end{aligned}
$$

Sendo $z$ o eixo correspondente $a L$, os eixos $r$ e $\theta$ de uma seção do tronco são correspondentes aos de uma seção adjacente, o que torna a matriz de coeficientes simétrica :

$$
\begin{aligned}
& \varepsilon_{r}=a_{11} \sigma_{r}+a_{12} \sigma_{\theta}+a_{13} \sigma_{z}+a_{14} \tau_{\theta z}+a_{15} \tau_{r z}+a_{16} \tau_{r \theta} \\
& \varepsilon_{\theta}=a_{12} \sigma_{r}+a_{22} \sigma_{\theta}+a_{23} \sigma_{z}+a_{24} \tau_{\theta z}+a_{25} \tau_{r z}+a_{26} \tau_{r \theta} \\
& \varepsilon_{z}=a_{13} \sigma_{r}+a_{23} \sigma_{\theta}+a_{33} \sigma_{z}+a_{34} \tau_{\theta z}+a_{35} \tau_{r z}+a_{36} \tau_{r \theta} \\
& \gamma_{\theta z}=a_{14} \sigma_{r}+a_{24} \sigma_{\theta}+a_{34} \sigma_{z}+a_{44} \tau_{\theta z}+a_{45} \tau_{r z}+a_{46} \tau_{r \theta} \\
& \gamma_{r z}=a_{15} \sigma_{r}+a_{25} \sigma_{\theta}+a_{35} \sigma_{z}+a_{45} \tau_{\theta z}+a_{55} \tau_{r z}+a_{56} \tau_{r \theta} \\
& \gamma_{r \theta}=a_{16} \sigma_{r}+a_{26} \sigma_{\theta}+a_{36} \sigma_{z}+a_{46} \tau_{\theta z}+a_{56} \tau_{r z}+a_{66} \tau_{r \theta}
\end{aligned}
$$

Como há um plano de simetria elástica perpendicular a z em cada ponto, então os coeficientes $a_{14}, a_{24}, a_{34}, a_{15}, a_{25}, a_{35}, a_{46}, a_{56}$ são iguais a zero. Como há dois planos de simetria elástica, radial e tangencial, então $a_{16}, a_{26}$, $a_{36}, a_{45}$ são também iguais a zero. Com isso : 


$$
\begin{aligned}
& \varepsilon_{r}=a_{11} \sigma_{r}+a_{12} \sigma_{\theta}+a_{13} \sigma_{z} \\
& \varepsilon_{\theta}=a_{12} \sigma_{r}+a_{22} \sigma_{\theta}+a_{23} \sigma_{z} \\
& \varepsilon_{z}=a_{13} \sigma_{r}+a_{23} \sigma_{\theta}+a_{33} \sigma_{z} \\
& \gamma_{\theta z}=a_{44} \tau_{\theta z} \\
& \gamma_{r z}=a_{55} \tau_{r z} \\
& \gamma_{r \theta}=a_{66} \tau_{r \theta}
\end{aligned}
$$

Com a introdução de constantes de elasticidade :

$$
\begin{aligned}
& \varepsilon_{r}=\frac{\sigma_{r}}{E_{r}}-\nu_{\theta r} \frac{\sigma_{\theta}}{E_{\theta}}-\nu_{z r} \frac{\sigma_{z}}{E_{z}} \\
& \varepsilon_{\theta}=-\nu_{r \theta} \frac{\sigma_{r}}{E_{r}}+\frac{\sigma_{\theta}}{E_{\theta}}+\nu_{z \theta} \frac{\sigma_{z}}{E_{z}} \\
& \varepsilon_{z}=-\nu_{r r} \frac{\sigma_{r}}{E_{r}}-\nu_{\theta z} \frac{\sigma_{\theta}}{E_{\theta}}+\frac{\sigma_{z}}{E_{z}} \\
& \gamma_{\theta z}=\frac{\tau_{\theta z}}{G_{\theta z}} ; \quad \gamma_{r z}=\frac{\tau_{\theta z}}{G_{\theta z}} ; \quad \gamma_{r \theta}=\frac{\tau_{r \theta}}{G_{r \theta}}
\end{aligned}
$$

No sistema de referência para a madeira :

$$
\begin{aligned}
& \varepsilon_{R}=\frac{\sigma_{R}}{E_{R}}-\nu_{T R} \frac{\sigma_{T}}{E_{T}}-\nu_{L R} \frac{\sigma_{L}}{E_{L}} \\
& \varepsilon_{T}=-\nu_{R T} \frac{\sigma_{R}}{E_{R}}+\frac{\sigma_{T}}{E_{T}}+\nu_{L T} \frac{\sigma_{L}}{E_{L}} \\
& \varepsilon_{L}=-\nu_{R L} \frac{\sigma_{R}}{E_{R}}-\nu_{L T} \frac{\sigma_{T}}{E_{T}}+\frac{\sigma_{L}}{E_{L}} \\
& \gamma_{T L}=\frac{\tau_{T L}}{G_{T L}} ; \quad \gamma_{R L}=\frac{\tau_{R L}}{G_{R L}} ; \quad \gamma_{R T}=\frac{\tau_{R T}}{G_{R T}}
\end{aligned}
$$

$E_{R}, E_{r}, E_{L}$ são os módulos de Young nas direções $R, T, L ; v_{T R}$ é o coeficiente de Poisson que caracteriza a compressão em $R$ para tração em $T$, etc., e $G_{T L}, G_{R L}, G_{R T}$ são os módulos transversais que caracterizam as variações de ângulo nas direções $T$ e $L, R$ e $L, R$ e $T$, respectivamente. Assim, para se caracterizar completamente a madeira, definem-se seis módulos de elasticidade e seis coeficientes de Poisson (Lekhnitskii, 1963). Investigações realizadas por Bodig e Jayne [BODIG,J. e JAYNE,B.A. (1982)] 
ressaltam que há grande variabilidade dos parâmetros elásticos, sendo as principais variáveis interferentes: espécies, velocidades de carregamento, temperatura, umidade, densidade da madeira. Apesar disso, apresenta as relações seguintes entre os módulos :

$E_{L}: E_{R}: E_{T} \cong 20: 1,6: 1$

$G_{L R}: G_{L T}: G_{R T} \cong 10: 9,4: 1$

$E_{L}: G_{L R} \cong 14: 1$

Estas relações não são constantes, pois variam com $E_{L}$. Os vários coeficientes de Poisson obedecem às relações seguintes :

$\frac{\nu_{L R}}{E_{L}}=\frac{\nu_{R L}}{E_{R}} ; \quad \frac{\nu_{L T}}{E_{L}}=\frac{\nu_{T L}}{E_{T}} ; \quad \frac{\nu_{R T}}{E_{R}}=\frac{\nu_{T R}}{E_{T}}$

A esta variabilidade natural soma-se a variação das formas de se obter os parâmetros elásticos. A definição destes está bem documentada no nosso meio - FUSCO (1993), FERREIRA (1994), MASCIA 1991) - mas sua obtenção tem sido bastante diversificada.

É possivel determinar-se os parâmetros elásticos por ensaios de compressão paralela às fibras, compressão inclinada em relação às fibras e em relação aos raios, tração paralela às fibras e tração inclinada em relação às fibras e aos raios, torção em placas - como especialmente referido por GOODMAN E BODIG (1970).

Uma vez conhecidos os valores do parâmetro mais importante e que determina a maioria das indicações para se usar a madeira - o módulo de elasticidade longitudinal $E_{L}$ - as relações dos outros parâmetros poderá ser estipulada razoavelmente, conhecendo-se lou determinando-se em 
laboratório) as equações que os relacionem. Em termos de 570 ensaios realizados em madeiras de coniferas e dicotiledôneas (compressão paralela, compressão inclinada e torção), BODIG e GOODMAN (1973) acrescentaram o ensaio de flexão em placas ao trabalho antecedente (de 1970) para determinar as equações procuradas, por exemplo :

$G_{L R}=3685.2 E_{L}^{0.23585}$

Em resumo, é possível estabelecer relações aproximadas para uso prático. Das relações [2.6] se tem :

$E_{L}: E_{R}: E_{T}: G_{L R}: G_{L T}: G_{R T} \cong 140: 11,2: 7: 10: 9,4: 1$

Com os índices de Poisson há variabilidade, como indicado nas Tabelas 2.1, 2.2, 2.3, 2.4, com a interdependência mostrada nas equações [2.7].

TABELA 2.1 - Valores dos indices de Poisson.

\begin{tabular}{ccc}
\hline Indice & Coniferas & Dicotiledôneas \\
\hline$v_{L R}$ & 0.37 & 0.37 \\
$v_{L T}$ & 0.42 & 0.50 \\
$v_{R T}$ & 0.47 & 0.67 \\
$v_{T R}$ & 0.35 & 0.33 \\
$v_{R L}$ & 0.041 & 0.044 \\
$v_{T L}$ & 0.033 & 0.027 \\
\hline
\end{tabular}

[Fonte : Bodig, J. e Jayne, B. A. (1982)].

Experimentação realizada por Mascia [MASCIA, N. T. (1991)] no Laboratório de Madeira e Estruturas de Madeira (LaMEM), em São Carlos, chegou a valores apresentados - de forma modificada - a seguir : 
TABELA 2.2 - Valores Comparativos.

\begin{tabular}{cccccc}
\hline Série c.p. & $E_{L} / E_{T}$ & $E_{L} / E_{R}$ & $E_{L} / G_{L T}$ & $E_{L} / G_{L R}$ & $E_{L} / G_{R T}$ \\
\hline$S_{1}$ & 10.336 & 7.363 & 8.412 & 7.607 & 53.411 \\
$S_{2}$ & 9.674 & 6.827 & 8.450 & 8.987 & 59.680 \\
$S_{3}$ & 13.784 & 8.467 & 10.249 & 8.960 & 84.779 \\
$S_{4}$ & 11.213 & 6.137 & 8.599 & 7.632 & 79.392 \\
$T_{C 1}$ & 11.171 & 7.415 & 8.277 & 9.931 & 53.807 \\
$T_{C 2}$ & 12.213 & 6.752 & 8.335 & 9.284 & 48.114 \\
$I_{1}$ & 18.786 & 10.322 & 21.708 & 29.094 & 50.642 \\
$A_{1}$ & 18.521 & 11.276 & 11.771 & 15.779 & 34.427 \\
$P_{1}$ & 7.417 & 5.213 & 17.821 & 10.083 & 47.042 \\
\hline Média & 12.568 & 7.752 & 11.514 & 11.869 & 56.810
\end{tabular}

Espécies utilizadas: Guapuruvu( Schizolobium parahyba)

Ipê ( Tabebuia impetiginosa)

Angico ( Parapiptadenia rigida)

Pinus ( Pinus elliottii)

[Fonte : Mascia, N. T. (1991)].

TABELA 2.3 - Valores obtidos.

\begin{tabular}{lllllll}
\hline Série c.p. & $v_{L T}$ & $v_{L R}$ & $v_{R T}$ & $v_{T L}$ & $v_{R L}$ & $v_{T R}$ \\
\hline$S_{1}$ & 0.6865 & 0.5585 & 0.8300 & 0.0645 & 0.0770 & 0.5300 \\
$S_{2}$ & 0.6359 & 0.5159 & 0.9611 & 0.0557 & 0.0713 & 0.6100 \\
$S_{3}$ & 0.7086 & 0.5932 & 0.9074 & 0.0606 & 0.0670 & 0.6125 \\
$S_{4}$ & 0.6238 & 0.6134 & 0.8673 & 0.0593 & 0.0711 & 0.5412 \\
$T_{C 1}$ & 0.4149 & 0.4166 & 0.6680 & 0.0318 & 0.0701 & 0.3541 \\
$T_{C 2}$ & 0.5019 & 0.4818 & 0.6802 & 0.0448 & 0.0662 & 0.3458 \\
$I_{1}$ & 0.4790 & 0.4345 & 0.6136 & 0.0270 & 0.0371 & 0.3532 \\
$A_{1}$ & 0.4549 & 0.5089 & 0.8068 & 0.0279 & 0.0484 & 0.4975 \\
$P_{1}$ & 0.3346 & 0.3701 & 0.6393 & 0.0477 & 0.0858 & 0.4509 \\
\hline Média & 0.5632 & 0.5154 & 0.7918 & 0.0465 & 0.0635 & 0.4805 \\
\hline
\end{tabular}

Média : exclusive $P_{1}$; Fonte : Mascia, N.T. (1991) p. 192. Madeiras analisadas : Guapurunu, Ipe, Angico, Pinus elliottii . 
TABELA 2.4 - Valores Comparados.

\begin{tabular}{ccccccc}
\hline & \multicolumn{3}{c}{ CONÍFERAS } & \multicolumn{3}{c}{ DICOTILEDÓNEAS } \\
indice & {$[1]$} & {$[2]$} & {$[1]-[2] /[1](\%)$} & {$[1]$} & {$[2]$} & {$[1]-[2] /[1](\%)$} \\
\hline$v_{L R}$ & 0.37 & 0.3701 & -0.03 & 0.37 & 0.5154 & -39.30 \\
$v_{L T}$ & 0.42 & 0.3346 & +20.33 & 0.50 & 0.5632 & -12.64 \\
$v_{R T}$ & 0.47 & 0.6393 & -36.02 & 0.67 & 0.7918 & -18.18 \\
$v_{T R}$ & 0.35 & 0.4509 & -28.83 & 0.33 & 0.4805 & -45.61 \\
$v_{R L}$ & 0.041 & 0.0858 & -109.27 & 0.044 & 0.0635 & -44.32 \\
$v_{T L}$ & 0.033 & 0.0477 & -44.55 & 0.027 & 0.0465 & -72.22
\end{tabular}

Fontes: [1] = Bodig e Jayne; [2] = Mascia,N.T.

Está razoavelmente bem estabelecido o conhecimento dos parâmetros de elasticidade da madeira, com mais ênfase à sua variabilidade do que propriamente ao seu valor:
$E_{L}>>E_{R}>E_{T}$
e
$G_{L T} \cong G_{L R}>G_{R T}$

\subsection{APLICAÇÃO DOS VALORES ÀS PONTES DE MADEIRA.}

De uma maneira geral, as pontes simples formam aspectos de placa na planta, com dois apoios extremos paralelos e transversais ao tráfego, e duas outras bordas longitudinais, paralelas e não conectadas diretamente à infraestrutura. No caso de estruturas de pontes, os efeitos relevantes são os momentos fletores longitudinal e transversal, as forças cortantes longitudinal e transversal e os momentos torçores de equilíbrio.

As estruturas construidas com madeira compõem longitudinalmente um meio contínuo, responsável pela transmissão dos esforços na estrutura para os apoios. Essa continuidade é funcional e os parâmetros que nela intervêm são $E_{L}, E_{T}$ e $E_{R}, G_{L T}, G_{L R}$ e $v_{L T}$ e $v_{L R}$. Pelos valores apresentados e para fins de análise destas estruturas, utilizam-se : 
- $E_{L}$;

- $E_{T}$, agrupando-se em um valor $E_{T}$ e $E_{R}$;

- $G_{L T}$, agrupando-se $G_{L T}$ e $G_{L R}$;

- $v_{L T}$, agrupando-se $v_{L T}$ e $v_{L R}$.

Adotando-se uma referência comparativa [BAKHT, B. (1983)] :

- $E_{T}=0.05 E_{L}$

- $G_{L T}=0.065 E_{L}$

- $v_{L T}=0.3$

- $E_{L} \geq 9600 \mathrm{MPa}$

A determinação dos parâmetros de rigidez da placa são diferenciados necessitando de critérios funcionais, diferentemente do uso comum. O caso geral de análise das placas ortotrópicas é dado pela equação diferencial (CUSENS, A. R. e PAMA, R. P., 1969) :

$D_{x} \frac{\partial^{4} w}{\partial \cdot x^{4}}+2 H \frac{\partial^{4} w}{\partial x^{2} \partial y^{2}}+D_{y} \frac{\partial^{4} w}{\partial y^{4}}=p(x, y)$

onde :

$\omega(x, y)$ é a função de deslocamento da estrutura;

$p(x, y) \quad$ é a função de carregamento da estrutura;

$D_{x} \quad$ é a rigidez longitudinal à flexão da ponte por metro de largura;

$D_{y} \quad$ é a rigidez transversal à flexão da ponte por metro de comprimento;

$D_{x y} \quad$ é a rigidez à torção por metro de largura;

$D_{y x} \quad$ é a rigidez à torção por metro de comprimento;

$D_{1}, D_{2}$ são as rigidezes combinados de torção;

$2 H \quad$ é a rigidez torcional total, tal que : $2 H=D_{y x}+D_{x y}+D_{1}+D_{2}$.

$(x, y) \quad$ coordenadas cartesianas do plano que contém a placa. 
Para a análise dos tabuleiros de pontes, de modo geral, há três possibilidades :

(1) $H^{2}>D_{x} \cdot D_{y}$ : a placa é rigida à torção e flexivel.

(2) $H^{2}=D_{x} \cdot D_{y}$ : a placa é isotrópica, tão rígida à torção quanto à flexão.

(3) $H^{2}<D_{x} \cdot D_{y}$ : a placa é rígida à flexão, sem rigidez à torção.

Em particular derivam-se :

(4) $D e(1)$, se $D_{y}=0$ : a placa é articulada para a flexão.

(5) $\mathrm{De}(3)$, se $H=0$ : a placa não trabalha com torção.

O diagrama a seguir resume o çaminhno teórico acima descrito.

PLACA ORTOTRÓPICA NO PLANO $(X, Y)$

$D_{x y}+D_{y x}+D_{1}+D_{2}=2 H \quad ; \quad w=$ deslocamento $=w(x, y) ;$

$p(x, y)=$ carregamento

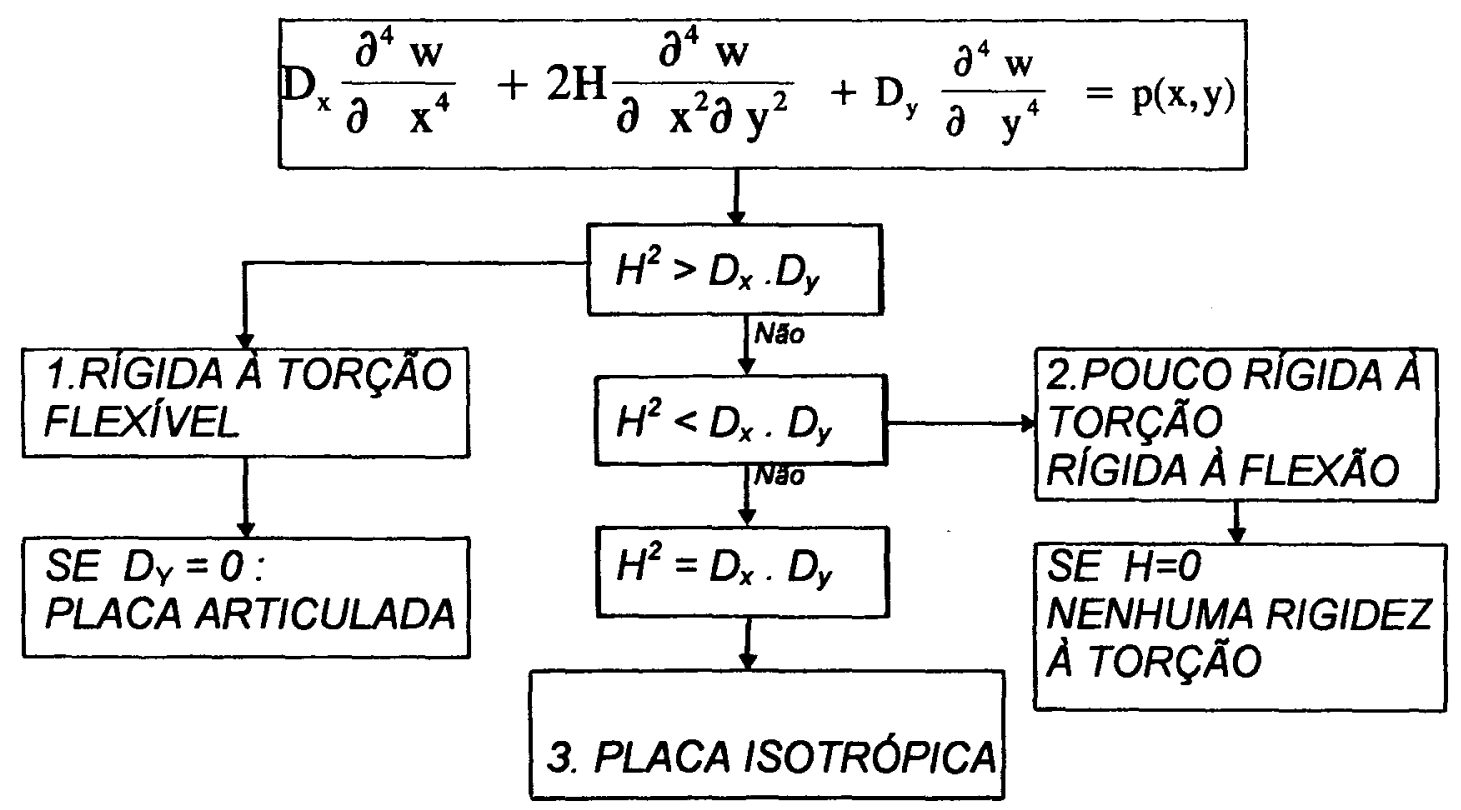

Para o caso de pontes de madeira calculam-se os parâmetros da placa ortotrópica conforme a tabela a seguir (BAKHT, 1983). 
TABELA 2.5 - Resumo de Valores para Cálculo

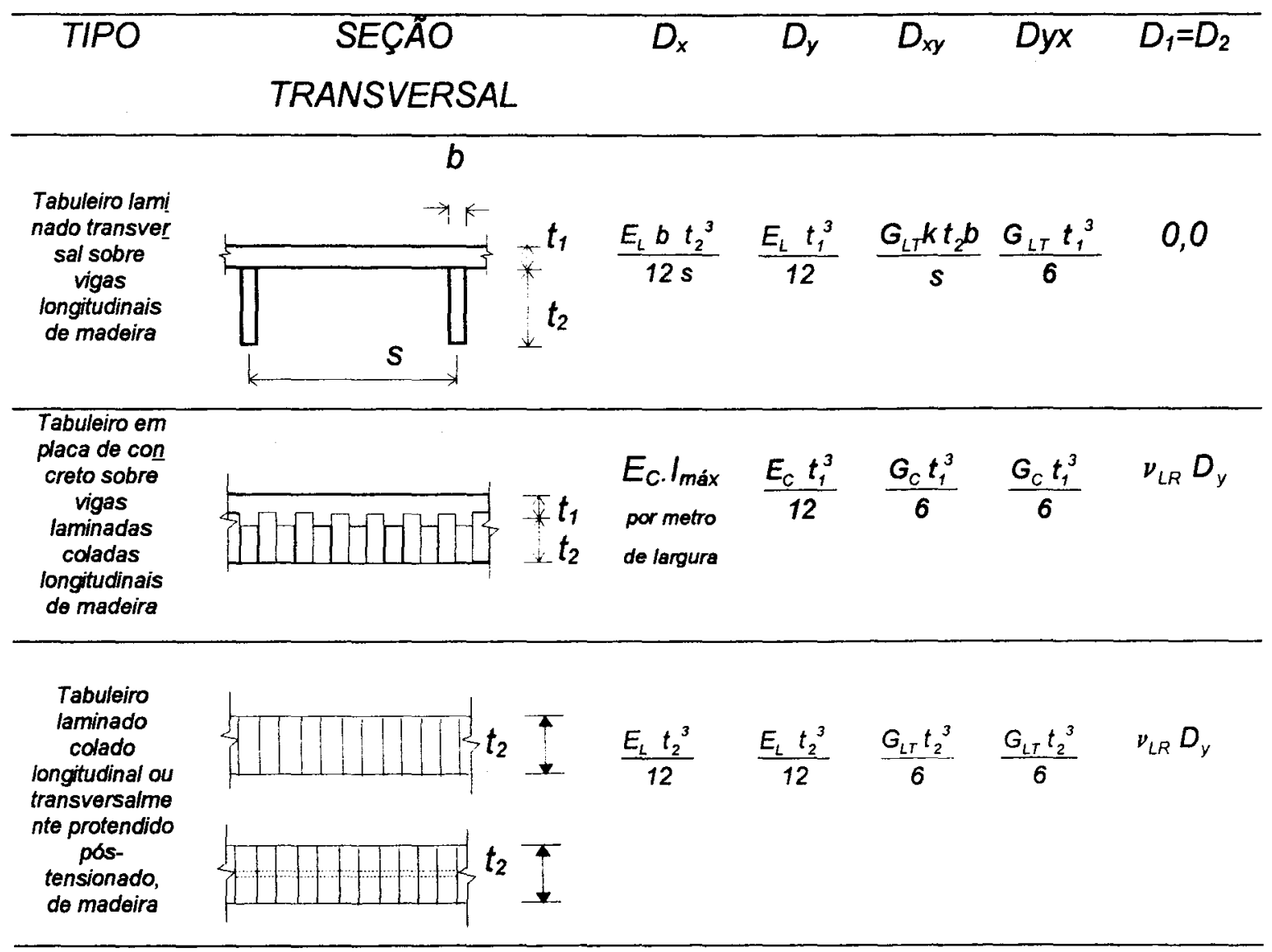

onde: $k$ é dado pela figura abaixo,

$E_{C}, G_{c}$ são do concreto

$I_{\text {máx }}$ é determinado com uso da relação modular $E_{C} / E_{L}$

$\mathrm{t} / \mathrm{b}>2: \mathrm{K}=0.333-0.21(\mathrm{~b} / \mathrm{t})$

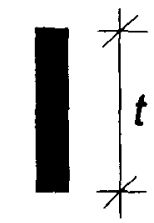

kt

b

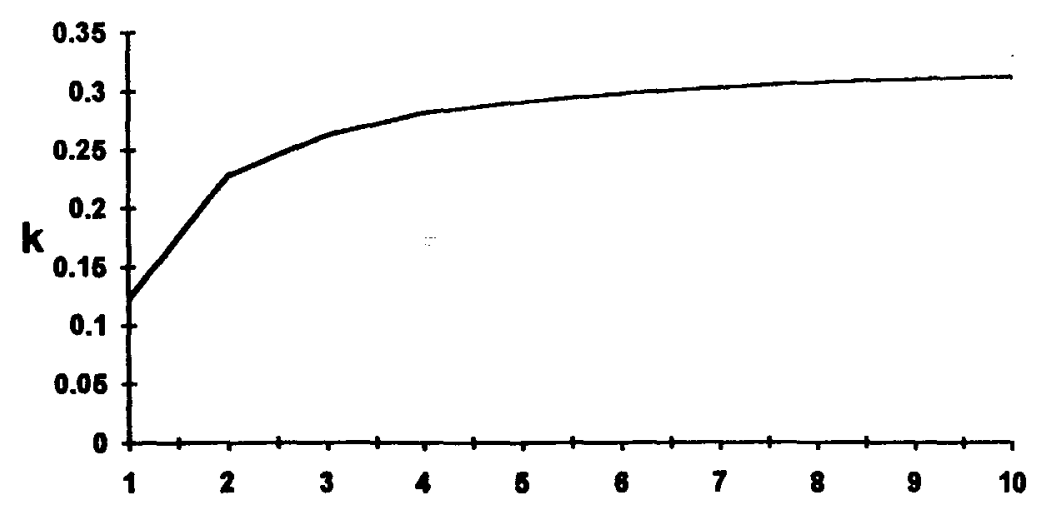

$\mathbf{t} / \mathbf{b}$ 
Esses parâmetros são determinados para o cálculo dos momentos fletores longitudinal e transversal, das forças cortantes longitudinal e transversal, gerados pelas ações permanentes e pelas ações acidentais.

Para a determinação dos efeitos das carga móvel, apresenta-se o método de Ontário, um modelo simplificado de cálculo que se baseia na teoria das placas ortotrópicas para ajustar os fatores determinantes do comportamento da ponte, no caso dos momentos fletores, e da analogia de grelha, no caso das forças cortantes. 


\section{3. - REVISÃO BIBLIOGRÁFICA}

\subsection{AMÉRICA DO NORTE}

Segundo UPPAL et al (1990a) havia em serviço, em 1976, 3700 quilômetros de pontes ferroviárias de madeira na América do Norte. Este número diminui desde então pela substituição das pontes de madeira por outros materiais.

Segundo OU e WELLER (1986), $12.6 \%$ das pontes com mais de $6 m$ de vão nos Estados Unidos (ou 71200) são de madeira. Somente no Serviço Florestal 7500 pontes de madeira estão em uso e mais estão em projeto e construção. As ferrovias têm mais de 2400 quilômetros de pontes e viadutos de madeira em pleno funcionamento.

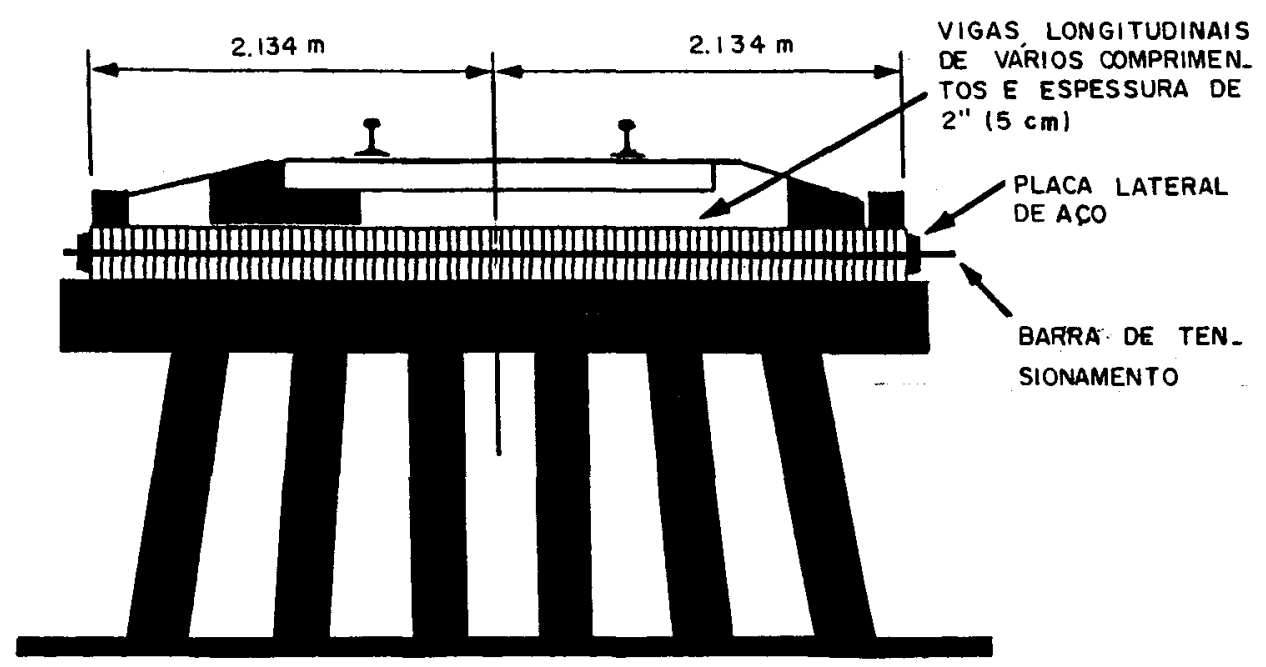




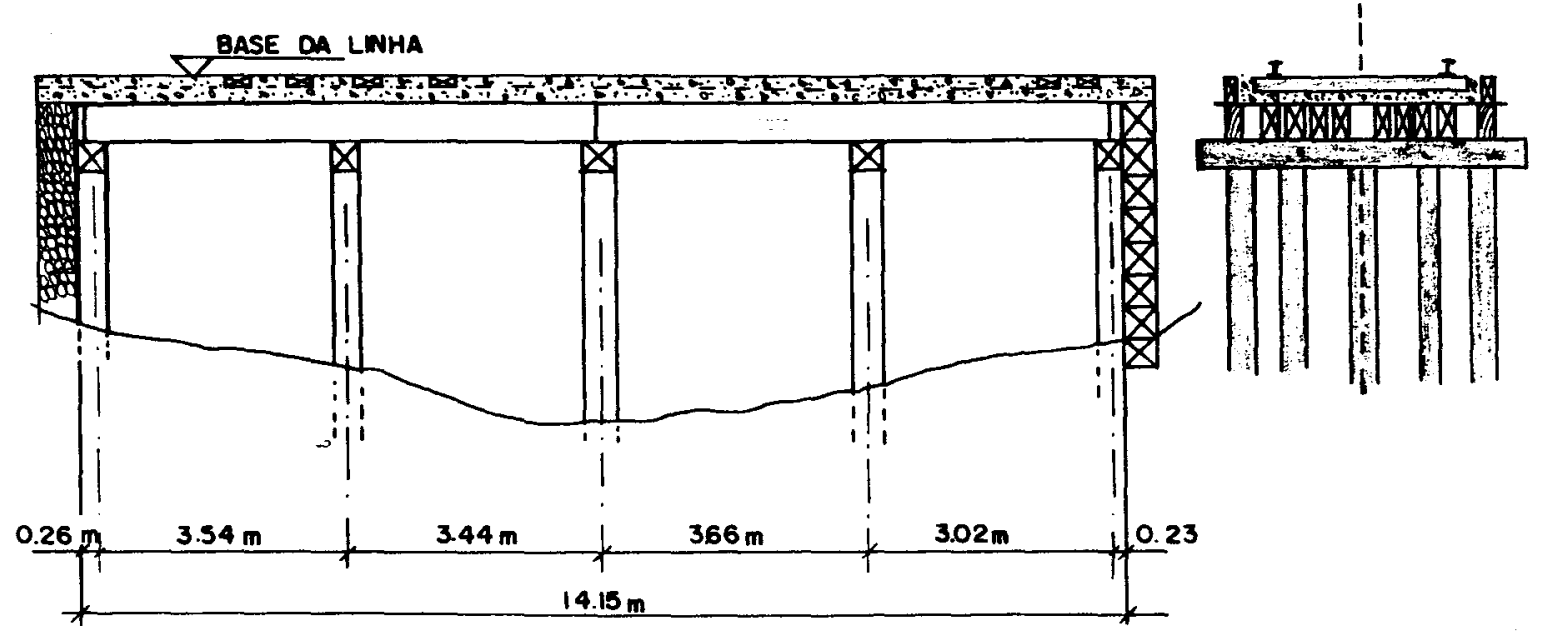

(A)

(B)

FIGURA 3.2 - Ponte ferroviária em madeira com tabuleiro lastrado

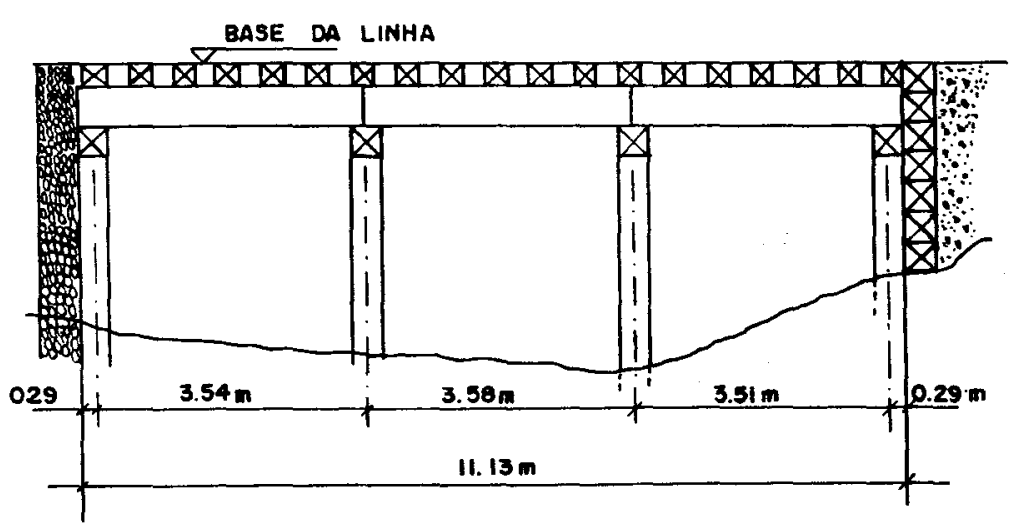

(A)

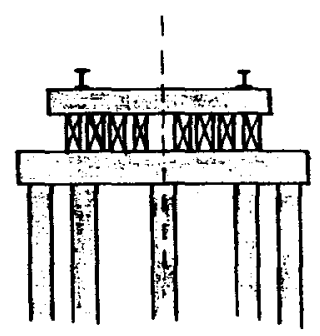

(B)

FIGURA 3.3 - Ponte ferroviária em tabuleiro aberto

\subsubsection{Canadá}

Das muitas construções em madeira existentes no Canadá nasceu a preocupação com a pequena durabilidade de um sistema barato, rápido e simples de se fazer - a placa de madeira laminada pregada.

Investigações conduzidas pela Província de Ontário, através do seu Ministério de Comunicações - Departamento de Engenharia Estrutural resolveram experimentar a protensão transversal de dupla camada naquelas placas como tentativa de recuperação e enrijecimento do conjunto. $A$ tentativa pioneira aconteceu em 1976 e foi monitorada por trés anos. Um 
corte da seção transversal, esquemático, é apresentado na Figura 3.4. A possibilidade de se dar curvatura transversal e também longitudinal pela protensão diferenciada é uma grande vantagem obtida pelo sistema, o que encorajou novas pesquisas.

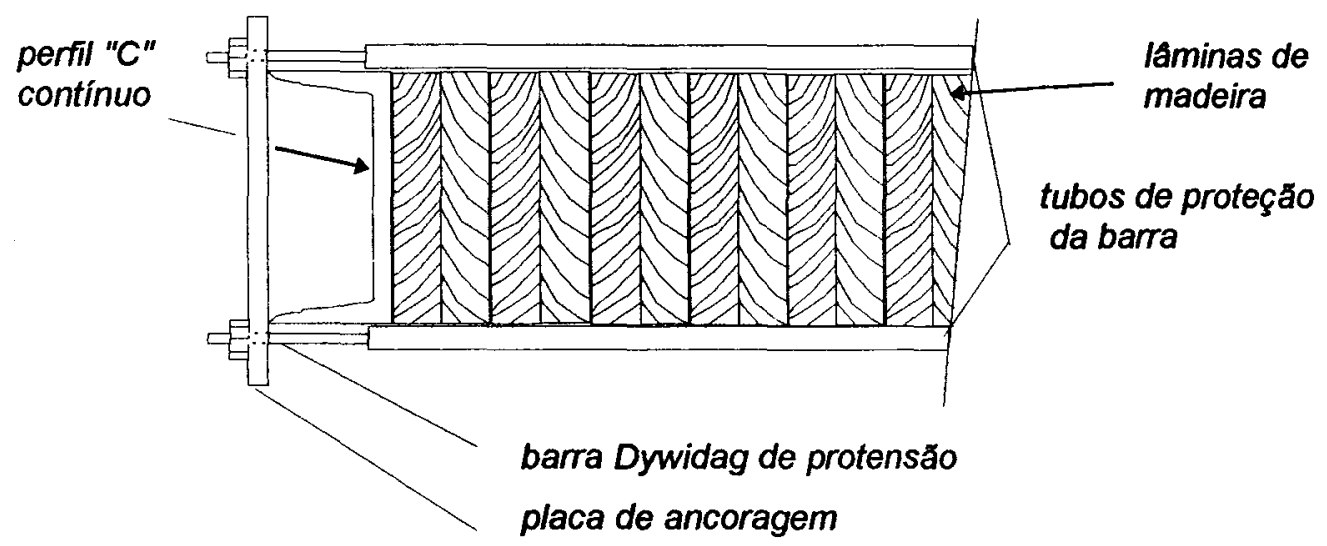

FIGURA 3.4 - Protensåo transversal para recuperaçăo estrutural.

No início da década de 1970, o uso de madeira para pontes estava virtualmente reduzido aos tabuleiros laminados pregados utilizando madeira serrada classificada, fornecendo vãos de até seis metros apenas. Além disso, estes tabuleiros apresentavam um sério problema para as equipes de manutenção: as pregações afrouxavam $e$ as lâminas longitudinais desprendiam-se (delaminação).

A menos que ocorresse uma idéia nova, a engenharia de pontes de madeira estava condenada à extinção, pois seria improvável a permanéncia da madeira desempenhando um papel sério na construção de pontes. Havia centenas de pontes de tabuleiros de madeira laminada pregada em toda a província de Ontário e o prejuizo econômico seria grande. Além disso, as madeiras utilizadas tinham os tamanhos mais disponiveis no mercado e, por esse singular motivo, representavam a melhor possibilidade para aperfeiçoamento futuro se os problemas associados a elas pudessem ser resolvidos (TAYLOR e RITTER,1990). Utilizando barras metálicas de alta resistência, o tabuleiro antigo seria reunido por compressão, criando-se o 
atrito adequado para restabelecer a continuidade transversal e a integridade estrutural para a distribuição das cargas.

A aplicação do sistema protendido transversal para a recuperação da ponte do Rio Pinckerel, na rodovia Trans-Canadá, na porção setentrional da província de Ontánio, provou-se um sucesso e várias provas de carga têm confirmado o desempenho superior destas pontes recuperadas com este sistema. Este sucesso detonou uma série extensa de pesquisas e desenvolvimentos, bancados pelo Ministério de Transportes de Ontário desde os primórdios dos anos 1970. Novos tabuleiros de madeira laminada tensionada ( $\mathrm{m} / \mathrm{t})$, usando uma única barra de aço por seção transversal, agora substituem o sistema pregado nos projetos de pontes de madeira. Essas pesquisas pioneiras permitiram que a segunda edição do Código de Cálculo de Pontes Rodoviárias de Ontário (ONTARIO HIGHWAY BRIDGE DESIGN CODE, 1983) já incorporasse diretrizes e especificações de cálculo para os tabuleiros de mitt.

Os primeiros tabuleiros construidos permitiram discutir os procedimentos mais adequados para a protensão. No tabuleiro longitudinal a limitação das larguras foi discutida e apreciada quando da recuperação da Sioux Narrows Bridge, realizado em 1982. A superestrutura é a de dois arcos treliçados, quase Bowstring, com tabuleiro inferior, e $\underline{64 \mathrm{~m}}$ de vão. $O$ tabuleiro contínuo, de $\underline{120 m}$ de extensão, foi construido em duas metades para se manter 0 fluxo do tráfego e depois as duas metades foram interconectadas e tensionadas para formar o meio contínuo necessário - as vigas transversais que sustentam o piso não foram substituídas. Construída em 1936, acreditase (TAYLOR e RITTER, 1990) que seja a maior ponte de madeira de vão simples da América do Norte. A ponte está aberta ao tráfego e permanece como um monumento à durabilidade da madeira para a construção das pontes rodoviárias. 
Outras aplicações do sistema laminado tensionado também foram desenvolvidas, com crescente aprendizado sobre seu desempenho. $\mathrm{Na}$ ponte sobre o Rio Aquasabon aplicou-se um tabuleiro tensionado transversal sobre vigas longitudinais de aço. Na primeira etapa, painéis do tabuleiro foram protendidos antes de serem levados a campo. Na segunda etapa cada painel foi posicionado sobre as vigas, então foram acoplados e tensionados contra o painel anterior, antes de serem fixados às longarinas de aço. Este método evitou a possível instabilidade que ocorreria se o tabuleiro fosse tensionado em toda a extensão $(42 m)$ de uma só vez. $\mathrm{Na}$ verdade, se alguma contenção à flambagem fosse necessária à protensão global de cada barra contra o tabuleiro, esta contenção afetaria seriamente os procedimentos e os resultados da protensão.

Em Fox Lake foi possivel aplicar um sistema de pórtico para um vão de $20 m$, totalmente pré-fabricado e transversalmente protendido com trabalho mínimo de fundações por causa das rochas sãs aflorantes no local. Aproveitando a localização, pré-fabricou-se pórticos com espessuras uniformes e ligações padronizadas com chapas metálicas galvanizadas a quente. A forma da estrutura é apresentada na figura 3.5.

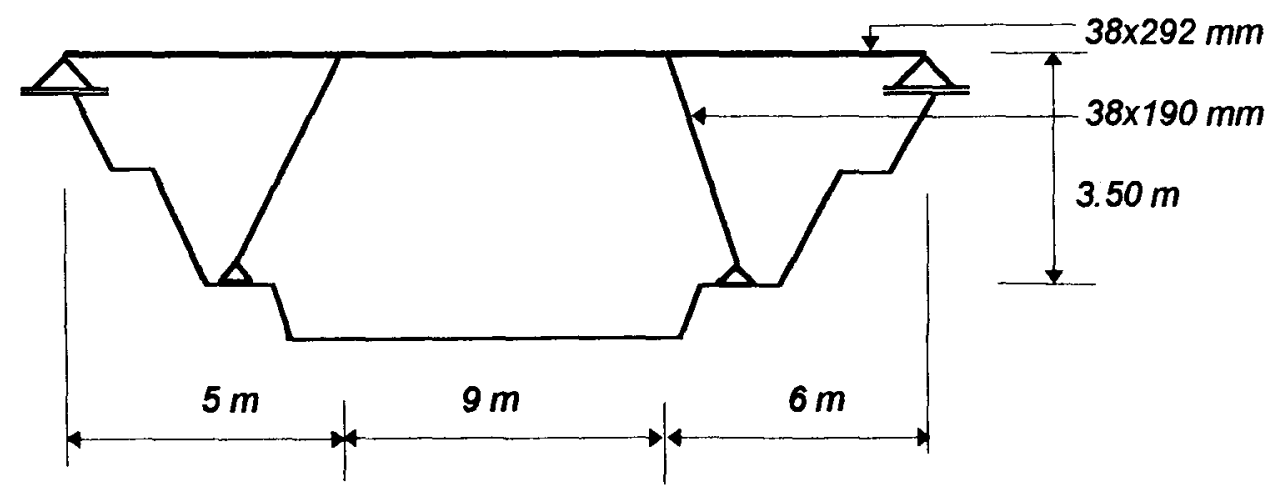

FIGURA 3.5 - Aspecto estrutural das placas que compoem o portico protendido da Ponte em Fox Lake, Ontário. 
As peças pré-fabricadas, pré-furadas, tratadas e já conectadas, foram posicionadas uma a uma (lado a lado), passou-se as barras de aço para protensão através dos furos e todas foram protendidas ao mesmo tempo, inclusive as pernas do pórtico. A estrutura finalizada foi carregada com o caminhão de 200.000 libras ( $900 \mathrm{kN}$ ) e a deflexão máxima do sistema foi de apenas $\underline{9 m m}$. A intenção inicial de se fazer um tabuleiro laminado transversal com vigas principais de aço foi avaliada em um custo de $50 \%$ superior pelo Ministério de Recursos Naturais de Ontário, proprietário da nova ponte. Embora essa forma esteja limitada a condições locais favoráveis, ficou evidenciada a viabilidade do sistema de madeira laminada tensionada em aplicações mais complexas.

Desenvolveu-se, também, conectores para a integração entre tabuleiros de madeira e vigas de aço, e sua aplicação em um vão de $50 \mathrm{~m}$ está sendo acompanhada pelo Ministry of Transportation of Ontario (MTO), com critérios de compatibilizaçào entre os materiais : o conector é soldado sobre o flange da viga de aço e cabe em um furo pré-executado de $150 \mathrm{~mm}$ de diâmetro no tabuleiro de madeira; em cada furo do tabuleiro cabem três conectores e o espaço é preenchido com argamassa não retraível, ou massa de calafetar.

O estudo de tabuleiros integrados também foi desenvolvido para suportar aplicações a maiores vãos, nascendo a idéia do tabuleiro celular onde almas são integradas aos tabuleiros para formar um sistema combinado. As almas são de chapas fibrosas laminadas ou vigas de madeira laminada colada de altura plena, Figura 3.6. A seção"T"é uma variação desta idéia e tem grande aceitação em toda a América do norte. 


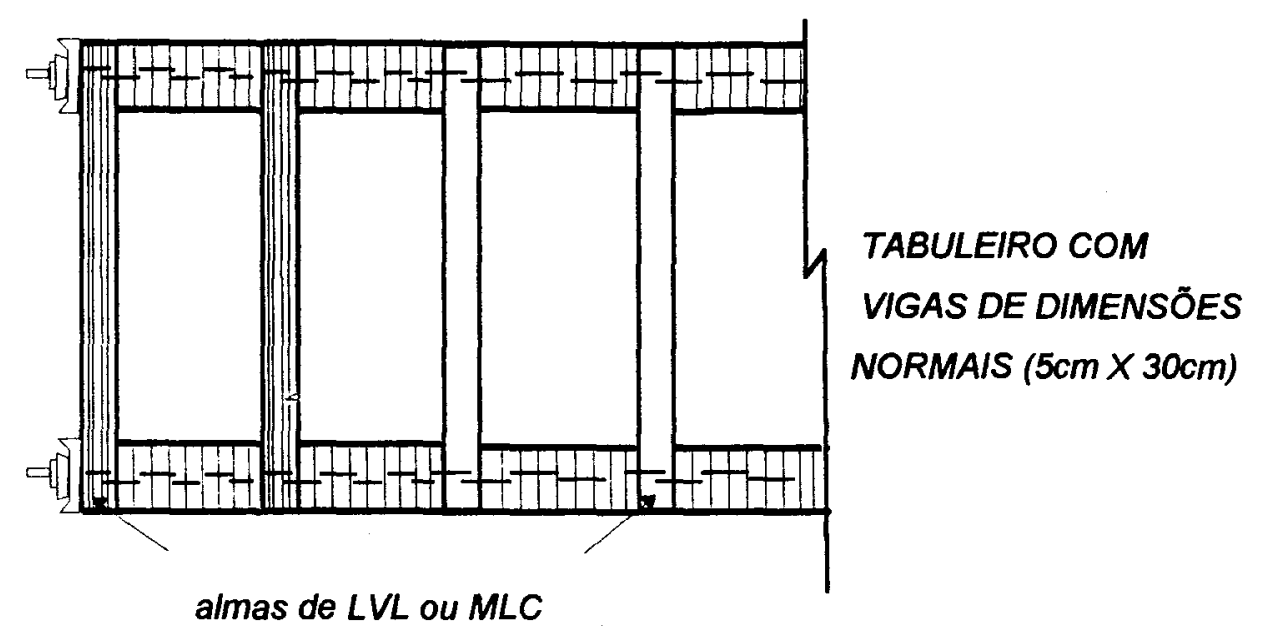

FIGURA 3.6 - Sistema com tabuleiro celular de madeira.

Nas concepções dos projetos pelo MTO foi analisado o projeto com treliças para a confecção das almas, porque as treliças são de produção simples, rápidas e padronizadas, variando a sua altura conforme necessidade do vão, podendo ser construídas por módulos, virtualmente compondo-as em qualquer tamanho. O problema é a realização das conexões, notadamente das diagonais aos banzos, especialmente das placas de aço galvanizadas: seu desempenho ante cargas repetitivas. O resultado experimental, inclusive de uma estrutura de $6 \mathrm{~m}$, foi conclusivo: as placas de aço são suscetíveis à fadiga sob carregamentos repetitivos. Os resultados estáticos, embora demonstrassem que a interação entre diagonais e tabuleiro pudesse ser conseguida, levaram à consideração de se utilizar almas sólidas compostas de placas de láminas com fibras paralelas - não o compensado, mas o veneer (LVL) - e o uso de treliças foi descartado.

Esta concepção de sistema integrado visa obter vãos de $60 \mathrm{~m}$ ou até mais, por isso o espaçamento das almas (ou o tamanho das células) é reduzido e esta pequena distância pode ser compensada com o uso de almas delgadas desde que sejam bem conhecidas as caracteristicas de resistencia à flexão e à torção dos materiais empregados. Nessas diretrizes os pesquisadores do MTO estão desenvolvendo a caracterização dos materiais e dos primeiros protótipos. 
Se a altura do sistema celular for menor, a capacidade, em termos de vão, será menor, mas o conjunto trabalhará por resistência à flexão e à torção. Deformações excessivas destas pontes, sejam em geral, sejam diferenciais dentro do conjunto, conduzirão a problemas graves de manutenção provocados pela fadiga induzida aos componentes e à ruína da camada de desgaste (capa asfáltica betuminosa).

Todas estas aplicações visam o aproveitamento de espécies de madeira locais e manufaturas já instaladas de produção, beneficiamento, tratamento e industrializaçào de estruturas de madeira para a confecção dos sistemas de piso, tanto quanto possivel.

\subsubsection{Estados Unidos}

Empresas privadas, agências governamentais e consultores estão envolvidos, em graus diversos, há bastante tempo, com pesquisa e desenvolvimento das pontes de madeira nos Estados Unidos. Embora tenha ocorrido o declínio tecnológico das construções até 1980 por causa do desinteresse dos construtores e escassez de material, podem ser citadas as instituições seguintes :

3.1.2.1. - American Institute of Timber Construction (AITC), que deu suporte nacional à produção de pontes de madeira especializando-se em produtos de madeira laminada colada $(\mathrm{m} / \mathrm{c})$. São marcos deste Instituto as especificações Standard Specifications of Structural Glued Laminated Timber (1974), AITC 117-74, para critérios de projeto, classificação e produção de peças estruturais de $\mathrm{mlc}$, e o relatório Modern Timber Highway Bridges : A State of the Art Report (1973), descrevendo a evolução dos sistemas estruturais para pontes de madeira laminada colada, com atenção às vigas principais e ao tabuleiro produzido com esses sistemas. O AlTC apresentou o Timber Construction Manual (1974) com estas informações e todas as 
exigências pertinentes às estruturas de $\mathrm{mlc}$ em geral e, na Parte 1, Seção 4, há um item específico para as pontes de madeira; na Parte 2 estão todas as especificações necessárias ao material: adesivos, presenvativos e métodos de trabalho.

\subsubsection{American Association of State Highway and Transportation} Officials (AASHTO), que tem apresentado critérios de distribuição de carga e especificações para cálculo, projeto e construção de pontes de madeira através da Standard Specifications of Highway Bridges (1989) desde 1931.

\subsubsection{Federal Highway Administration (FHWA) e O Transportation} Research Board (TRB) que, em conjunto com a AASHTO e diversos Departamentos Rodoviários Estaduais, têm desenvolvido pesquisas nacionais desde 1962 com o National Cooperative Highway Research Program (NCHRP). Este programa tem vários temas e recursos financeiros aprovados pelo Congresso Nacional e implementado também pelo National Research Council através das universidades. Em particular interesse, o National Cooperative Highway Research Program tem as áreas 10-Materiais e Construção : Especificações, Procedimentos e Práticas; e 12-Projeto : Pontes. Nesta área estão diversos projetos temáticos, como o 12-26 (Distribuição de Cargas de Rodas em Pontes Rodoviárias), o 12-28(4) (Métodos de Reforço para Pontes Rodoviárias Existentes), o 12-33 (Desenvolvimento de Especificações Abrangentes para Pontes e Comentários), onde está o 12-33A (Estruturas de Madeira e Adequação Normativa), em desenvolvimento desde 1988. Este projeto de pesquisa visa 0 desenvolvimento de uma especificação completamente nova no formato Load and Resistance Factor Design (LRFD) probabilistico, com fatores de ponderação para cargas e resisténcias, e sua versão final será apresentada à AASHTO para avaliação e posterior adoção. 
3.1.2.4. American Railway Engineering Association (AREA), que tem apresentado no seu Manual for Railway Engineering as recomendações de cálculo e construção de pontes e cavaletes - pilar, estaca e travessas de madeira, tensões para madeira serrada, exigências de construção e manutenção, tabelas de carregamento e desenhos típicos para diversos carregamentos ferroviários. 。

\subsubsection{Forest Service, United States Department of Agriculture (FS-} USDA), através do Forest Products Laboratory (FPL) que gerencia todos os parques nacionais, áreas de recuperação ambiental $e$ desenvolvimento de projetos em estruturas de madeira, em especial pontes de madeira.

3.1.2.6. American Society of Civil Engineers (ASCE), que conduziu dois estudos sobre as pontes de madeira. O Committee on Wood in the Structural Division of the ASCE compilou extensa bibliografia sobre o projeto de pontes de madeira em 1975, e classificou um conjunto de especificações normativas em Critérios Principais e Critérios Suplementares, tanto para madeira serrada como para madeira laminada colada. Outro estudo, conduzido pelo ASCE Technical Committee on Timber Bridges apresentado por Gutkowski e Williamson (1983) mostrou um resumo dos avanços tecnológicos conseguidos em pontes de madeira e inclui discussões a respeito de novos materiais combinados com a madeira, técnicas de tratamento, manufatura, as melhorias nos métodos de preservação contra a deterioração, 0 desenvolvimento de novas concepções nos sistemas estruturais de pontes de madeira, o avanço nas técnicas de projeto e de análise de pontes de madeira.

Um inventário nacional das situações das pontes iniciou a mobilização destes agentes quando o TRB os reuniu na conferência BRIDGE ENGINEERING em St. Louis, Missouri (1978). Na ocasião foi divulgado que, 
no sistema viário principal, havia 40.000 pontes estruturalmente deficientes nos EUA e os códigos normativos não modificavam esta situaçăo. Em 1984 houve outra conferência e os agentes passaram a dar atenção aos novos desenvolvimentos que surgiram no Canadá e já constavam da segunda edição do ONTARIO HIGHWAY BRIDGE DESIGN CODE (1983), com as pontes de madeira laminada prctendida. Os estudos, coordenados pela FHWA, mostraram (NATIONAL BRIDGE INVENTORY, 1987) que $41 \%$ das 578000 pontes rodoviárias dos EUA constituiam-se em estruturalmente deficientes ou funcionalmente obsoletas, totalizando 237.000 pontes necessitando de reparo, reforço ou substituição.

Ainda em 1983, o Committee on Wood da ASCE realizou um workshop intitulado Structural Wood Research : State-of-the-Art and Research Needs onde o Painel 4 trabalhou com estruturas pesadas e pontes. Foi salientado o desenvolvimento dos processos de tratamento e proteção da madeira com o aperfeiçoamento dos projetos, como o uso de uma superfície asfáltica para a pista de rolamento como proteção a ciclos frequentes de mudanças dimensionais provocadas pela variação de umidade, acompanhados de tratamentos a pressão para impregnação da madeira com as substâncias preservantes. Especial ênfase é dada à preferência por tratamentos em base oleosa, com creosoto ou pentaclorofenol - este recebeu mais intensa restrição das agências de proteção ao meio ambiente (EPA's) posteriormente. $O$ creosoto é o tratamento preservativo que oferece melhor resistência à umidade e é indicado tanto para as vigas como para os painéis do tabuleiro, mas não para as partes das pontes que tenham contato com o homem, como os guarda-corpos. Neste caso utilizam-se os tratamentos à pressão em base aquosa que, se não são tão agressivos ao homem, levam a madeira a trabalhar bastante - isto é, inchar-retrair-inchar..., com ciclos de variação dimensional. No caso de madeiras laminadas coladas, duas conclusões são importantes:

1. Tratamento em base aquosa : deve ser feito nas peças de madeira antes de se processar a colagem; 
2. Tratamento em base oleosa : deve ser feito nas peças de mlc depois de todos os furos executados, isto é, nas peças já coladas, antes da montagem final.

Ainda em relação aos tratamentos, concluiu-se que o envelope de preservativos do material deve estar íntegro, de modo que a madeira não tratada não seja exposta aos agentes de deterioração - razão pela qual furações no local da obra devam ser previstas e pré-executadas (antes do tratamento final).

Os desenvolvimentos tecnológicos do sistema produtivo também foram salientados: novos materiais e novas formas de apresentação dos materiais; abordagem sistêmica para as configurações estruturais; melhoria dos sistemas de cálculo através de recursos computacionais. Os desenvolvimentos até então podem ser sistematizados na figura seguinte :

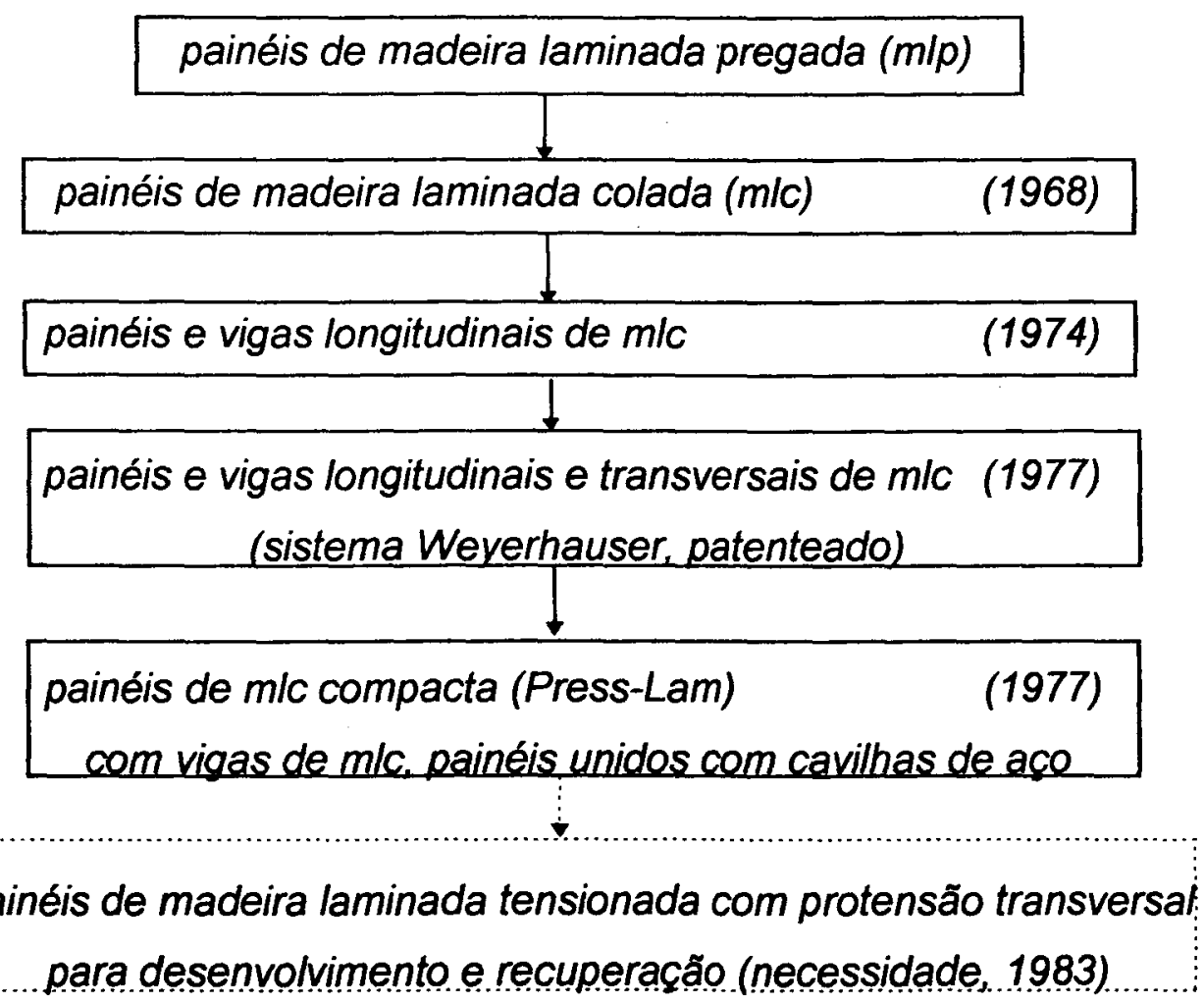

As necessidades de pesquisas salientaram os desenvolvimentos já paralelos e bem-sucedidos no Canadá. 
Isto gerou a percepção do alto custo e do severo impacto econômico para os Estados Unidos. Com a maioria das estruturas de pontes localizam-se em vias rurais ou de ligação local, em vias de duas faixas de tráfego, dignosticou-se que tinham o perfil adequado para as pontes de madeira. Os avanços tecnológicos no tratamento, preservação e projeto em madeira

- tornou as pontes de madeira uma alternativa segura, atraente e econômica ao aço e ao concreto. As pontes fazem a comunicação terrestre dos mercados local, regional e nacional, dando apoio à expansão de negócios, permitindo trocas, vendas, viagens, acelerando o ritmo econômico que, em retorno, dá ao poder público renda adicional em taxas e serviços. As pontes de madeira modernas ainda possibilitam expandir este padrão, usando ánores de espécies disponiveis e trabalhadores locais.

Em 1989, neste contexto, o Congresso dos Estados Unidos lançou a Timber Bridge Initiative (TBI) - Iniciativa em Pontes de Madeira - para melhoria das comunicações rurais e revitalização destas economias usando a madeira para a construção de pontes. Com estes recursos, foram construídas pontes demonstrativas - para pedestres e para veículos (235 até dezembro de 1992), viabilizando os objetivos fundamentais :

1. Melhoria das Vias de Transporte Rurais.

2.Expansão do Mercado de Produtos de Madeira.

3.Criação de Serviços Industriais para Construção de Pontes de Madeira.

Metas intermediárias foram propostas:

i. Pontes Demonstrativas: estimular a consciência de alternativas viáveis e eficientes às técnicas e materiais tradicionais de construção de pontes.

ii. Pesquisa: otimizar o equilíbrio entre a tecnologia existente e a tecnologia em desenvolvimento no uso da madeira como material estrutural.

iii. Transferência Tecnológica e Gerenciamento da Informação: gerenciar a informação sobre uso da madeira em infra-estrutura de transportes e transferir tecnologia e informação a um grande nümero de usuários. 
iv. Revitalização Rural: estabilizar e revitalizar o desempenho econômico das unidades produtoras através do desenvolvimento das indústrias de serviço (processamento, beneficiamento, tratamento, pré-montagem) e expansão de mercados.

No âmbito da $\underline{\text { TBI }}$ montou-se escritórios de referência, sendo o principal em West Virginia, o Timber Bridge Information Resource Center (TBIRC), que reuniu as iniciativas das agências governamentais (AASTHO, FHWA, TRB, USDA-FS) com as universidades em todo o País e, ainda, cadastrou pesquisadores e projetistas e reuniu toda a bibliografia produzida e de interesse sobre pontes de madeira e delegou metas às unidades de pesquisa. Os frutos já começam a aparecer: três projetos básicos foram detalhados para aplicação pela $\underline{\text { IBI }}$ em todos os Estados Unidos:

1. a ponte em placa protendida transversalmente;

2. a ponte com vigas de madeira laminada colada longitudinais e protendida transversalmente;

3. a ponte em placa celular, com vigas longitudinais de madeira laminada colada, protendida transversalmente nos dois planos e com diafragmas intermediários.

Estes projetos básicos estão aqui apresentados como projetos Tipo $A, B$ e $C$ respectivamente (Figura 3.7). As especificações de projeto, fabricação, montagem, tensionamento, métodos de construção, vãos e detalhes estão apresentados no ANEXO A.

Um exemplo típico das construções usando placas de madeira laminada pregada (década de 1970) também está apresentado no ANEXO A. 


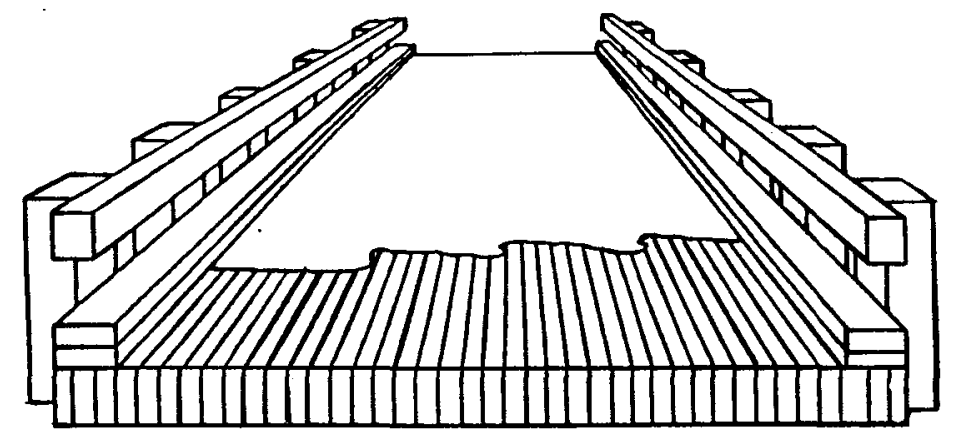

(a)

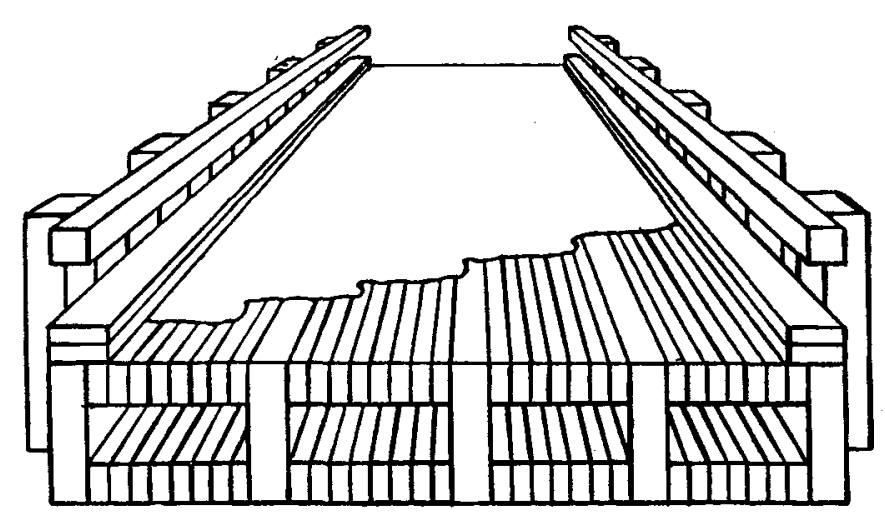

(b)

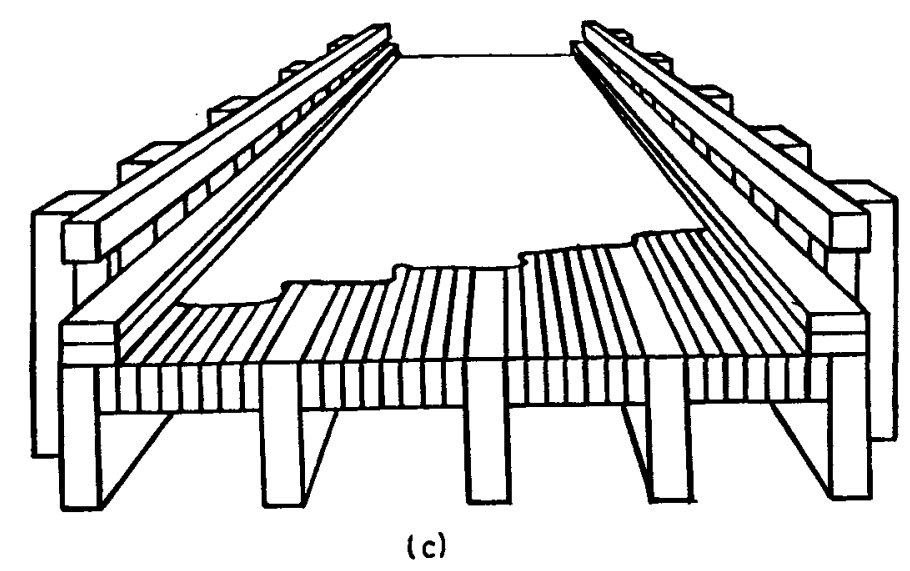

FIGURA 3.7 - Pontes de Madeira Laminada Tensionada (mlt), West Virginia University, da TBI.
a) Placa;
b) Placas com Vigas de madeira laminada colada (mlc);
c) Celular com nervuras de mlc. 


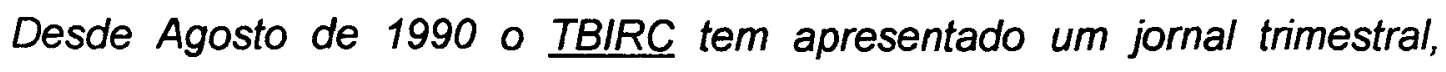
"Crossings" com sistemática atualização de informações e publicações que têm se tornado disponiveis.

Exemplos de esforço bem-sucedido já estão disponíveis em um manual de amplo espectro : Timber Bridges : Design, Construction, Inspection and Maintenance [RITTER, 1990], com 18 capitulos e abordando :

- madeira como material para construção de pontes e tipos de pontes de madeira;

- preservação e proteção de pontes de madeira;

- conceitos básicos do projeto com madeira;

- ações e forças em pontes de madeira;

- projeto de superestruturas em viga, em tabuleiro longitudinal (tensionado ou não);

- sistemas de guarda-corpo e superfícies de rolamento para tabuleiros de madeira;

- fabricação e construção de pontes de madeira;

- inspeção de pontes para deterioração;

- manutenção;

- recuperação;

- substituição.

Após a edição deste manual, aperfeiçoamentos já estão sendo estudados, como um tabuleiro longitudinal de dupla camada, transversalmente tensionado, Figura 3.8 e auxiliado com chapas metálicas.

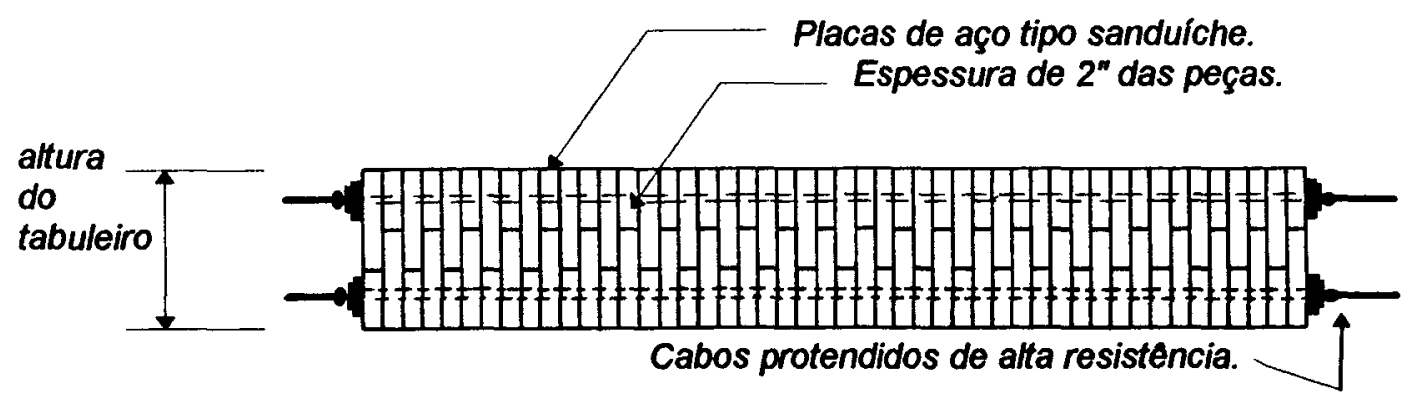

FIGURA 3.8 - Tabuleiro de mit de dupla camada. 
Em 1991 a AASHTO publicou a Guide Specification for the Design of StressLaminated Wood Decks, uma recomendação para o cálculo e projeto de pontes de madeira laminada tensionada, não sendo ainda incorporada à Norma AASHTO (Standard Specifications for Highway Bridges) de 1989.

Em 1992 terminou a construção da maior ponte rodoviária, para duas faixas, em madeira, em todo o mundo. É uma estrutura suspensa em estais, que passam em duas torres em forma de arco gótico. Tem 469 pés (143 m) de extensão, com dois vãos laterais de 108 pés ( $33 \mathrm{~m}$ ) e um vão central de 253 pés $(77 \mathrm{~m})$. Apresenta 16 pés $(4,9 \mathrm{~m})$ de largura, foi instalada em Junho e Julho daquele ano para a abertura ao tráfego em Setembro, na ligação do aeroporto com a área urbana de Hiroshima no Japão. O piso constitui-se de uma "treliça de banzos paralelos" com almas de madeira entre os "banzos". Os módulos foram produzidos em treze partes, cada uma correspondendo ao cabo de suspensão (doze, de 1-7/8" de diâmetro - $48 \mathrm{~mm}$ ) e ao apoio da torre. As dimensões das peças são 8-3/4" (222 mm) x 24" (610 mm) para a parte superior e 8-3/4" (222 mm) x 27" (686 mm) para a inferior, em madeira laminada colada $(\mathrm{m} / \mathrm{c})$. Todas as peças de alma são de 8-3/4" (222 $\mathrm{mm})$ × $9^{\prime \prime}$ $(229 \mathrm{~mm})$ de $\mathrm{m} / \mathrm{c}$. Os painéis longitudinais de m/c têm 6-3/4" (171 mm) x 48" $(1219 \mathrm{~mm})$, apoiados em vigas de piso de aço, espaçadas de 9pés $(2,74 \mathrm{~m})$, conformam o tabuleiro da ponte. As superfícies de m/c foram protegidas com uma capa geotextil e uma camada de asfalto para impermeabilização e superfície de rolamento. Todas as peças de mlc foram tratadas à pressão e toda a ferragem foi galvanizada a quente. 

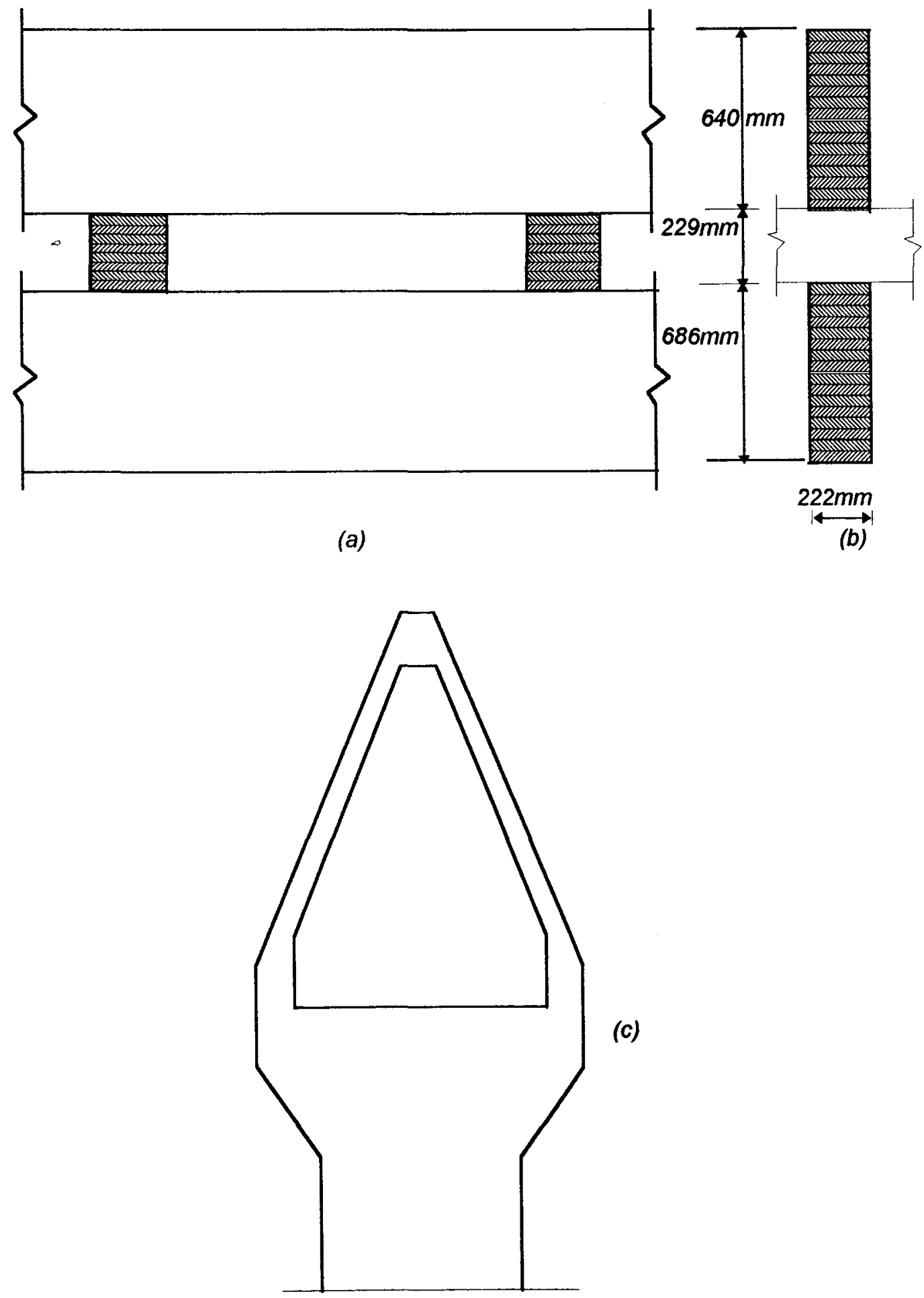

(c) 


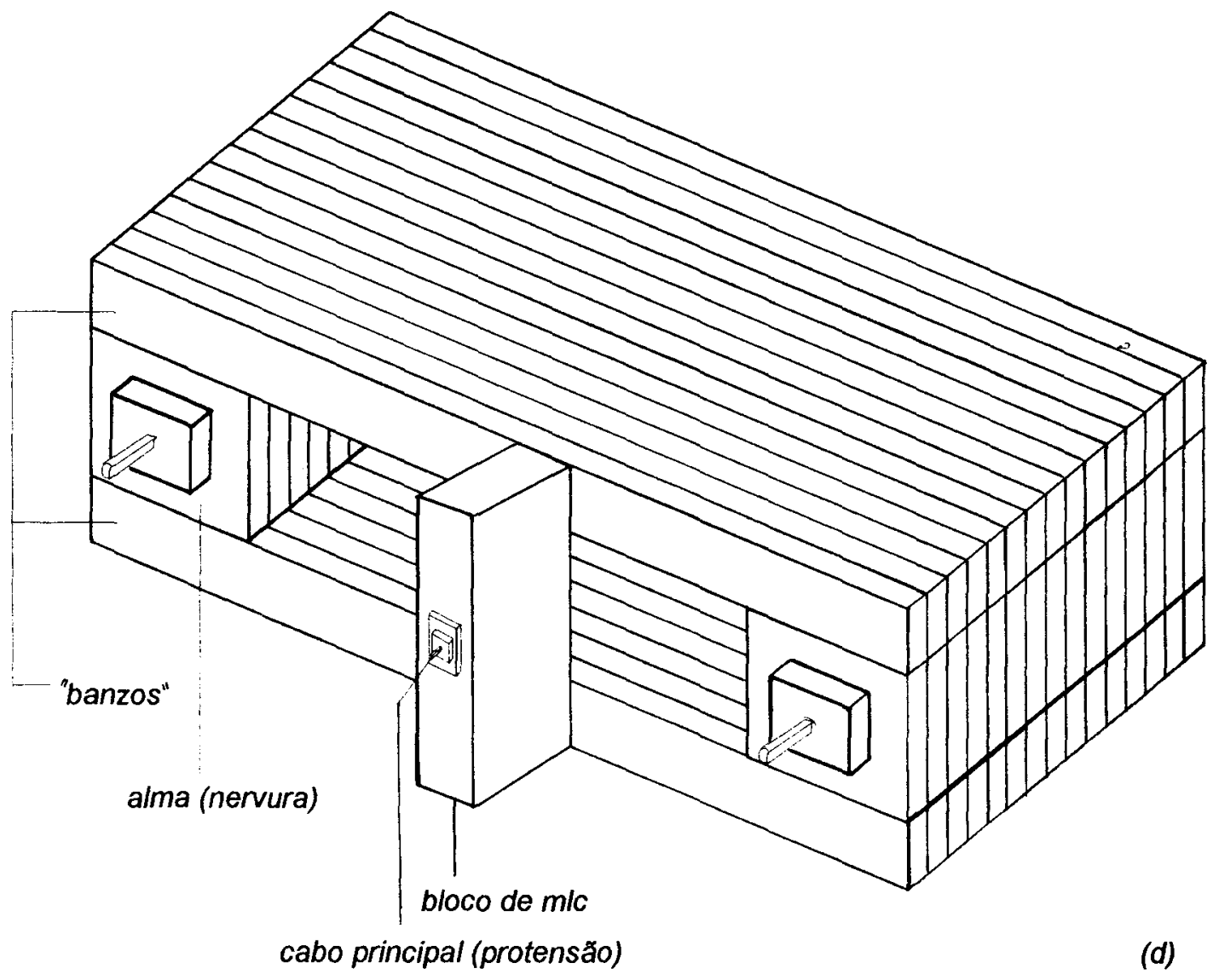

FIGURA 3.9 - Aspectos principais da Hiroshima Bridge : Vistas das vigas laminadas.

(a) lateral;

(b) seção transversal;

(c) aspecto da torre da ponte;

(d) modulo do sistema de "banzos paralelos".

A Iniciativa em Pontes de Madeira uniu os institutos de pesquisa num programa amplo na América do Norte. Hoje, Canadá e Estados Unidos detêm o que existe de melhor em tecnologia, projeto e construção de pontes de madeira em todo mundo. Há um intercâmbio entre os institutos do Ministry of Transportation of Ontario (MTO), Forest Products Laboratory (FPL) e Federal Highway Administration (FHWA). As pesquisas em andamento neste âmbito, são : 


\section{CRITÉRIOS DE PROJETO.}

- Informações sobre propriedades de madeiras de diversas espécies - red oak, red maple, cottonwood, yellow poplar - para aplicações em pontes. A disponibilidade de madeira de dicotiledôneas, atualmente, na América do Norte, é grande e estudam-se novas aplicações nãousuais para algumas madeiras não chamadas de nobres, como a cottonwood.

- Desempenho de sistemas de madeira laminada colada; produtos estruturais novos (também não-usuais, como para a red maple).

\section{APERFEICOAMENTO DE SISTEMAS DE PONTES.}

- Experimentação para determinar a exeqüibilidade de pontes de "treliças laminadas tensionadas" (Universidade do Estado de Maine).

\section{CRITÉRIOS DE CALCCULO PARA PONTES DE MLT.}

- Análise de efeitos de juntas de topo em tabuleiros de mitt para refinamento dos procedimentos de cálculo que considerem esse efeito na variação da rigidez do tabuleiro.

- Sistemas de conectores e dados de fadiga para tabuleiros de milt.

- Eficácia de sistemas de molas de disco para manter as forças nas barras de protensão nas pontes de $\underline{\mathrm{m} / \mathrm{t}}$.

- Sistemas de madeira laminada tensionada (mlt) usando madeira laminada colada ( $m / c)$ em seções $T$ e caixão.

- Programas de monitoramento nacionais e locais.

\section{PRESERVATIVOS.}

- Eficácia de preservativos e repelentes de água em madeiras de cerne avaliações estão sendo realizadas através de amostras (plantadas no 
solo, em cultura de fungus cellars) tratadas somente com CCA, CCA mais o hidro-repelente ou estabilizadores, e amostras não-tratadas para controle.

- Desempenho de uma ponte com tabuleiro de madeira laminada tensionada tratada com CCA, visando a análise e recomendações possiveis para uso alternativo de preservantes de base aquosa para tabuleiros de madeira laminada tensionada.

- Novos preservativos - ainda não estão completos os estudos para a avaliação de 4 novos preservantes com possibilidades de aplicações a madeiras a utilizar-se em pontes.

- Tratamentos e métodos para tratamento no local das peças das pontes pesquisa de equipamentos, formulação de preservativos e procedimentos para efetivamente se tratar cortes, furos de inspeção $e$ outras descontinuidades provocadas nos envelopes de preservativos pelas operações construtivas ou de manutenção $e$ inspeção.

\section{INSPECÃO E REABILITACÃO.}

- Métodos para avaliação no local, utilizando a tecnologia de ondas de pressão, diferenciando os tipos e a integridade estrutural das pontes.

- Diretrizes para projeto e aplicação de camadas asfálticas de proteção e impermeabilização para pistas de rolamento sobre tabuleiros de madeira, analisando as características de comportamento dos diversos tipos e com aplicação de membranas e/ou geotéxteis como interface.

- Efeitos de temperaturas muito baixas no desempenho de pontes de madeira laminada tensionada.

- Equipamentos e métodos para determinação da rigidez efetiva das pontes de madeira laminada tensionada construídas com madeira serrada.

Acompanhamento do desempenho e resistência das pontes de madeira laminada tensionada. 


\section{IECNOLOGIA E TRANSFEREANCIA DE INFORMACOCES.}

- Projetos-padrão e Especificações para Superestruturas de Pontes de Madeira. Está em pleno desenvolvimento os desenhos padrão e especificações construtivas para superestruturas de pontes de madeira:

(a) vigas de m/c com tabuleiro transversal de m/c;

(b) tabuleiro longitudinal de m/c;

(c) tabuleiro longitudinal de $\mathrm{mlt}$;

(d) tabuleiro longitudinal laminado interpregado;

(e) tabuleiros de madeira sobre vigas de aço.

- Desenvolvimento das especificações da AASHTO para projetos de pontes de madeira: este projeto de pesquisa envolve todas as agências através do National Cooperative Highway Research Program (NCHRP), para apresentar as especificações no formato probabilístico LRFD.

\subsection{BRASIL}

\subsubsection{Introdução}

O Brasil possui território de $8.511 .965 \mathrm{~km}^{2}$, com $15.719 \mathrm{~km}$ de fronteiras terrestres e $7.408 \mathrm{~km}$ de praias litorâneas, no Oceano Atlântico. Ocupa a porção centro-oriental da América do Sul e é formado por terrenos antigos (Árqueo-Proterozóicos), em geral recobertos por sedimentação mais recente (64\% do território) e divididos em maciços antigos e bacias sedimentares (93\% do território apresenta altitudes inferiores a $900 \mathrm{~m}$ ). 


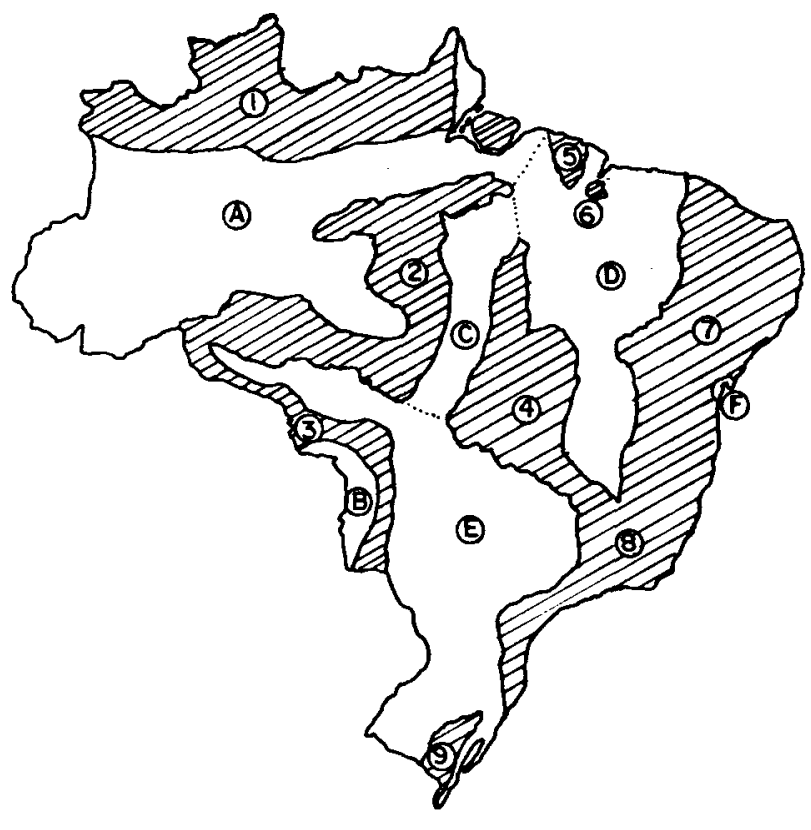

\begin{tabular}{|l} 
ESTRUTURA GEOLOGICA \\
\hline BACIAS SEDIMENTARES \\
\hline A - AMAZONICA \\
\hline B - PANTANAL \\
\hline - - CENTRAL \\
\hline D - MEIO-NORTE \\
\hline E - PARANAICA \\
\hline F - RECONCAVO \\
\hline ESCUDOS CRISTALINOS \\
\hline 1 - GUIANAS \\
\hline - - NÚCLEO SUL AMAZONICO \\
\hline 3 - NÚCLEO BOLIVIO-MATOGROSSENSE \\
\hline 4 - NÚCLEO ARAGUAIO-TOCANTINO \\
\hline 5 - NÚCLEO GURUPI \\
\hline 6 - NÚCLEO PERIZES \\
\hline 7 - NÚCLEO NORDESTINO \\
\hline 8 - NÚCLEO ATLANTICO \\
\hline 9 - NÚCLEO SUL-RIO-GRANDENSE \\
\hline
\end{tabular}

FIGURA 3.10 - Estrutura Geológica do Territorio Brasileiro.

FONTE: Almanaque Abril, 1991.

\begin{tabular}{|c|c|}
\hline & RELEVO \\
\hline & PLANICIE AMAZÓNICA \\
\hline & PLANTCIE DO PAMPA \\
\hline & PLANICIE COSTEIRA \\
\hline & COMPLEXO DO PANTANAL \\
\hline$\hat{\wedge} \hat{\wedge}$ & PLANALTO ATLÁNTICO \\
\hline$m m$ & PLANALTO DAS GUIANAS \\
\hline & PLANALTO CENTRAL \\
\hline & PLANALTO MERIDIONAL \\
\hline
\end{tabular}

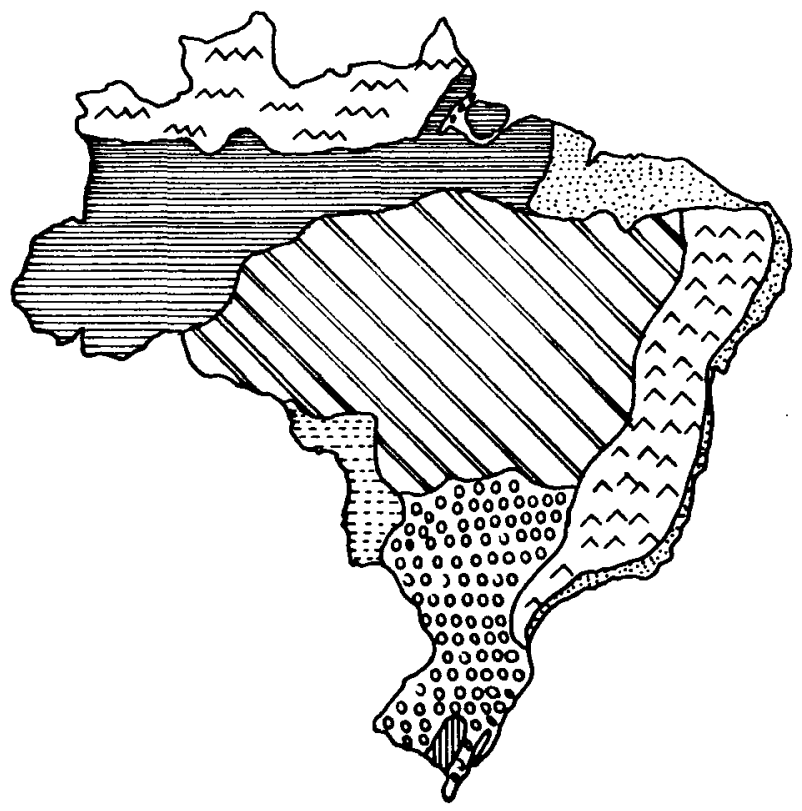

FIGURA 3.11 - Relevo do Território Brasileiro, Planícies e Planaltos.

FONTE: Almanaque Abril 1991. 
As baixas latitudes fazem-se sentir no predomínio dos climas quentes e a atuação de massas de ar tropical continental, equatorial, polar e tropical atlântica faz com que haja predomínio de climas úmidos, propiciando uma rede hidrográfica numerosa e com elevados volumes de água.

No Centro-Sul do País a barreira formada pelo Planalto Atlântico é mais intensa fazem com que os rios que ai nascem ou fluam diretamente para a Planície Costeira ou tomem a vertente continental. É desta forma que se estabeleceu uma miríade de rios de planalto com grandes potenciais hidrelétricos - o que exige, porém, grandes obras de engenharia para os realizar e tornar navegáveis o seu curso. O exemplo mais característico desta vertente é o Rio Paraná, alimentado por rios quase paralelos e extensos (mais de $1000 \mathrm{~km}$ cada): Grande, Tietê, Paranapanema, Iguaçu. Cada um destes formam sub-bacias com importante eixo de comunicações e, com os terrenos e clima, compõem um estímulo ao florescimento das civilizações; a implementação de infra-estrutura tornou esta região a mais ocupada populacionalmente no País.

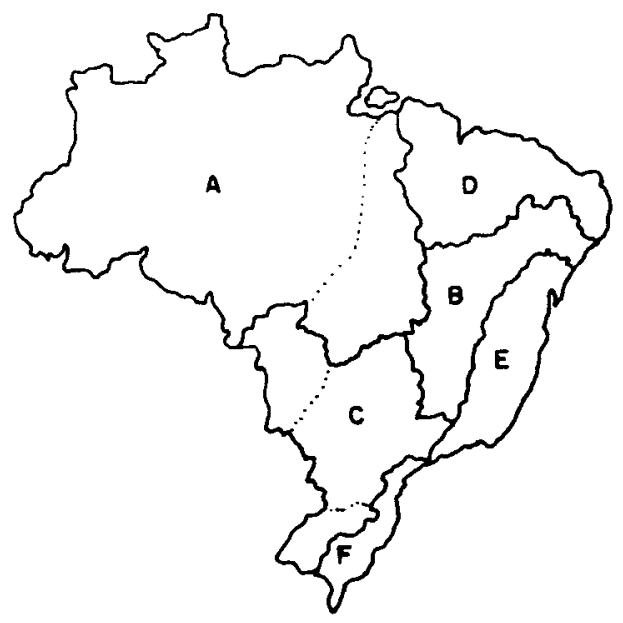

\begin{tabular}{|l|l|l|}
\hline $\begin{array}{l}\text { BACIAS } \\
\text { HIDROGRÁFICAS }\end{array}$ & $\begin{array}{l}\text { AREAS } \\
\left(\mathrm{km}^{2}\right)\end{array}$ & $\%$ PAIS \\
\hline A - AMAZÓNICA & 4787717 & 56.25 \\
B - SÃO FRANCISCO & 613133 & 7.20 \\
C - PLATINA & 1415245 & 16.63 \\
D- SECUND. (NE) & 884835 & 10.40 \\
E- SECUND. (E) & 569310 & 6.69 \\
F- SECUND. (S) & 223688 & 2.63 \\
TOTAL & & 99.80 \\
\hline
\end{tabular}

FIGURA 3.12 - Bacias hidrográficas no Brasil.

FONTE: Almanaque Abril, 1991.

Os principais rios, em extensão total, são:

1. Amazonas $(7025 \mathrm{~km})$.

2. Paraná $(4025 \mathrm{~km})$.

3. Juruá $(3283 \mathrm{~km})$. 
4. Madeira ( $3240 \mathrm{~km}$ ) (maior rio exclusivamente brasileiro).

5. Purus $(3210 \mathrm{~km})$.

6. São Francisco $(3161 \mathrm{~km})$.

7. Tocantins $(2640 \mathrm{~km})$.

8. Araguaia $(2630 \mathrm{~km})$.

9. Japurá ( $2200 \mathrm{~km})$.

10. Uruguai $(2078 \mathrm{~km})$.

11. Paraguai $(2020 \mathrm{~km})$.

12. Tapajós $(2000 \mathrm{~km})$.

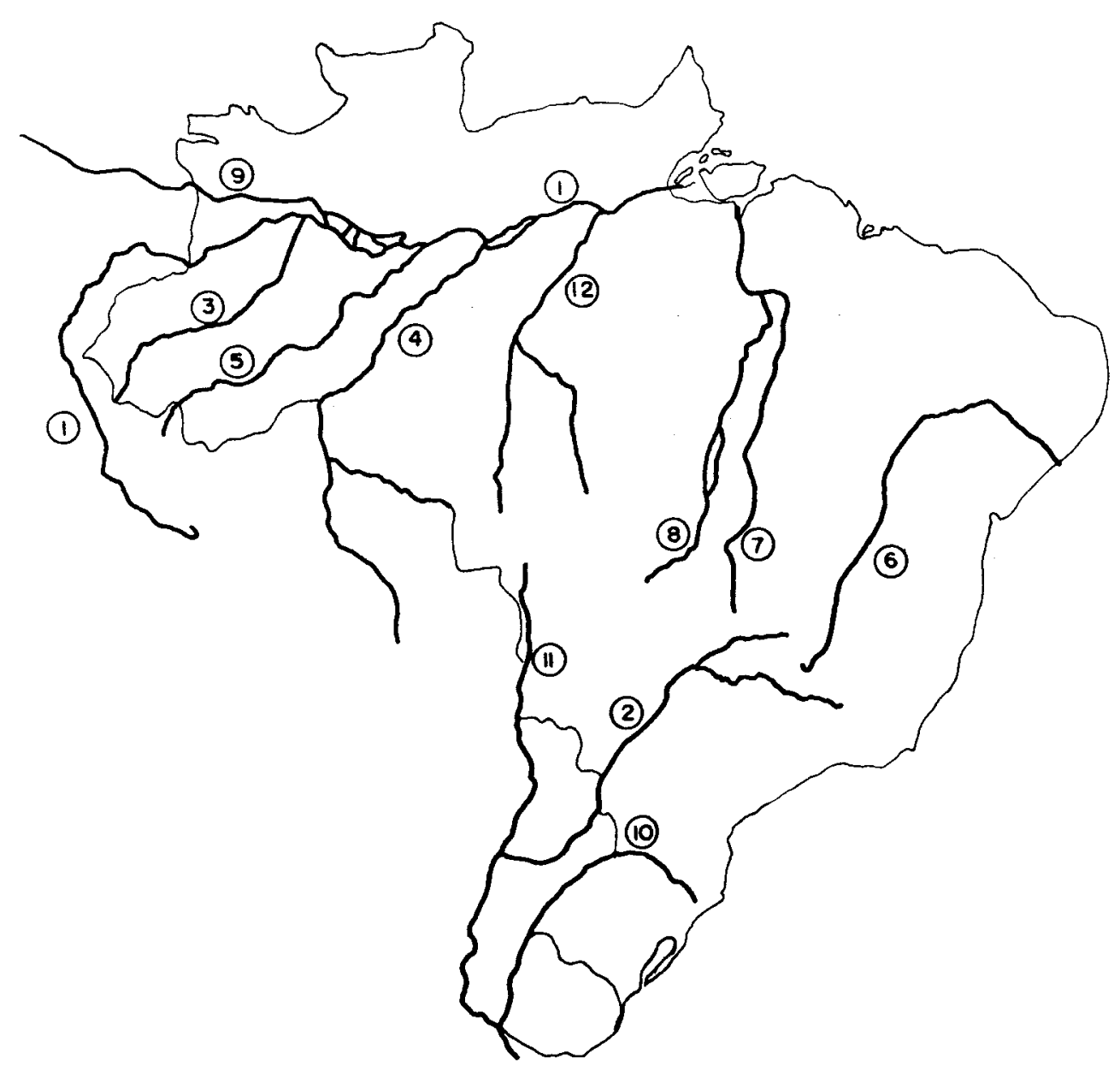

FIGURA 3.13 - Mapa com a localizaçăo dos rios Sul-Americanos citados.

FONTE: Circulo do livro 1994. 
Se nos planaltos já existe indicação de rios com porte hídrico a se considerar, deve-se notar que na Bacia Amazônica, além do Rio Amazonas, encontram-se 7000 (sete mil) afluentes e há $23000 \mathrm{~km}$ de rios navegáveis por embarcações de porte.

As linhas de comunicação terrestre, para se implantar em todo país, exigem dos engenheiros civis conhecimentos para realizar obras de artes de todo porte, pequenas, médias, grandes e "imensas".

Uma análise sobre os desenvolvimentos tecnológicos e o conhecimento já produzido, pontes já construídas e novas pontes sendo demandadas podem indicar caminhos esquecidos pela engenharia nacional no que diz respeito às pontes de madeira. A produção deste conhecimento no Brasil começou a ser duradoura a partir mesmo da implantação das ferrovias e alastrou-se com o crescimento do interior do País.

\subsubsection{Histórico.}

A partir do advento da Proclamação da República o Governo do Brasil encorajou imigrantes a ocuparem áreas ainda vazias no interior do País. Alemães, italianos, suiços, espanhóis, portugueses e, posteriormente japoneses vieram para os Estados do Rio de Janeiro, Espírito Santo, São Paulo, Paraná, Santa Catarina e Rio Grande do Sul.

Os produtores de café detinham o poder econômico então e a expansão do plantio desde o estado do Rio de Janeiro até o Oeste de São Paulo e Norte do Paraná trouxe a necessidade de artesãos, fabricantes e empreendedores com o conhecimento tecnológico da madeira - as matas naturais com grande reserva biológica estavam a impedir o avanço da fronteira agrícola. No primeiro quarto deste século já se construiam estruturas de grande impacto no escoamento da produção e na circulação de pessoas, bens e serviços. O grande exemplo desta era foi a Ponte Pênsil de Chavantes, na 
divisa das Províncias de São Paulo e Paraná, sobre o Rio Paranapanema. Destruida em 1924 por ocasião do Movimento Tenentista, a ponte foi reconstruída e esteve em serviço desde 1924 até 1932, quando foi novamente destruída durante o Movimento Constitucionalista. Foi construida mais uma vez, com torres, ancoragens e pista totalmente novos, em uma posição ao lado da anterior. Esta Ponte Pênsil de Chavantes foi seriamente danificada com a grande enchente de 1983, quando o nivel do Rio Paranapanema atingiu as transversinas e solicitou o cabo como tirantes do arco provocado pelo arrastamento lateral da estrutura no sentido do fluxo fluvial. Tombada pelo Conselho de Defesa do Patrimônio Histórico em 1985, foi reformada em 1987 e recuperada em 1989, estando em plena operação hoje. A evolução do sistema é mostrada nas figuras a seguir.

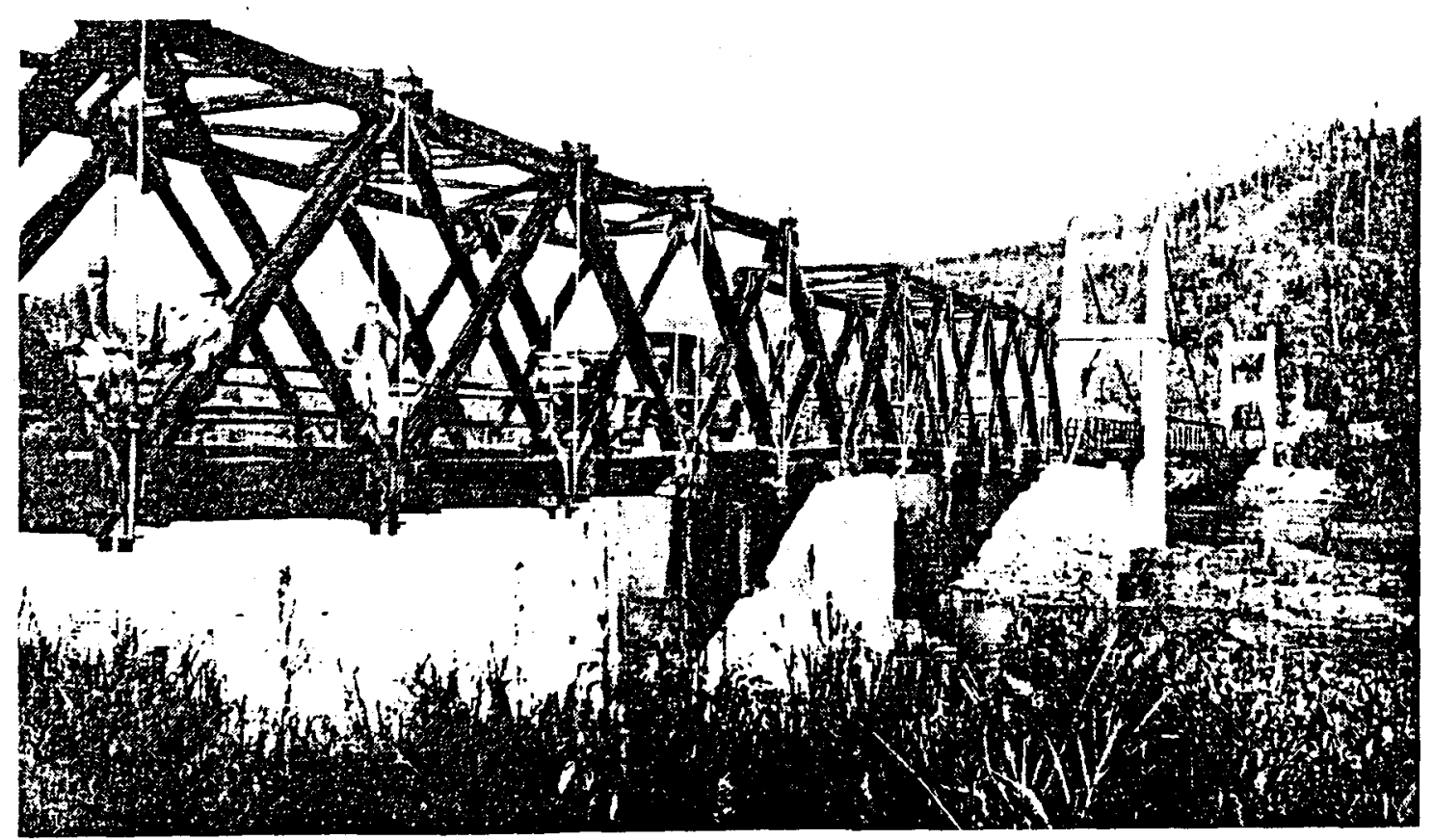

FIGURA 3.14 - Primeira Ponte Pênsil de Chavantes, dois văos treliçados e um văo pênsil de $75 \mathrm{~m}$ (extensăo : $120 \mathrm{~m}$ ). 


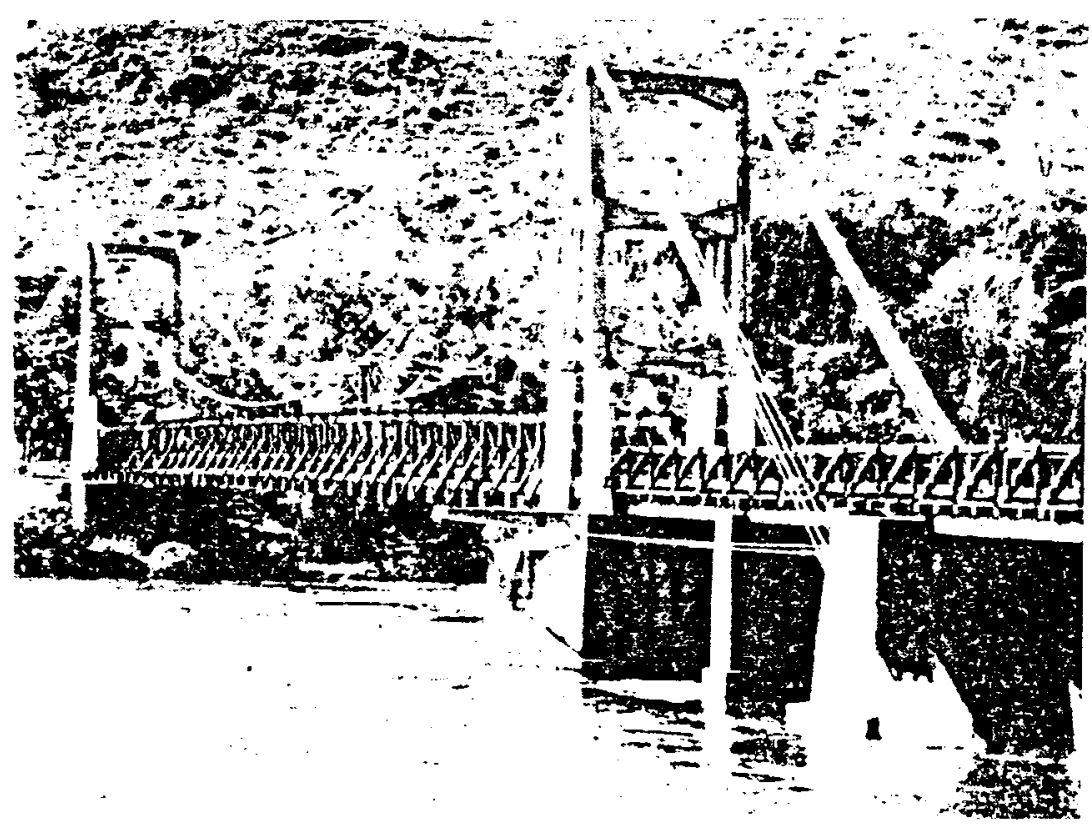

(a)

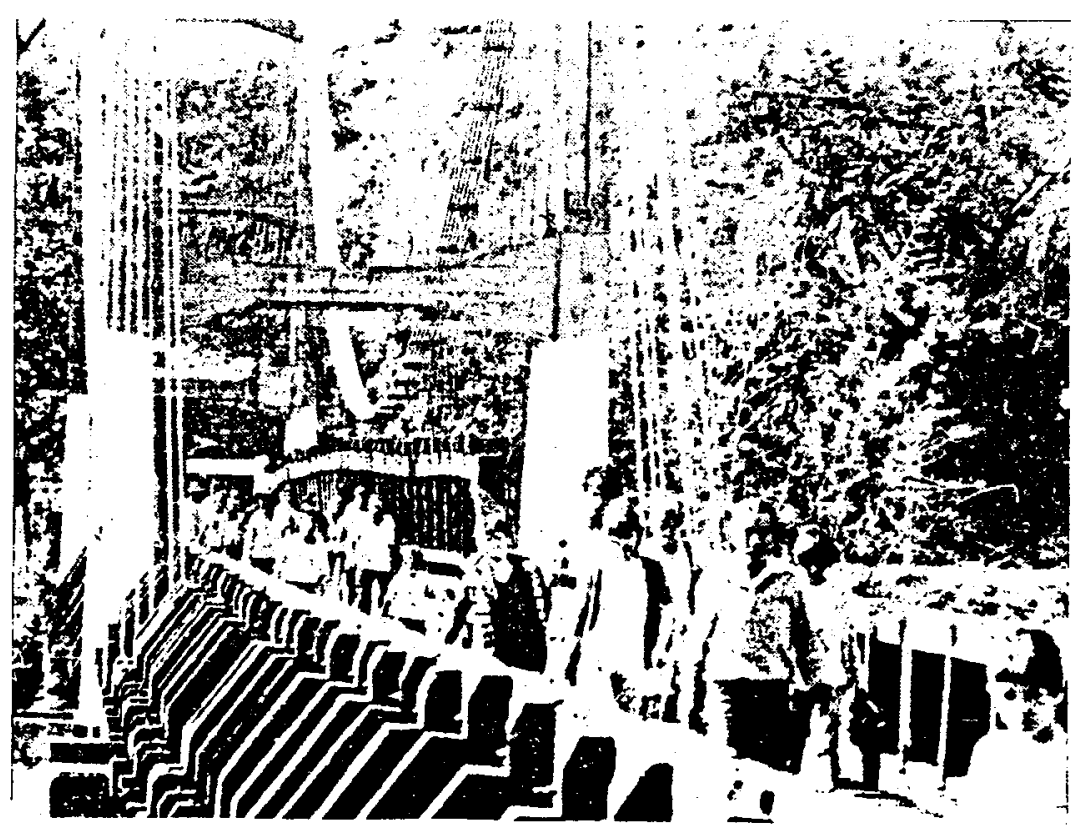

(b)

FIGURA 3.15 (a) Vista Lateral da Terceira Ponte Pensil de Chavantes;

(b) Aspecto dos cabos e das contençठes das transversinas. 
A execução de sistemas estruturais arquitetônicos e eficientes foi a grande preocupação de um construtor excepcional de estruturas de madeira no Brasil: Erwin Hauff. Seu trabalho foi minuciosamente compilado e salientado por CESAR (1991), e incluiu notáveis pontes de madeira.

O então chamado Sistema Hauff compreendia a utilização de treliças de madeira de várias formas, especialmente com emprego de arcos, com barras treliçadas conectadas com cavilhas de madeira. As seções das barras não eram robustas como resultaria do uso de seções maciças, $e$ empregava-se o carbolineum para preservação da madeira.

O Sistema Hauff foi muito utilizado em coberturas de galpões, em cimbramentos de estruturas de concreto - e recordes construtivos, segundo Vasconcelos (1992) foram atingidos na Ligação Mairinque-Santos da Estrada de Ferro Soracabana: em cimbramentos e em pontes ferroviárias de concreto armado. O Sistema Hauff foi também empregado em pontes urbanas, das quais a Ponte Grande inaugurada em $1930 \mathrm{com} 52 \mathrm{~m}$ de vão (Figura 3.16) foi recorde construtivo na América do Sul.

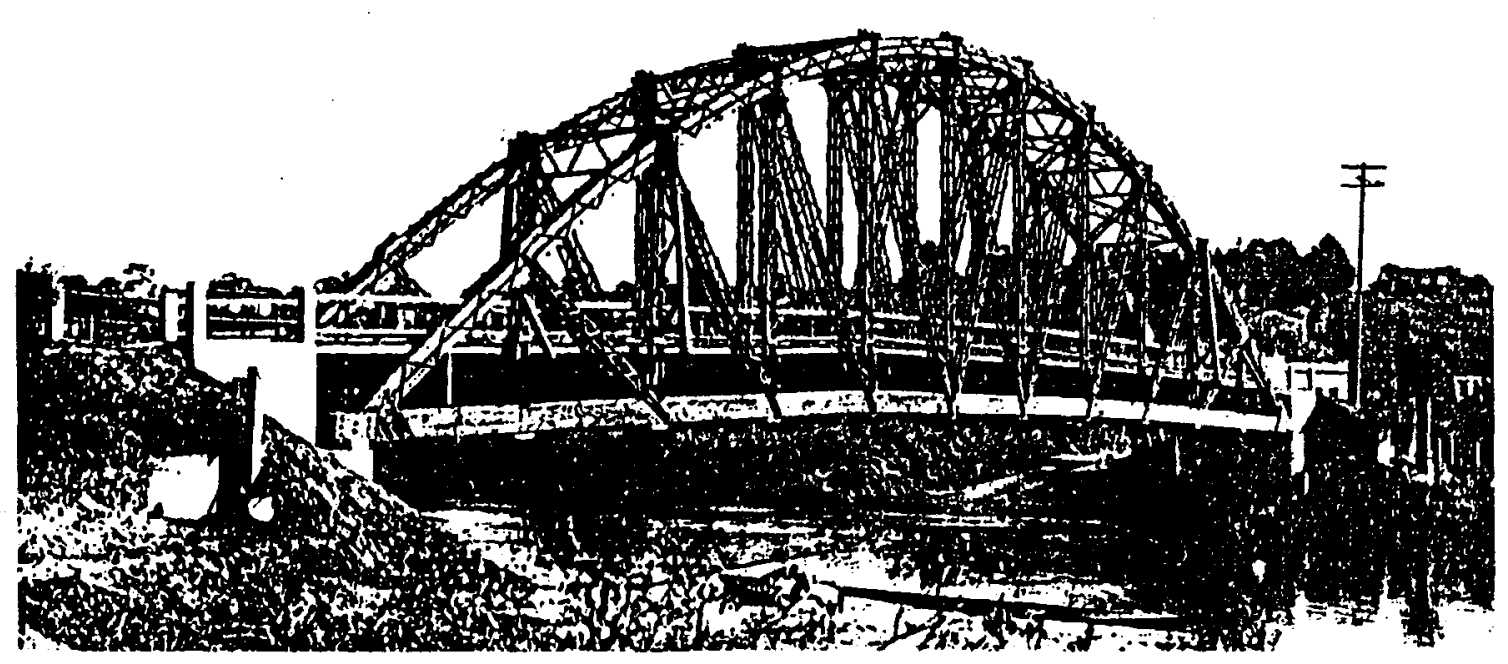

FIGURA 3.16 - Ponte Grande rio Tiete, entre Såo Paulo e Guarulhos. 
Outro destaque foi a Ponte da Rua São Felipe, também sobre o Rio Tietê em São Paulo - Capital (Figura 3.17), com 38m de vão.

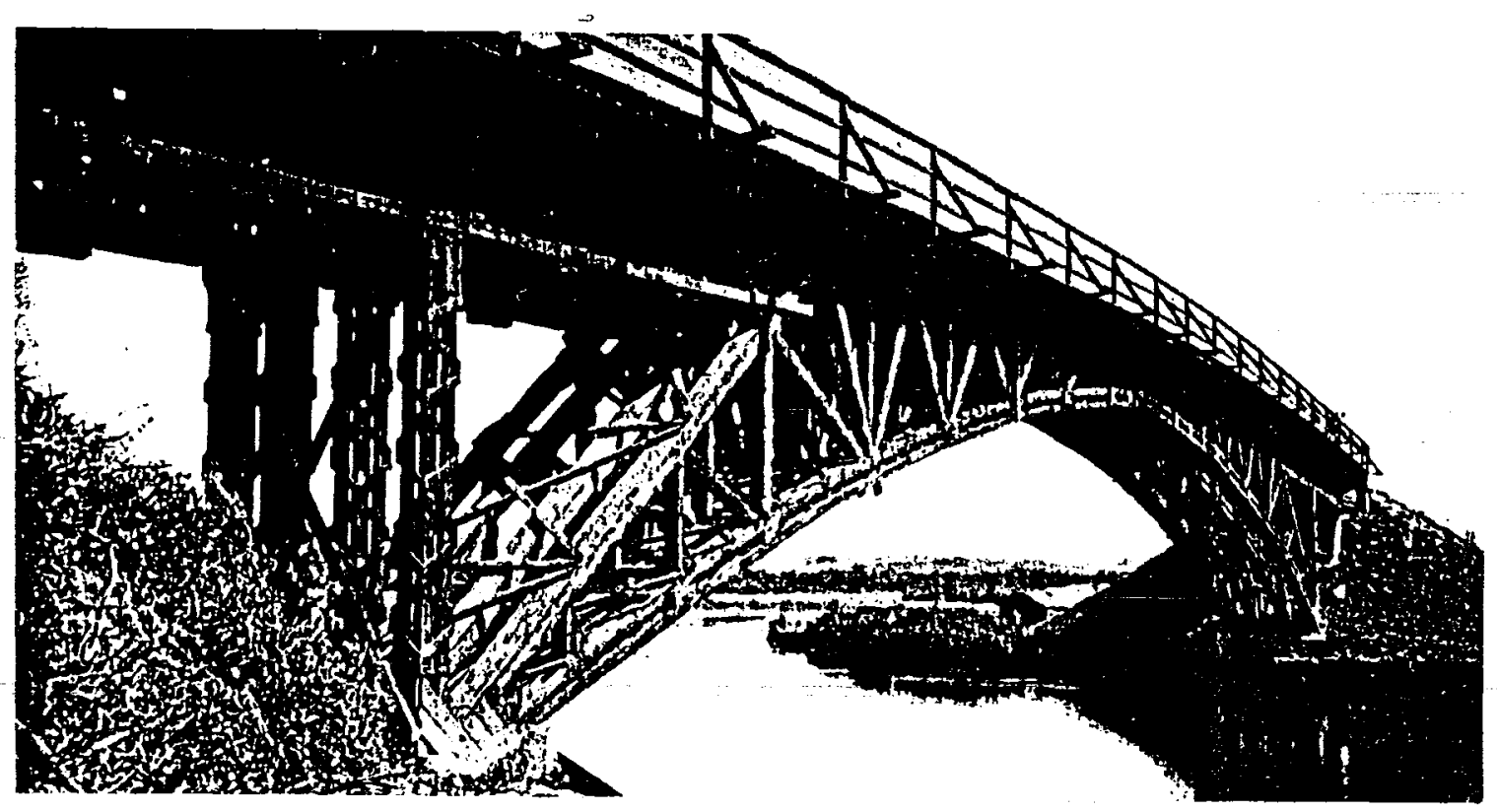

FIGURA 3.17 - Ponte da Rua Săo Felipe.

O Sistema Hauff foi difundido e muito aplicado no Norte do Paraná. Exemplos são mostrados nas figuras seguintes, construídos entre 1945 e 1960. 
$\varangle$
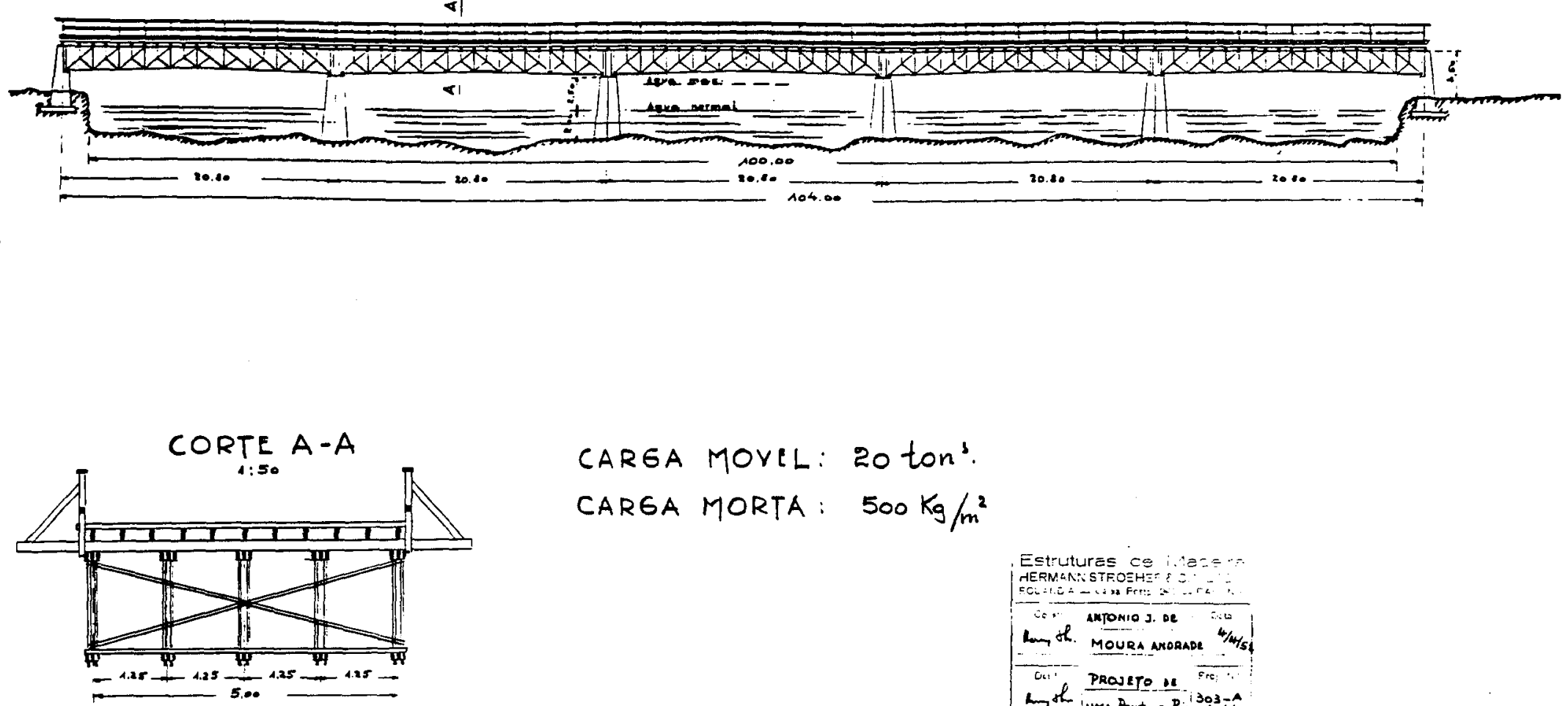

CARGA MOVEL: 20 ton'.

CARGA MORTA: $500 \mathrm{Kg} / \mathrm{m}^{2}$ 
O declínio das construções em madeira acompanhou o intenso desenvolvimento das construções em concreto armado no Brasil a partir dos anos 1950. Alguns fatos importantes desta fase são:

1. A substituição do Tabuleiro da Ponte Hercílio Luz. O piso original de madeira (1926) foi trocado por chapas de aço corrugadas revestidas com concreto asfáltico (1960).

2. Substituição das pontes de madeira por pontes de concreto armado na expansão da malha urbana da Capital de São Paulo (1958-1965).

3. Mudança de enfoque dos empreendedores em construções de estruturas de madeira - passaram a dedicar-se a construções em aço e em concreto.

As construções de pontes restringiram-se à tecnologia de construção rural. Exemplos são mostrados nas Figuras 3.19, 3.20 e 3.21 a seguir. 


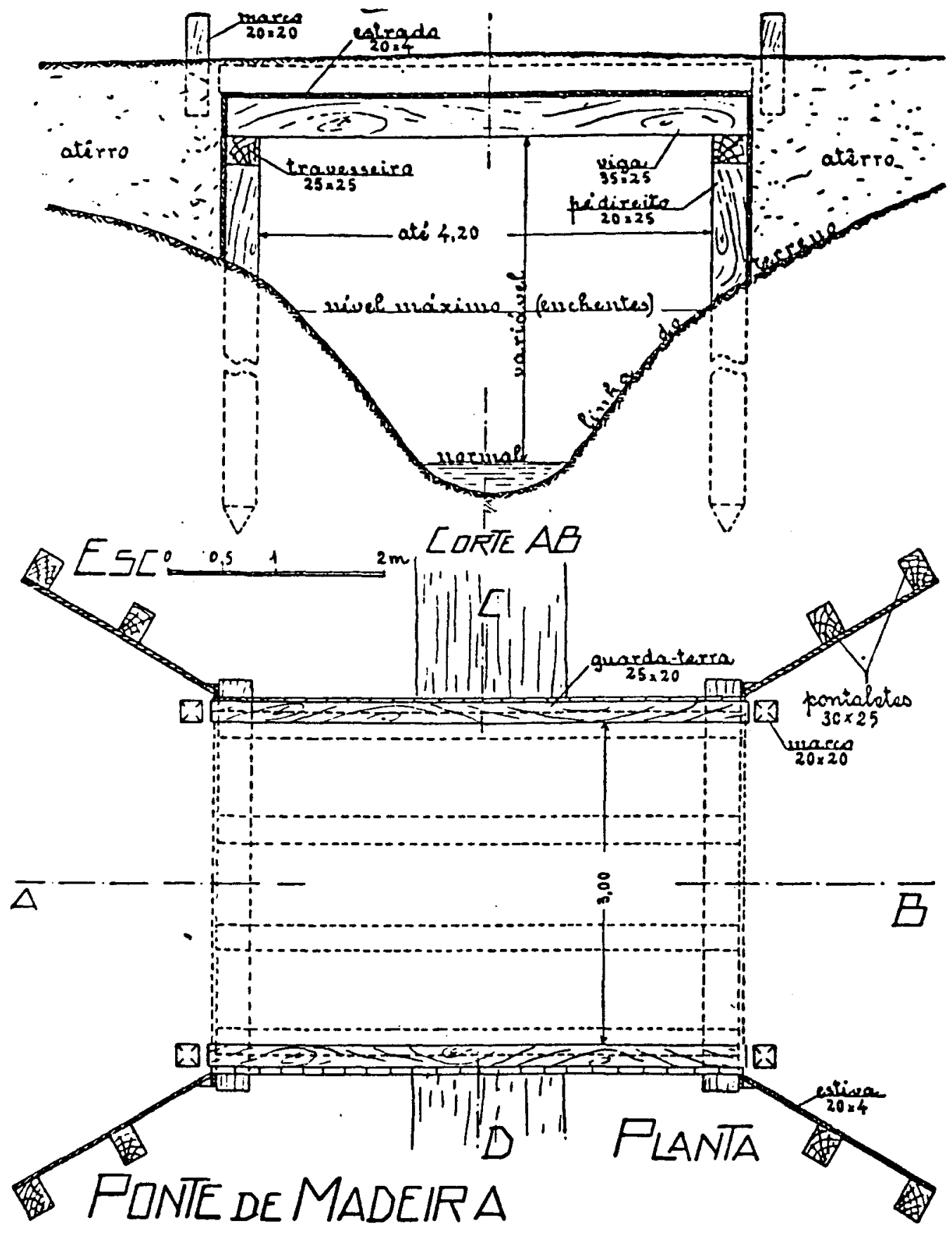

FIGURA 3.19 - Ponte de madeira com aterro - até 4.50m de vão. 


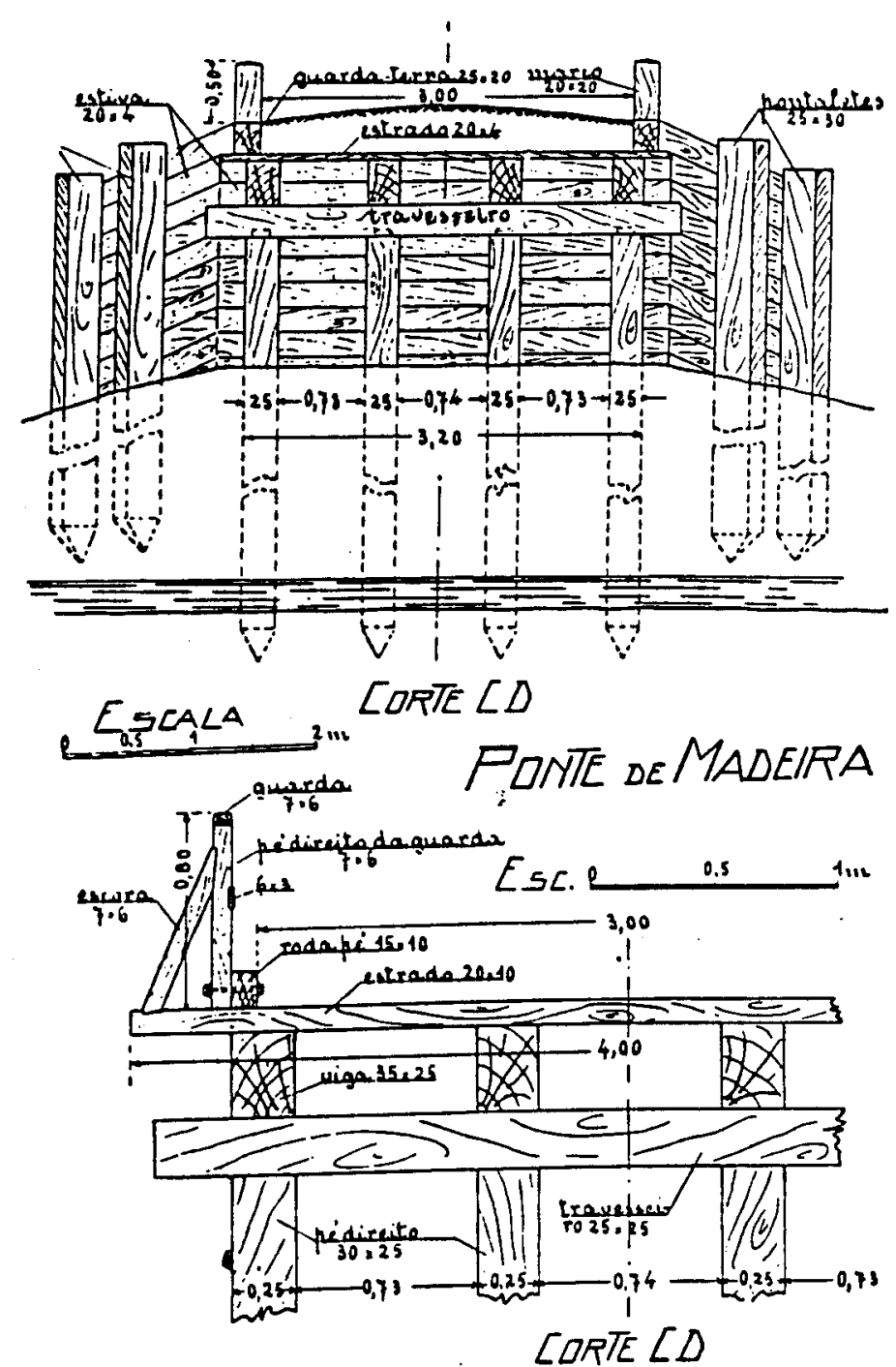

Disposicäs de estrado seil terra e coul guarda
He DiRELH t.) GUARDA...)

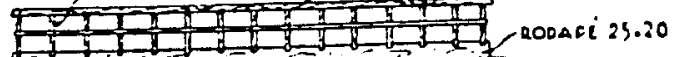

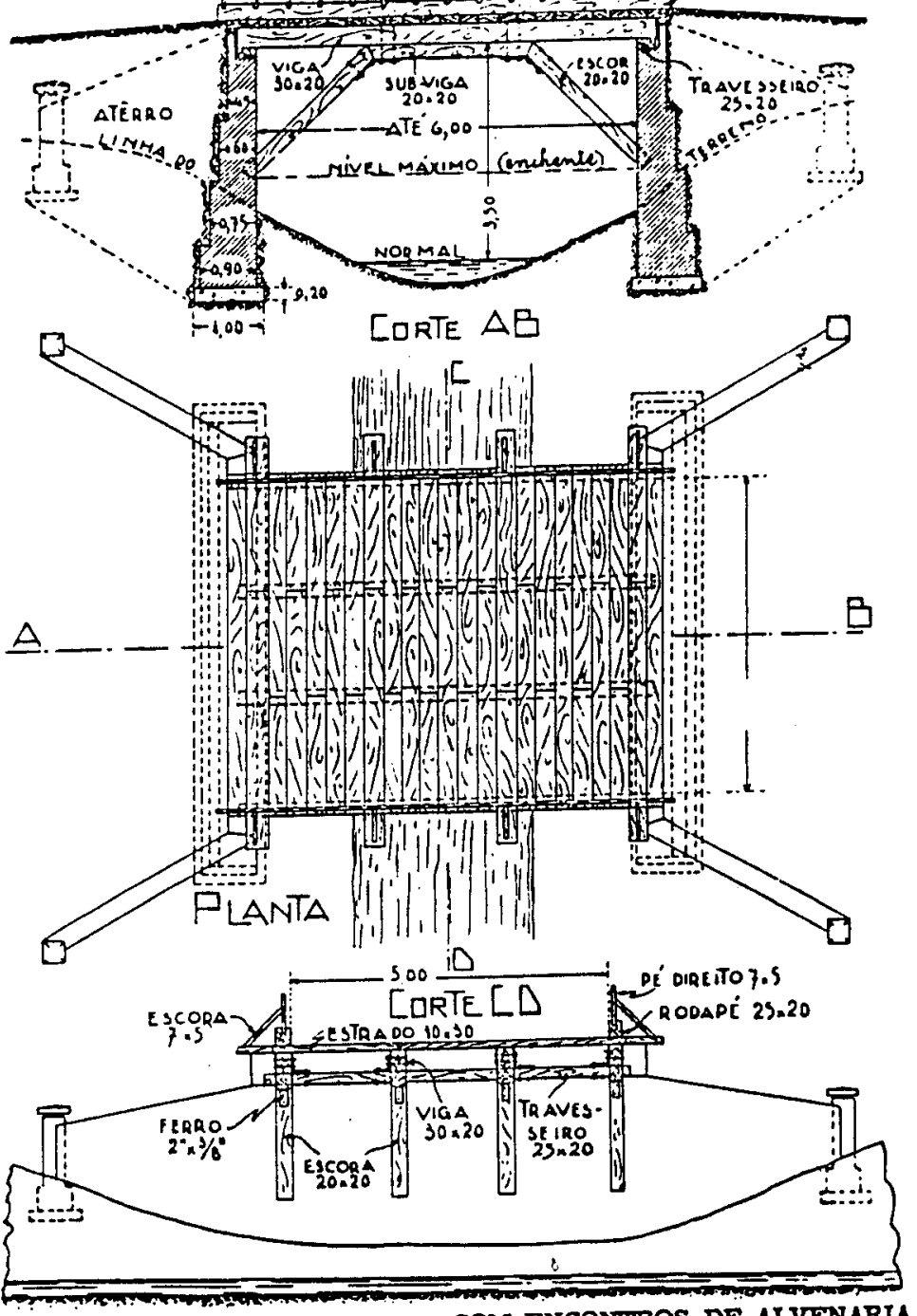

PONTE de MADEIRA COM ENCONTROS DE ALVENARIA 


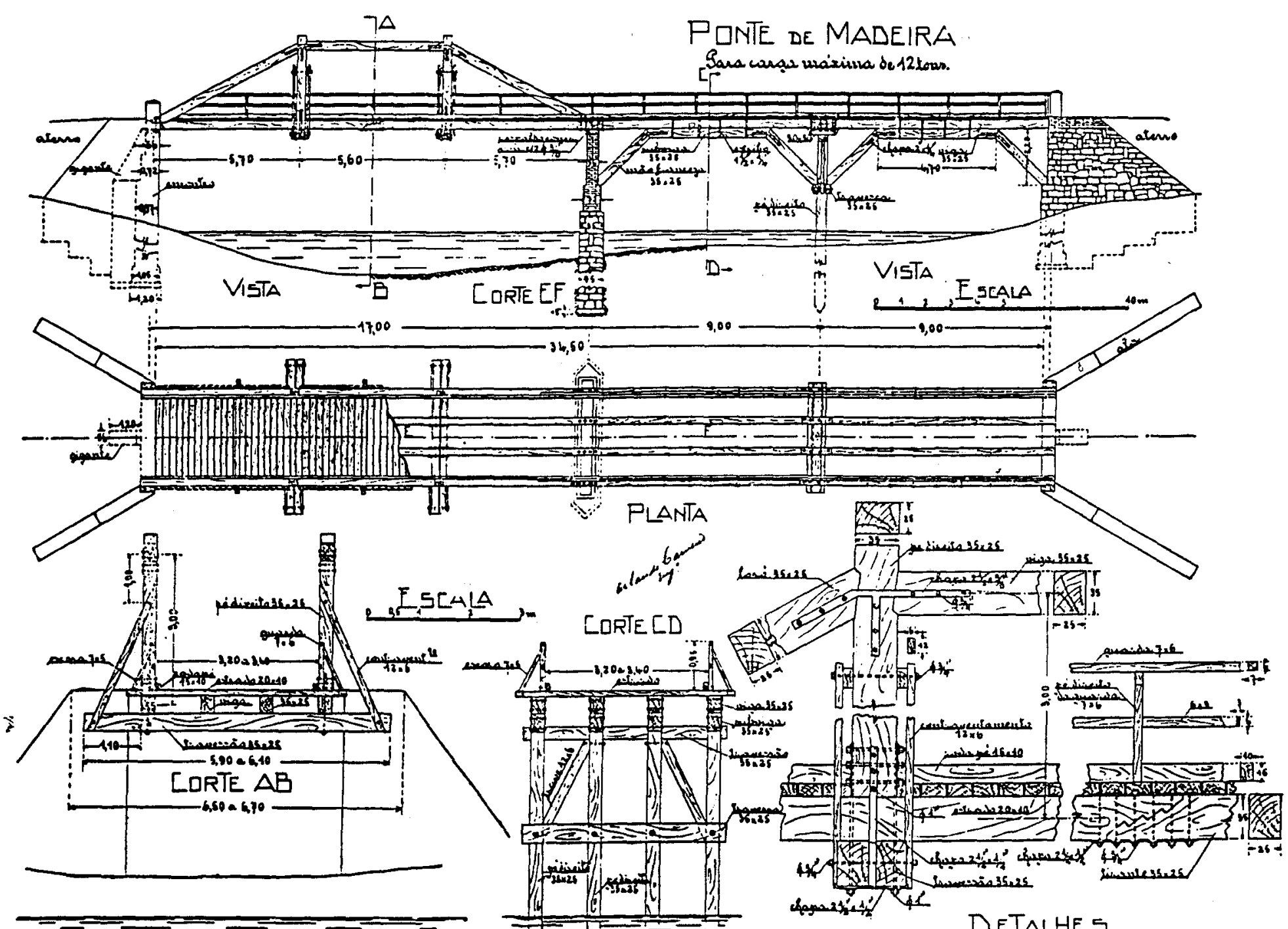

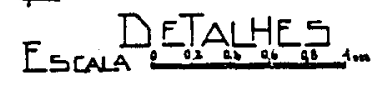


Por falta de especialização profissional, quando o Governo Federal decidiu ocupar a Amazônia com a implantação de rodovias e uso de madeira para a construção de suas pontes, somente o Grupamento de Engenharia do Exército possuía corpo técnico capacitado em projeto de pontes de madeira. Assim foram realizadas obras em madeira nas rodovias Cuiabá-Santarém, Transamazônica e Perimetral Norte.

BEGER ${ }^{1}$ salientou que a mão-de-obra contratada não possuía sequer capacidade interpretativa de desenhos para construir as pontes da BR-163, Cuiabá-Santarém. Como conseqüência os projetos foram repartidos, vãos de $40 \mathrm{~m}$ foram reduzidos a dez vãos de 4,0 $\mathrm{m}$ e os desenhos apresentados em verdadeira grandeza. Grandes prejuízos e retardamento do cronograma previsto foram as conseqüências imediatas destas atividades.

Passados 20 anos destas intervenções, sabe-se ${ }^{2}$ que no Estado do Pará, no trecho da Transamazônica, restam $680 \mathrm{~km}$ transitáveis. Há mais de 170 pontes de madeira, a maioria delas em estado precário, precisando de manutenção ou reconstrução.

As pontes de madeira usualmente construidas no Brasil são simples, de construção rápida e, de modo geral, apresentam estanqueamentos de madeira sucessivos sobre os quais se apoiam as vigas longitudinais e, sobre estas, é fixado o tabuleiro transversal. Algumas vezes sobre as estacas executam-se cavaletes com a disposição de uma viga transversal sob as vigas longitudinais. Os vãos são de $4 \mathrm{~m}$ a $5 \mathrm{~m}$ de cada vez e em geral estas pontes são contínuas, como ilustrado nas figuras a seguir.

\footnotetext{
${ }^{1}$ Comunicaçăo pessoal, Setembro de 1988.

${ }^{2}$ Documento Especial, TV Manchete, 03/01/1992.
} 


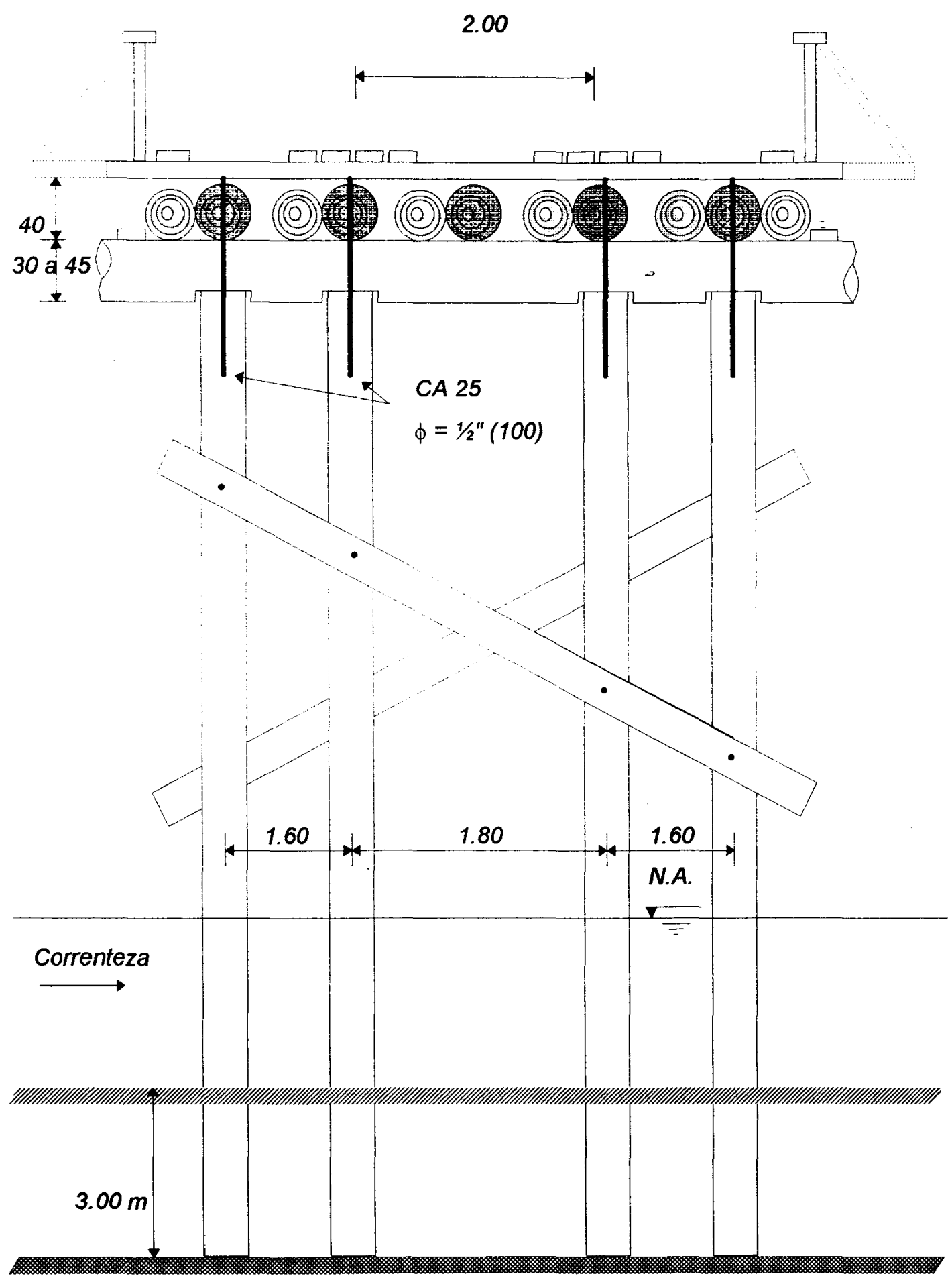




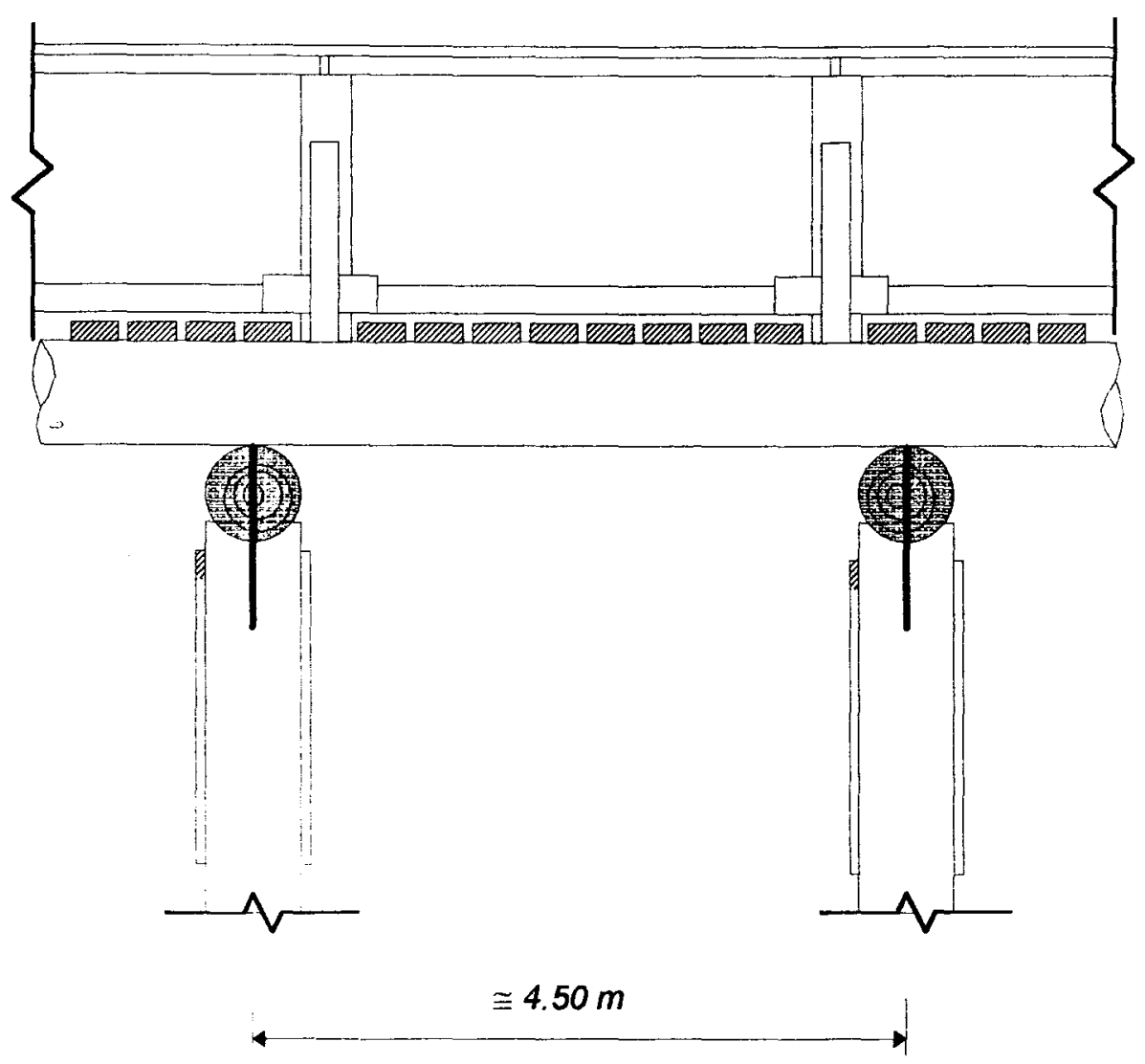

FIGURA 3.23- Seção Longitudinal - Ponte ITAVUVU.

Em alguns casos o tabuleiro é fechado (isto é, forma um meio contínuo) e aproveita-se o plano do tabuleiro para se regularizar a pista de rolamento com concreto asfáltico ou concreto armado, pavimentando assim a superfície de rolamento.

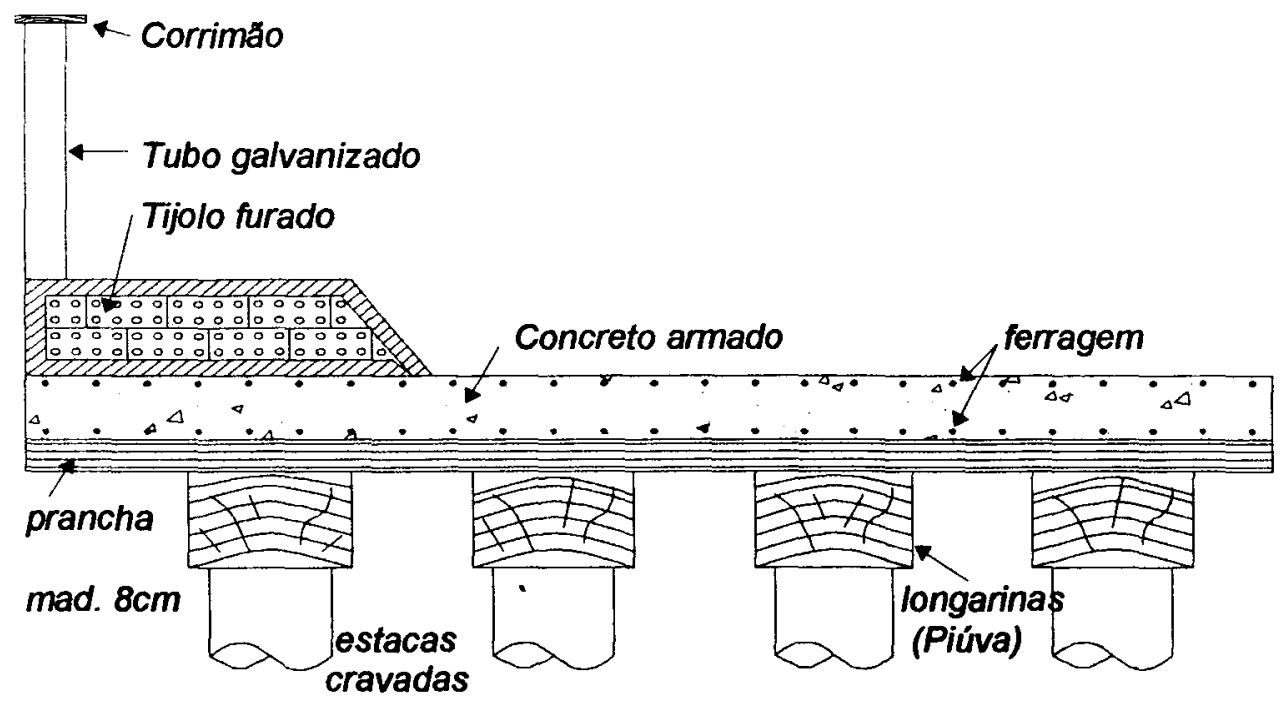

FIGURA 3.24 - Ponte típica da Prefeitura municipal de Cuiabá (MT). 


\subsubsection{O Laboratório de Madeiras e Estruturas de Madeira (LaMEM).}

A partir de 1973 o Laboratório de Madeiras e Estruturas de Madeira, da Escola de Engenharia de São Carlos, Universidade de São Paulo, organizou-se para pesquisa e atendimento à coletividade. Programas de experimentação foram implementados $e$ as primeiras necessidades foram atendidas com execução de estruturas para o Departamento de Estradas e Rodagem (DER), em 1975; para a Companhia Nitro-Química (1977) e Grupo Itaú (1977).

Estes atendimentos pioneiros firmaram posição de relevância e inovação tecnológica no país, razão pela qual os projetos são aqui sumariamente apresentados.
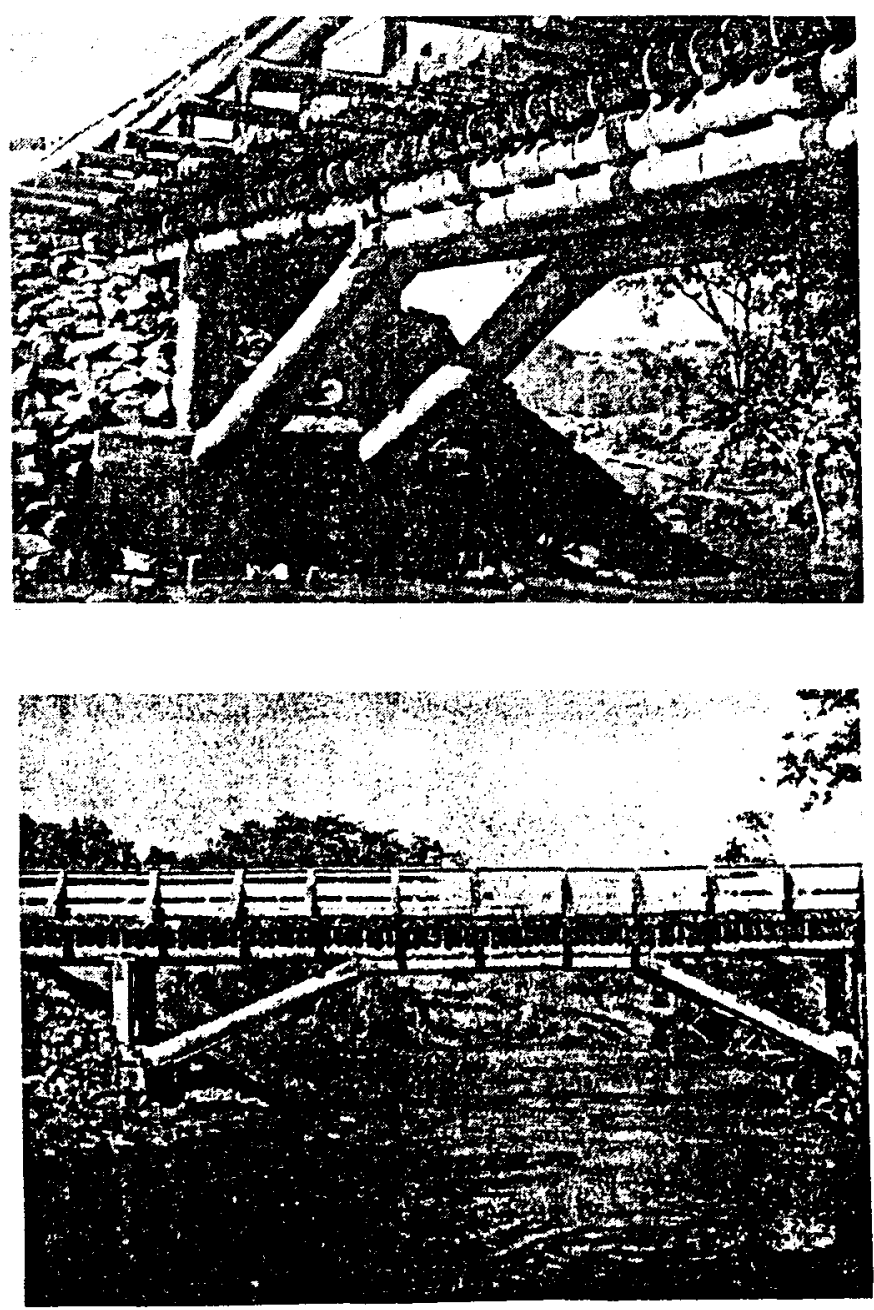

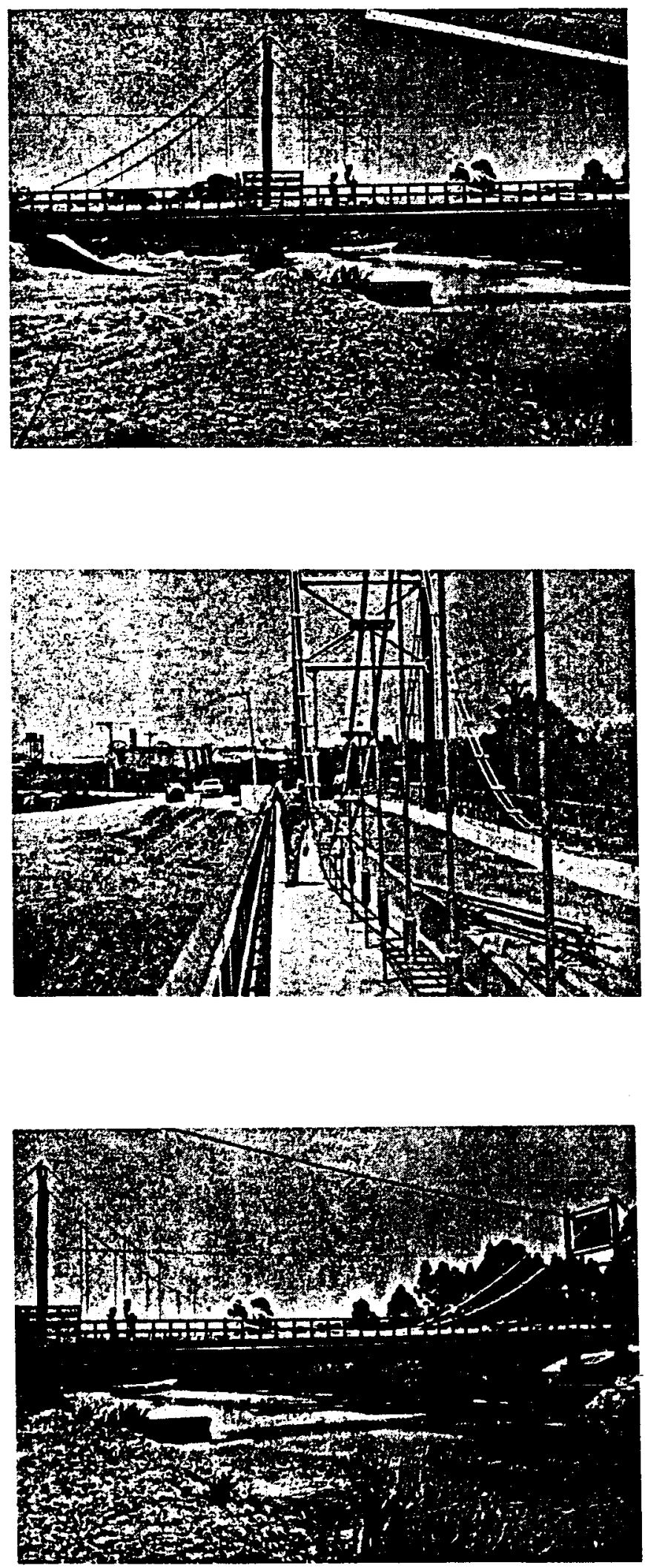
A base deste trabalho foi realizada por HELLMEISTER (1978), Pontes de Eucalipto citriodora tese apresentada com o sistema de postes combinados, verticalmente, para formar as vigas, e horizontalmente, para montar o tabuleiro. Os postes são dispostos com os diâmetros de base e de topo alternados, compensando-os de modo a se ter, na viga, altura uniforme.

A partir destes projetos pioneiros, o ritmo de pesquisas desta unidade se acelerou e vários trabalhos foram concluídos. SZÜCS (1979) desenvolveu a aplicação de treliças a pontes de madeira utilizando anéis metálicos como conectores. Uma treliça contínua para $40 \mathrm{~m}$ de extensão e $20 \mathrm{~m}$ de vão principal teve sua geometria estudada para acomodar os esforços e a resolução de cada nó de ligação foi apresentada com seu processo de montagem. Sua forma final tem simetria modular (em torno do apoio) e simetria global (no meio do vão). Tem 3,80 $\mathrm{m}$ de largura e balanços laterais de 1,50 m no tabuleiro (passagem de pedestres).

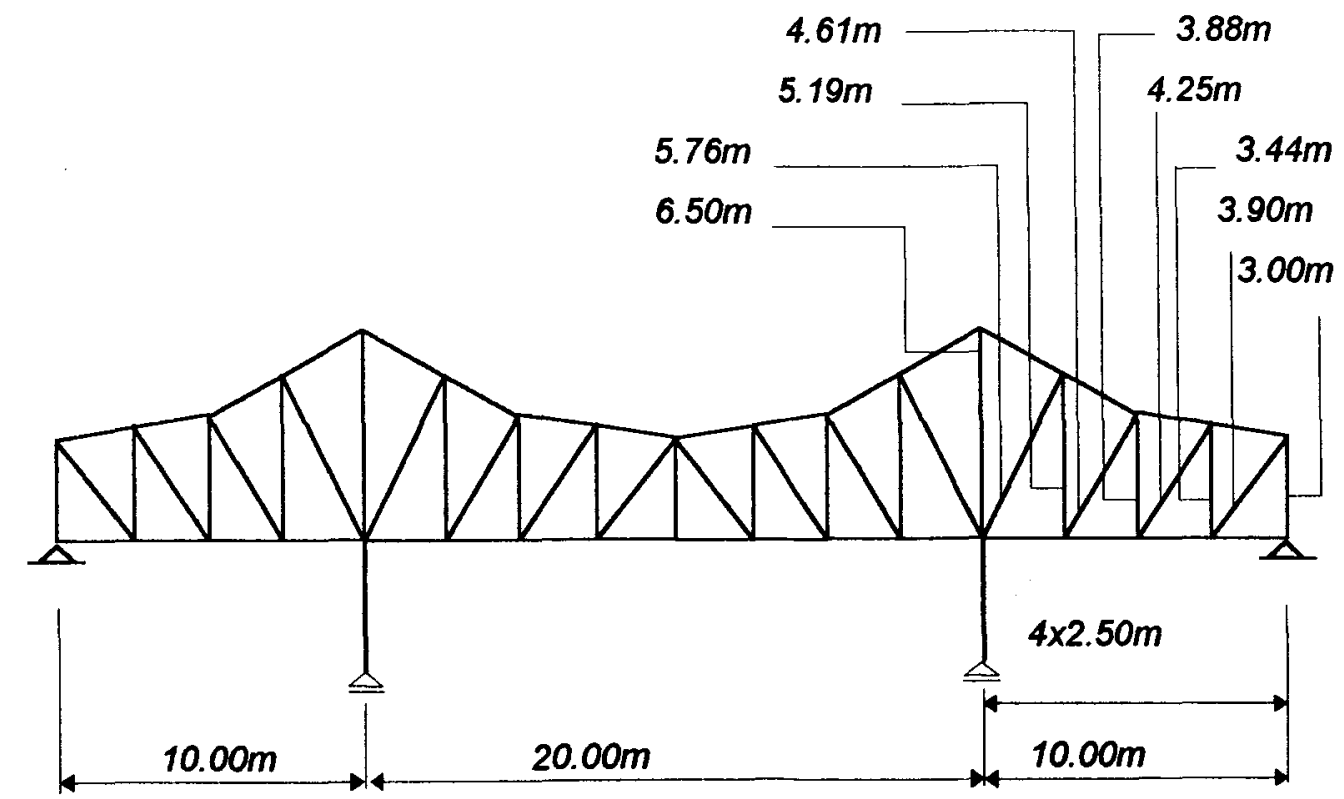


HORTEGAL (1979) apresenta o projeto de uma ponte pênsil de madeira, com $40 \mathrm{~m}$ de vão central e dois vãos laterais de $20 \mathrm{~m}$, calculada de acordo com as Teorias Elástica e a dos Deslocamentos. O tabuleiro é composto de postes e a viga de rigidez é de madeira laminada colada. Para análise do sistema construtivo foi montado, no Laboratório de Madeiras e Estruturas de Madeira (LaMEM), um modelo reduzido em proporção 1: 6.67 que foi posteriormente avaliado com carregamentos estáticos por DIAS (1983). A geometria proposta foi experimentalmente aprovada e seu esquema está apresentado na Figura 3.28.

LOGRADO (1980) apresentou um estudo de viabilidade de aplicação de pontes de Eucalipto Citriodora com vigas armadas. Após descrição e análise dos sistemas possiveis de construção das vigas com o uso de tirantes externos, superiores e inferiores, chegou-se à escolha de um sistema de escoras em madeira com forma de "W". As vigas e tabuleiro são de postes roliços, chegando-se ao projeto e dimensionamento de uma ponte de $20 \mathrm{~m}$ de vão, uma faixa de tráfego, Classe 36 , e uma ponte de $18 \mathrm{~m}$ de vão, duas faixas de tráfego, Classe 36. O diâmetro médio das vigas utilizadas (um poste e escoras) foi de $30 \mathrm{~cm}$ e o ângulo de funcionamento dos tirantes foi de $20^{\circ}$ junto do apoio. O resultado final é apresentado na Figura 3.29 a seguir.

Foi confeccionado um modelo especial de viga armada e ensaiada no Laboratório, e sua análise apresentou boa concordância com os resultados do cálculo teórico. 


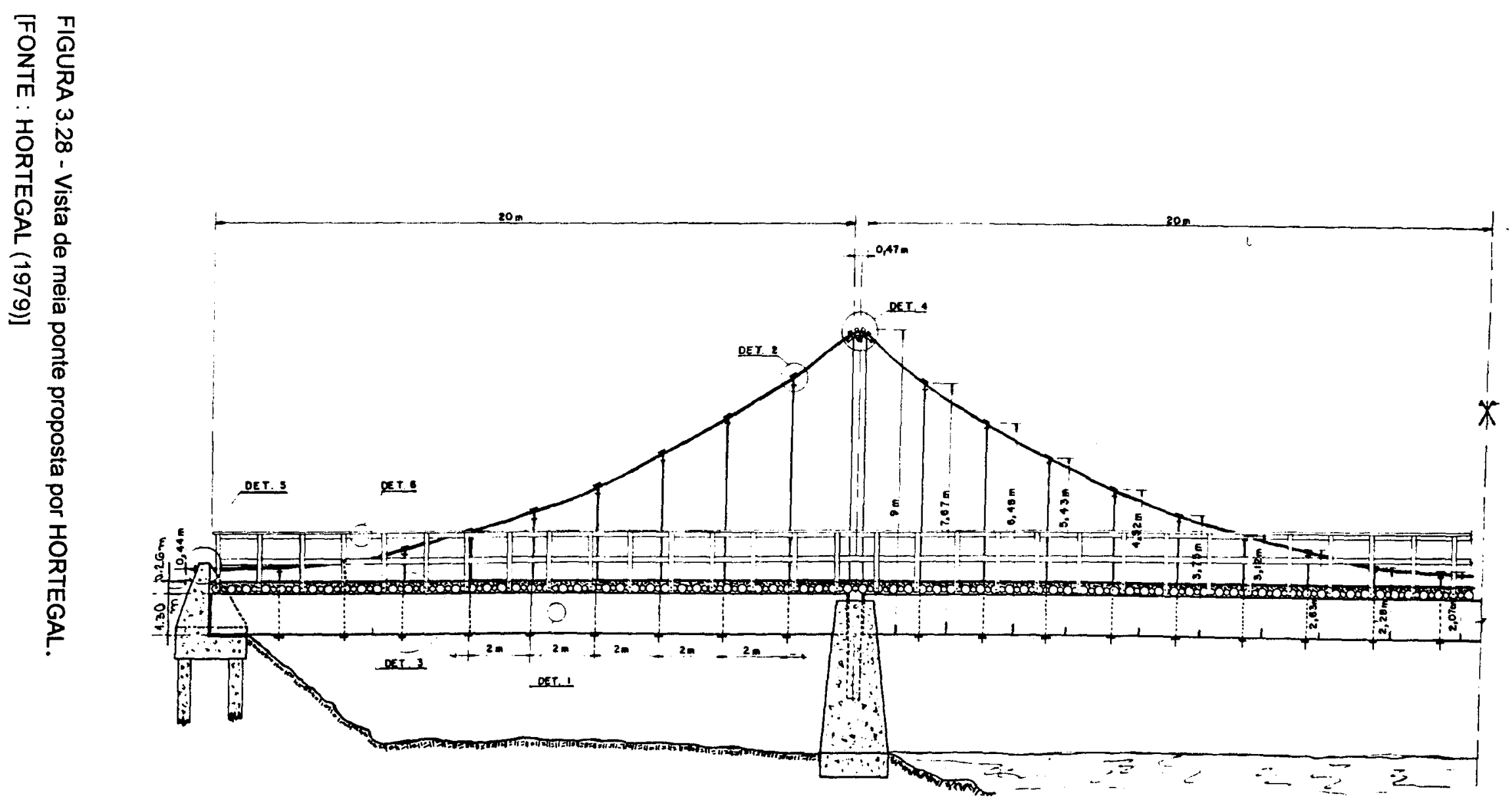



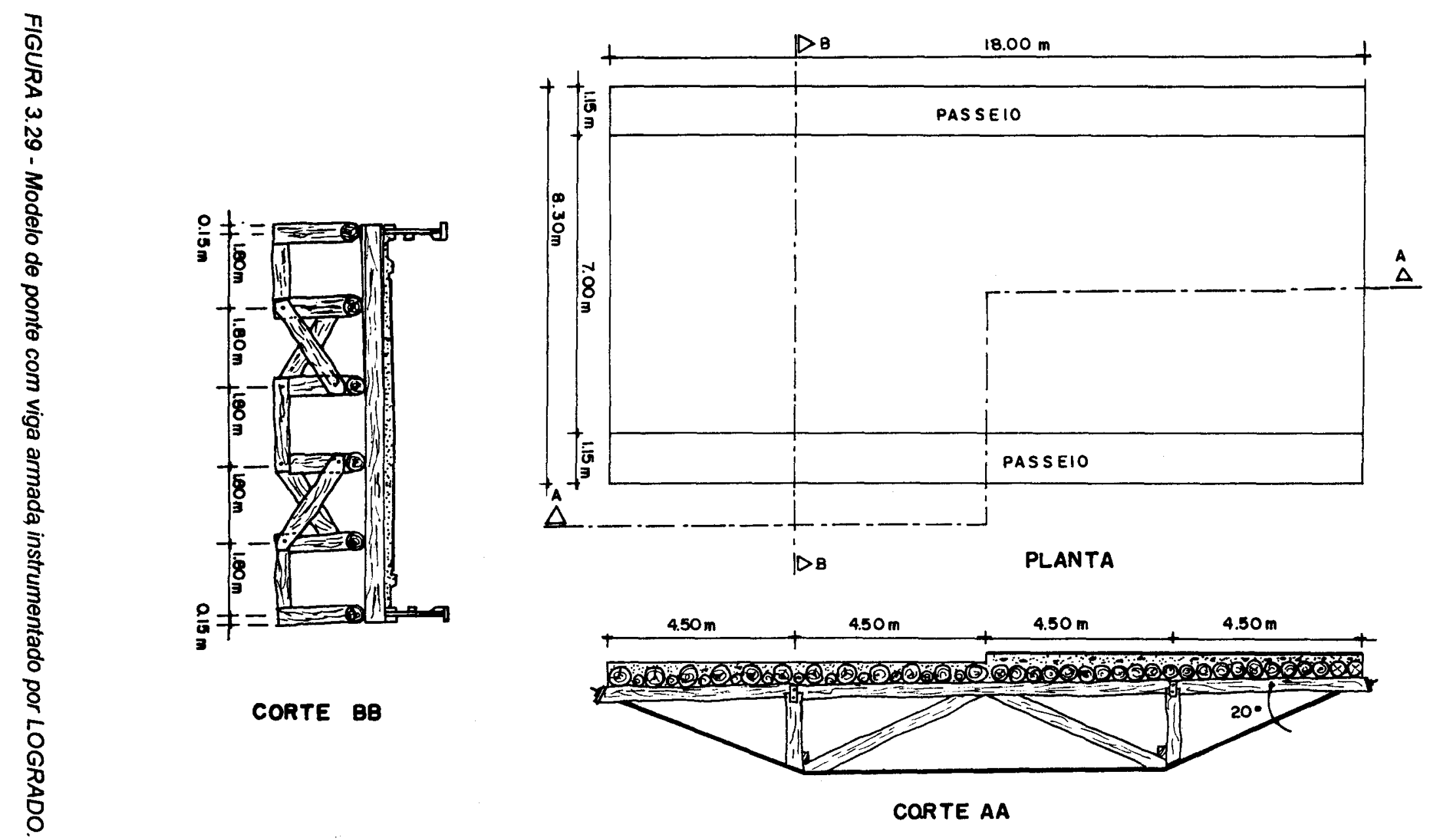
LOGSDON (1982) apresentou uma série de dados necessários para o cálculo de pontes de madeira, utilizando o sistema proposto por Hellmeister e sistematizando os dados, para Classe 36 , em três projetos completos :

- $\quad$ simplesmente apoiados, vigas bicirculares duplas, vão de $8 \mathrm{~m}$.

- contínua sobre pilares, vigas bicirculares duplas, vãos de $6 \mathrm{~m}, 8 \mathrm{~m}, 6 \mathrm{~m}$.

- $\quad$ pórtico de postes e vigas bicirculares, vão de $20 \mathrm{~m}$.

DIAS (1987) apresentou o trabalho Contribuição para o Estudo da Distribuicão Transversal de Cargas em Pontes de Madeira onde aborda 0 sistema estrutural de Eucalipto roliço, postes combinados, montando um sistema de placa sobre vigas, levando-se em conta a contribuição da capa de regularização de concreto sobre os postes do tabuleiro - o que, constatou-se, não é permanente, pois o concreto fissura-se e perde a continuidade que daria aquele acréscimo de rigidez necessário à ação de placa.

Considerando, então, a continuidade transversal das peças do tabuleiro sobre as vigas longitudinais, é feita a comparação entre a análise simplificada, isostática e a análise pela analogia de grelha de um protótipo composto de quatro vigas longitudinais, para uma faixa de tráfego e Classe 12.

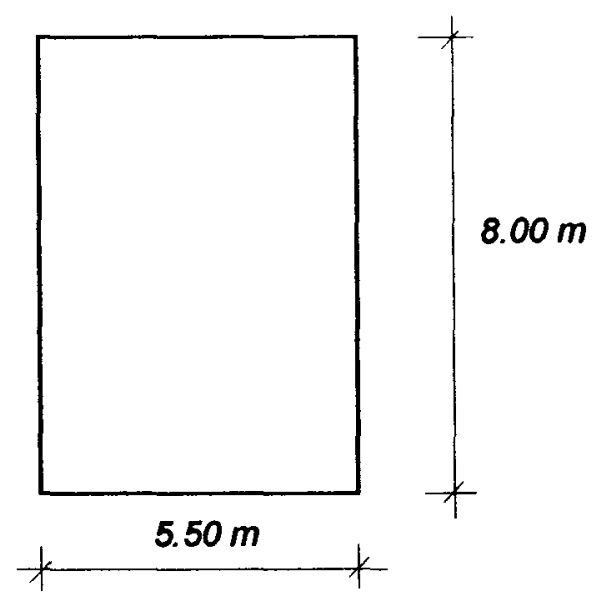

(a) 


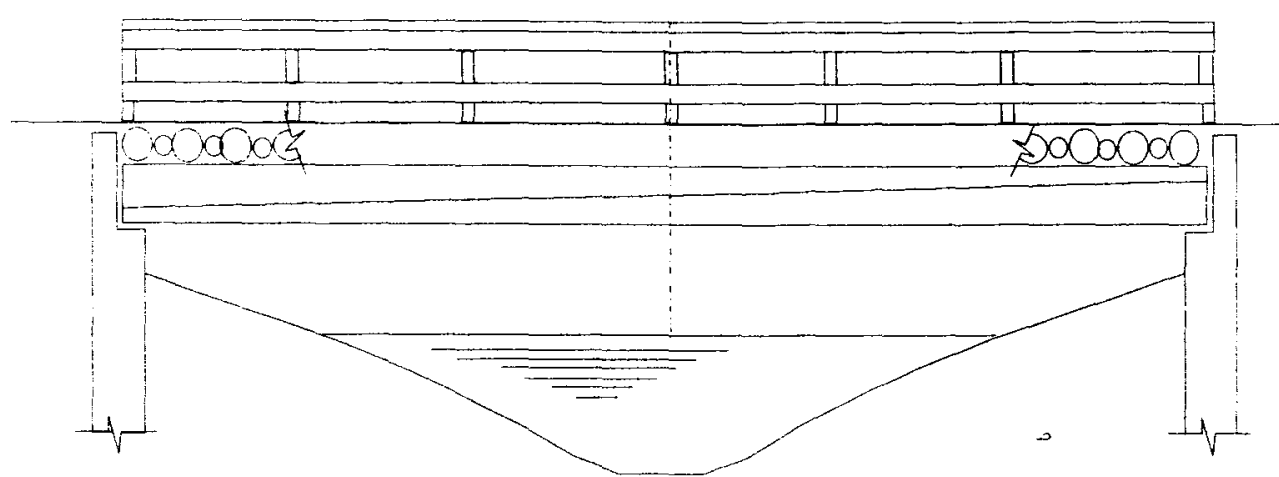

(b)

$8.00 \mathrm{~m}$

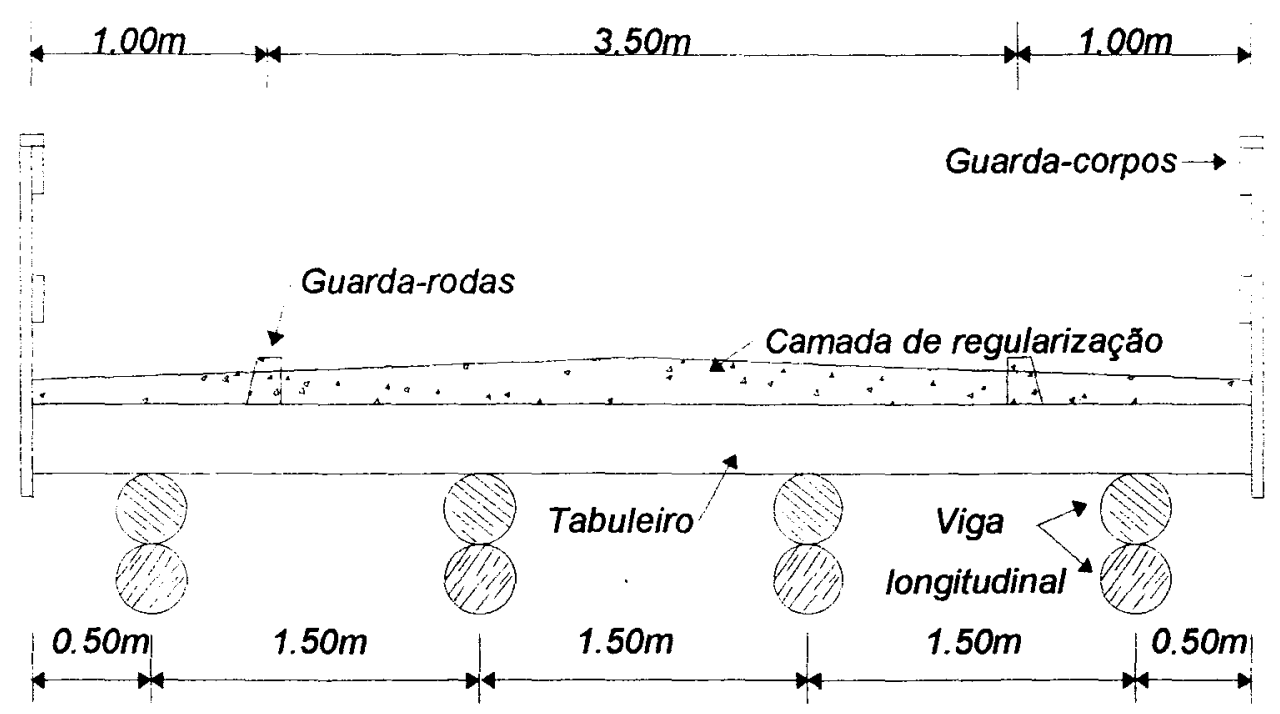

FIGURA 3.30 - Ponte de Eucalipto Citriodora usada no estudo de DIAS (1987).

A análise dos resultados pela analogia de grelha e pelo método simplificado da NBR 7190 - Projeto e Execucão de Estruturas de Madeira (1982), permitiu comparação entre os valores gerados pelas açōes permanentes $e$ móveis.

Para o momento fletor no meio do vão da viga interna, a teoria simplificada oferece valor $6,3 \%$ superior (ação permanente) e $36,5 \%$ superior (ação do trem-tipo). Para a viga externa, a teoria simplificada oferece valor $6,6 \%$ inferior (ação permanente) e 0,7\% inferior (ação do trem-tipo) no valor no momento fletor. 
Para os esforços cortantes no apoio, na viga interna, as diferenças entre o método simplificado e a analogia de grelha são, para os momentos fletores das ações permanentes e móveis, de $3,8 \%$ e $9,3 \%$ superiores, respectivamente. Para a viga externa, as diferenças são de $4,2 \%$ inferior $e$ $7,4 \%$ superior, respectivamente.

Para as flechas das vigas no meio do vão, obteve-se para a kiga interna, diferenças de $5,5 \%$ e $40,6 \%$ superiores, respectivamente, para as ações permanentes e móveis. Para a viga externa, as diferenças foram de $6,5 \%$ e 7,0\% inferiores, respectivamente.

Esta análise de grelha foi realizada como tabuleiro discretizado em sete transversinas. $O$ aspecto da grelha resultante é mostrado na figura a seguir.

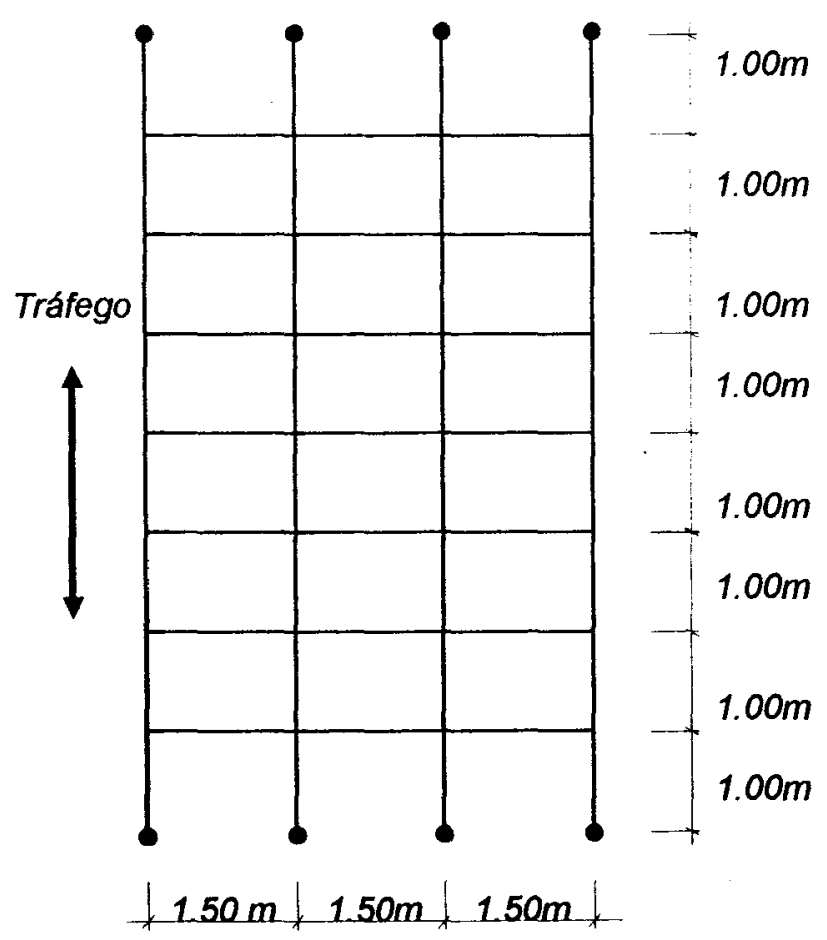

FIGURA 3.31 - Grelha idealizada para a analise (DIAS, 1987).

Foi realizada a instrumentação em modelo, com escala 1 $1: 3.33$ do protótipo mostrado na Figura 3.30 anterior, com 2,40 m de vão, 1,65 m de largura $e$ $0,45 m$ de espaçamento entre vigas. Tendo sido respeitada a razão de semelhança mecânica (diâmetro dos postes do tabuleiro e diâmetro da viga combinados com o produto de inércia El ), optou-se pelo uso de uma viga de 
um poste, ao invés de dois, com $14 \mathrm{~cm}$ de diâmetro, e tabuleiro formado com peças roliças de diâmetros entre 40 e $60 \mathrm{~mm}$. O comportamento medido ( flechas e deformações ) do modelo apresentou ótima concordância com o cálculo pela analogia de grelha usando a discretização proposta.

MATTHIESEN (1987) apresentou diversos estudos experimentais com ensaios de modelos. O primeiro foi a análise do comportamento em Laboratório de modelos com escala geométrica de redução de 1 : 33.3 de um protótipo de 9,60m de largura, $20 \mathrm{~m}$ de vão e altura $h$, calculada em ante-projeto com o valor de $85 \mathrm{~cm}$, para duas faixas de tráfego e Classe 36 . Realizados com Pinho do Paraná (Araucaria angustifolia), os modelos ficaram com as seguintes dimensões:

\begin{tabular}{cccccccc}
\hline ESCALA & & \multicolumn{2}{c}{ VÃO $(\mathrm{cm})$} & \multicolumn{2}{c}{ LARGURA $(\mathrm{cm})$} & ALTURA $(\mathrm{cm})$ & PEÇAS MACIÇAS $(\mathrm{N})$ \\
\hline $1: 33.3$ & $:$ & 60 & $\times$ & 28.8 & $\times$ & 2.5, & uma peça \\
\hline $1: 20$ & $:$ & 100 & $\times$ & 60 & $\times$ & 4.0 & três peças \\
\hline
\end{tabular}

O segundo modelo não representa o protótipo acima, mas outro protótipo de $20 m \times 12 m \times 0,80 \mathrm{~m}$. Este modelo foi analisado com duas faixas de tráfego e duas passarelas, e depois sem as faixas para uso de pedestres. Foi construído com três pranchas coladas lateralmente e analisado considerando-se o carregamento e sua posição, necessários à obtenção das flechas admissiveis no modelo - cargas correspondentes a uma roda e a um e dois trens-tipo. Concluiu-se que as bordas da placa sob ensaio não contribuem significativamente para reduzir as cargas críticas mas contribui para reduzir as deflexões.

MATTHIESEN realizou também ensaios em modelos compostos por vigas, pois as placas dos protótipos apresentava dimensões incompativeis com as dimensões das madeiras disponiveis. Uma alternativa para a composição da placa estudada mostrou-se inviável economicamente - a composição de grandes vigas, de madeira laminada colada ou não, coladas lateralmente para compor a placa. Então estudou-se a interligação lateral de vigas de madeira como alternativa. 
Aplicando uma razão de semelhança geométrica de 1:4 e trabalhando com seções de Peroba Rosa (Aspidosperma polyneuron) de $6 \mathrm{~cm} \times 16 \mathrm{~cm}$ e $5 \mathrm{~m}$ de comprimento, ter-se-ia um protótipo de $20 \mathrm{~m}$ de vão, $64 \mathrm{~cm}$ de altura $e$ 9,60 $m$ de largura. O modelo foi analisado para o carregamento em meia faixa, com $60 \mathrm{~cm}$ de largura e 10 vigas, interligadas com barras de aço de $19 \mathrm{~mm}$ de diêmetro, espaçadas entre si de $1,0 \mathrm{~m}$ e, posteriormente, reduzido este espaçamento a $0,5 \mathrm{~m}$.

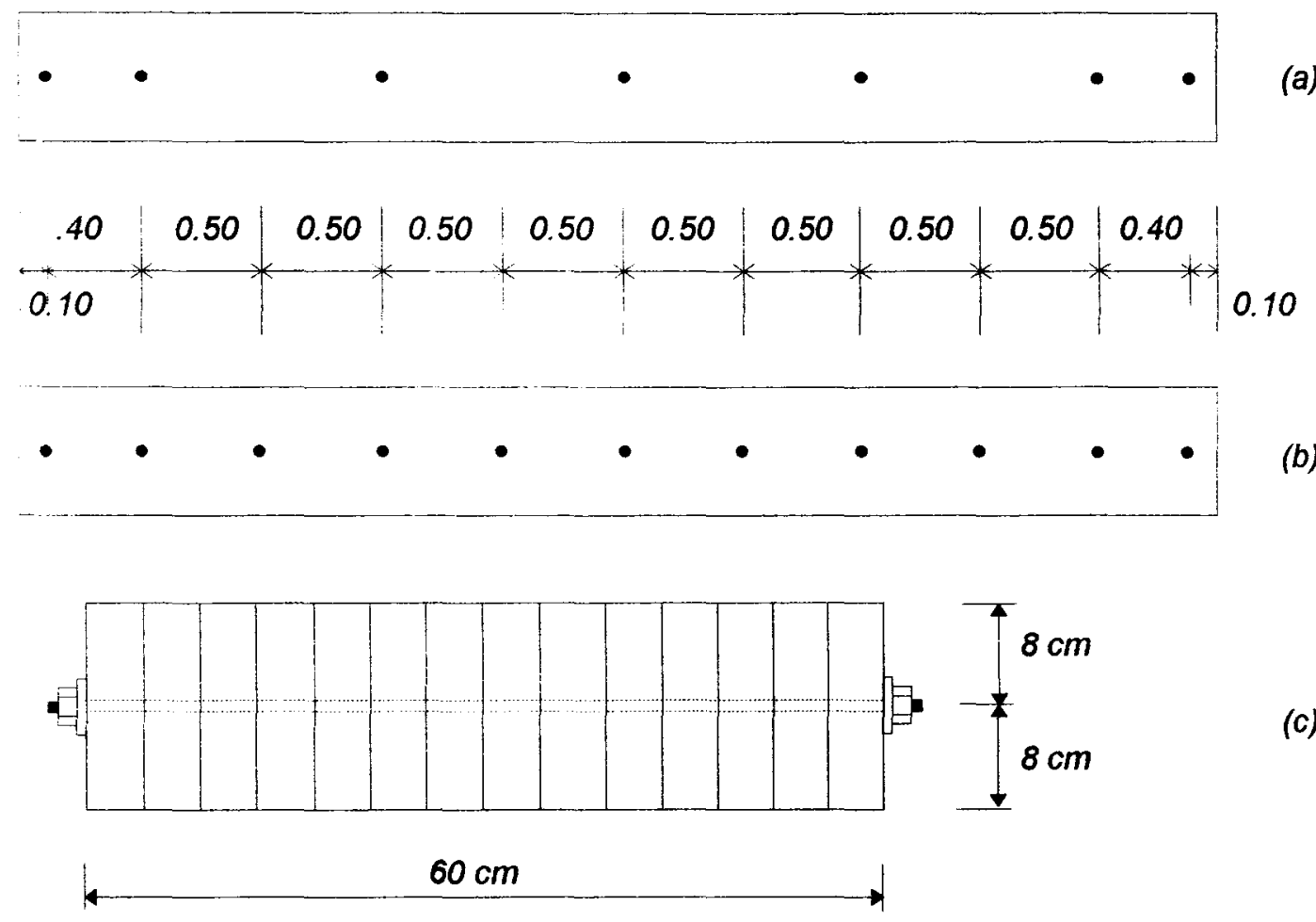

(a)

(c)

FIGURA 3.32 - Modelo de Tabuleiro, de Peroba Rosa :

(a) Posicionamento de sete barras de aço;

(b) Posicionamento de onze barras de aço;

(c) Seçåo Transversal [MATTHIESEN, 1987].

Os ensaios com o modelo de dez vigas e onze barras de aço mostraram resistência $18 \%$ a $20 \%$ superior ao modelo com sete barras de aço, atingindo a flecha admissivel com maior distribuição transversal dos deslocamentos sob forças concentradas. MATTHIESEN afirma, neste ponto, que não foi dado grande aperto nas barras de aço, evitando-se comprimir lateralmente as vigas que compuseram as placas, mas se credita uma parcela da distribuição da carga ao atrito lateral entre as vigas. 
Alargando-se, posteriormente, os furos passantes onde se alojam as barras de aço de 9,5 mm de diâmetro para 12,7 $\mathrm{mm}$ e afastando-se as vigas entre si de $2 \mathrm{~mm}$ a $3 \mathrm{~mm}$, a interligação entre as vigas foi feita por anéis metálicos de $63,5 \mathrm{~mm}$ de diâmetro centrados no eixo dos furos passantes.

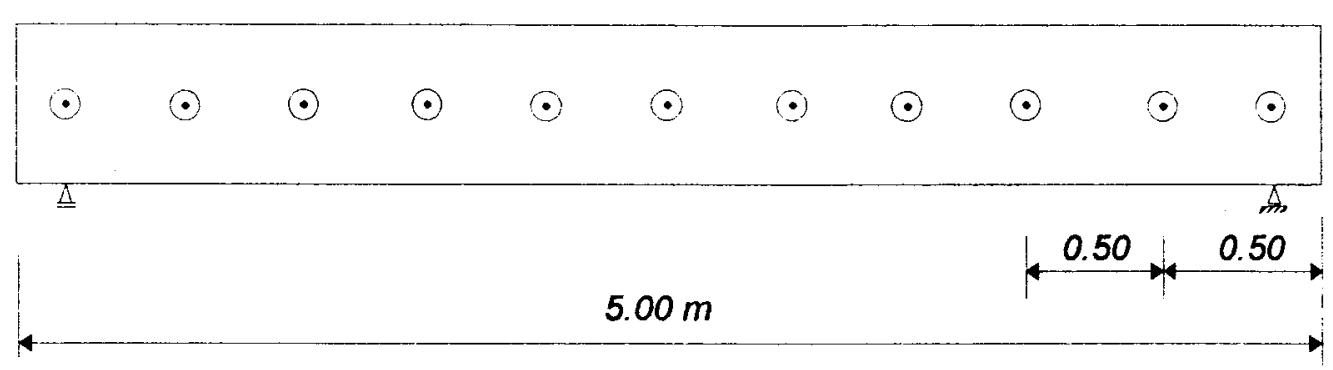

FIGURA 3.33 - Modelo com onze linhas de barras de aço e anéis metálicos.

Os carregamentos foram repetidos no modelo de dez vigas, concluindo-se que os resultados foram de $8 \%$ a $9 \%$ superiores em relação aos anteriores, com melhores resultados na solidarização do conjunto. Com este estímulo, acrescentou-se nove vigas interligadas por anéis - compondo um módulo caracterizado com antecedência - e foi montado um modelo para uma faixa de tráfego, também na escala 1:4 com dezenove vigas de $6 \mathrm{~cm} \times 16 \mathrm{~cm}$ de Peroba Rosa. Após sucessivos ensaios, observou-se boa distribuição transversal das flechas e comportamento de placa elástica.

Estes ensaios possibilitaram um prosseguimento experimental com postes, caracterizando-os e vinculando-os lateralmente, como aperfeiçoamento da idéia original de HELLMEISTER (1978), desta vez combinando vigas de um e de dois postes longitudinais. A conclusão posterior deste estudo foi que a grelha montada com postes solidarizados lateralmente é funcional e viável quanto ao comportamento estrutural, onde as vigas transversais efetivamente existentes têm seu cómputo devido à rigidez dos anéis e da barra de aço, tanto para a estrutura de seção simples quanto para a nervurada, produzida por postes de Eucalipto Citriodora longitudinalmente dispostos. 


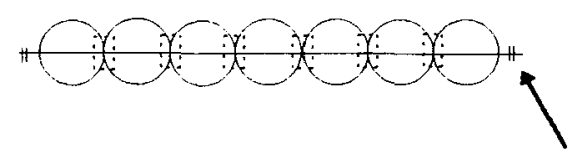

tirante de aço

(a) SEÇÃO SIMPLES ATIRANTADA

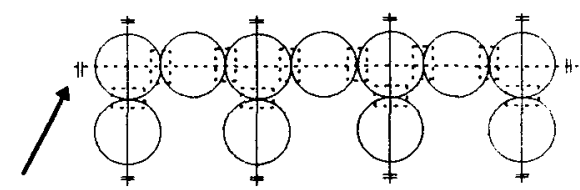

(b) SEÇÃO NERVURADA

FIGURA 3.34 - Seçס̃es dos modelos analisados por Matthiesen (1987).

Mais recentemente, NASCIMENTO (1993) investigou a possibilidade de se tensionar um tirante de aço posicionado através de furos em vigas de madeira dispostas lado a lado formando o sistema laminado tensionado.

Usando barras de aço de CA-32 de $12,7 \mathrm{~mm}$ de diâmetro, a protensão transversal teve seu valor limitado a um máximo teórico de $42 \mathrm{kN}$ (limite de escoamento da barra) mas o máximo prático obtido foi de $28 \mathrm{kN}$ (aperto manual de porcas e contra-porcas nas laterais da placa de madeira) contra as chapas de apoio. $O$ autor estipulou um mínimo necessário de $30,8 \mathrm{kN}$ para manter a integridade da placa de madeira.

NASCIMENTO conclui que a deformação por flexão da placa acrescentou tensão à barra transversal, tal como o trabalho precedente de MATTHIESEN (1987).

\subsubsection{Escola Politécnica - USP.}

ALMEIDA (1989) apresentou um trabalho inovador gerado no Setor de Madeiras do Laboratório de Estruturas e Materiais da Escola Politécnica, na Universidade de São Paulo: Pontes Estaiadas de Madeira. Com este trabalho, a autora pesquisou a viabilidade operacional de se substituir uma prática profissional inexistente por investigações experimentais sucessivas, visando a implantação de um protótipo de $63 \mathrm{~m}$ de extensão (33 $m$ de vão central) e $10 \mathrm{~m}$ de largura. 


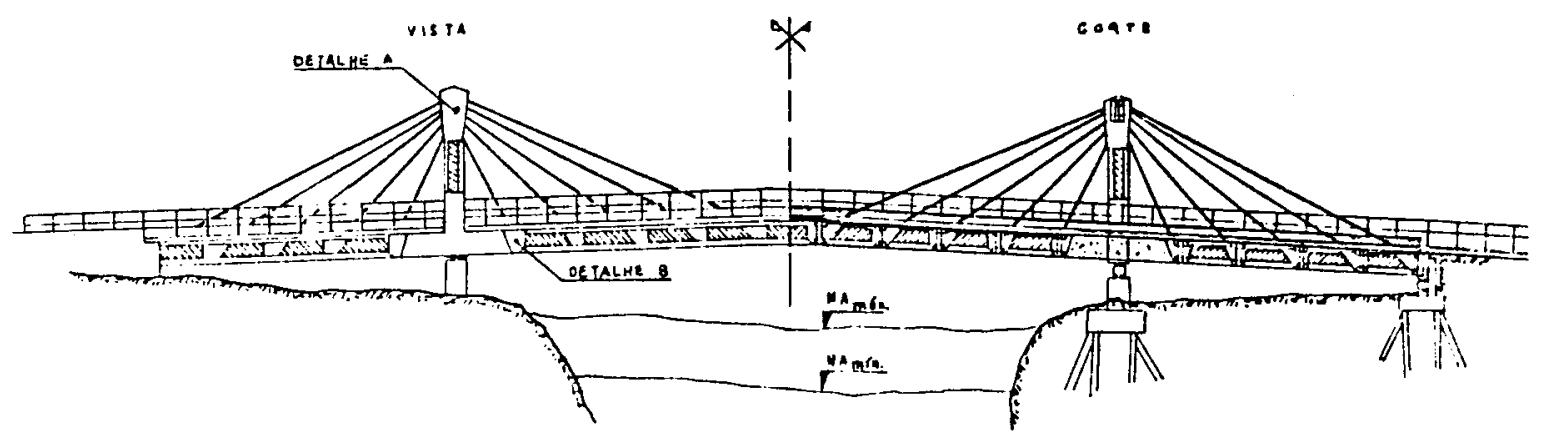

(a)

(b)

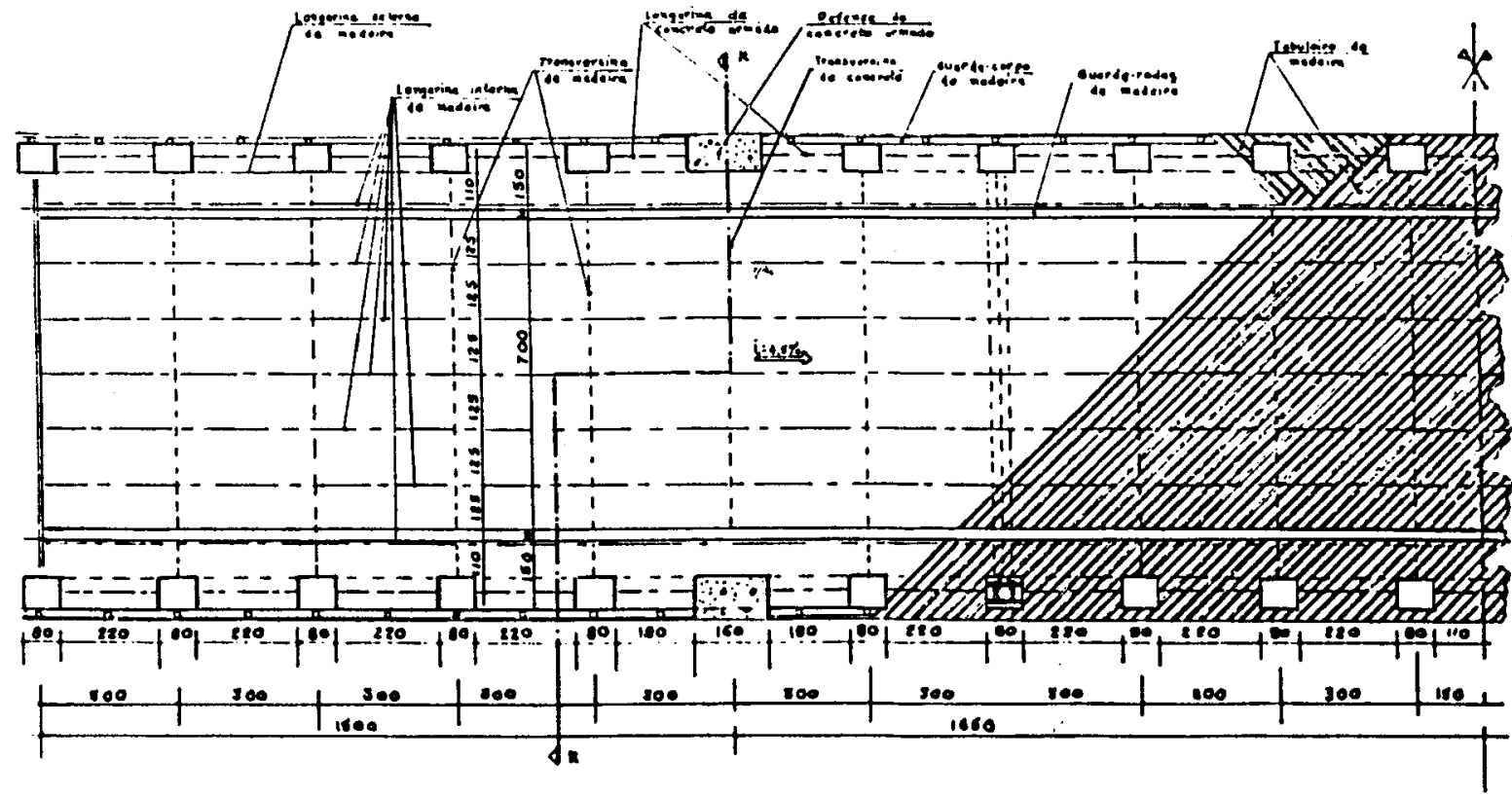

(c) 


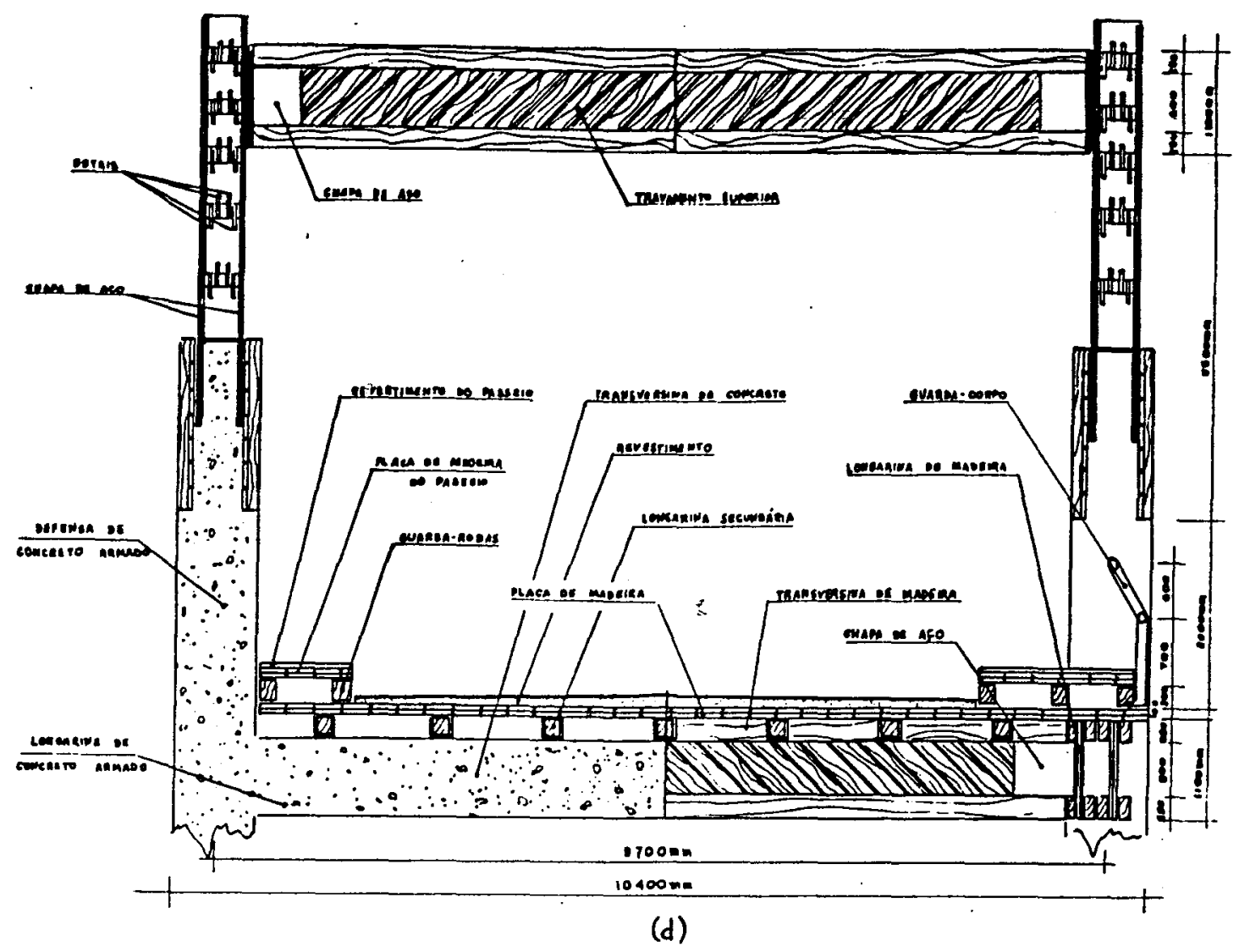

FIGURA 3.35 - Ponte Estaiada proposta por ALMEIDA:

(a) Elevaçăo; (b) Corte; (c) Planta; (d) Seção transversal.

[FONTE: ALMEIDA, 1989].

O conjunto é tal que, na borda do tabuleiro, há duas longarinas externas de madeira, mais sete longarinas internas de madeira afastadas de 1,25 m entre si, e a cada 3,00 $\mathrm{m}$ há uma transversina - de concreto nas torres, de madeira nos vãos. $O$ corte $X-X$ apresenta esta situação (anterior).

Para viabilizar esta concepção, utilizou-se o sistema de tábuas cruzadas pregadas, aproveitando a metodologia anteriormente desenvolvida por ALMEIDA \& FUSCO (1989). A superestrutura usa vigas compostas a partir de tábuas dispostas em diagonal, dupla e opostas, mutuamente pregadas, solidarizadas por pregos a mesas de vigotas de madeira e que apóiam um tabuado, também de tábuas cruzadas em diagonal pregadas formando uma placa. 
As vigas de alma simples e dupla e a placa foram ensaiadas e, caracterizado o seu comportamento, analisadas numericamente. Um modelo desta proposta está na Cidade Universitária, Campus de São Paulo da USP.

Completando esta abordagem das ligações pregadas ALMEIDA (1990) apresentou Estruturas de Grande Porte de Madeira Composta dedicando-se à confecção de uma ponte no Rio Sorocaba, em Iperó (SP), cuja implantação foi detalhada e instrumentada com uma prova de carga. Nesta ponte, as vigas longitudinais de madeira diagonalmente dispostas e pregadas mutuamente suportam um tabuleiro intermediário, posição onde foram colocados enrijecedores de alma para se evitar a flambagem local (disposto horizontalmente) e, nos pontos de contato das vigas transversais e apoios, colocou-se enrijecedores verticais, solidarizados às vigas por cantoneiras e parafusos de aço, estabilizando o plano de trabalho da estrutura. A ponte tem $28,50 \mathrm{~m}$ de vão e está apresentada nas figuras seguintes.

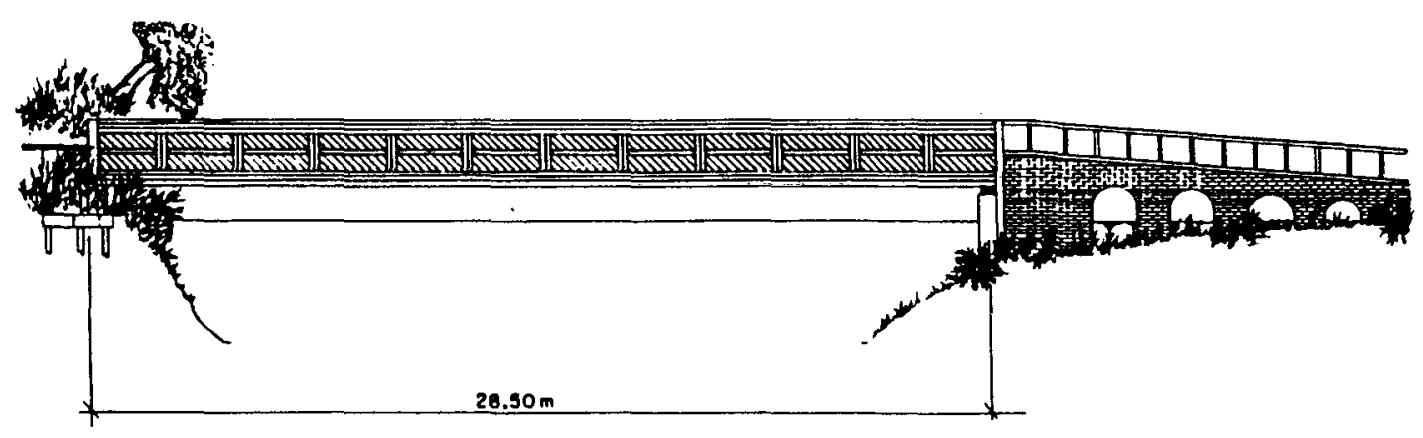



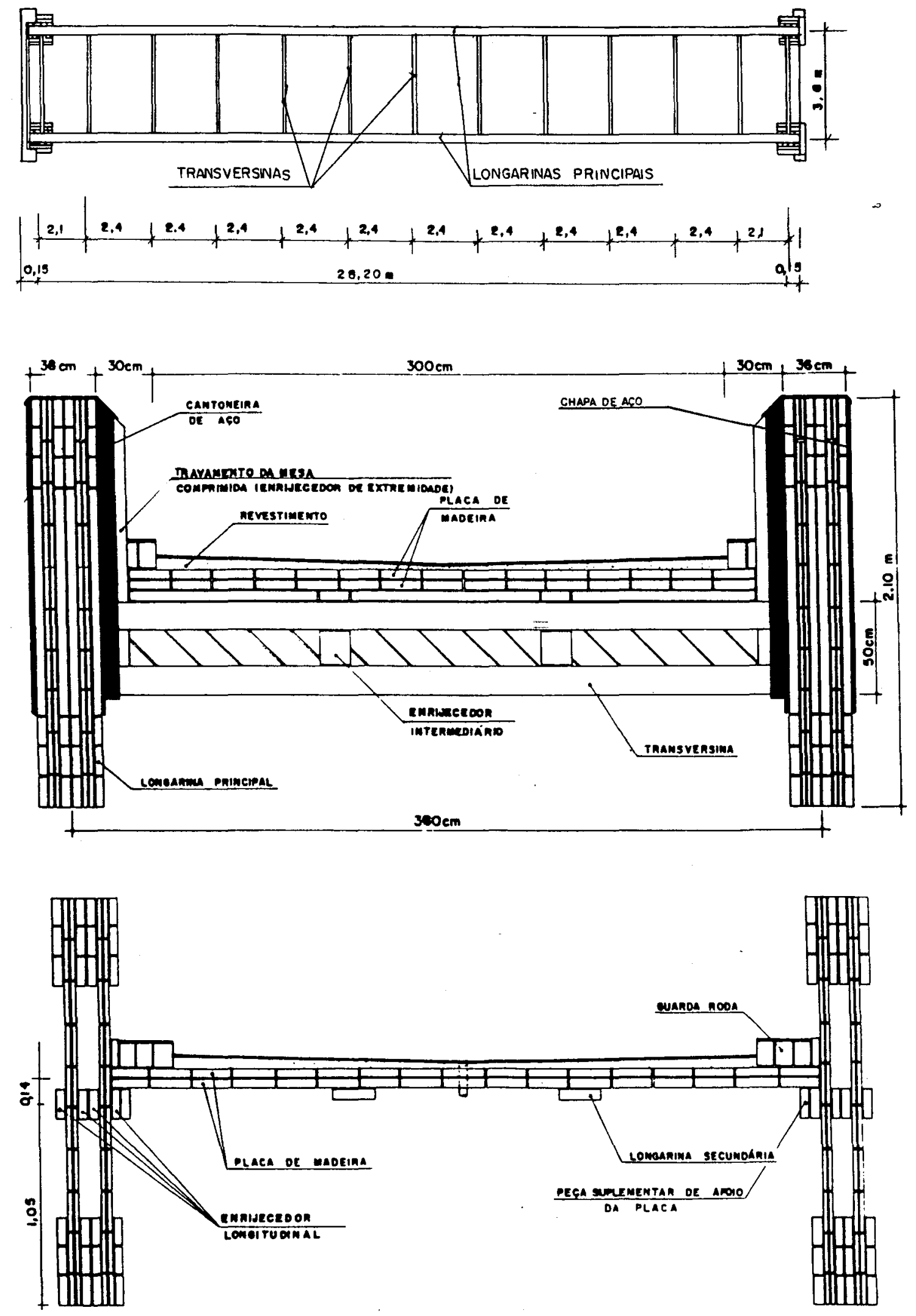

FIGURA 3.36 - Ponte de Iperó sobre o Rio Sorocaba.

[FONTE: ALMEIDA, 1990]. 


\subsubsection{Outras Instituições}

SZÜCS (1986) pesquisou a solidarização de postes roliços com diâmetros compensados (sistema Hellmeister), desta vez através de tarugos de aço e parafusos passantes, visando seu aproveitamento para pontes de madeira de $20 \mathrm{~m}$ de vão e classes 12, 24 e 36 (NBR 7188/82), durante os anos de 1984 e 1985 no Estado de Santa Catarina. Analisando modelos em Laboratório, na Universidade Federal de Santa Catarina (UFSC), o autor conclui que não há necessidade de acréscimo de altura no cálculo dos tarugos, contrariamente ao requerido pelos anéis. A espessura dos tarugos é função da tensão de escoamento do aço por cisalhamento na linha de interface e seu espaçamento é função da resistência da madeira que pode ser cisalhada pela base ou topo da chapa que forma o tarugo. São utilizados parafusos para manter os postes alinhados montando a viga principal. A eficiencia do sistema de ligação observada no modelo pouco reduzido foi de $75 \%$ a $79 \%$ do valor teórico e o autor adotou $80 \%$ para o cálculo.

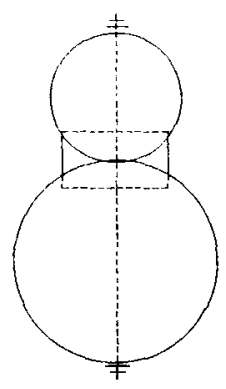

seção transversal

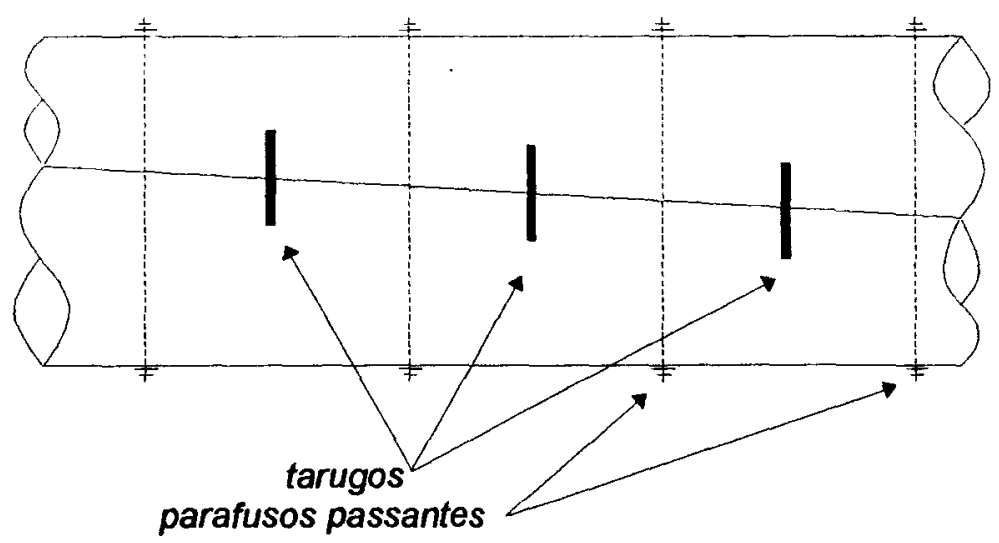

elevaçåo

(esquemática)

FIGURA 3.37- Aspecto de montagem da viga bicircular com tarugos de aço.

YOJO et al (1993) apresentaram uma contribuição do Instituto de Pesquisas Tecnológicas do Estado de Sáo Paulo (IPT) ao desenvolvimento de estruturas de madeira para travessias: uma passarela de madeira de 
reflorestamento, tratada, construída no Bairro do Butantã, na cidade de São Paulo.

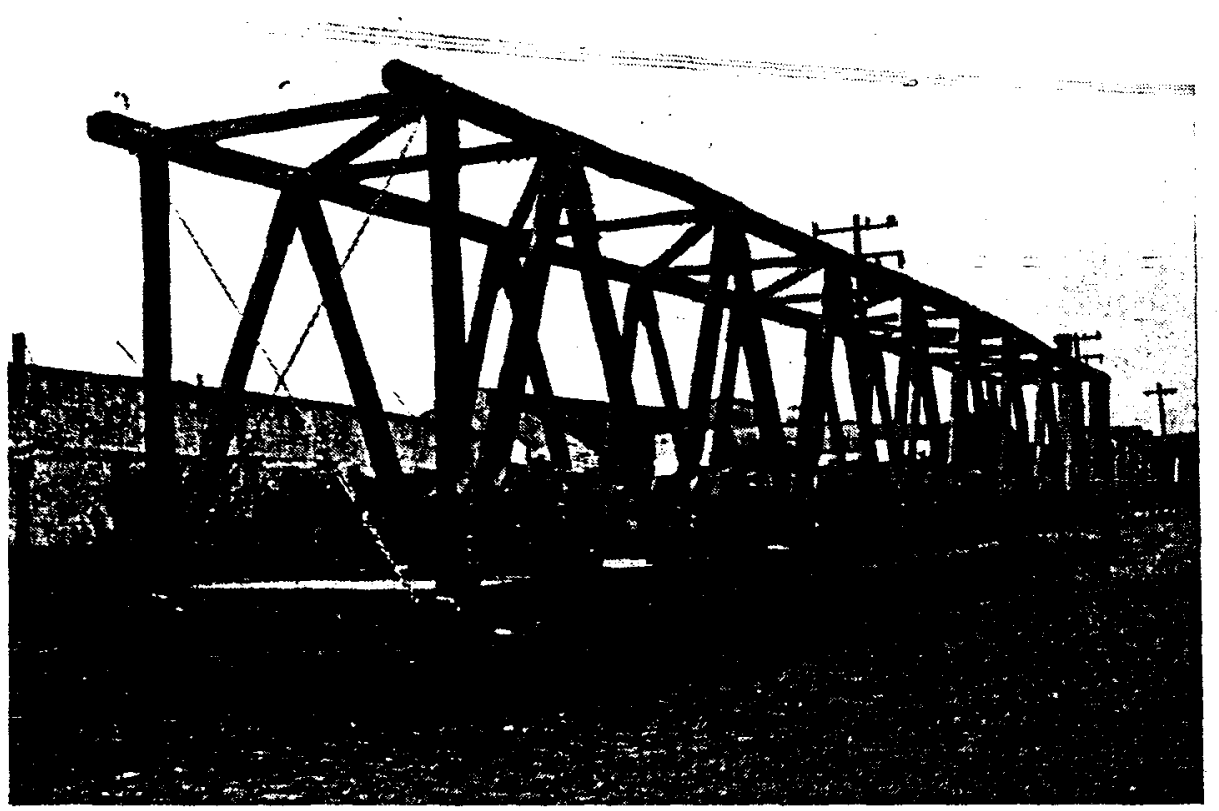

FIGURA 3.38 - Estrutura montada.

O projeto estrutural foi baseado em um sistema formado por elementos de pórtico e treliça em madeira. O vão livre teórico é de $32,40 \mathrm{~m}$, sendo coberto pela união de dois elementos de poste ligados por parafusos e chapas metálicas soldadas. A estrutura foi dimensionada baseando-se na Norma NBR 7190/82 "Cálculo e Execução de Estruturas de Madeira", prevendo-se uma carga acidental vertical constante na Norma NBR 7188/84 "Carga Móvel em Ponte Rodoviária e Passarela de Pedestre". Segundo esta Norma a carga acidental deve ser de $5 \mathrm{kN}$ por metro quadrado. Além disso, foi considerada uma carga de vento segundo a Norma NBR 6123/88 "Forças Devidas ao Vento em Edificações".

As partes da estrutura foram pré-fabricadas no IPT e transportadas em módulos praticamente acabados até o local de instalação, onde os dois módulos do vão central foram unidos antes do seu içamento. 
A infra-estrutura foi executada em concreto armado.

O volume total de madeira consumida, inclusive nas duas rampas de acesso, foi de aproximadamente $40 \mathrm{~m}^{3}$ de postes tratados de Eucalipto utilizadas na estrutura propriamente dita, e aproximadamente $20 \mathrm{~m}^{3}$ de pranchões de Pinus tratado, utilizados como piso - executado no sistema de pranchas cruzadas.

CALIL JR et al (1993) apresentaram o trabalho Passarela Pênsil com Vigas Principais de Madeira, discorrendo resumidamente sobre sua tipologia. $O$ trabalho apresenta o projeto e a construção de uma passarela pênsil de $4 \mathrm{~m}$ de largura por $105 \mathrm{~m}$ de comprimento e vão livre de $78 \mathrm{~m}$, construída sobre - Rio Piracicaba na cidade de Piracicaba, SP. As vigas longitudinais e transversais são treliçadas, compostas de peças retangulares de $6 \mathrm{~cm}$ por $16 \mathrm{~cm}$ de Eucalipto Citriodora ligadas através de parafusos metálicos galvanizados. O tabuleiro é composto por duas camadas de tábuas cruzadas perpendicularmente, formando um ângulo de 45 graus com o eixo longitudinal da estrutura. As tábuas do tabuleiro são de Eucalipto Tereticornis, com espessura de $2,5 \mathrm{~cm}$ e $20 \mathrm{~cm}$ de largura, pregadas às vigas principais. As torres de sustentação dos cabos principais são de aço. O comportamento estrutural da passarela na prova de carga realizada foi plenamente satisfatório e dentro dos limites de deformação calculados.

\section{Esta passarela é a maior do Hemisfério Sul construída com estrutura de madeira.}

\subsubsection{Madeiras de Reflorestamento no Brasil}

Após ciclos económicos agrícolas sucessivos, parte do País perdeu grandes áreas de reservas florestais de seus domínios originais e em outra parte a extinção das florestas modificou definitivamente a paisagem para 0 surgimento das caatingas do sertão semi-árido nordestino. 
Já existe no País um projeto para recuperação ambiental diferenciado, atuando em niveis locais e regionais para obtenção de reserva de fitomassa de grandes proporções para efeitos produtivos múltiplos de interesse nacional, com validação ecológica e social. Este projeto é o Floram $^{3}$ (1990) (flor : floresta; am : ambiente), com os níveis :

- florestas sociais;

- florestas para reabilitação de solos;

- florestas para bloqueio de desertificação;

- florestas para reperenização de drenagem;

- florestas hibridas de interesses sócio-econômicos e cultural;

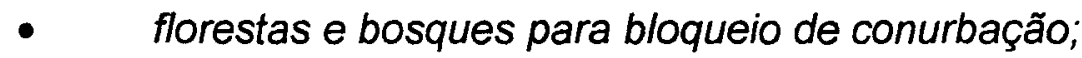

- revegetação e bosqueamentos viáveis para as regiões semi-áridas.

Este projeto não é uma política florestal mas poderá ser incorporado por ela, trazendo prescrições adequadas e fortalecendo econômica e ecologicamente o desenvolvimento social e florestal dentro do País.

A demonstração da viabilidade operacional de programas de reflorestamentos nos deve levar à observação da estratégia de suprimento de matéria-prima para aplicações diversas no ambiente tecnológico do futuro. Não apenas essências nativas, nem exclusivamente espécies exóticas. Não somente madeira bruta ou beneficiada, nem unicamente produtos industrializados.

O ambiente social e econômico deverá sempre ser interferente e colaborador para que demandas e estratégias possam ser atendidas ao menor tempo, menor custo e melhor relação benefício/custo.

${ }^{3}$ Revista Estudos Avançados USP - Projeto FLORAM : uma plataforma. 
A aplicação de madeiras de reflorestamento, pois, não se restringe ao uso de Eucaliptos e Pinus, embora sejam os gêneros disponíveis no mercado Centro-Sul do Pais atualmente. O replantio sistemático fortalecendo o abastecimento no mercado em um horizonte de 30 anos ou mais certamente propiciará menor pressão pela oferta de madeira de grandes qualidades sem que as expécies acabem ou as distâncias de fretes inviabilizem os empreendimentos. Além disso, há espécies dos gêneros disponiveis com qualidades suficientes para serem substitutas das espécies com maior demanda.

A disponibilidade futura de madeira de espécies nativas qualificadas para uso estrutural deverá, assim, ser objeto de reflorestamento tanto quanto o plantio dos gêneros já disponíveis, Eucaliptos e Pinus.

Dos reflorestamentos existentes as espécies recomendadas [SALES, 1991] para aplicação em pontes são os Eucalyotus : citriodora tereticornis, punctata, maculata, paniculata.

\subsection{AUSTRÁLIA}

Nos mais recentes desenvolvimentos da tecnologia envolvendo as pontes de madeira, além dos países antecedentes, é necessário incluir-se a Austrália. Também é um país de dimensões continentais, como Canadá, Estados Unidos e Brasil (área total de $7682300 \mathrm{~km}^{2}$ ) e produtor de madeira.

Desde 1990 já está implantada na Austrália a mesma cultura de desenvolvimento da Timber Bridge Initiative (TBI), através de um programa cooperativo conjunto - Australia - United States Timber Bridge Program (AUSTIM), que visa implantar a tecnologia de pontes protendidas. 
Na International Timber Engineering Conference (London), YTTRUP e LAW (1991) apresentaram um resumo sobre o desempenho estrutural de várias pontes de madeira australianas, rodoviárias e ferroviárias. A tipologia mais comum é a de ponte em vigas, com vãos de $9 \mathrm{~m}$ a $14 \mathrm{~m}$ nas rodovias e de $5 \mathrm{~m}$ a $8 \mathrm{~m}$ nas ferrovias, de seções roliças (postes) ou retangulares, vigas compostas com ligações por parafusos. Os sistemas treliçados existem nas rodovias, com vãos de $20 \mathrm{~m}$ a $80 \mathrm{~m}$, mas nas ferrovias há muito poucas pontes treliçadas.

No sistema ferroviário da província de Queensland, encontram-se mais de $100 \mathrm{~km}$ de pontes de madeira (cerca de 17000 vãos) com idades até 120 anos.

No sistema rodoviário da província de New South Wales há cerca de 1000 pontes de vigas e 100 pontes treliçadas; além disso, no sistema municipal (vicinais) há ainda mais pontes.

No país todo, há provavelmente 5000 pontes que já ultrapassaram seu nivel de eficiência, carecendo de reparo ou substituição com custo estimado de US $\$ 15.000 .000,00$. Mesmo que a política de substituição destas pontes hoje deficitárias já esteja em implementação, não se reduzirá a importância das pontes de madeira no papel de interligação terrestre do país, por causa da excelente performance já demonstrada por elas. Por exemplo, pontes projetadas para a passagem lenta de unidades "pesadas" (16 toneladas) suportam hoje veículos de 40 toneladas nas velocidades de tráfego rodoviário modernas.

As pontes de vigas típicas do sistema construtivo adotado na Austrália adotam vigas roliças aparelhadas na face e acomodadas geometricamente ao vão, com o tabuleiro fixado diretamente às vigas, figura 3.39. 


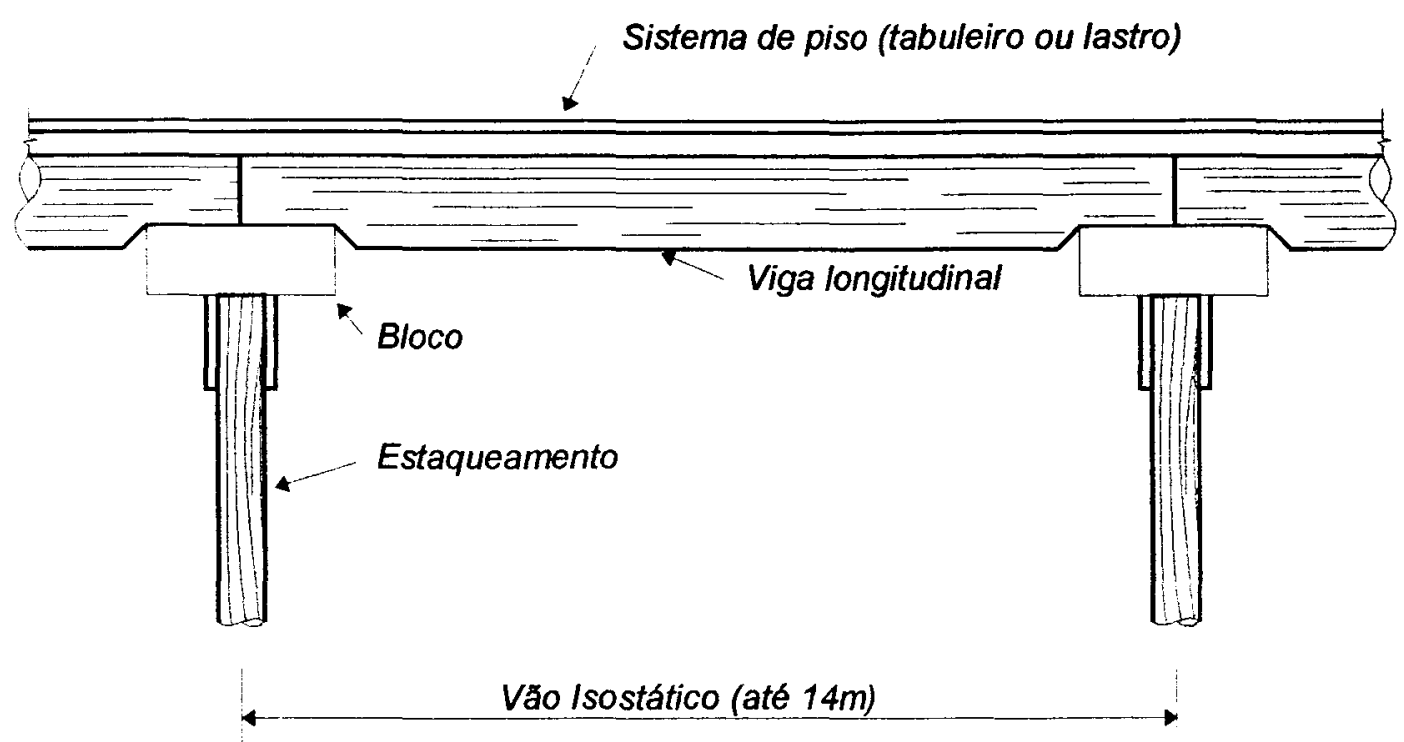

FIGURA 3.39 - Ponte Rodoviária Típica Existente na Austrália até a década passada.

Em julho de 1994 houve a Pacific Timber Engineering Conference realizada em Gold Coast, Austrália. A grande afluência dos pesquisadores em todos os continentes fez desta Conferência um grande sucesso. Na ocasião, divulgou-se que os países em que se implementam protótipos com 0 sistema construtivo de madeira laminada tensionada são:

a) Canadá.

b) Estados Unidos.

c) Austrália.

Os vários trabalhos apresentados nesta Conferencia, sobre as pontes de madeira, podem ser divididos em três categorias:

1. Estudos de desempenho e aperfeiçoamento de sistema construtivo.

2. Apresentação de projetos.

3. Relatos com o estado-da-arte tecnológica dos países.

Conseguiu-se uma troca de informações que atualizam as possibilidades de uso do sistema laminado tensionado, particularmente quanto ao uso de 
madeiras de dicotiledôneas. Se com madeiras de coniferas se deve esperar uma relaxação da força na barra de $50 \%$ (e até $60 \%$ ), há casos instrumentados com perdas médias inferiores a $20 \%$ no mesmo período de dois anos [TAYLOR,R. e KEITH,J.(1994)] com as madeiras de folhosas.

O desempenho superior dos tabuleiros confeccionados com barras Dywidag - desenvolvidas para o uso em concreto protendido - e madeiras de dicoledôneas está trazendo um enorme impulso à construção de pontes de madeira porque possibilita o uso imediato da madeira disponível no mercado, sem delas exigir grandes dimensões ( bitolas e/ou comprimentos especiais). Com isso, as construções combinadas ( seções $T$, caixão, celular) ganharam impulso também na Austrália, usando veneer de Pinus radiata e duplo tabuleiro com madeiras de folhosas. A maior ponte laminada protendida construída com sistema laminado tensionado é celular, tem $60 \mathrm{~m}$ de comprimento e é contínua sobre 6 vãos, com largura de $8 \mathrm{~m}$.

Uma sequência de pesquisas definidoras dos parâmetros necessários à implantação de pontes de madeira protendidas na Austrália está sendo realizada na University of Technology, Sydney conjuntamente com as responsáveis pelo planejamento de transportes. A primeira grande fase de pesquisa iniciou-se em 1990 com os estágios seguintes:

\section{Definição, Especificação e Finalização dos Procedimentos de Ensaio.}

Este trabalho é necessário para se determinar como se comportam o material $e$ as estruturas montadas, e seu desempenho medido e compreendido. Foram construídos tabuleiros de até $8,5 \mathrm{~m}$ (e partes de até $4,8 \mathrm{~m}) \mathrm{em}$ laboratório. Estes tabuleiros foram carregados para que se estabelecesse um limite de utilização (por medidas de flechas) para 0 comportamento de placas e se comparasse com a análise teórica (teoria de placa ortotrópica). Ensaios adicionais foram realizados para que se conhecesse o estado limite último de resistência e o comportamento pós- 
colapso. Esta condição experimental foi decisiva para se qualificar os limites de resistência e comportamento estrutural sob condições de sobrecargas extremas.

\section{Registro, Análise e Interpretação dos Resultados de Ensaio.}

Esta etapa possibilita fundamentar um método analítico para previsão de comportamentos que, por sua vez, permite preparar procedimentos racionais de cálculo estrutural. É a parte crucial de pesquisa e desenvolvimento.

\section{Construcão, Supervisão e Monitoração de Pontes-Protótipo.}

Tão essencial quanto o desenvolvimento de critérios, a disseminação de informações tecnológicas às autoridades constituídas (poder local, regional e nacional) precisa de confirmações práticas de desempenho que só são obtidas pela implantação de protótipos que sejam monitorados e demonstrem sua suficiência em campo. Este é o argumento definitivo para que os consultores e futuros profissionais se engajem na importante área de implementação de tecnologia pelo seu efeito-demonstração. Assim, adiciona-se à experiência em laboratório medidas reais do comportamento no meio-ambiente definitivo, fornecendo documentação significativa para a análise estrutural das pontes-protótipo.

Atualmente o programa de desenvolvimento experimental foi desmembrado em doze estágios principais, conforme CREWS et al (1994):

ESTÁGIO 1: Propriedades Físicas dos Componentes de Madeira.

ESTAGIO 2: Ensaio em Frações de Tabuleiros.

ESTÁGIO 3: Derivação das Propriedades das Placas Ortotrópicas.

ESTÁGIO 4: Ensaio em Carga de Ruptura. 
ESTÁGIO 5: Efeitos de Tratamentos e Ensaios de Acabamento Superficial.

ESTÁGIO 6: Monitoração de Campo e Pontes-Protótipo.

ESTÁGIO 7: Documentação do Tabuleiros em Placa.

ESTÁGIO 8: Seções Compostas.

ESTÁGIO 9: Monitoração de Campo e Pontes-Protótipo Celulares.

ESTÁGIO 10: Ensaios de Componentes de Pontes Celulares.

ESTÁGIO 11: Documentação de Combinação de Seções.

ESTÁGIO 12: Estabelecimento de uma Base de Dados.

MUIR(1994) aplica-se à investigação tecnológica e aponta o "faça" e o "não faça" na construção das pontes de madeira:

1. Construir tabuleiros com caída suficiente para drenar a água tão eficazmente quanto possivel. Esta preocupação levou os europeus e americanos a colocar telhados sobre as pontes pioneiras, que tiveram grande durabilidade.

2. Garantir que as fibras extremas estejam tratadas - o calcanhar de Aquiles das peças estruturais, tabuleiros e estacas de madeira.

3. Evitar a exposição ao tempo de superficies largas ou de seções de extremidade, sempre que possivel.

4. Selar as superficies largas de vigas e sempre especificar madeiras duráveis adequadas às aplicações expostas ao tempo.

5. Sempre ancorar o piso com a medula para baixo e o alburno tratado para cima. 
6. Para adicionar valor à aplicação dada, respeite e obedeça à legislação ambiental em vigor. $O$ uso de produtos adequados e aprovados é sinal de qualidade.

7. Preparar e comprometer-se com um programa simples de manutenção - preventiva, para cada projeto, para garantir a vida útil prolongada da estrutura. Estes programas podem ser feitos de tal modo que sejam simples de aplicar e baratos.

8. Quando se especificar ou comprar madeira, explicar ao fornecedor de madeira o propósito de seu pedido. O fornecedor consciente da legislação e das práticas de manejo sustentado deverá se encarregar de fornecer a melhor madeira disponivel para a intenção desejada pelo preço tolerável.

\subsection{A CONJUNTURA BRASILEIRA.}

As Normas Brasileiras atuais, em que se pese o estágio de revisão da NBR 7190 (Cálculo e Execucão de Estruturas de Madeira) da Associação Brasileira de Normas Técnicas (ABNT), não contemplam disposições construtivas que considerem o projeto de pontes em placa, protendidas ou não, e outros sistemas mais modernos que o sistema estrutural que usa vigas. Esta conjuntura foi discutida por PRATA (1992). É necessário incorporar as disposições da NBR 8681 (Ações e Sequrança nas Estruturas), da NBR 7188 (Carga Móvel em Ponte Rodoviária e Passarela de Pedestre), ou da NBR 7189 (Cargas Móveis para o Projeto Estrutural de Obras Ferroviárias), à sistemática de cálculo de pontes de madeira. Além destas, é necessário adicionar especificações construtivas desde as dimensões das peças, seu tratamento, industrialização e montagem até acabamento e uso final. Alguns subsídios para esta orientação estão nos ANEXOS A e B. Outros estão no Capítulo 4. 
NASCIMENTO et al (1993) propuseram as condições a serem satisfeitas pelas estruturas laminadas protendidas, a saber:

- teor de umidade máximo de $18 \%$;

- emendas dispostas modularmente;

- compressão interlaminar mínima de $700 \mathrm{kN} / \mathrm{m}^{2}$ em serviço;

- ancoragens simples (em placas discretas);

- tabuleiro com revestimento asfáltico de 5 a $7,5 \mathrm{~cm}$ com membrana geotêxtil na interface;

- utilização de cilindros hidráulicos de protensão e barras especiais.

O trabalho desenvolvido por NASCIMENTO (1993), porém, não atingiu a protensão mínima necessária para se induzir a compressão interlaminar mínima $\left(700 \mathrm{kN} / \mathrm{m}^{2}\right)$, tornando válido seu trabalho experimental apenas do ponto de vista de uso de uma placa de madeira semelhante à realizada por MATTHIESEN (1987).

Por outro lado, a aplicação de tratamento com creosoto torna a superfície do tabuleiro compatível com o alcatrão e betume do concreto asfáltico da superfície de desgate, propiciando adesão física e quimica e impermeabilizando mais eficientemente o tabuleiro. Por esta razão principal, - geotêxtil é aplicado somente quando o tabuleiro tem tratamento hidrossolúvel e o revestimento asfáltico é indispensável. 


\section{4 - PONTES EM PLACA - O MÉTODO Ontario Highway Bridge Design Code (OHBDC)}

O método simplificado adotado pelo OHBDC aplica o método $(\alpha, \theta)$ [CUSENS e PAMA(1969)] e usa um parâmetro "D" para balizar o dimensionamento das estruturas; foi desenvolvido pela idealização da estrutura da ponte como placa ortotrópica.

O método de carregamento de Ontário é apresentado por ser mais próximo do carregamento real, definido pelo DNER, hoje ocorrente nas rodovias brasileiras (ver ANEXO D). A Norma Brasileira NBR 7188 - Carga Móvel em Ponte Rodoviária e Passarela de Pedestre (1984) da Associação Brasileira de Normas Técnicas (ABNT) traz um carregamento bastante diverso que, se aplicado no procedimento de cálculo apresentado não altera a metodologia proposta e, além disto, torna a aproximação para as proporções da superestrutura mais rápida - o ante-projeto é expedito e bem aproximado do necessário no projeto final.

Existe uma família de parâmetros determinada para cada tipo de estrutura, tirados a partir de investigações em campo e simulações numéricas em computador, utilizando fatores adimensionais especificos relacionando as rigidezes da placa ortotrópica. Esses parámetros são dados para pontes com uma, duas, três e quatro faixas de tráfego. É dada, também, uma família desses valores para as solicitações :

- momento fletor longitudinal;

- momento fletor transversal;

- força cortante longitudinal;

- força cortante transversal. 
Apresenta-se, a seguir, o desenvolvimento do método simplificado e algumas aplicações de seu rápido caminho de solução para projeto e análise de estruturas de pontes, incluindo-se diversas tipologias de pontes de madeira.

\subsection{MÉTODO SIMPLIFICADO PARA DETERMINAÇÃO DE MOMENTOS} LONGITUDINAIS.

O método do fator $\boldsymbol{D}$, desenvolvido sob a idealização da ponte como placa ortotrópica, baseia-se na premissa de que o modo de distribuição dos momentos fletores longitudinais na seção transversal é razoavelmente independente da posição longitudinal da carga e da seção transversal sob consideração.
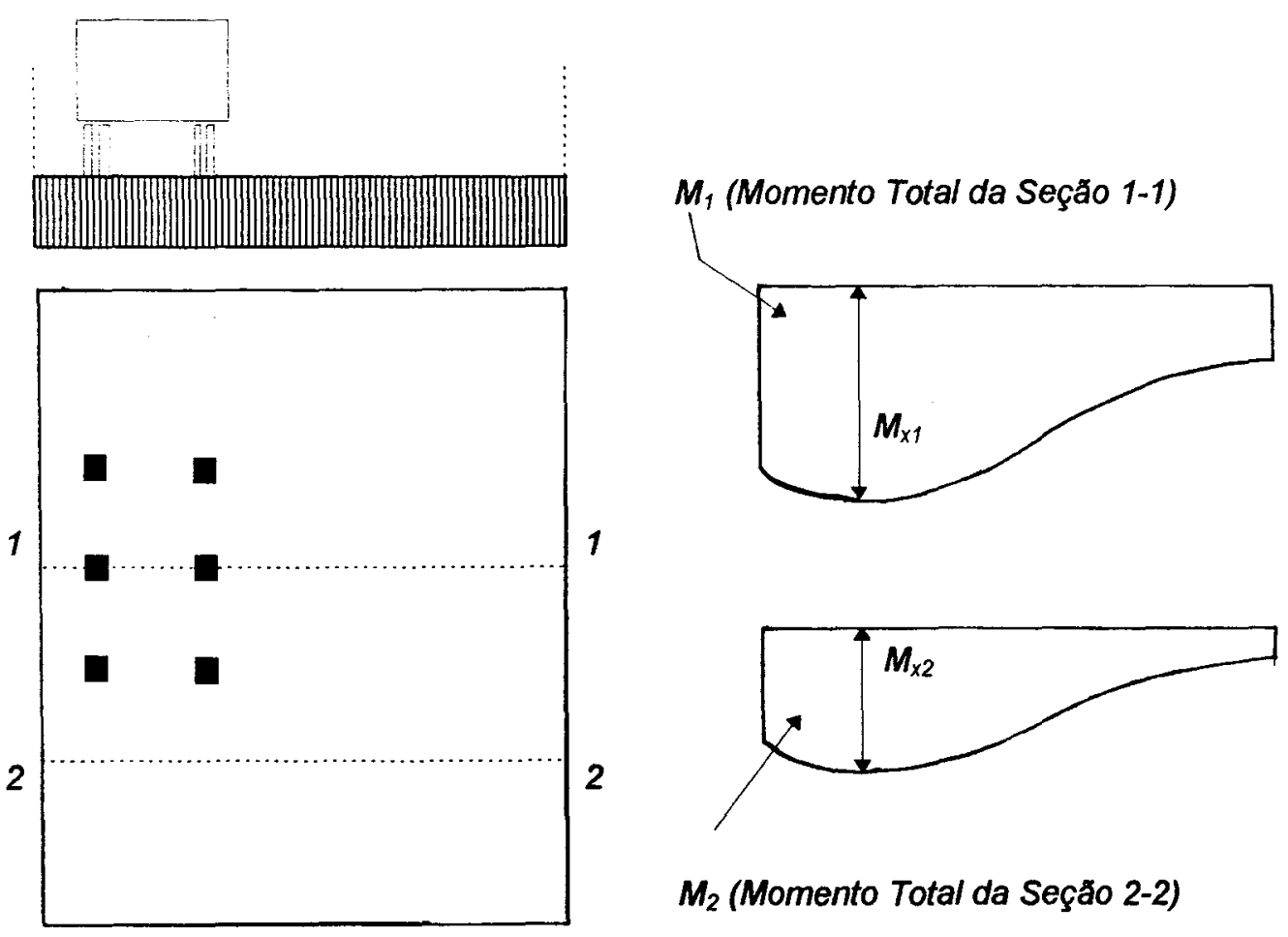

$M_{2}$ (Momento Total da Seçăo 2-2)

FIGURA 4.1 - Modelo de distribuiçăo transversal para momentos longitudinais.

De acordo com o ilustrado pela Figura 4.1, matematicamente :

$\frac{M_{x 1}}{M_{1}} \cong \frac{M_{x 2}}{M_{2}}$ 
O conceito do fator " $D$ " pode ser aplicado com referência à Figura 4.2, que apresenta a distribuição transversal do momento $M_{x}$ em uma ponte em placa sobre vigas, idealizada como placa ortotrópica. 0 momento fletor total da carga móvel, $M_{q}$, que a segunda viga a partir da esquerda (junto da parcela de tabuleiro associada) deverá sustentar é igual à área hachurada do diagrama de momentos fletores mostrado. Se chamar-se de $M_{x, m a ́ x} a$ intensidade do momento fletor longitudinal máximo e dar-se de $S$ uniforme $o$ espaçamento entre as vigas, então, esta área vale, aproximadamente :

$$
A \cong M_{x, \text { máx }} . S
$$

Assim,

$$
M_{q}=M_{x, \operatorname{máx}} \cdot S
$$
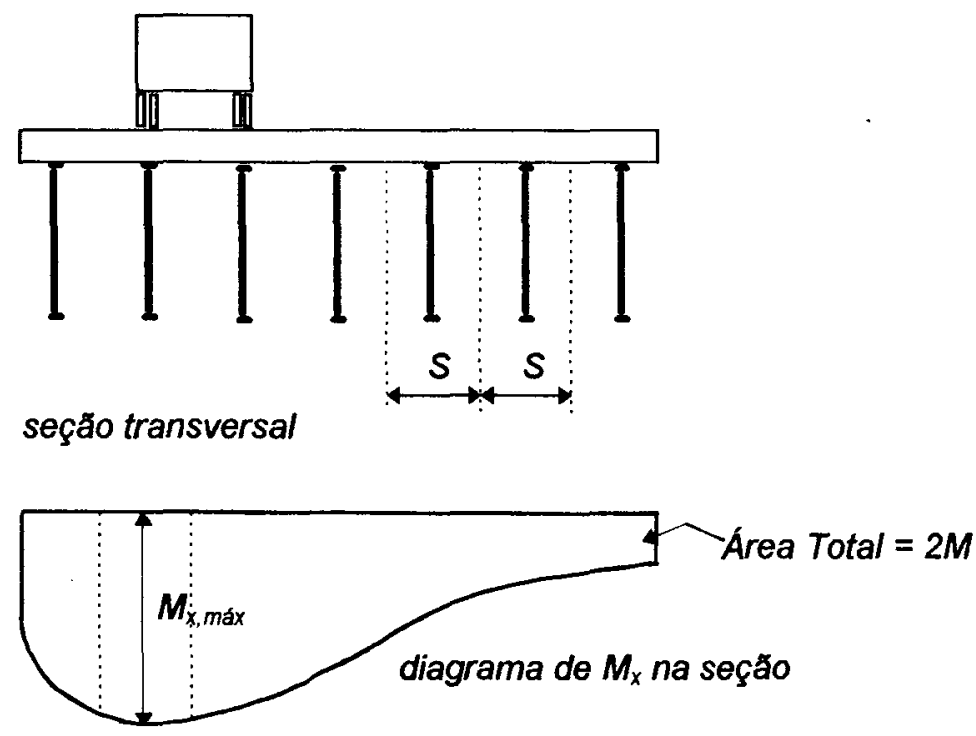

FIGURA 4.2 - Distribuiçăo Transversal do Momento Longitudinal $M_{x}$.

Seja $M$ a metade do momento fletor total devido a um veículo, ou por metade do trem-tipo longitudinal, na seção sob análise. Para a determinação do valor de $M_{x, \text { máx }}$, existe um fator "D" tal que:

$D=\frac{M}{M_{x, \text { ma x }}}$

Isto é, conhecido " $D$ ", pode-se determinar $M_{x, \text { max }}$. Substituindo-se [4.2] em [4.1] se tem : 
$M_{g}=S \cdot \frac{M}{D}$

Assim, se o valor de "D" é conhecido para uma dada ponte, o máximo momento da carga móvel em uma largura $S$ da ponte pode ser obtido como uma fração $S / D$ do momento fletor da viga $M_{q}$ devido a uma linha de rodas. $O$ afastamento $S$ representa um padrão da seção transversal (se existir um). Nas pontes em placas, $S$ é adotado como a largura unitária.

O erro de aproximação dado em [4.1] pode ser reduzido significativamente se $M_{x, \text { máx }}$ for substituído pela média de $M_{x}$ ao longa da largura $S$ limitada. Esta alteração foi realizada na obtenção dos valores de $M_{x, m a ́ x}$ e também de " $D$ ", tomando-se a média de $M_{x}$ na vizinhança do momento de pico em uma faixa de 2,00 m, tendo as cargas das rodas áreas de contato de:

$0.46 \mathrm{~m}$ (longitudinal) $\times 0.81 \mathrm{~m}$ (transversal) $=0.3726 \mathrm{~m}^{2}$

Os principais fatores que afetam a distribuição transversal da carga móvel, em uma ponte que é realisticamente idealizada como placa ortotrópica, são:

- rigidezes à flexão, longitudinal e transversal, da ponte;

- rigidezes à torção, longitudinal e transversal, da ponte;

- relação entre largura e vão (o aspecto da planta) da ponte;

- tipo de carga de projeto (uniformemente distribuída, linearmente distribuída ou carga de caminhão);

- largura do carregamento em relação à largura da ponte;

- número de cargas de projeto na direção transversal;

- distância do veículo à borda, isto é, a distância transversal entre uma borda longitudinal livre da ponte e a carga mais próxima.

O método da American Association of State Highways and Transportation Officials (AASHTO) agrupa os fatores acima listados em um valor único de "D", que é suposto constante para um dado tipo de ponte. Esta supersimplificação pode resultar em valores errôneos em alguns casos, e 
correções são feitas para diferenciar regiões da ponte neste método apresentado, podendo o fator " $D$ " mudar em pontes do mesmo tipo.

\subsubsection{Limitações na Geometria das Pontes}

Para que uma ponte possa ser idealizada satisfatoriamente como uma placa ortotrópica, deve satisfazer com proximidade às seguintes condições :

a. sua largura (2b) é constante.

b. as condições de apoio equivalem-se a apoios lineares.

c. se presente, o ângulo de esconsidade é não maior que $20^{\circ}$.

d. se curva em planta, a relação $L^{2} / b R$ deve ser menor que 1,0 .

e. se tiver seção transversal de placa sólida ou vazada, deve ter altura uniforme.

f. a rigidez total à flexão da seção transversal permanece constante no mínimo nos $50 \%$ centrais de cada vão.

g. quando em placa sobre vigas, haverá no mínimo quatro vigas longitudinais igualmente espaçadas e de mesma rigidez à flexão.

h. se estrutura celular, haverá pelo menos três células iguais.

i. quando em placas sobre vigas o balanço transversal, se existente, não excederá $60 \%$ do espaçamento entre vigas, nem $1,80 \mathrm{~m}$. Além disso a borda mais externa de faixa de tráfego não distará mais de $1,00 \mathrm{~m}$ do centro da viga longitudinal mais externa.

O requisito para o apoio ser bastante próximo de uma linha (ou equivalente) é aplicável apenas quando a solicitação que está sendo pesquisada está nas vizinhanças do apoio, como no caso de momentos fletores longitudinais em apoios intermediários de pontes de vãos múltiplos ou cisalhamentos longitudinais próximos dos apoios. A condição de apoio de uma ponte em placa sobre vigas, na qual todas as vigas longitudinais estão apoiadas, pode ser satisfatoriamente observada como apoio em linha.

Apoios discretizados nas pontes em placa (maciça ou vazada) só poderăo ser considerados apoios em linha se estiverem espaçados em mais de 
2,00m. Este valor é estipulado com base no fato de que os momentos fletores e forças cortantes longitudinais nas placas ortotrópicas são tomadas pela média em faixas de $2,00 \mathrm{~m}$ de largura para a obtenção dos valores de $\boldsymbol{D}$ regentes no cálculo.

Quando uma ponte esconsa é analisada, seu vão esconso pode ser usado - na análise como se fosse o vão reto. Limita-se o ângulo de esconsidade a $20^{\circ}$ para se garantir que os momentos torçores - que costumeiramente não são calculados diretamente nas análises simplificadas - não sejam grandes a ponto de causarem problemas. Para as pontes em placas sobre vigas, 0 ângulo de esconsidade pode ser até de $30^{\circ}$.

A analogia entre uma ponte em placa sobre vigas e uma ponte em placa ortotrópica torna-se precária quando há menos de quatro vigas longitudinais, razão pela qual é imposta a limitação sobre o número de vigas - e, também, sobre o número de células das estruturas celulares. É proposta outra forma de análise para as pontes com somente duas vigas longitudinais.

Quando as cargas estão do lado de fora da viga mais externa de uma ponte em placa sobre vigas, a idealização ortotrópica da estrutura torna-se suspeita e pode fornecer resultados contra a segurança. A limitação de se posicionar a faixa de tráfego mais externa no máximo a 1,0 $\mathrm{m}$ da viga mais exterior, no sentido do balanço, garante que o método, fundamentado nesta idealização, não seja utilizado naqueles casos.

As limitações de geometria das pontes está ilustrada na Figura 4.3.

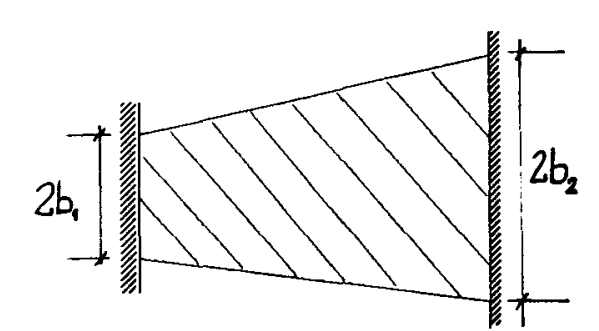

(a)

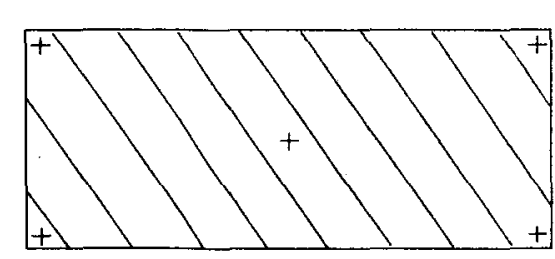

(b) 


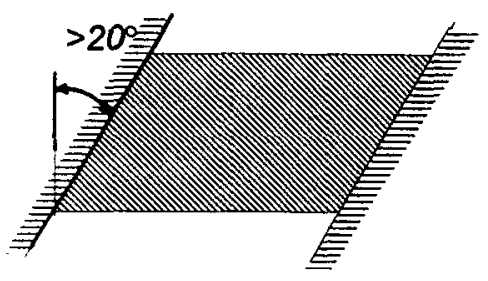

(c)

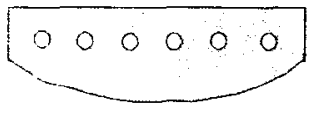

(e)

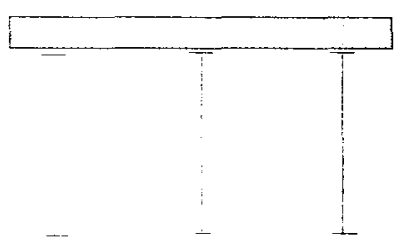

(g)

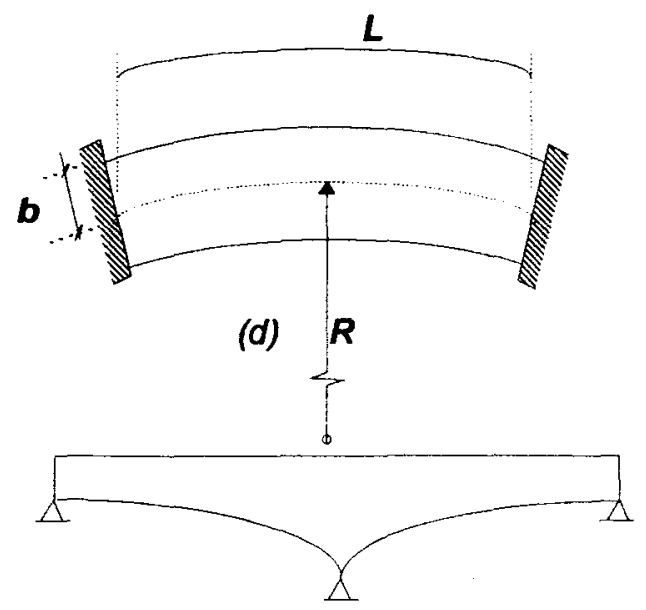

(f)

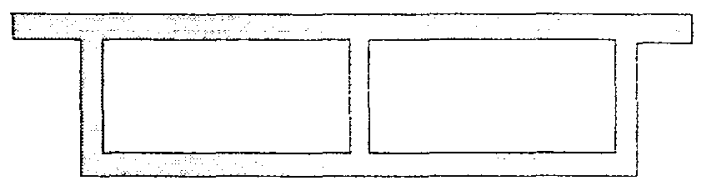

(h)

FIGURA 4.3 - Pontes que não podem ser analisadas por métodos simplificados:

(a) planta de uma ponte com largura variável;

(b) planta de uma ponte em placa com poucos apoios isolados;

(c) planta de uma ponte esconsa com ángulo de esconsidade maior que 20;

(d) ponte curva em planta, com $L^{2} / B R$ maior que 1,00;

(e) ponte com seção transversal năo uniforme;

(f) elevaçăo lateral de ponte com seção năo uniforme na porçăo central (50\% do văo);

(g) seçăo de ponte em placa sobre vigas com menos que quatro vigas;

(h) ponte de seção celular com menos que três células.

O método de análise para os carregamentos de Ontário e da AASHTO diferenciam porções internas e externas da seção transversal de uma ponte e fornecem valores distintos de $D$ para cada.

Porções externas em pontes em placa (maciça ou vazada) são os 2,00 m mais exteriores, na faixa longitudinal junto à borda livre. Porções internas, naturalmente, são as regiōes contidas entre as duas porções externas da seção transversal. 
Em pontes em placas sobre vigas, com as vigas espaçadas entre si de mais de 2,00 $\mathrm{m}$, a porção externa refere-se às vigas exteriores e a porção interna às vigas contidas no interior. Entretando, em casos em que o espaçamento entre vigas é bem menor que 2,00 m-como nas pontes de madeira com vigas longitudinais serradas - então todas as vigas nas faixas externas de 2,00 m de largura serão consideradas na porção exterior.

$A$ adoção de uma faixa de $2,00 \mathrm{~m}$ de largura para se definir as porções externas de uma seção transversal (Figura 4.4) é conexa com o procedimento analítico usado na derivação do método simplificado. Neste procedimento, os momentos fletores longitudinais nos 2,00 $\mathrm{m}$ mais exteriores da seção da placa ortotrópica correspondente são tomados pelo valor médio para se chegar ao valor de "D" aplicável a esta parte da seção transversal.

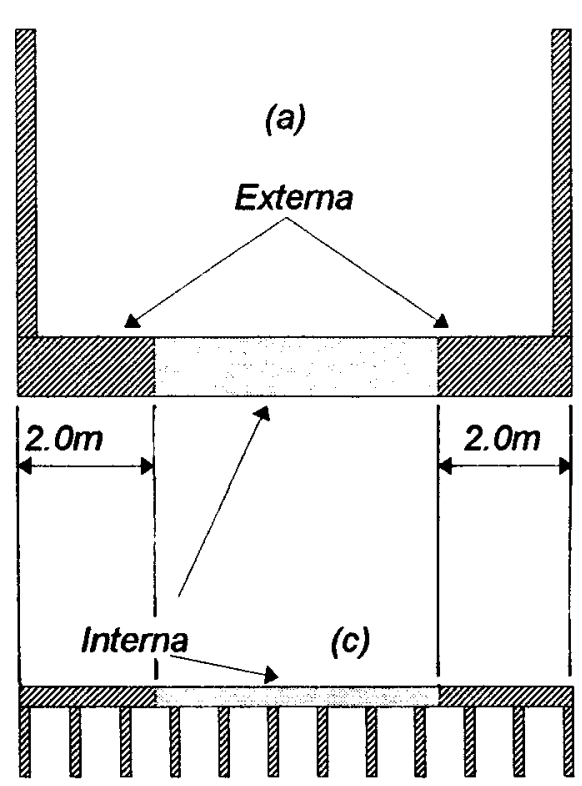

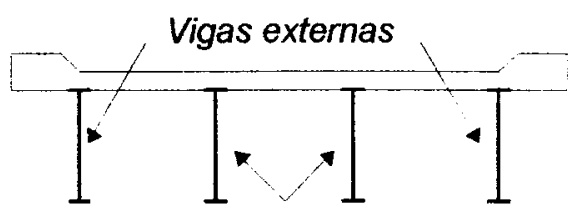

Vigas internas

(b)

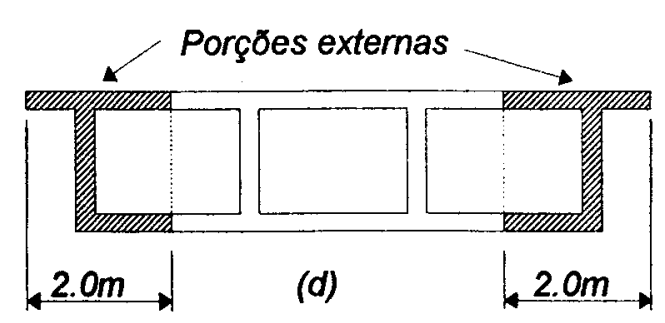

FIGURA 4.4 - Demarcação das porçסes externas e interna nas seçð̌es transversais das pontes :
(a) em placa;
(c) placa sobre vigas de madeira serrada;
(b) em placa sobre vigas;
(d) estrutura celular.

\subsubsection{O Método de Carregamento de Ontário}

A metodologia para os métodos simplificados foi desenvolvida para a Norma de Cálculo de Pontes Rodoviárias de Ontário (Ontario Highway Bridge Design Codel primeira e segunda edições. O desenvolvimento desta 
metodologia foi realizado em Ontário e apresentado por CSAGOLY e DORTON (1978). A Norma de Ontário, diferentemente de outros códigos normativos, tem toda uma seção dedicada a especificar os métodos permitidos de análises de pontes. Um dos objetivos foi desenvolver um método simplificado que não fosse significativamente diferente, em sua natureza, do método AASHTO, sendo porém, capaz de fornecer resultados mais precisos.

O carregamento de cálculo de Ontário é de dois tipos :

- 1. Um caminhão de cinco eixos com as linhas de rodas afastadas entre si $1,80 \mathrm{~m}$.

- 2. Uma carga uniformemente distribuída e o mesmo caminhão de cinco eixos acima, com as cargas por eixo em $70 \%$ do valor do caso 1 .

A primeira composição é denominada carregamento de cálculo com veículotipo e a segunda de carregamento de cálculo da faixa. Cada faixa de tráfego da ponte deve ser carregada ou pelo carregamento de cálculo do veículo ou pelo carregamento de cálculo da faixa, em correspondência com aquele que produzir maiores efeitos de carga móvel.

Detalhes dos carregamentos de cálculo são demonstradas na Figura 4.5, com as cargas de avaliação utilizadas para a determinação da resistência das pontes já construídas. Há três níveis de cargas de avaliação :

- as cargas de nivel três são as mesmas cargas de cálculo descritas acima;

- as cargas de nivel dois são as de nível três subtraidas de um eixo;

- as cargas de nível um são as de nivel três subtraídas de dois eixos.

As cargas uniformemente distribuídas variam com a classe da rodovia, determinada em função da frequência diária mínima do veículo de projeto, mostrados abaixo:

QUADRO 4.1 : Classificaçăo das rodovias

\begin{tabular}{ccc}
\hline Classe & $\begin{array}{c}\text { Frequência diária de } \\
\text { veículos }\end{array}$ & $\begin{array}{c}\text { Número de caminhóes-tipo por dia } \\
\text { nas pistas }\end{array}$ \\
\hline$A$ & $N>4000$ & $T>1000$ \\
$B$ & $1000 \leq N \leq 4000$ & $250 \leq T \leq 1000$ \\
$C$ & $N<1000$ & $T<250$ \\
\hline
\end{tabular}




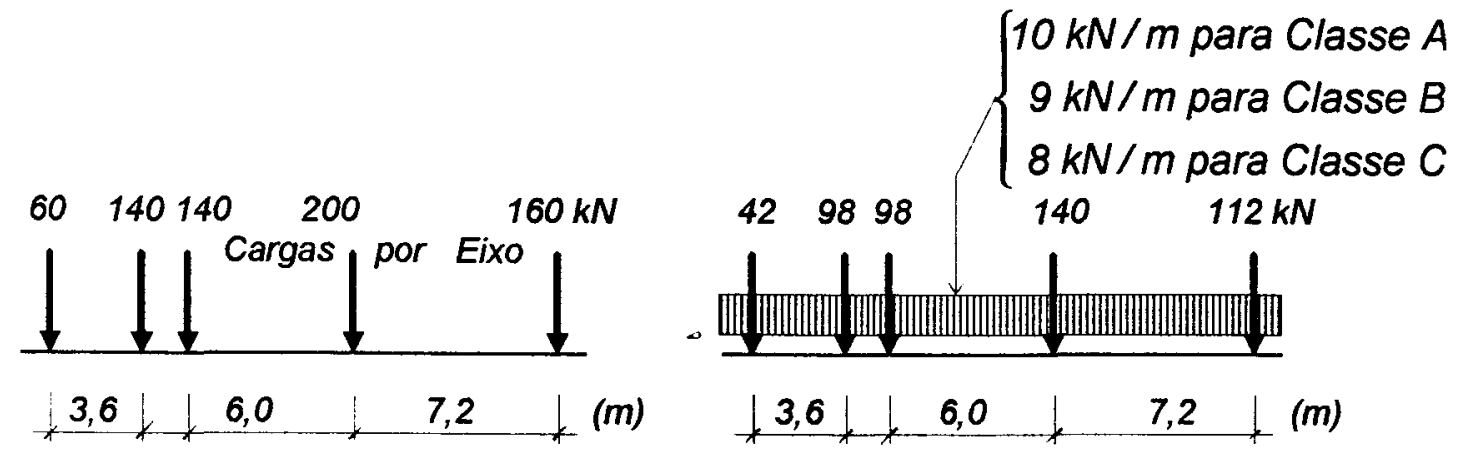

1,2

1,2

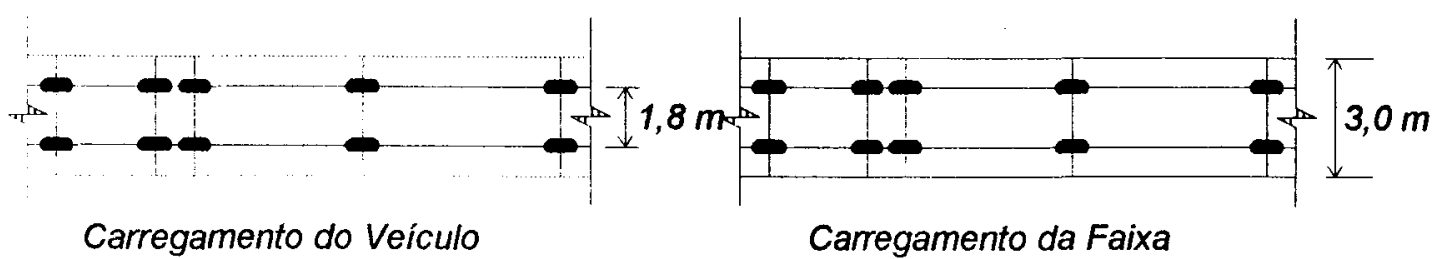

(a)
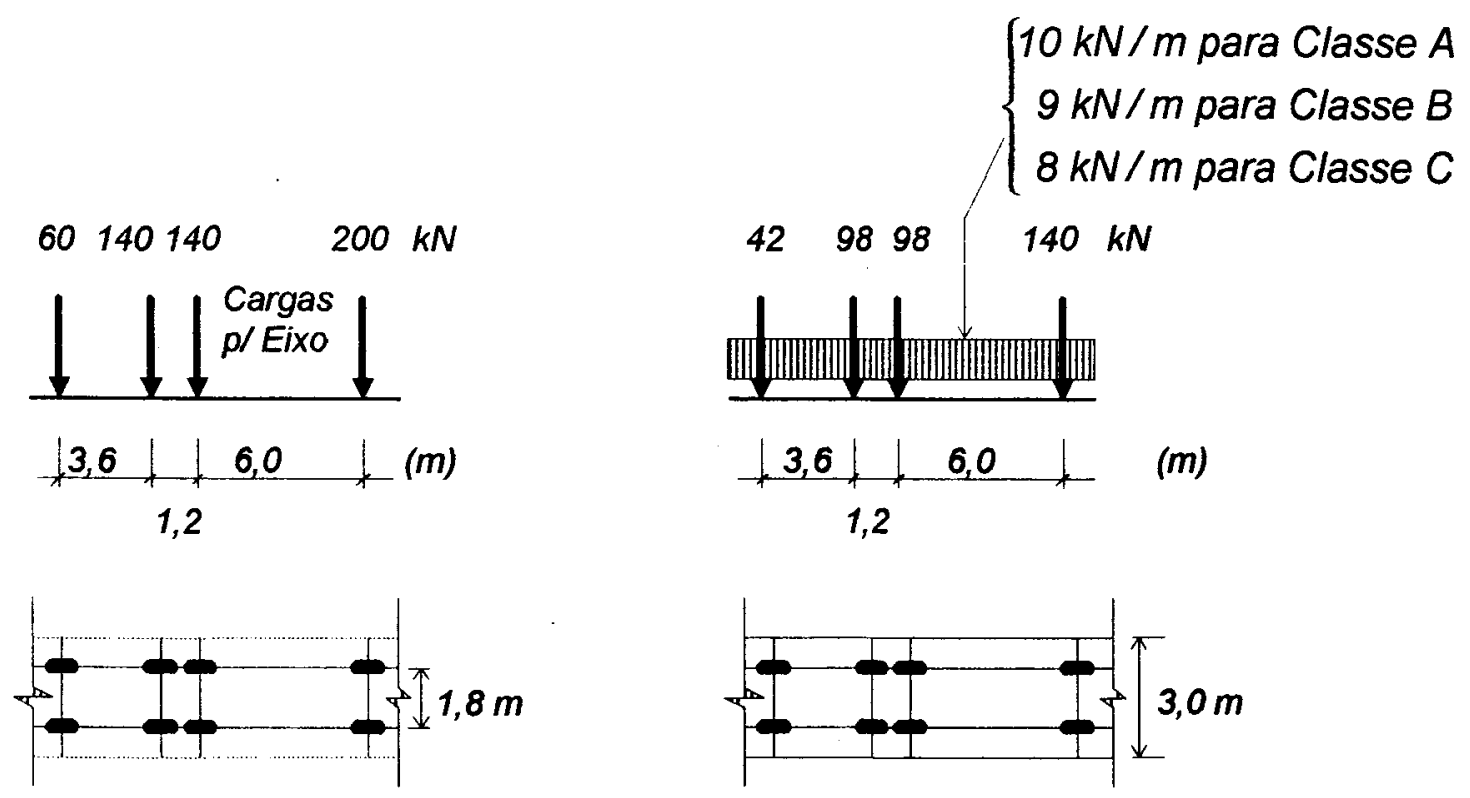

Carregamento do Veículo

Carregamento da Faixa

(b) 


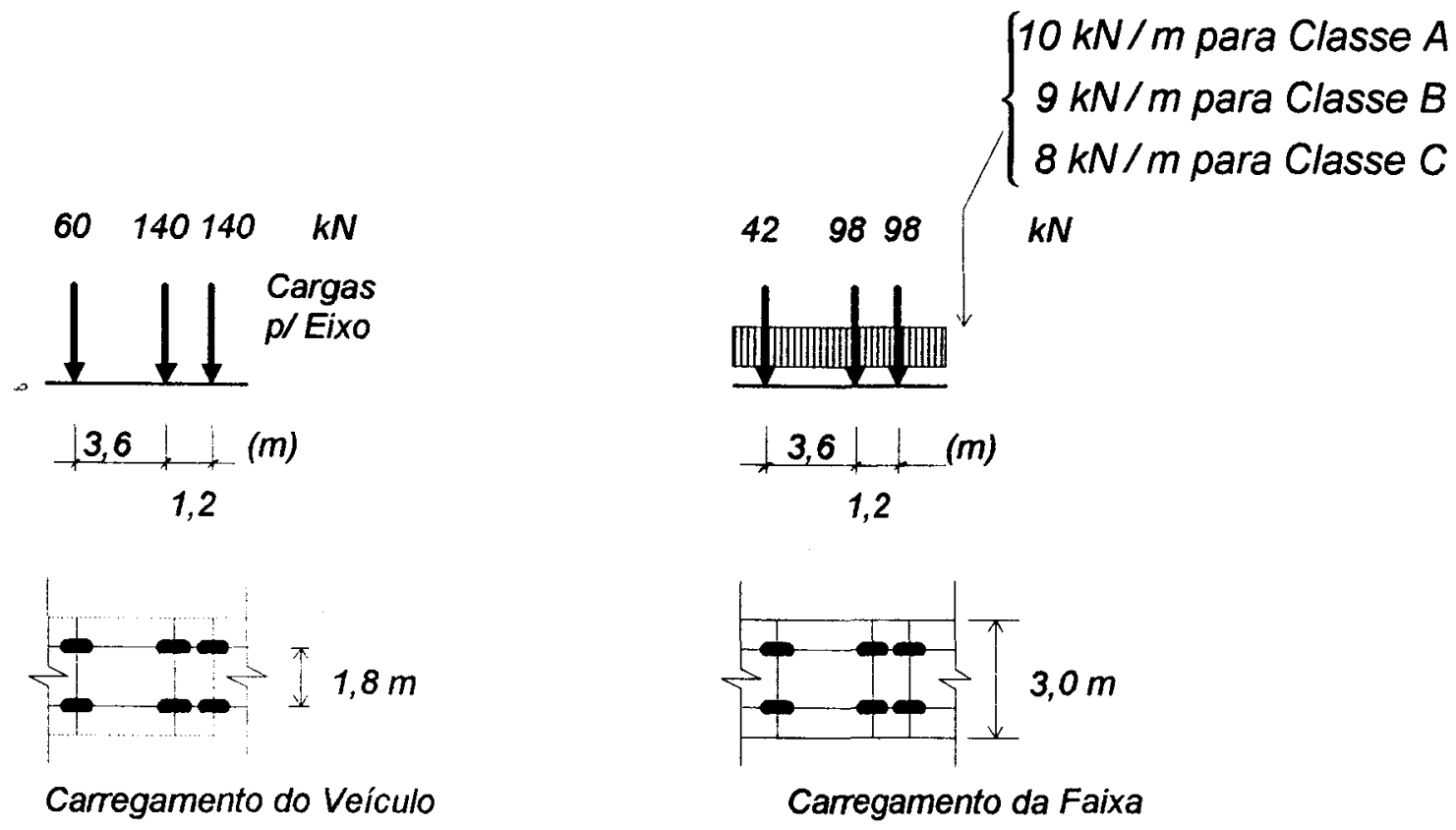

(c)

FIGURA 4.5 - Carregamento Ontário:
(a) Nivel 3;
(b) Nivel 2;
(c) Nivel 1.

As classes das vias em função da frequência diária dos veículos tipos são mostrados no Quadro 4.1.

Em geral, os carregamentos da faixa têm significado real para vãos maiores, onde os efeitos máximos das cargas são causados por mais de um veículo em uma faixa. A carga uniformemente distribuída evidencia a necessidade de se considerar mais de um veículo de cálculo em cada faixa, independentemente do número de faixas e de vãos da estrutura.

Os momento fletores máximos de vãos simples devidos a uma linha de rodas do veículo de projeto, ou metade da carga da faixa, são mostrados na Figura 4.6 para a função do vão. Observa-se que o tamanho do vão começa a influir no momento máximo para as várias classes apenas a partir de $26 \mathrm{~m}$. 

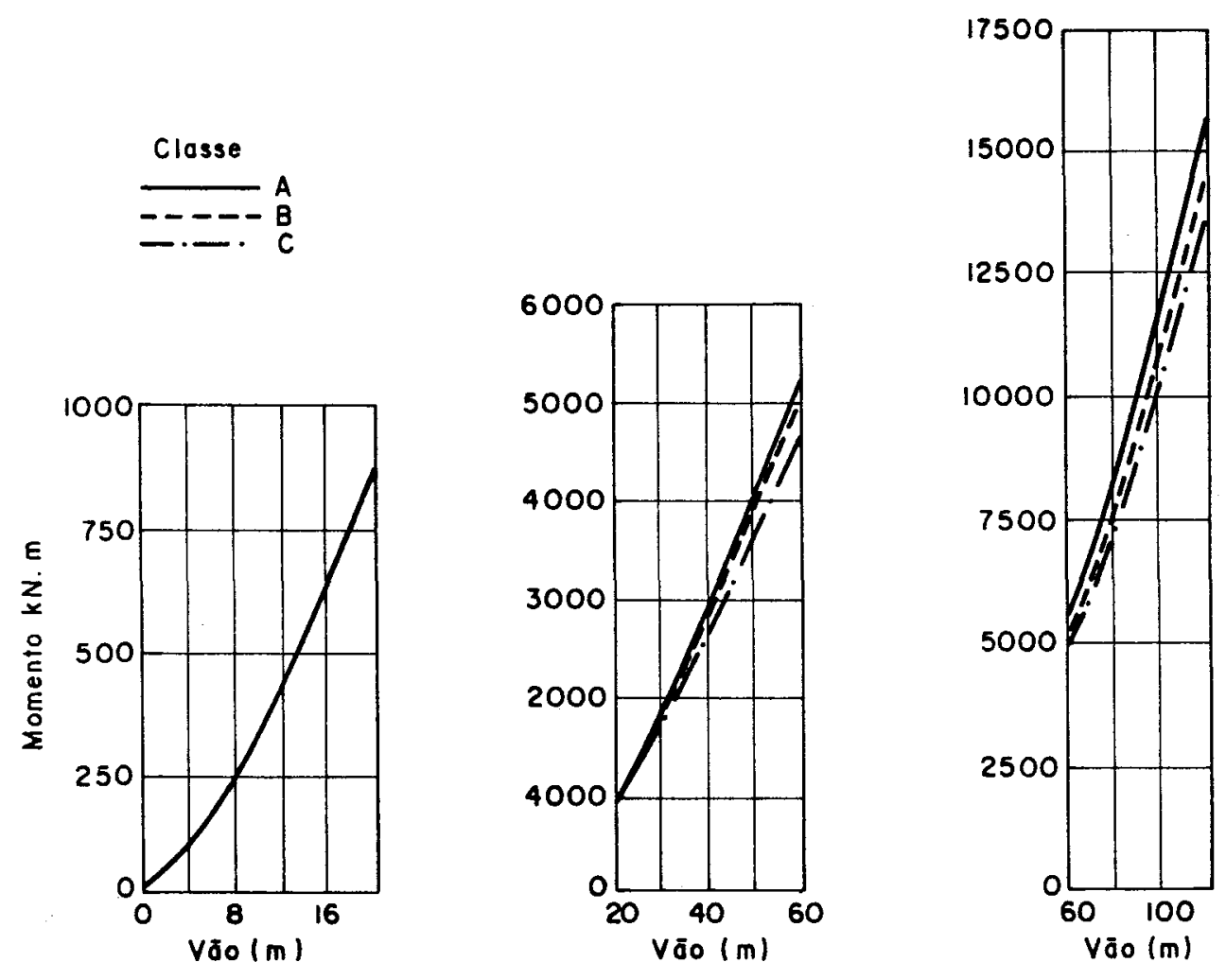

FIGURA 4.6 - Momentos fletores gerados por meio caminhão ou meia faixa carregada.

Se houver mais de uma faixa carregada em uma ponte, o carregamento de cálculo é reduzido para considerar maior a mobilização das rigidezes da estrutura e estão mostrados no Quadro 4.2.

QUADRO 4.2 : Fatores de Reduçăo de Cargas.

\begin{tabular}{clllll}
\hline Número de faixas Carregadas & \multicolumn{3}{l}{ Composição do carregamento de cálculo } \\
\hline 1 & $W$ & & & \\
2 & $0.9 W$ & $0.9 W$ & & \\
3 & $0.8 W$ & $0.8 W$ & $0.8 W$ & \\
4 & $0.7 W$ & $0.7 W$ & $0.7 W$ & $0.7 W$ \\
\hline
\end{tabular}


O Código $O H B D C$ especifica que o número de faixas de tráfego em uma ponte seja obtido pela divisão da largura útil total (distância calçada a calçada ou entre guarda-rodas) em faixas de largura igual para cálculo mostrada no Quadro 4.3. Reconhecendo que o número real de faixas de tráfego possa diferir do número usado no cálculo, o OHBDC indica que, na avaliação do estado limite último e estado limite de utilização tipo II, o número a utilizar para cálculo é o do Quadro 4.3 mas, na consideração do estado limite de utilização de fadiga, o número real de faixas de tráfego da ponte e as posições transversais dos veículos a ele correpondentes serão usados.

QUADRO 4.3 : Número de faixas de Cálculo, OHBDC.

\begin{tabular}{lc}
\hline Largura Transversal $(2 b)$ da Ponte $(m)$ & Número de faixas \\
\hline até 6 & 1 \\
$6.0 \leq 2 b \leq 10.0$ & 2 \\
$10.0 \leq 2 b \leq 13.5$ & 3 \\
$13.5 \leq 2 b \leq 17.0$ & 4 \\
$17.0 \leq 2 b \leq 20.5$ & 5 \\
$20.5 \leq 2 b \leq 24.0$ & 6 \\
$24.0 \leq 2 b \leq 27.5$ & 7 \\
mais de 27.5 & 8 \\
\hline
\end{tabular}

\subsubsection{Consideração da Carga Dinâmica.}

Conforme a prática comum o OHBDC permite que seja usada a análise estática equivalente para as cargas móveis, que é feita pelo uso de um fator chamado de aceitação de carga dinâmica, DLA. A carga estática equivalente é igual à carga real multiplicada por 1+DLA.

Para os elementos da placa de tabuleiro cujo dimensionamento é governado por uma carga isolada de uma roda ou duas cargas de um eixo (simples ou duplo) do veículo de cálculo, o fator DLA vale 0.4 . 
Quando o carregamento é outro, não sendo uma roda isolada ou eixo isolado, o fator DLA vale 0,3 para todas as peças transversais. DLA vale 0,3 também para todos os vãos simples não maiores que $22 \mathrm{~m}$ de comprimento e todas as superestruturas compostas de vãos contínuos em que nenhum deles seja superior a $22 \mathrm{~m}$.

Para todos os componentes principais e aqueles não abordados acima, os fatores DLA para as cargas por eixo são dados na Figura 4.7, e dependem da primeira frequência de oscilação de flexão da ponte.

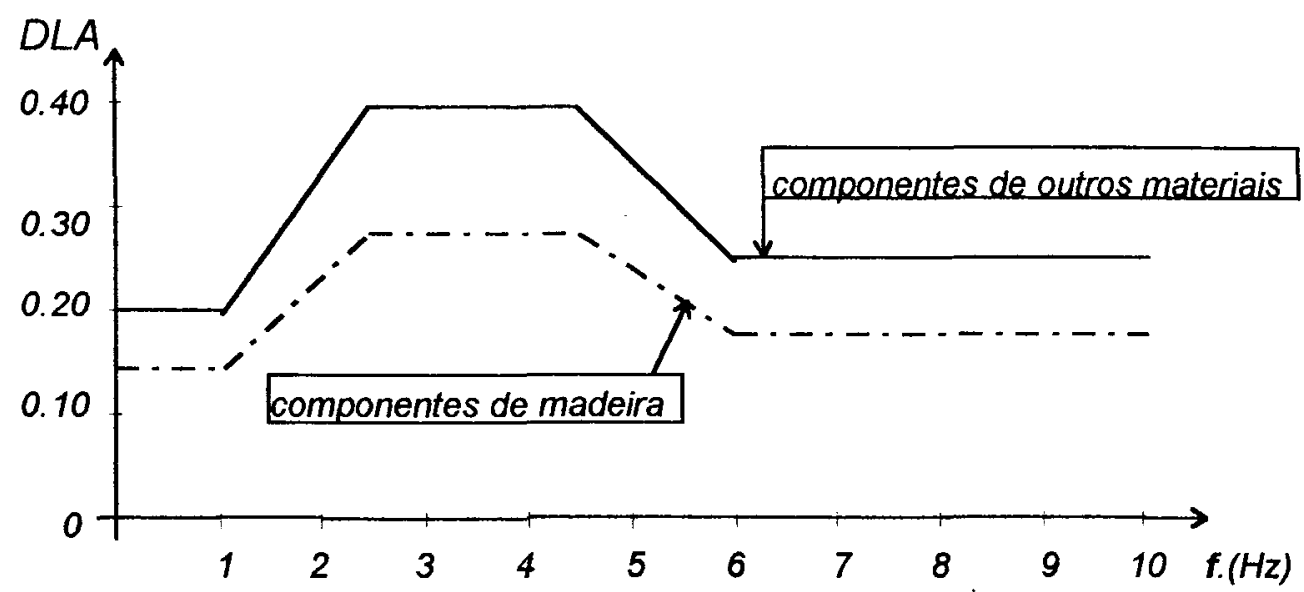

DLA para componentes de madeira $=0,7 \times$ DLA para componentes de outros materiais.

FIGURA 4.7 - Fator de aceitação de carga dinâmica conforme o Ontario Highway Bridge Design Code (OHBDC).

O fator DLA para a porção da faixa de tráfego de cálculo carregada uniformemente é especificado igual a $\underline{\mathbf{0 , 1 0}}$.

Para ante-projeto, o comentário ao código sugere os seguintes valores para DLA para carregamento em uma faixa:

- vãos simples entre $22,5 \mathrm{me} 60,0 \mathrm{~m}$ : $\quad 0,40$

- vãos simples maiores que $60,0 \mathrm{~m}$ : $\quad 0,20$

- pontes contínuas, vãos entre $22,5 \mathrm{~m}$ e $60,0 \mathrm{~m}$ : 0,40

- pontes contínuas, vãos maiores que $60,0 \mathrm{~m}$ : $\quad 0,20$ 


\subsubsection{Base de desenvolvimento do Método Ontário}

Considere-se a Equação Geral Diferencial de Placas :

$$
D_{x} \frac{\partial^{4} w}{\partial x^{4}}+2 H \frac{\partial^{4} w}{\partial x^{2} \partial y^{2}}+D y \frac{\partial^{4} w}{\partial y^{4}}=p(x, y)
$$

onde:

$(x, y)$ é o plano horizontal onde se situa a placa, coordenadas cartesianas;

$w(x, y)$ é a superfície deformada da placa;

$p(x, y)$ é o carregamento aplicado perpendicularmente ao plano da placa;

$D_{x}$ é a rigidez à flexão longitudinal (no sentido do tráfego) da placa;

$D_{y}$ é a rigidez à flexão transversal da placa;

$2 H$ é a rigidez total à torção da placa, isto é :

$$
2 H=D_{x y}+D_{y x}+D_{1}+D_{2}
$$

onde:

$D_{x y}$ e $D_{y x}$ são as rigidezes torcionais;

$D_{1}$ e $D_{2}$ são as rigidezes combinadas associadas à flexão.

Definem-se os parâmetros adimensionais de torção e de flexão, respectivamente, por:

$$
\alpha=\frac{H}{\sqrt{D_{x} \cdot D_{y}}} \quad e \quad \theta=\frac{b}{L} \cdot \sqrt[4]{\frac{D_{x}}{D_{y}}}
$$

o Código de Ontário exige que, para a análise dos estados limites último e de utilização tipo II, sejam carregadas tantas vezes faixas de tráfego em uma ponte até que se determine qual combinação produz o máximo efeito. 0 método, a seguir descrito, foi desenvolvido para pontes de uma, duas, três e quatro faixas de tráfego, para as diversas condiçס̃es de carregamento das faixas. A condição na qual, após a aplicação dos fatores relevantes de redução, se produzirem os máximos momentos longitudinais, é a condição determinante que governa o comportamento da estrutura. Casos determinantes do carregamento em pontes com diferentes números de 
faixas de tráfego e valores de $(\alpha, \theta)$ anteriormente definidos são apresentados na Figura 4.8.
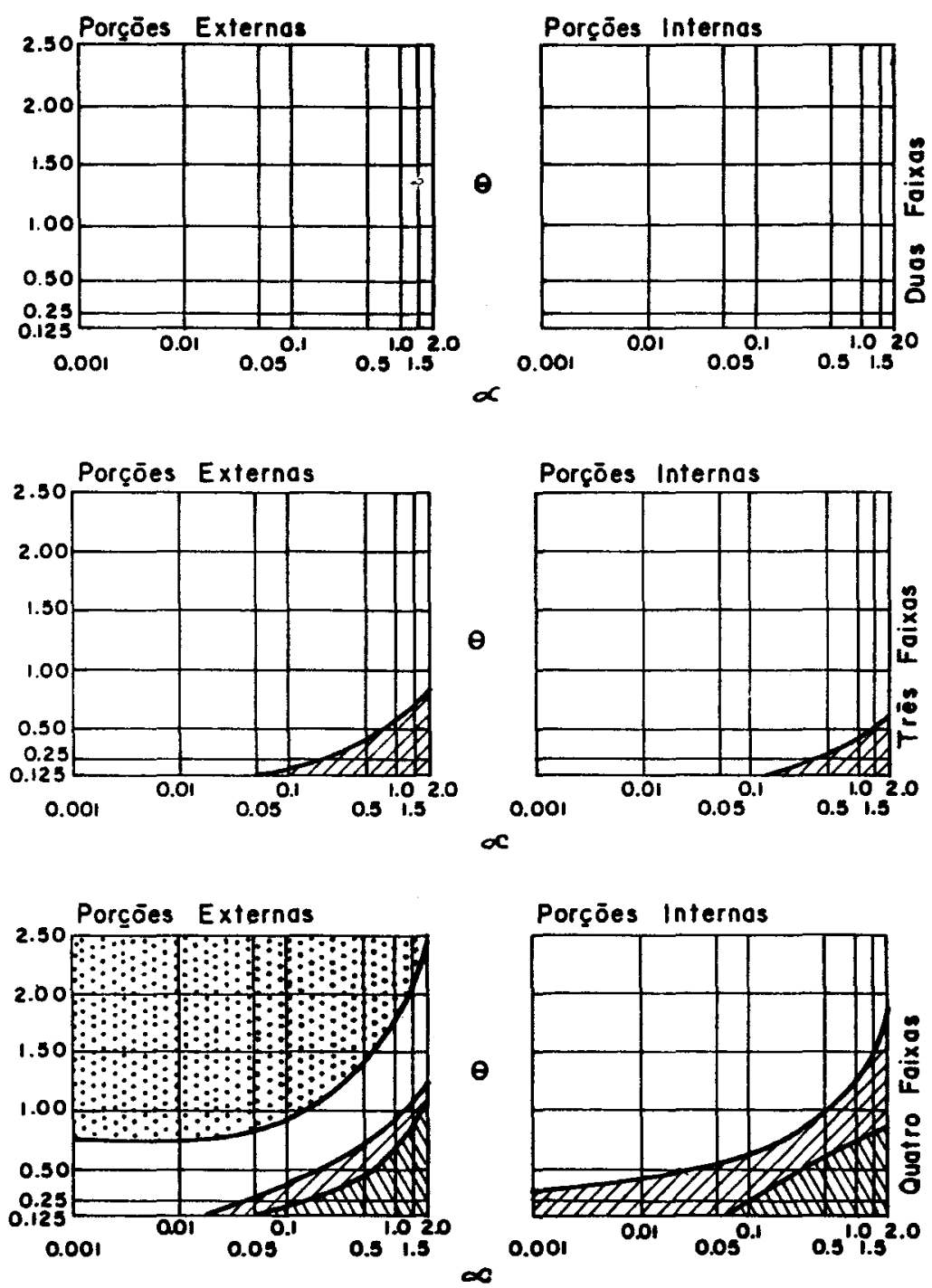

Legenda:

Fi:i:0 - uma faixa carregada é determinante.

$\square$ - duas faixas carregadas săo determinantes.

WIIIZ - três faixas carregadas săo determinantes.

dillillill - quatro faixas carregadas săo determinantes.

FIGURA 4.8 - Casos determinantes de carregamento correspontes ao OHBDC, tres e quatro faixas de tráfego (para uma e duas faixas os carregamentos em uma e duas faixas săo os determinantes, respectivamente). 
QUADRO 4.4 : Momento Longitudinal Inicial, $D_{d}(m)$ :

TIPO DE PONTE

NÚMERO DE FAIXAS DE

CÁLCULO

\begin{tabular}{cccccc} 
& & 1 & 2 & 3 & 4 \\
\hline $1 . E m$ placa maciça, placa vazada ou & 1,75 & 2,00 & 2,25 & 2,50
\end{tabular} nervurada (de modulação quase

quadrada).

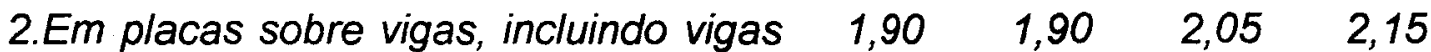

longitudinais de aço e tabuleiro de

madeira.

3. Em vigas de madeira laminada colada $\begin{array}{llll}1,90 & 1,90 & 2,05 & 2,15\end{array}$ com tabuleiro de madeira.

$\begin{array}{llllll}\text { 4. Em vigas de madeira serrada com } & 1,80 & 1,80 & 1,85 & 1,90\end{array}$ tabuleiro de madeira.

5.Em madeira laminada com protensão $\begin{array}{llll}1,90 & 1,90 & 2,05 & 2,15\end{array}$ transversal.

$\begin{array}{lllll}\text { 6.Composta madeira-concreto. } & 1,70 & 1,70 & 1,75 & 1,80\end{array}$

Os vários passos no cálculo dos momentos longitudinais gerados pelas cargas móveis tanto nas porções interna quanto externas das pontes são dados a seguir.

\subsubsection{Método passo a passo}

1. Obter um valor inicial de $D$, chamado $D_{d}$, no Quadro 4.4 , de acordo como tipo de ponte (superestrutura) e o número de faixas para cálculo.

2. Calcular a fração de carga inicial, $S / D_{d}$, onde $S$ é o espaçamento real entre vigas longitudinais (no caso de ponte em placa sobre vigas), ou a distância entre almas no caso de placas vazadas, ou 1,00 $\mathrm{m}$ no caso de placas maciças, pontes de madeira laminada protendida transversalmente, 
pontes compostas madeira-concreto com laminações longitudinais de madeira e cobrimento de concreto.

3. Tratando a estrutura da ponte como viga unidimensional, obter os momentos fletores (diagramas) devidos a meio trem-tipo (uma linha longitudinal de rodas do veículo) ou ao carregamento da faixa, Figura 4.5.

4. Multiplicar os momentos acima por $\left[\left(S / D_{d}\right) .(1+D L A)\right]$ para se obter os momentos iniciais da carga móvel, onde DLA é o fator de consideração da carga dinâmica anteriormente discutidos. Observar que o fator de modificação para o carregamento em várias faixas (QUADRO 4.2) está implícito nos valores de $D_{d}$ (QUADRO 4.4) e não deve ser aplicado novamente. No caso de carregamentos das faixas, que consistem em cargas de eixos e cargas uniformemente distribuídas é necessário aplicar os diferentes valores de DLA aos momentos gerados pelos dois tipos de cargas.

5. Assumir que os momentos encontrados sejam suportados por uma largura $S$ da ponte, para as porções externas e interna, e sobre esta base encontrar uma proporção inicial da estrutura.

6. Calcular $\alpha$ e $\theta$ :

$\alpha=\frac{H}{\sqrt{D_{x} \cdot D_{y}}} \quad$ e $\theta=\frac{b}{L} \sqrt[4]{\frac{D_{x}}{D_{y}}}$

7. Calcular $\mu$ :

$$
\mu=\frac{W_{\theta}-3.3}{0.6} \leq 1.0
$$

onde $W_{\bullet}$ é a largura da faixa de tráfego em metros. 
8. Correspondentes aos valores de $\alpha$ e $\theta$ e o número de faixas de tráfego para o cálculo da ponte, obter os valores de D, separadamente, para as partes externas e interma da ponte e o valor de $\boldsymbol{C}_{\boldsymbol{f}}$, dos diagramas das Figuras 4.9(a) a $4.9(d)$.

9. Calcular os valores finais de $\boldsymbol{D}_{d}$ separadamente ípartes externas e interna):

$D_{d}=D\left(1+\frac{\mu C_{f}}{100}\right)$

10. Para cada porção, externa e interna, obter os momentos finais de cálculo, à carga móvel, pela multiplicação dos momentos da carga móvel devidos a uma linha de rodas ou carga da faixa (passo 3 acima) por [ $\left.\left(S / D_{d}\right) .(1+D L A)\right]$ onde $D_{d}$ tem o valor adequado à porção externa ou interna (passo 9 acima). Novamente observar respeito aos diferentes valores de DLA para as cargas de eixo e uniformemente distribuídas que se aplicam.

Um resumo dos procedimentos acima é representado na Figura 4.10.

Não obstante o relato acima, o Código OHBDC determina que o valor de $\boldsymbol{D}_{d}$ para as pontes de madeira laminadas pregadas longitudinalmente deve ser fixado igual a $0,85 \mathrm{~m}$, porções externas e interna.

$\mathrm{Na}$ análise do estado limite de utilização de tipo I (vibrações, fadiga), existem outros procedimentos (item 4.1.6). 
D,

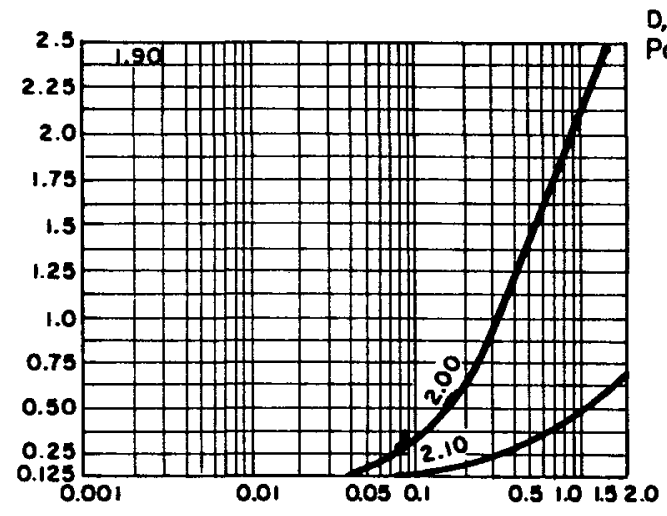

Portes Externos
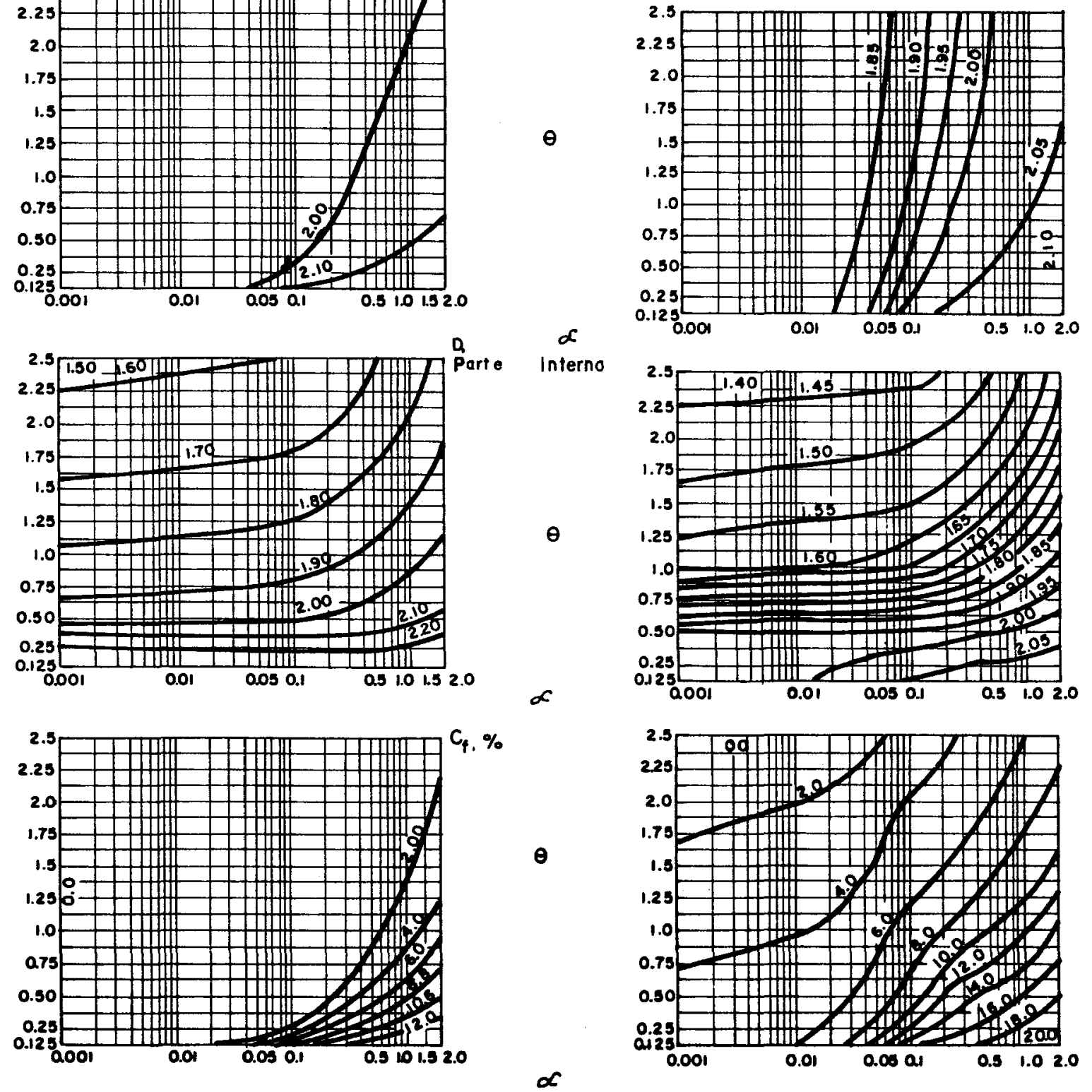

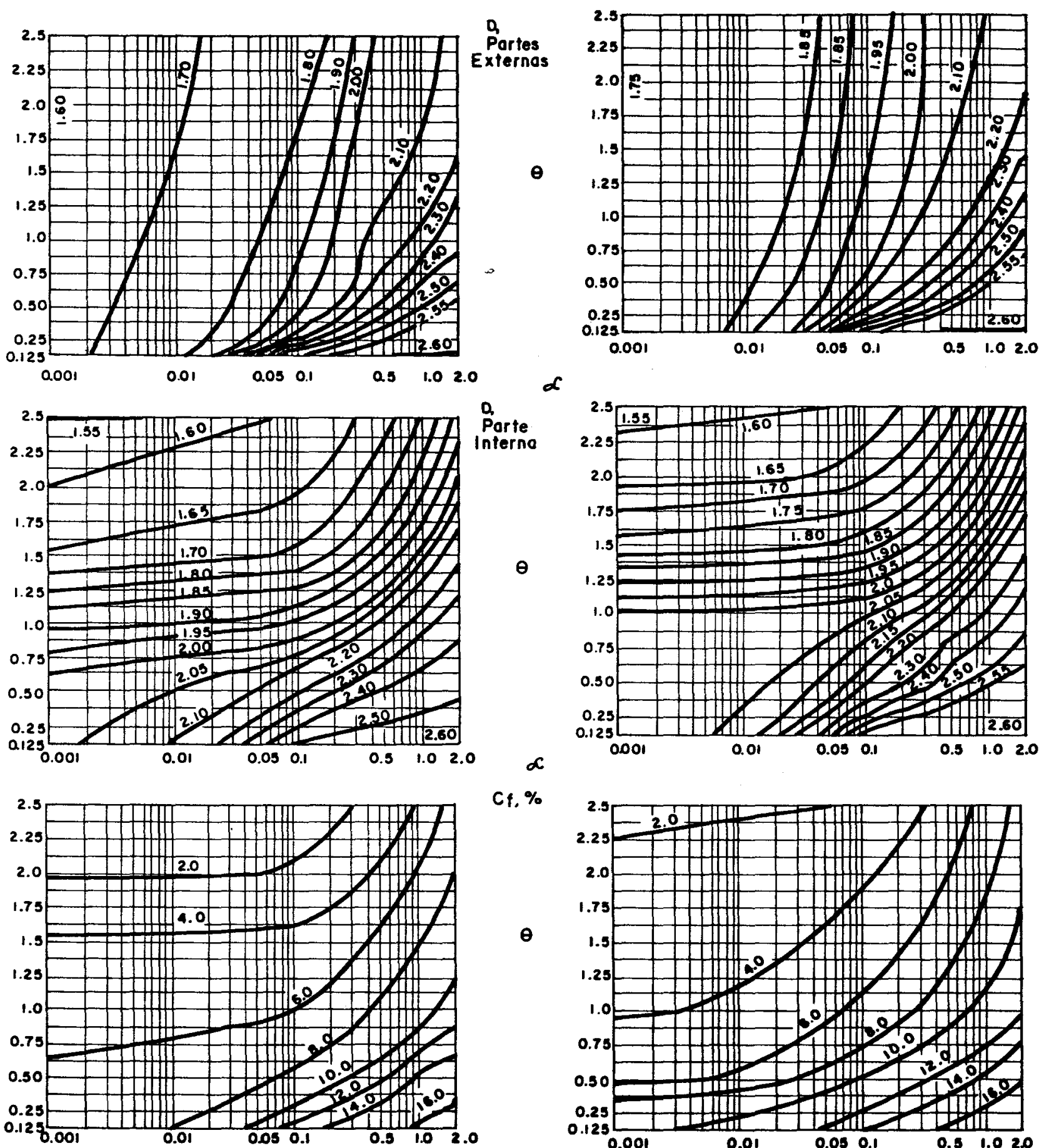

$C f, \%$

$\theta$

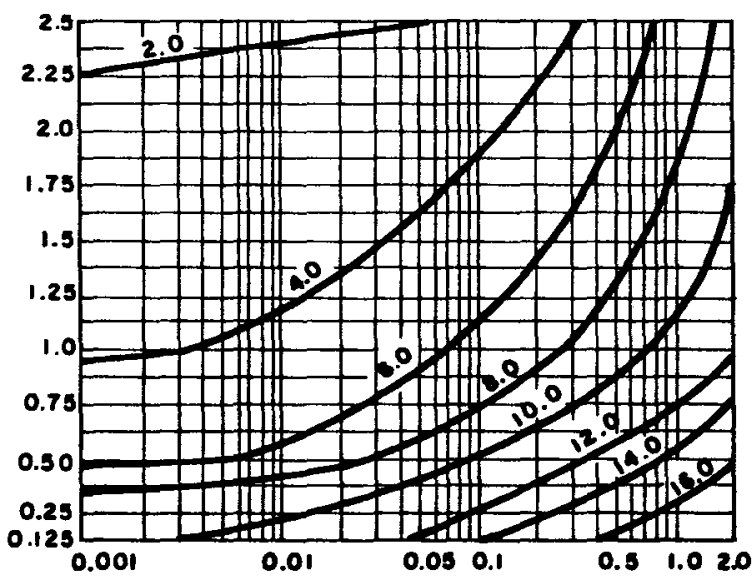

(c)

(d)

Figura 4.9 - Diagramas de $D$ e $C_{f}$.

a) pontes de uma faixa de tráfego;

b)pontes de duas faixas de tráfego;

c) pontes de três faixas de tráfego;

d) pontes de quatro faixas de tráfego. 


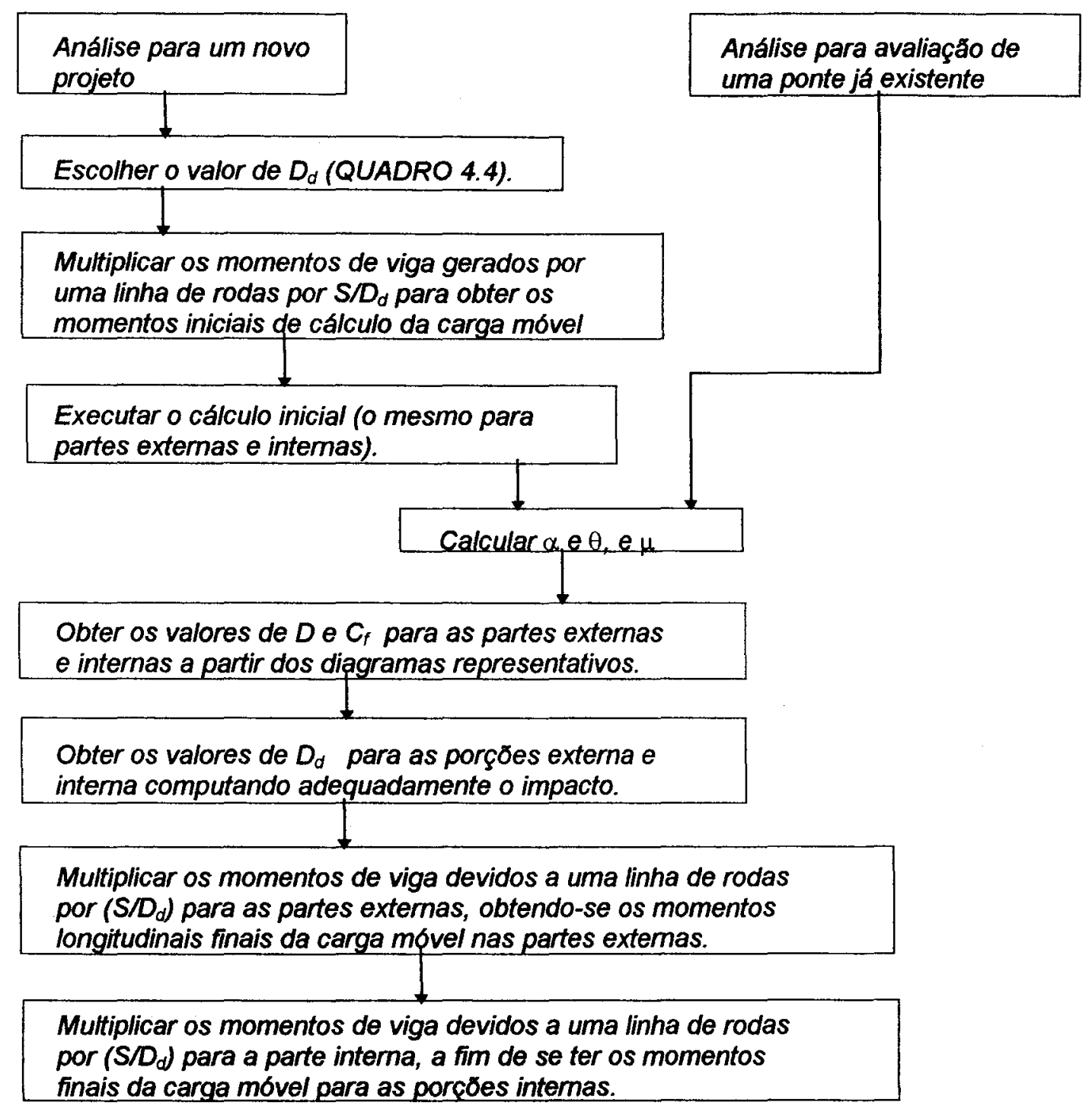

FIGURA 4.10 - Diagrama de procedimentos descritos, OHBDC, estado limite de utilização de tipo II e estado limite último.

\subsubsection{Método Simplificado - Estado Limite de Utilização Tipo I (SLS I)}

Para esta análise, a estrutura é carregada em uma única faixa de tráfego. A análise é realizada considerando-se a estrutura acomodada inicialmente (já dimensionada, portanto) e o valor de $D$ é aquele obtido por um veículo isolado em sua posição normal de tráfego posicionado transversalmente. 
Neste caso não se separa a análise em porções externa e interna da seção transversal da ponte, mas tal estudo pode ser realizado se o calculista assim o quiser. O calculista poderá, também, escolher usar os momentos das partes externas para as partes internas - os momentos exteriores serão sempre maiores que os das partes interiores da seção transversal. Por isso, o método de análise consiste em posicionar o veículo de projeto na posição transversal externa. A posição usual de trânsito pode ser diferente, mas deve adicionalmente considerar o aumento da distância veículo-borda e os enrijecimentos existentes - uma discussão complementar é dada no OHBDC.

O método determina os passos seguintes:

1.Usando os valores já calculados de $\alpha, \theta$ e $\mu$ da análise anterior, obter os valores de $\boldsymbol{D}$ e $\boldsymbol{C}_{\boldsymbol{f}}$ dos diagramas da Figura 4.9a (ponte de uma só faixa de tráfego) ou da Figura 4.11a, 4.11b e 4.11c (pontes de duas, três e quatro faixas de tráfego para cálculo).

2. Obter os valores de $D_{d}$ :

$$
D_{d}=D\left(1+\frac{\mu C_{t}}{100}\right)
$$

3. Obter os momentos de cálculo da carga móvel multiplicando-se o momento fletor devido a uma linha de rodas por $\left(S / D_{d}\right) .(1+D L A)$, para partes externas e internas. O momento fletor, no caso do carregamento é o mesmo calculado para a análise no estado limite último (anterior).

4. Se o veículo for posicionado no meio da faixa de tráfego, levar em conta a distância veículo-borda aumentada. 
Q

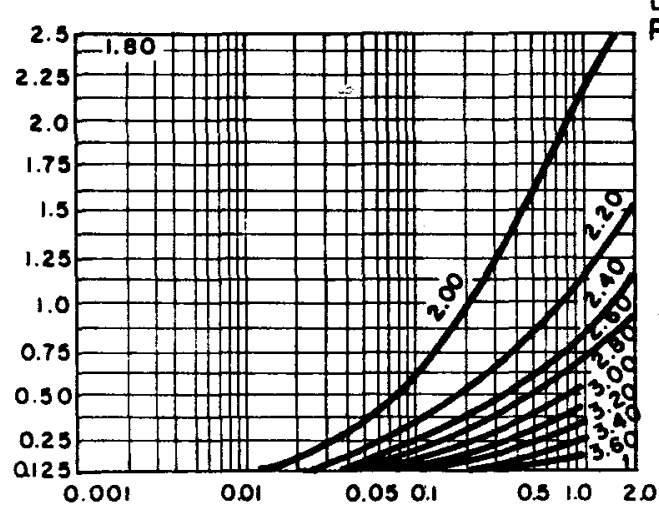

Portes Externas
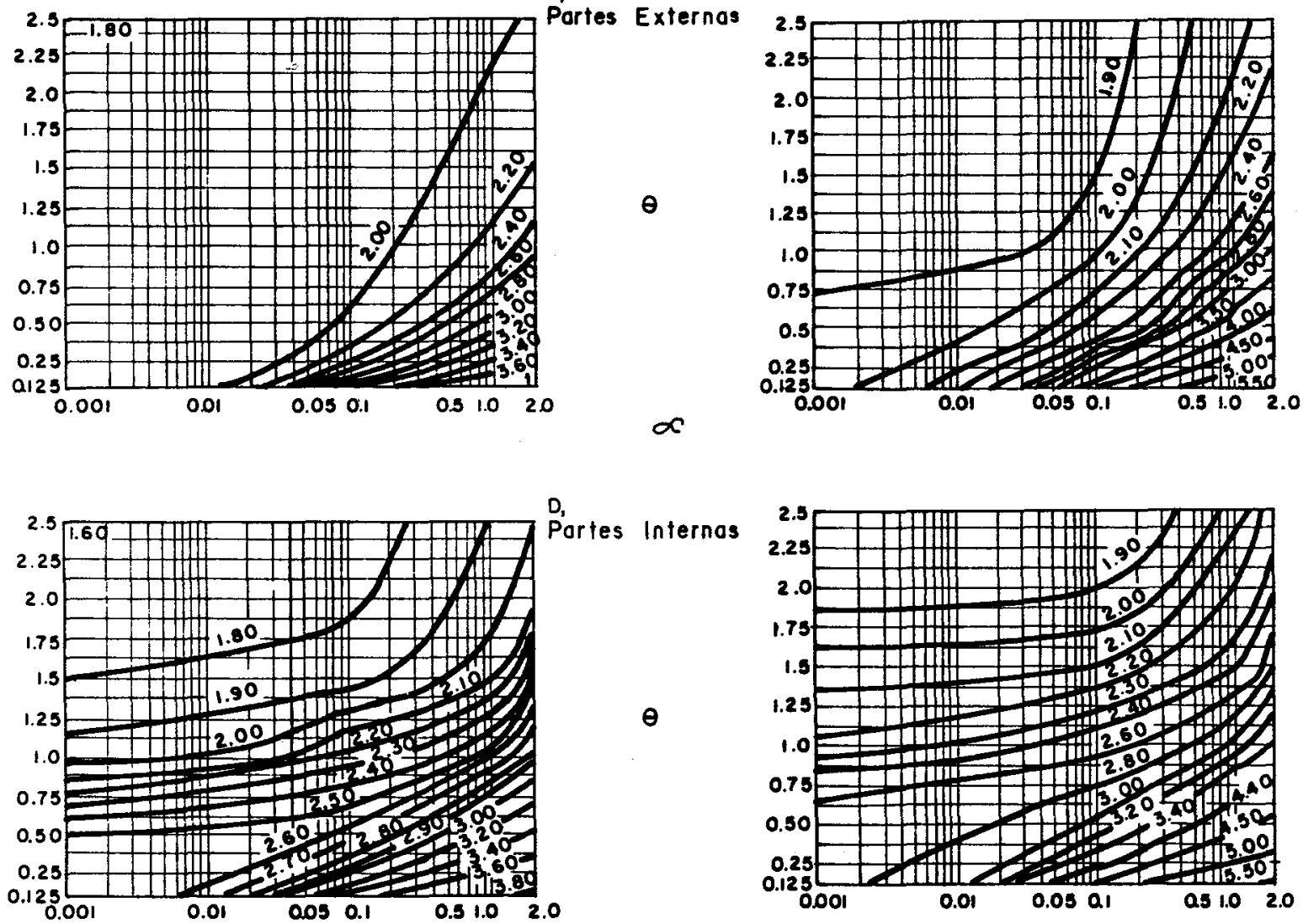

$\theta$

$\infty$

Partes Internas

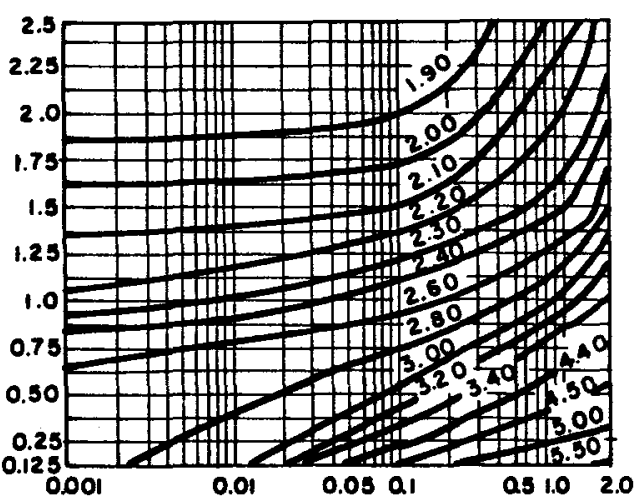

$\alpha$

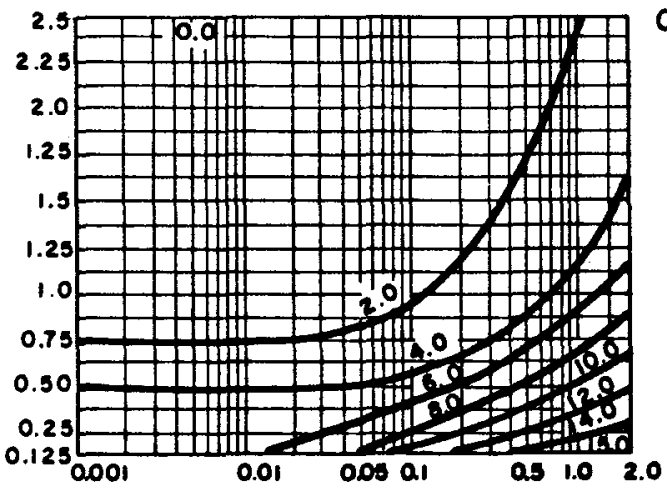

$c_{f}, \%$

$\theta$

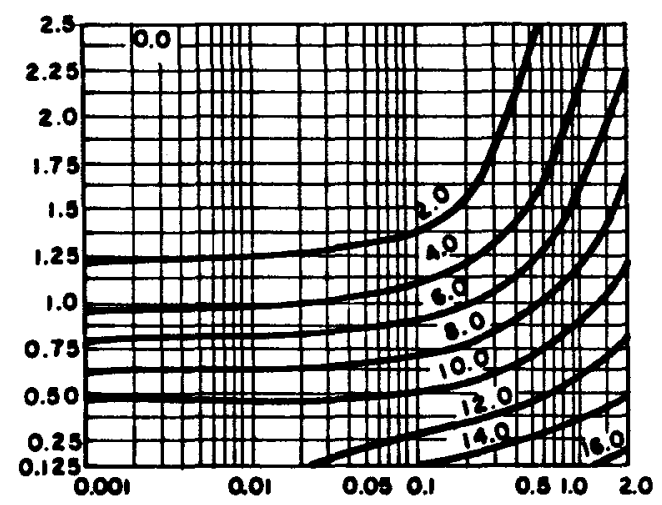

$\infty$

(a)

(b) 
$\theta$

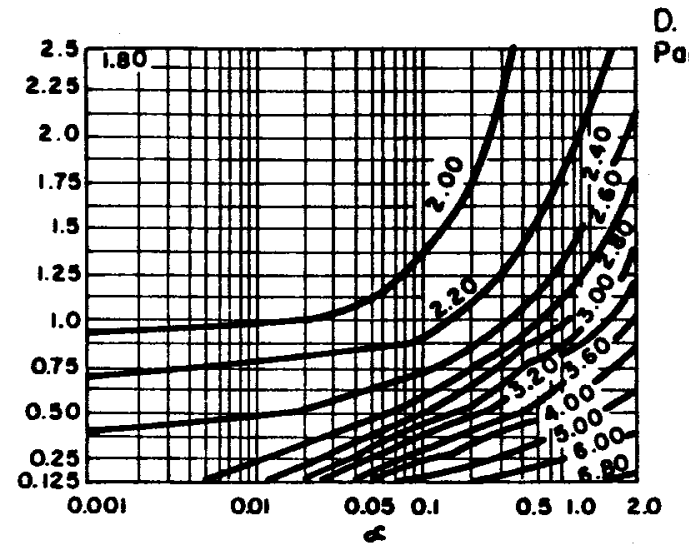

D.

Portes Externos

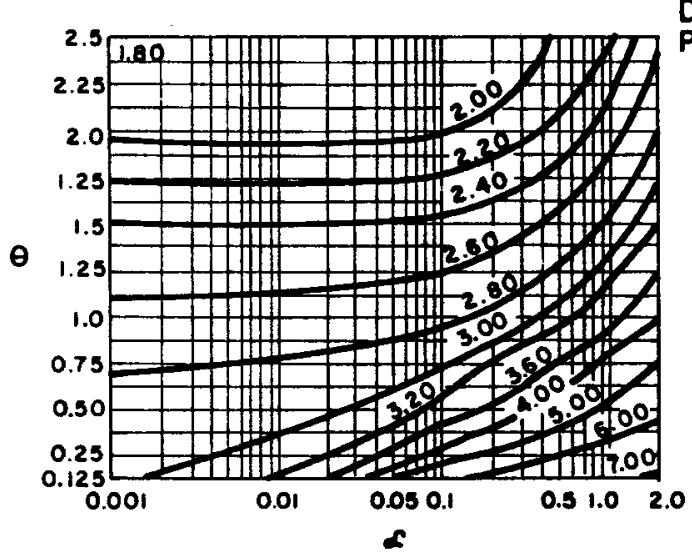

D.

Parte Interno

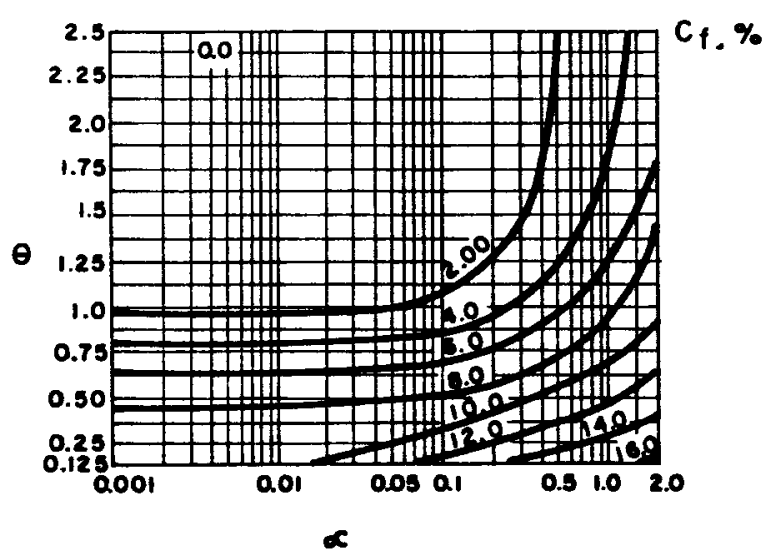

(c)

FIGURA 4.11 - Diagramas de $D$ e $C_{f}$, estado limite de utilizaçăo tipo 1, uma faixa de tráfego carregada (SLS I, OHBDC):

a)pontes de duas faixas de tráfego;

b) pontes de trés faixas de tráfego;

c) pontes de quatro faixas de tráfego. 


\subsection{OS MOMENTOS FLETORES TRANSVERSAIS.}

Os momentos fletores que atuam na estrutura da ponte no plano perpendicular ao tráfego dos veículos são denominados transversais. A sua intensidade é combatida diretamente pela rigidez transversal da placa no caso das pontes de madeira em placa sobre vigas ou em placas transversalmente protendidas.

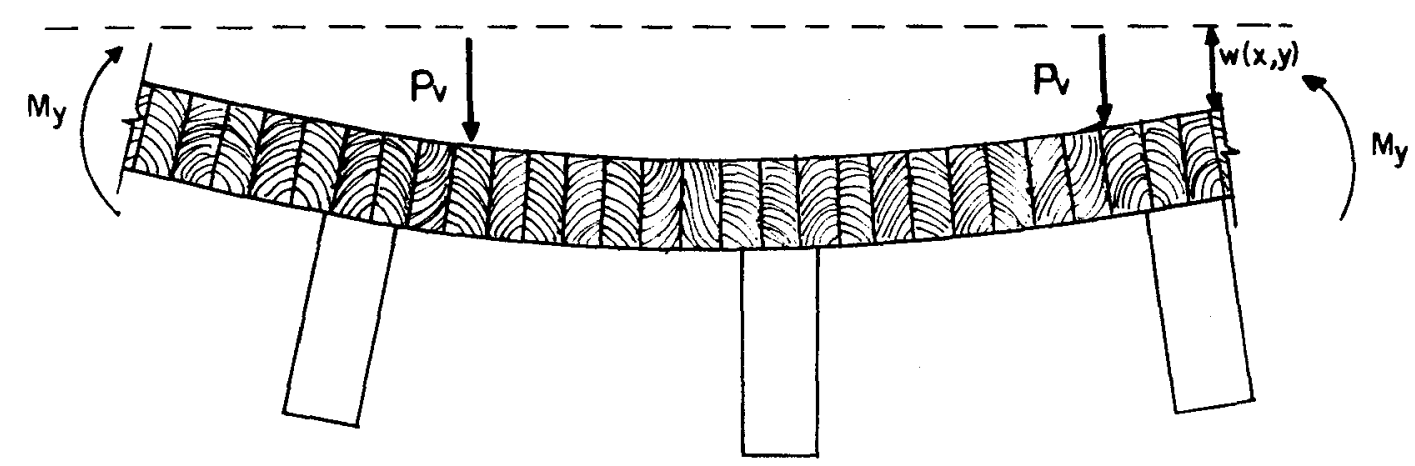

FIGURA 4.12 - Seção parcial da placa deformada sob ação de $M_{y}$ gerado por um eixo carregado do veículo; a linha tracejada indica a superficie indeformada.

Dadas as condições de vínculo naturais das pontes, as bordas livres transversais apresentam momento fletor nulo e, se a ponte tiver só um vão, o momento fletor transversal nos apoios lineares será nulo porque a curvatura transversal é igual a zero. Um aspecto da distribuição longitudinal do momento transversal é mostrado na Figura 4.13.

No caso das pontes em placa sobre vigas pode-se dividir a ação do momento fletor transversal em dois termos; um deles considerando a deformação da placa, mantendo as vigas indeformadas - termo conhecido por momento local. O momento local é calculado pela disposição da placa em um certo número de apoios lineares paralelos e inextensiveis. 0 outro termo é chamado momento global e pode ser calculado como uma gre/ha, onde o carregamento é aplicado d̀s vigas e a rigidez da placa é distribuída d̀s 
vigas equivalentes, ou como uma placa ortotrópica onde a rigidez longitudinal é distribuída uniformemente na largura da placa. No caso de placas sobre vigas, ambos os cálculos determinam valores dos momentos globais mais momentos locais superiores aos momentos fletores efetivos [BAKHT e JAEGER, 1985].

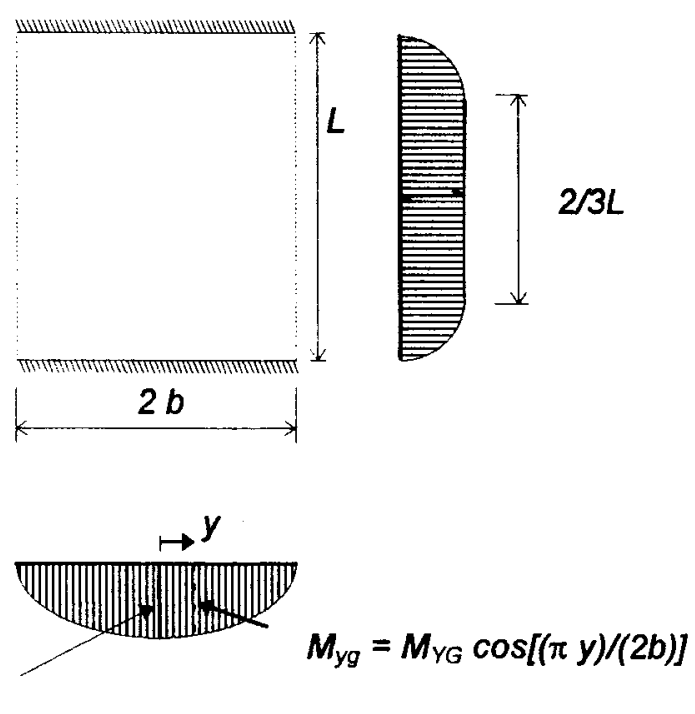

FIGURA 4.13 - Distribuiçăo de $M_{y}$ : transversal, valor máximo; longitudinal, envoltória das distribuiçס̃es possíveis.

Alternativamente poder-se-ia analisar os momentos máximos medindo-se as deflexões e analisando a curvatura do sistema estrutural. Este princípio foi utilizado para calibrar a análise realizada pelos programas gerais de análise das estruturas das pontes, pois a curvatura transversal sob cargas concentradas é bastante pronunciada e a determinação dos efeitos nas derivadas de ordem superior não sofre interferência tão intensa. Os erros na medida das flechas e na determinação da curvatura efetiva são mais danosos ao cálculo do que na análise em si. Outros fatores importantes são a determinação dos módulos de Young - já discutidos - e da posição transversal da carga. 
No caso de pontes rodoviárias a análise do momento fletor transversal máximo é feita com veículos de duas linhas de rodas, com o efeito teórico máximo sendo gerado por uma linha de rodas central - equidistante das bordas livres. Assim, o momento máximo positivo será obtido com o veículo no centro da ponte, tracionando as fibras inferiores e arqueamento ilustrado na Figura 4.12. Entretanto, poderá-ocorrer - por causa da geometria e simetria (ou não) da seção transversal - que os momentos locais máximos não sejam correspondentes à posição do veículo que gera os momentos globais máximos e, então, a prática de somar as parcelas será ainda mais conservadora.

Por outro lado, momentos transversais que causam tração nas fibras superiores ocorrem somente em pontes largas (quatro ou mais faixas de tráfego) e quando houver dois veículos junto às bordas livres, dipostos simetricamente. Nesta condição os momentos negativos que ocorrem junto às cargas (locais) não podem ser somados aos momentos negativos globais que ocorrem na porção central, descarregada, da ponte.

Outra possibilidade de momentos transversais negativos é a ocorrência de balanços laterais de porções da placa do tabuleiro. Esses momentos máximos ocorrem sobre a viga de borda e podem ser determinados considerando o balanço lateral fixado na porção interior (engaste).

Quando se tiver uma placa sem vigas longitudinais, os momentos transversais correspondentes à flexão total da placa são os momentos globais e o método dado no OHBDC para as placas sobre vigas aplica-se às pontes em placa considerando-se a parcela dos momentos globais somente.

Quando se tiver uma placa sobre vigas longitudinais, os momentos fletores globais nos apoio sáo nulos mas o momento fletor local pode não ser nulo porque poderá existir curvatura das vigas ou da placa, entre as vigas. 


\subsubsection{Métodos Analíticos para Pontes em Placa Sobre Vigas.}

Os métodos de análise são aplicáveis às pontes que podem, realisticamente, ser idealizadas como placas ortotrópicas. Conforme a discussão acima, são dadas as parcelas dos momentos locais, positivos e negativos, e momentos globais, positivos e negativos.

\subsubsection{Momentos Locais}

As intensidades dos momentos fletores sob cargas concentradas aumentam rapidamente quando a área de contato sob a carga diminui e essa razão é o fundamento principal para a delimitação correta desta área de contato, pois define com maior rigor a intensidade do momento fletor.

As rodas mais pesadas dos veículos do Sistema Ontário têm área de contato de $600 \mathrm{~mm} \times 250 \mathrm{~mm}$ e a área carregada efetiva no plano médio da placa é obtido através da dispersão em $45^{\circ}$. Exigindo-se uma capa de rolamento de $75 \mathrm{~mm}$ e espessura da placa de $20 \mathrm{~cm}$, o resultado é uma área efetivamente carregada de $950 \mathrm{~mm}$ (transversal) por $600 \mathrm{~mm}$ (longitudinal) sob cada extremidade do eixo. 

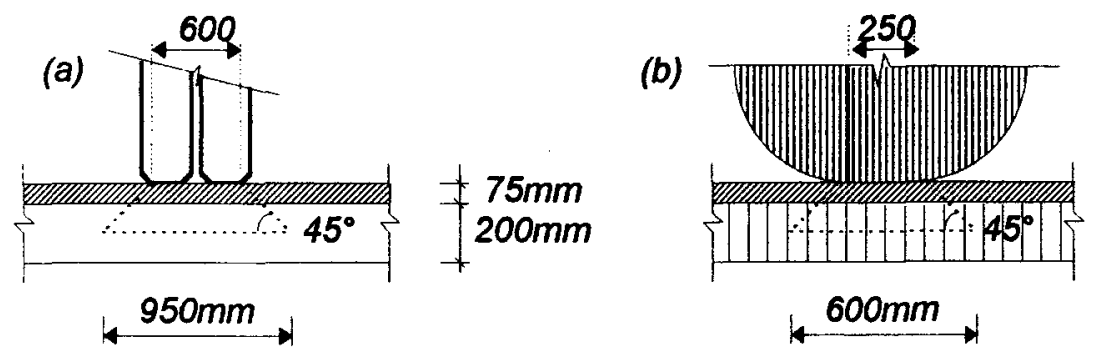

(c)

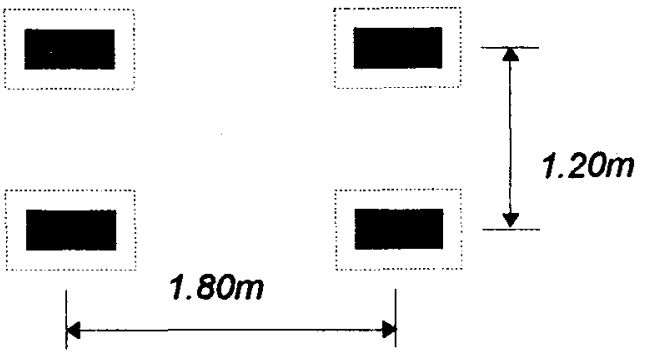

FIGURA 4.14 - Dispersăo da carga de rodas no tabuleiro:
a) transversal;
b) longitudinal;
c) planta (eixo duplo, OHBDC).

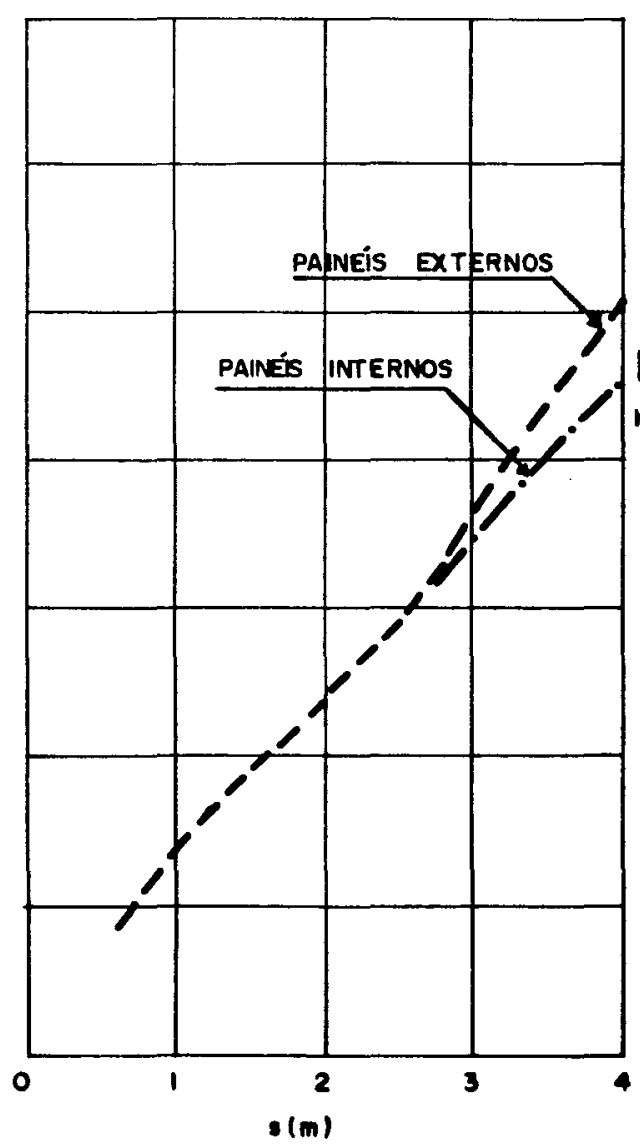

Momentos locais negativos

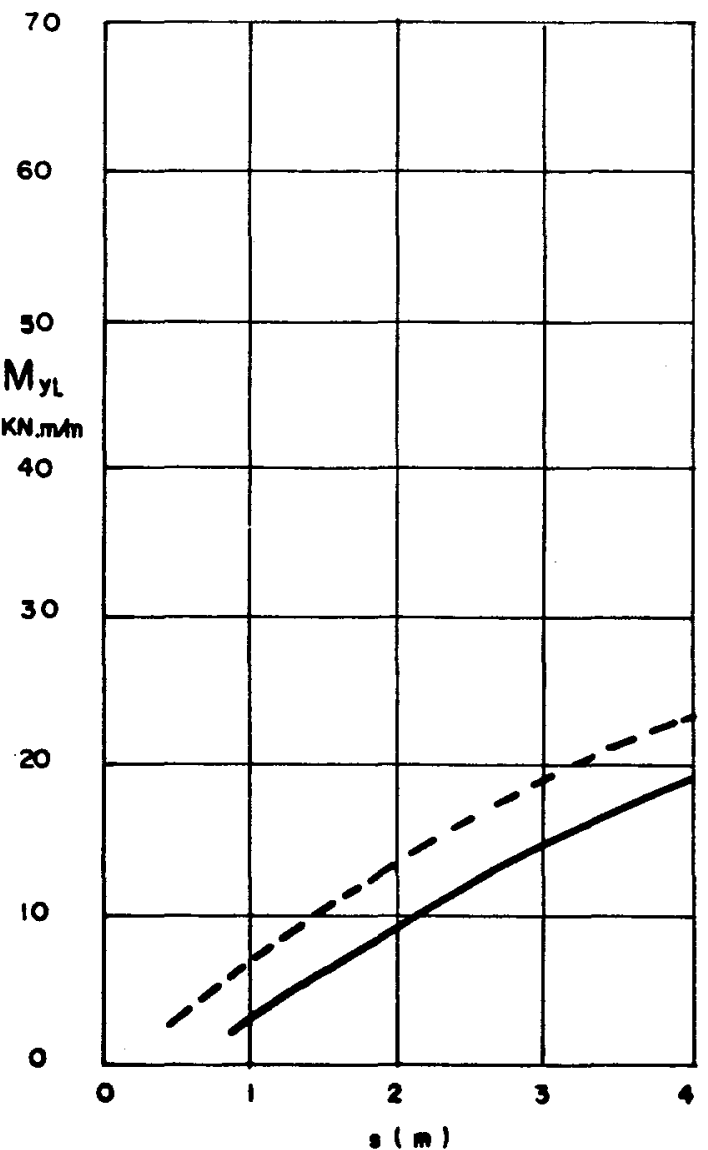

Momentos locais positivos

FIGURA 4.15 - Momentos Locais, carregamento OHBDC. 
As curvas da figura acima são aplicáveis ao caminhão de projeto e aos três niveis do veículo-tipo pois os momentos transversais locais máximos são determinados principalmente por dois veículos adjacentes com os eixos mais pesados juntos um do outro - e tais eixos são comuns a todos os veículos de avaliação. Os momentos transversais dados na Figura 4.15 são não ponderados, mas os valores negativos (tração nas fibras superiores) são bem maiores que sua compensação positiva (tração nas fibras inferiores).

\subsubsection{Momentos Globais}

Os momentos fletores transversais globais, $M_{Y G}$ para pontes em placas sobre vigas, ou momento transversal total para pontes em placa, são determinados passo a passo graficamente e recomenda-se, para as pontes largas que tenham momentos globais negativos, dimensioná-las para a intensidade do momento transversal global positivo encontrado.

1.Calcular $\theta$ :

$$
\theta=\frac{b}{L}\left[\frac{D_{X}}{D_{Y}}\right]^{0.25}
$$

2.Em função do valor de $\theta$ e da largura $2 b$ encontrar 0 valor do momento fletor transversal global dos gráficos da Figura 4.16.

3.Se $\theta$ e $2 b$ forem diferentes dos fornecidos, interpolar linearmente em $\theta$ e em $2 b$ para determinar o valor de $M_{\mathrm{YG}}$ final.

4.Os momentos tranversais globais obtidos correspondem ao nivel 3 de avaliação. Para avaliação nos niveis 2 e 1, os momentos globais devem ser reduzidos pela razão entre os momentos longitudinais gerados pelo veículo sob avaliaçăo e os momentos gerados pelo veículo-tipo (nível 3):

$M_{Y G}^{(2)}=M_{Y G}^{(3)} \cdot \frac{M_{X}^{(2)}}{M_{X}^{(3)}} \quad$ no caso de avaliação nível 2 
As curvas da figura acima são aplicáveis ao caminhão de projeto e aos três níveis do veículo-tipo pois os momentos transversais locais máximos são determinados principalmente por dois veiculos adjacentes com os eixos mais pesados juntos um do outro - e tais eixos são comuns a todos os veículos de avaliação. Os momentos transversais dados na Figura 4.15 são não ponderados; mas apresentam valores negativos (tração nas fibras superiores) bem maiores que sua compensação positiva (tração nas fibras inferiores).

\subsubsection{Momentos Globais}

Os momentos fletores transversais globais, MYg para pontes em placas sobre vigas - momento transversal total para pontes em placa - são calculados passo a passo graficamente e recomenda-se, para as pontes largas que tenham momentos globais negativos, calculá-las para a intensidade do momento transversal global positivo determinado.

\section{Calcular $\theta$ :}

$\theta=\frac{b}{L}\left(\frac{D_{X}}{D_{Y}}\right)^{0.25}$

2.Em função do valor de $\theta$ e da largura $2 b$ encontrar o valor do momento fletor transversal global dos gráficos da Figura 66.

3.Se $\theta$ e $2 b$ forem diferentes dos fornecidos, interpolar linearmente em $\theta$ e em $2 b$ para determinar o valor de $M_{Y G}$ final.

4.Os momentos tranversais globais obtidos correspondem ao nível 3 de avaliação. Para avaliação nos niveis 2 e 1, os momentos globais devem ser ponderados pela razão entre os momentos gerados pelo veículo sob avaliação e os momentos gerados pelo veículo tipo (nivel 3), longitudinais :

$M_{Y G}^{(2)}=M_{Y G}^{(3)} \cdot \frac{M_{x}^{(2)}}{M_{x}^{(3)}} \quad$ no caso de avaliação nível 2. 


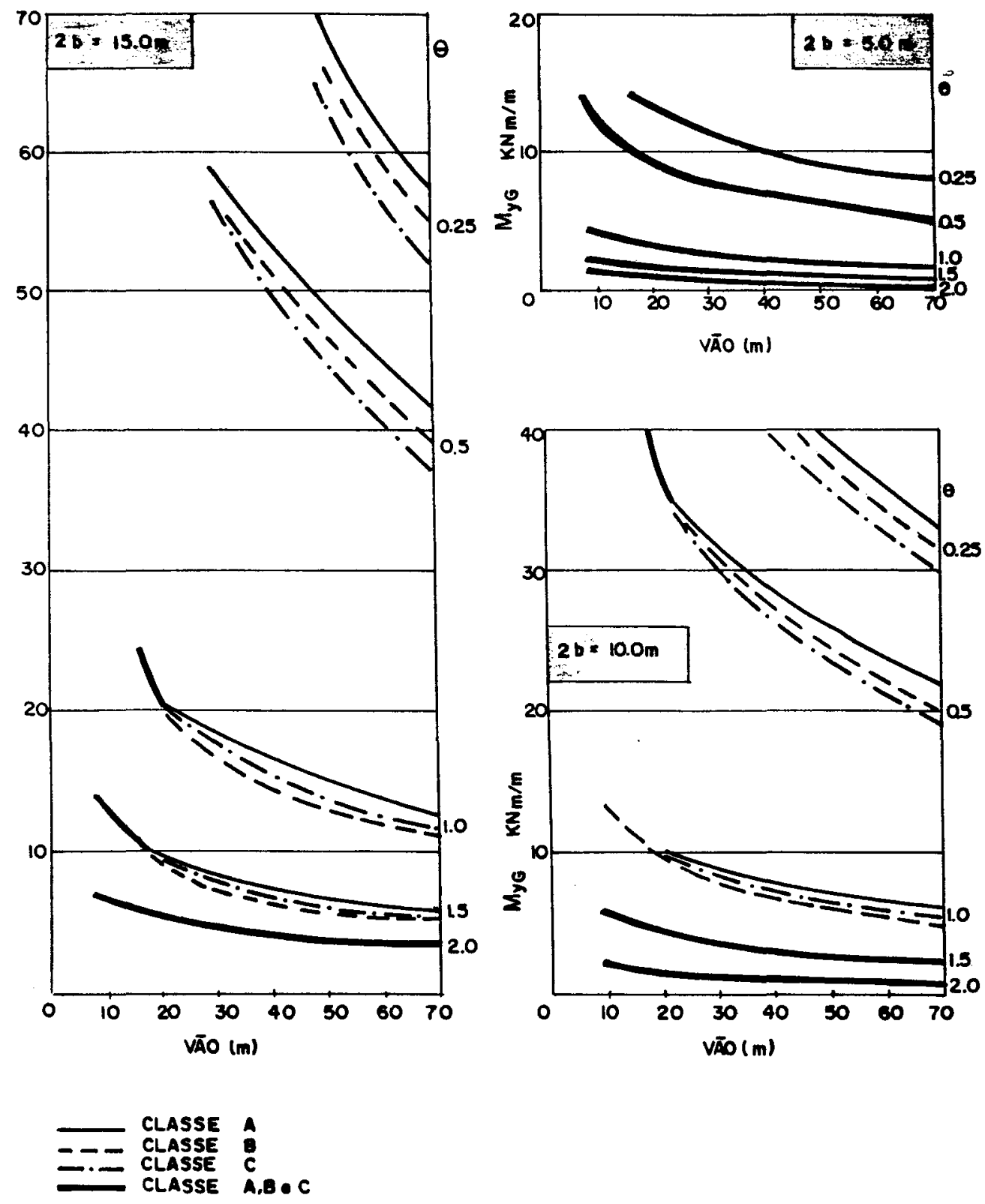

FIGURA 4.16 - Momentos Transversais Globais em pontes em placa sobre vigas, gerados pelo carregamento OHBDC. 


\subsection{FORÇAS CORTANTES NAS PONTES EM PLACA.}

\subsubsection{Cisalhamento Longitudinal.}

O termo "cisalhamento longitudinal" refere-se à força cortante vertical que atua em uma faixa longitudinal da ponte. Em ponies simplesmente apoiadas esta resposta estrutural é aquela que, nos apoios, pode ser tomada como igual à reação vertical do apoio.

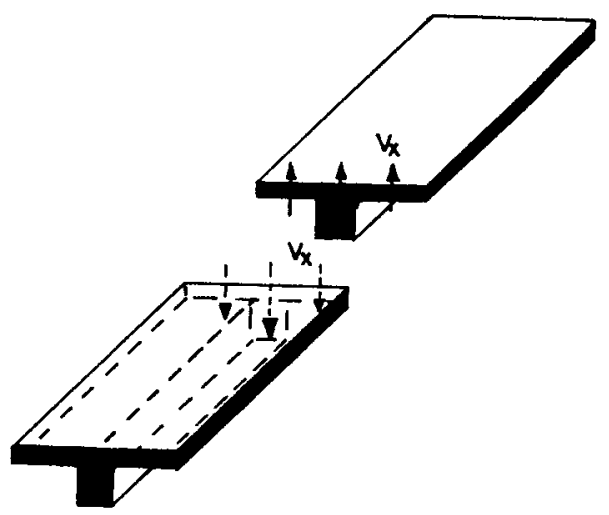

FIGURA 4.17 - Definição de $V_{x}$ em seçס̃es contíguas, em uma faixa da ponte.

A distribuição transversal dos esforços cortantes é bem diferente da distribuição transversal dos momentos fletores longitudinais. 0 método dado no Ontario Highway Bridge Design Code (OHBDC) analisa as forças cortantes através da analogia de grelha, pois este é um efeito prontamente identificável em uma grelha, e este valor é confrontado com o método da placa ortotrópica, para calibrar-se os coeficientes de distribuição transversal. Por exemplo, a estrutura mostrada na Figura 4.18, ponte em placa sobre vigas, com duas posições de veículo para carregamento, apresenta as distribuiçöes transversais de momentos fletores e forças cortantes longitudinais dado. Os parâmetros básicos valem $\alpha=0,1$ e $\theta=1,0$. 


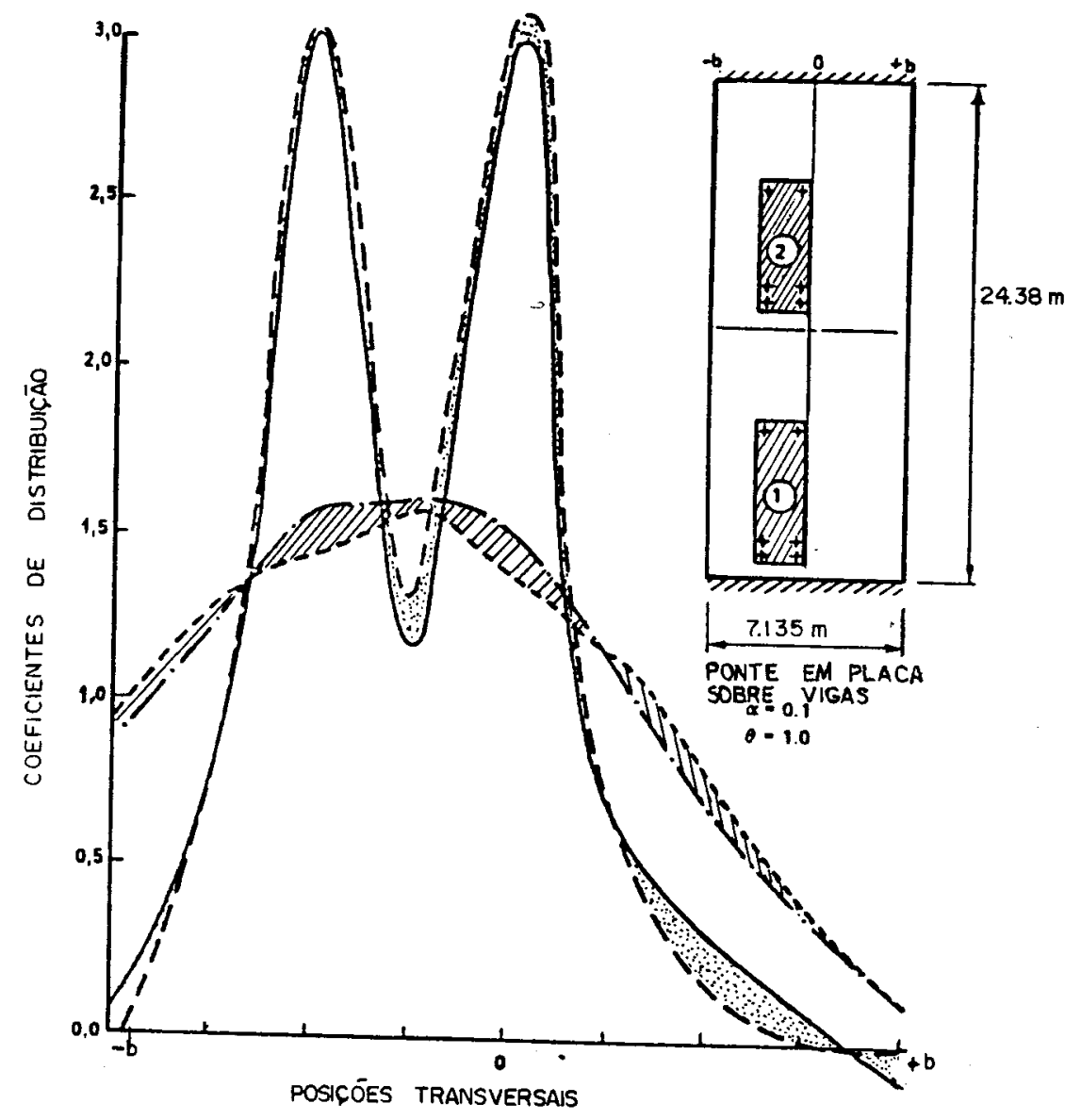

- Carregamento tipo 1 - Força Cortante Longitudinal no apoio.

- - C Carregamento tipo 2 - Força Cortante Longitudinal no meio do văo.

-.-.-.- Carregamento tipo 1 - Momento Fletor Longitudinal no meio do văo.

- - Carregamento tipo 2 - Momento Fletor Longitudinal no meio do văo.

FIGURA 4.18 - Distribuição Transversal de Momentos e Cortantes Longitudinais.

Pode-se ver que, apesar de uma flutuação bem mais pronunciada e correspondente à carga sob rodas, a distribuição de $V_{x}$ que corresponde a um coeficiente de distribuição de 3,11 é mais razoavelmente independente da posição sob consideração em relação ao carregamento dado do que a distribuição dos momentos, mais branda e correspondente a um coeficiente de distribuição de 1,6. Esta observação é justificada pelo fato de que, se se puder obter as forças cortantes a partir dos momentos fletores então 0 sistema plano se comporta como viga. Com efeito, se se considerar o 
carregamento $e$ as seções $A, B, C$, da placa dada, afastados do carregamento, sendo $B$ a seção média entre $A$ e $C$ e $\underline{\Delta x} O$ afastamento longitudinal delas, então :

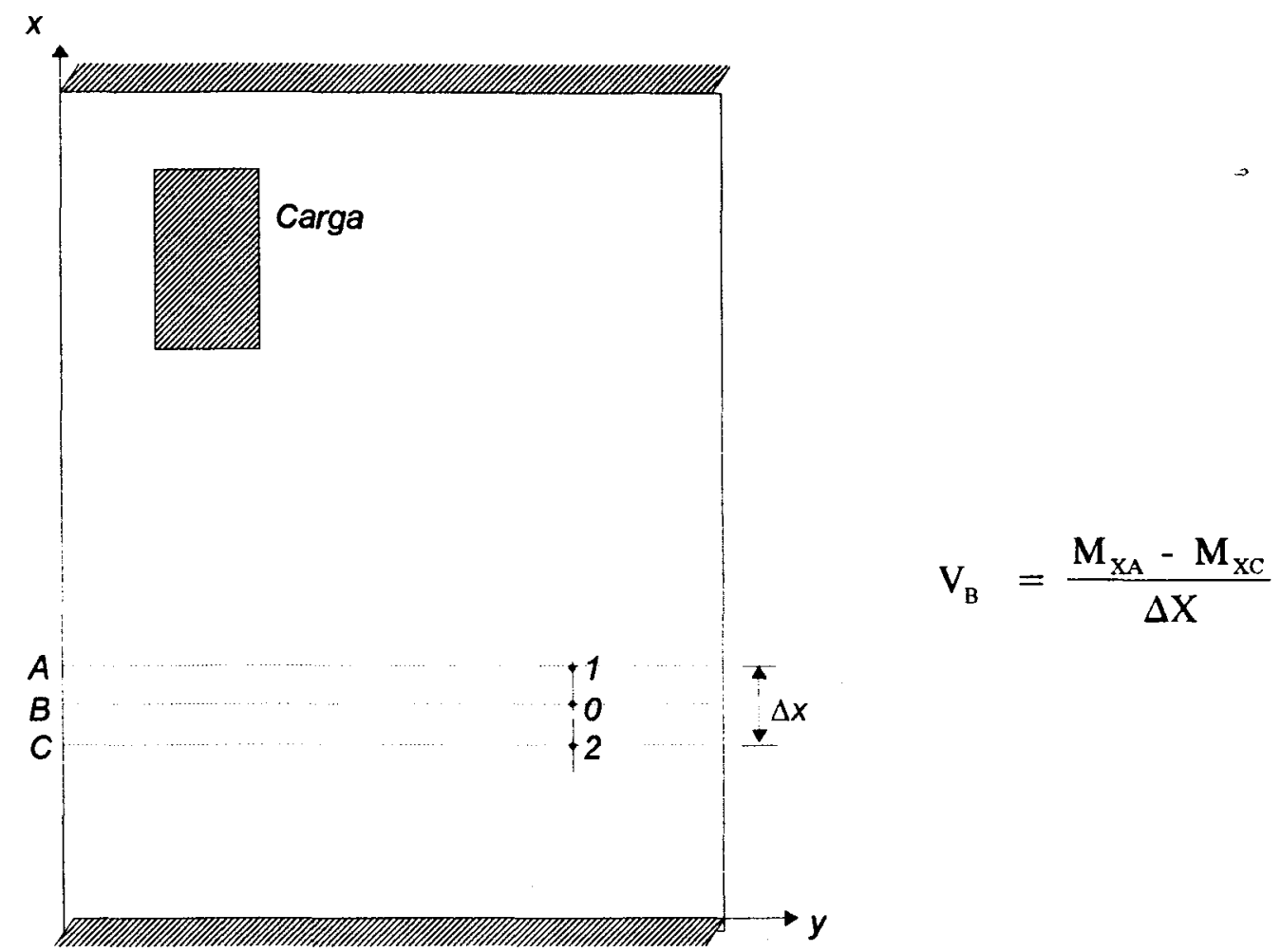

FIGURA 4.19 - Posiçào relativa à carga móvel das seçóes analisadas

Neste caso, $V_{B}$ é o valor numérico gerado pela diferença finita de $V_{x}=\partial M_{x} / \partial x$. Considerando-se os pontos 1 e 2 das seções $A$ e $C$, pode-se encontrar que $M_{X 1}=K M_{X A}$ e $M_{X 2}=K M_{X B}$ (da hipótese de independência de modo de distribuição de $M \operatorname{com} x$ ). Assim, num ponto $O$ da seção $B$ :

$$
\begin{aligned}
& \mathrm{V}_{\mathrm{xo}}=\frac{\mathrm{M}_{\mathrm{x} 1}-\mathrm{M}_{\mathrm{X} 2}}{\Delta \mathrm{X}}=\frac{\mathrm{K} \mathrm{M}_{\mathrm{XA}}-\mathrm{K} \mathrm{M}_{\mathrm{xC}}}{\Delta \mathrm{X}} \\
& \mathrm{V}_{\mathrm{xo}}=\mathrm{K} \frac{\mathrm{M}_{\mathrm{XA}}-\mathrm{M}_{\mathrm{xC}}}{\Delta \mathrm{X}} \\
& V_{x 0}=K V_{B}
\end{aligned}
$$


Para se ajustar o método e ilustrar as diferenças a ponte da figura anterior foi idealizada como grelha e a discretização em vigas longitudinais está mostrada a seguir. A posição 1 do veículo é referida. As seções 1 e 2 distam $0,61 m$ do centro do vão.

TABELA 4.1 - Análise de Grelha ge uma ponte, momentos e cortantes Jongitudinais.

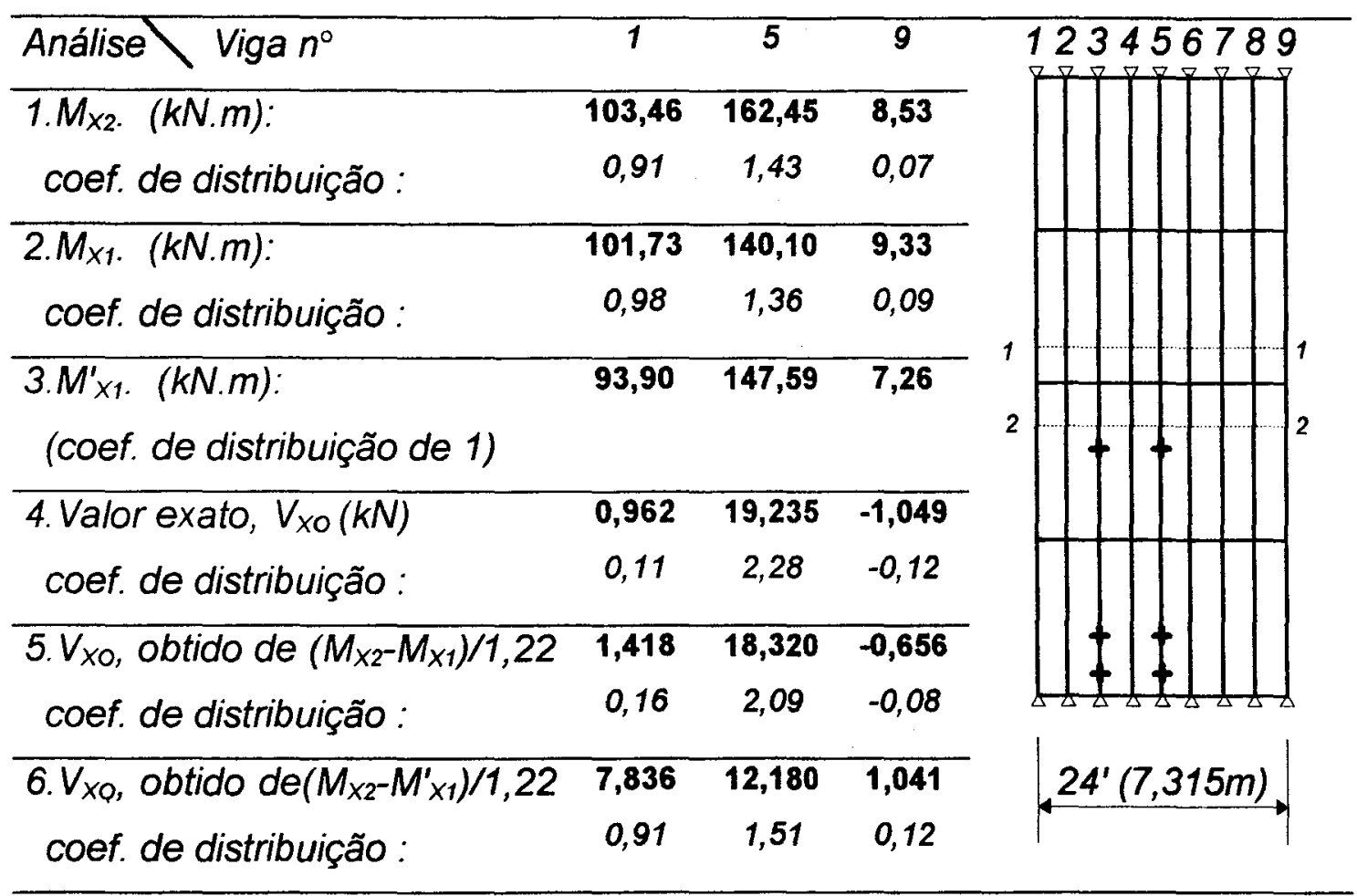

Como se vê nas linhas 1 e 2, os momentos em seções próximas não são os mesmos, nem os coeficientes de distribuição - mas estes são razoavelmente próximos. No entanto, a força cortante tem coeficientes de distribuição (linha 4) significativamente diferentes. O valor da força cortante estimada pelos momentos fletores está na linha 5 e os valores da força cortante e dos coeficientes de distribuição têm a mesma ordem de grandeza dos obtidos pela análise de grelha (linha 4).

Sabendo-se o valor do momento médio da seção 1-1(103,46 kN.m) e os coeficientes na seção 2-2, o momento estimado para a seção 1-1 é $M_{X \text { t, }}^{\prime}$ identificado na linha 3 da Tabela. $M_{x 1}^{\prime}$ e $M_{x 1}$ não são significativamente diferentes e têm a mesma ordem de grandeza. Usando-se estes momentos 
estimados para se calcular a força cortante, os resultados apresentados na linha 6 da Tabela mostram-se substantivamente diferentes do valor real obtido da análise de grelha (linha 4), repetindo o ilustrado na Figura 4.19.

\subsubsection{Método para Análise}

O método simplificado para análise das forças cortantes longitudinais foi desenvolvido e apresentado por BAKHT e JAEGER (1985), e a forma do método é a mesma, isto é, uma abordagem do tipo $D$ é utilizada. Os valores de $D$ para os momentos fletores foram obtidos pela análise de placas ortotrópicas e para as forças cortantes serão obtidos pela analogia de grelha.

Os detalhes de uma seção transversal particular não são conhecidos quando um método geral é desenvolvido para as diferentes seções transversais e tipos de pontes. Por isso, a idealização como grelha é feita em duas etapas. Primeiro, a ponte é idealizada como placa ortotrópica. Segundo, a placa ortotrópica é idealizada como grelha possuindo nove vigas longitudinais igualmente espaçadas e sete vigas transversais igualmente espaçadas.

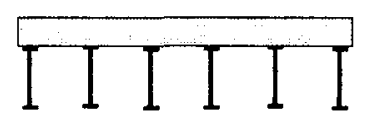

(a)

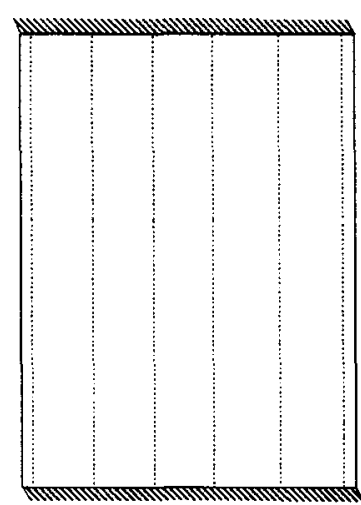

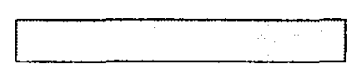

(b)

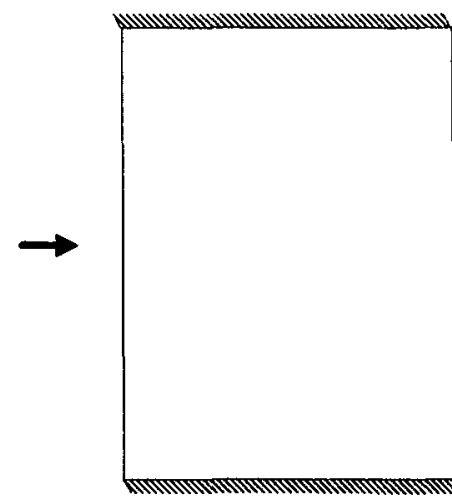

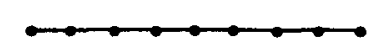

(c)

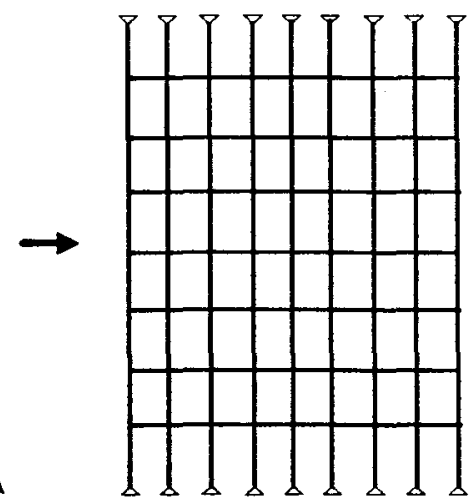

FIGURA 4.20 - (a) Ponte real.

(b) Placa ortotrópica.

(c) Grelha equivalente. 
A força cortante, em termos do deslocamento $w(x, y)$, é definida por:

$V_{x}=D_{x} \frac{\partial^{3} w}{\partial x^{3}}+\left(D_{Y X}-D_{X Y}+D_{1}\right) \frac{\partial^{3} w}{\partial x \partial y^{2}}$

$V_{x}$ inclui as variações dos momentos torçores, em uma grelha completa os momentos torçores estão presentes gerando componentes horizontais para o equilibrio vertical e sua percepção é mais rápida pelo engenheiro. Por esta razão escolheu-se a grelha para a obtenção dos valores correspondentes ao cisalhamento longitudinal.

As limitações do método à geometria da ponte são as mesmas anteriormente apresentadas para as estruturas que possam ser idealizadas como placas ortotrópicas.

Uma grelha típica como a mostrada na idealização compreende um número de vigas longitudinais iguais, cada uma com rigidez à flexão El, rigidez à torção GJ e comprimento L. Tais longarinas são igualmente espaçadas entre si de $\mathbf{h}$ e são interconectadas por vigas transversais igualmente espaçadas, cada uma com rigidez à flexão $E I_{T}$ e rigidez à torção $G J_{T}$. Para comparação com o comportamento da placa ortotrópica, os parâmetros podem ser colocados em equivalência :

$$
\begin{aligned}
& E I=D_{X} \cdot h \\
& E I_{T}=D_{y} \cdot \Delta x \\
& G J=D_{X Y} \cdot h \\
& G J_{T}=D_{Y X} \cdot \Delta x
\end{aligned}
$$

Os resultados de análises rigorosas mostraram que os valores de $D$ para um dado tipo de estrutura de ponte com um dado número de faixas de tráfego varia dentro de um intervalo pequeno. Confirmou-se que, especificando-se um único valor e tendo-se um número de faixas especifico, o erro máximo envolvido é de $5 \%$. 
Os resultados da análise de grelha foram interpolados para obter os valores de $D$ correspondentes a um espaçamento de vigas de $2 \mathrm{~m}$, exceto para pontes compostas madeira-concreto e pontes laminadas transversalmente pós-tensionadas nas quais uma largura de $1 \mathrm{~m}$ foi usada para se tomar a média dos efeitos, sendo os valores de $\boldsymbol{D}$ obtidos a partir destas médias. No caso de vigas com espaçamento menor que $2 \mathrm{~m}$, considerar o valor real através da equação:

$$
D_{d}=\left[\frac{S}{2}\right]^{0.25} \cdot D
$$

onde $S$ é o espaçamento em metros.

Os valores de D são dados na Tabela 4.2

TABELA 4.2 - Valores de D para Força Cortante Longitudinal, em metros, OHBDC.

\begin{tabular}{|c|c|c|c|c|c|c|c|c|}
\hline $\begin{array}{l}\text { Tipo de Superestrutura da } \\
\text { Ponte }\end{array}$ & $\begin{array}{c}\text { Número } \\
1\end{array}$ & $\begin{array}{l}\text { de } \mathrm{Fa}_{2} \\
\mathbf{2}\end{array}$ & as, $E$. & L. Ut. & $N, E$ & $\begin{array}{l}\text { L. U. } \\
2\end{array}$ & $\begin{array}{l}e E . L \\
3\end{array}$ & Ut. ${ }_{4}^{11}$ \\
\hline $\begin{array}{l}\text { Placas maciças ou } \\
\text { vazadas }\end{array}$ & 2,05 & 2,10 & 2,25 & 2,50 & 2,05 & 1,95 & 1,95 & 2,15 \\
\hline Placas sobre vigas * & 1,75 & 1,80 & 1,90 & 2,10 & 1,75 & 1,70 & 1,85 & 1,90 \\
\hline $\begin{array}{l}\text { Tabuleiro laminado } \\
\text { transversal sobre vigas } \\
\text { longitudinais de madeira* }\end{array}$ & 1,75 & 1,80 & 1,90 & 2,10 & 1,75 & 1,70 & 1,85 & 1,90 \\
\hline $\begin{array}{l}\text { Placa de concreto sobre } \\
\text { tabuleiro de madeira } \\
\text { laminado longitudinal }\end{array}$ & 1,85 & 1,95 & 2,10 & 2,30 & 1,85 & 1,70 & 1,85 & 1,90 \\
\hline $\begin{array}{l}\text { Tabuleiros de madeira } \\
\text { laminada protendidos }\end{array}$ & 1,65 & 1,75 & 1,85 & 2,00 & 1,65 & 1,70 & 1,80 & 1,85 \\
\hline
\end{tabular}

"Se S for menor que 2.0m usar Equação [4.6].

Um exame dos valores dado na Tabela revelará algumas "inconsistências" em seus padrões. $O$ valor de $D$ diminui quando o número de faixas passa de uma para duas, no caso de análise em estado limite último, mas começa a aumentar quando passa de duas para trés faixas de tráfego. Após considerar os fatores de redução pelo carregamento simultâneo em várias faixas de tráfego, os valores determinantes de $\boldsymbol{D}$ surgem do caso de duas faixas 
adjacentes carregadas. A razão para esta ocorréncia é a maior proximidade das linhas de rodas do mesmo veículo, resultando em uma concentração mais intensa de $V_{x}$, diminuindo o valor de $\boldsymbol{D}$. Qualquer acréscimo posterior no número de faixas apenas aumenta a largura da ponte, e reduz o fator de ponderação para presença de mais veículos sobre a ponte, resultando em mais porções da seção transversal disponíveis para compartilhar a carga e aumentando o valor de $\boldsymbol{D}$.

Os valores máximos dos esforços cortantes longitudinais não são tão sensiveis à posição transversal dos veículos como os momentos fletores. Por isto, as porções interna e externas da seção são submetidas aos mesmos máximos, e esta é a razão pela qual não há distinção entre partes externas e interna, e o valor estipulado pela análise simplificada é aplicado a toda a seção transversal da ponte. Apresenta-se na Tabela 4.3 os números de faixas da ponte e o número de faixas carregadas que define 0 valor de $D$ conforme a tipologia da superestrutura.

TABELA 4.3 - Número Determinante de Faixas Carregadas, Esforço Cortante, OHBDC.

\begin{tabular}{lllll}
\hline Tipo de Superestrutura da Ponte & \multicolumn{5}{c}{ Número de Faixas da Ponte } \\
& \multicolumn{1}{c}{1} & 2 & 3 & 4 \\
\hline Placa Maciça ou Vazada & 1 & 2 & 2 & 2 \\
Placa Sobre Vigas & 1 & 2 & 2 & 2 \\
Tabuleiro Laminado Transversal e Vigas de & 1 & 2 & 2 & 2 \\
$\quad$ Madeira & & & & \\
Placa combinada, concreto sobre madeira & 1 & 2 & 2 & 2 \\
Tabuleiro Laminado Tensionado & 1 & 2 & 2 & 2 \\
\hline
\end{tabular}




\subsubsection{Método para o Carregamento OHBDC.}

O carregamento, os fatores de impacto, larguras das faixas já foram apresentados. As forças cortantes determinantes para as vigas simples devidos a uma linha de rodas ou carregamento de meia faixa são dados na Figura 4.21.

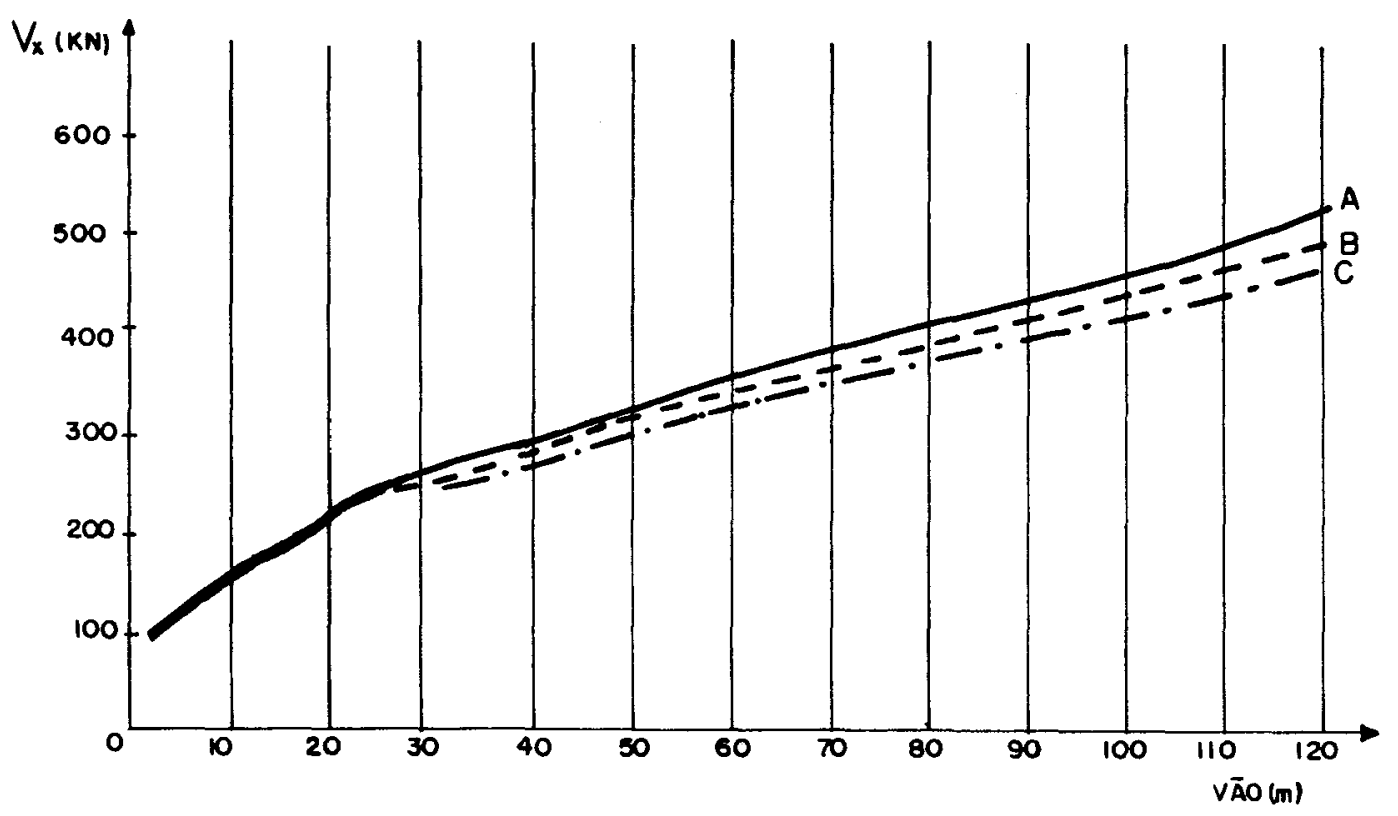

FIGURA 4.21 - Forças cortantes, carregamento em meia-pista.

Os passos para se determinar as forças cortantes longitudinais geradas pela carga móvel são :

1.Escolher um valor de $\boldsymbol{D}$, para os estados limites de análise, na Tabela 4.2 de acordo com o número de faixas de tráfego de cálculo e o tipo da ponte. Quando o espaçamento de vigas longitudinais, se presentes, for menor que $2,0 \mathrm{~m}$, corrigir o valor obtido na tabela por:

$$
D_{d}=\left\{\frac{s}{2}\right)^{0.25} \cdot D
$$

onde $s$ é o espaçamento entre as vigas em metros. Nos outros casos, $D_{d}=$ D. 
2. Calcular a fração de carga $\left(s / D_{d}\right)$, onde s é :

- o espaçamento real das vigas longitudinais (pontes em placa sobre vigas);

- o espaçamento entre almas das placas vazadas e estruturas celulares;

- 1,0 m, no caso de placas maciças, placas protendidas e placas compostas madeira-concreto.

3.Considerando a ponte como uma viga unidimensional determinar os diagramas da força cortante devidos a uma linha de rodas do veículo (metade do trem-tipo longitudinal) ou metade do carregamento da faixa.

4. Multiplicar a força cortante obtida por [(s/Dd). $(1+D L A)]$ para se obter o valor de cálculo da força cortante longitudinal. Este valor é aplicável tanto às partes interna quanto externas.

\subsubsection{Cisalhamento Transversal.}

O Código Normativo de Pontes Rodoviárias de Ontário especifica que se deve calcular o valor da força cortante transversal $V_{Y}$ apenas nas estruturas em que este seja o modo predominante de transferência transversal das cargas entre vigas longitudinais. Se os métodos adotados forem calculados para outros tipos de superestruturas, nas quais a flexão transversal é o principal modo de transferência de carga, então os valores calculados do esforço cortante transversal serão sempre superiores aos reais; o quanto mais rigida transversalmente como um todo a estrutura, tanto maior a superavaliação.

Os métodos fornecem o máximo valor de $V_{y}$, que atua na vizinhança imediata das cargas concentradas. Se, por exemplo, o afastamento entre as vigas rígidas longitudinais for grande, então o valor de pico de $V_{Y}$ diminui muito rapidamente quando se afasta transversalmente na seção do local da carga concentrada. Por esta razão os métodos foram desenvolvidos com base na teoria de placa articulada. 
A placa articulada é um caso particular da placa ortotrópica na qual a rigidez transversal de $D_{y}$ é igual a zero. Neste caso pode-se usar um parâmetro adimensional relacionando as propriedades e formas da estrutura para se fazer a análise. Este parâmetro é:

$$
\beta=\pi\left[\frac{2 b}{L}\right] \sqrt{\frac{D_{X}}{D_{X Y}}}
$$

Neste caso, $D_{x y}$ refere-se a toda inércia torcional das vigas prismáticas. Assim, para as pontes de madeira em placa laminada protendida se têm os valores indicados na Tabela 4.4.

TABELA 4.4 - Rigidezes a Computar para análise de placa articulada.

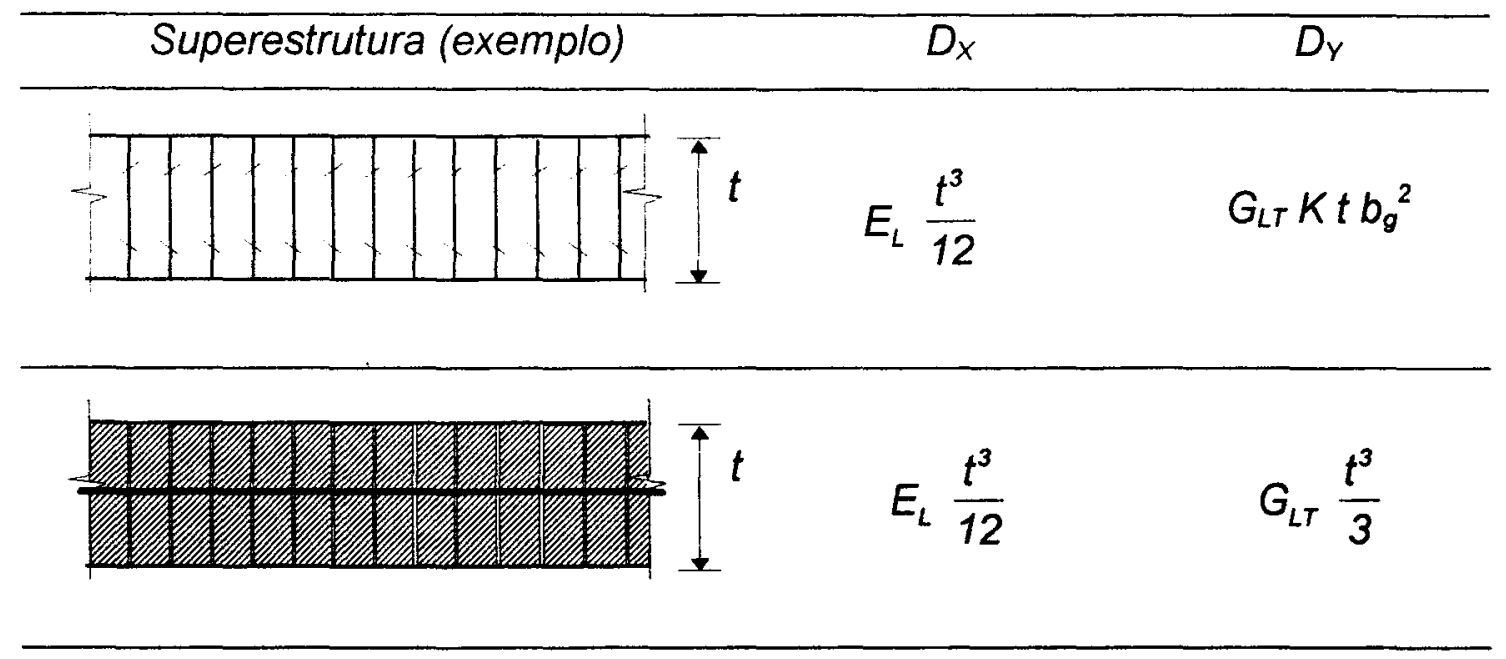

É útil notar-se que, com todos os parâmetros já definidos anteriormente, a rigidez torcional da ponte de madeira laminada protendida está inteiramente agrupada no valor dado na Tabela acima. Para a determinação dos parâmetros nos cálculos dos momentos e cortantes longitudinais $(\alpha, \theta)$, os valores haviam sido distribuídos de acordo com o comportamento real da estrutura. Para a força cortante transversal, no entanto, concentrar os valores torcionais e tomar $D_{y}$ igual a zero implica em forçar as lâminas adjacentes a cisalhar as barras de protensão na vizinhança da ação da carga móvel. Este esforço é exatamente a força cortante $V_{Y}$ que se quer 
determinar. Além disso, a distribuição da carga na placa ortotrópica depende da somatória das rigidezes à torção e não apenas de um valor particular.

\subsubsection{O Método de Cálculo para o Carregamento OHBDC.}

A análise das estruturas é feita com o parâmetro $\beta$ e a força cortante transversal é obtida graficamente. Os valores determinantes de $V_{y}$ são aplicáveis a todos os níveis de avaliação da carga móvel.
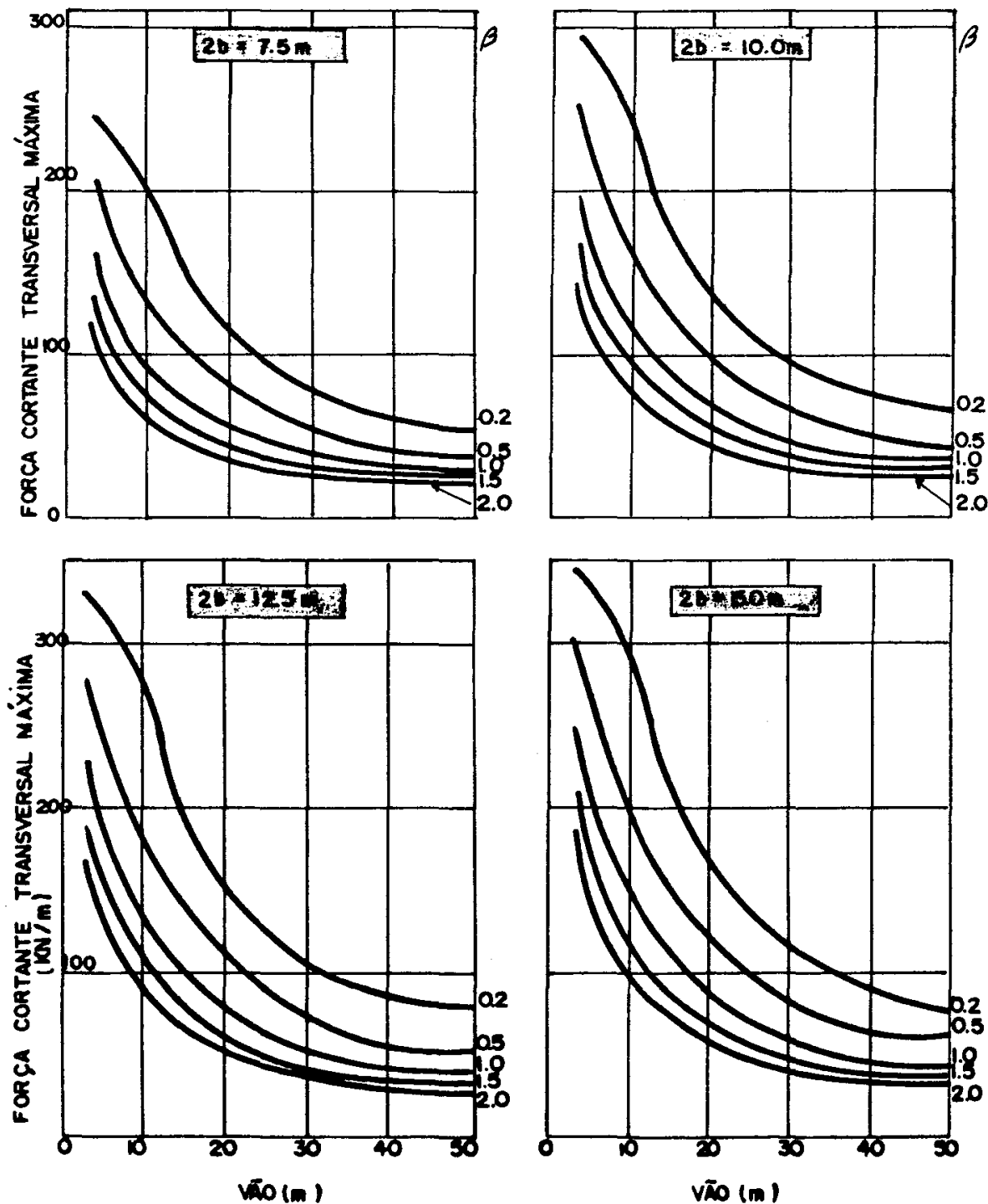

(a) 

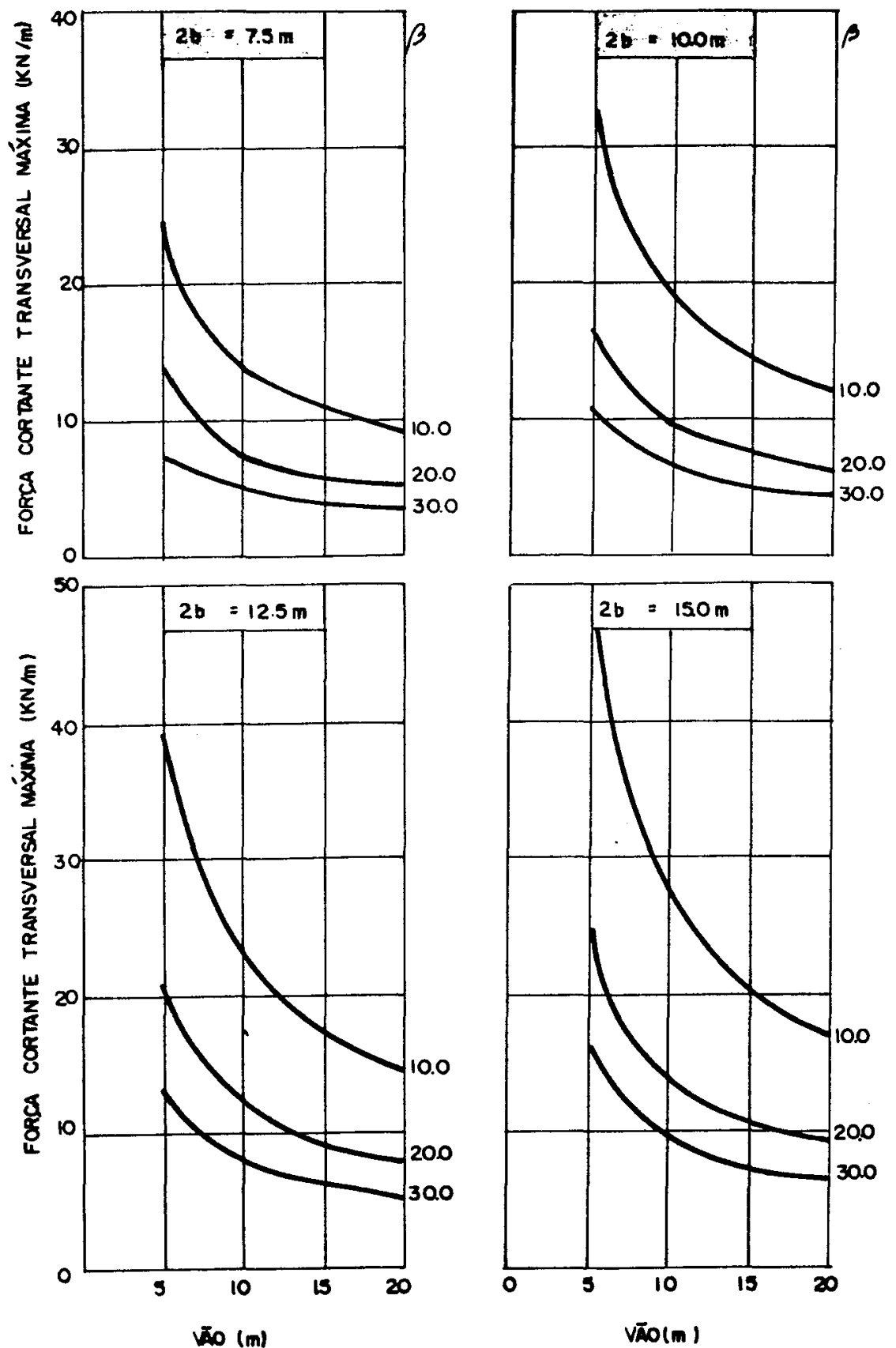

(b)

FIGURA 4.22 - Força cortante transversal máxima nas pontes:

(a) rigidez maior;

(b) rigidez torcional menor. 
Para as pontes de madeira laminadas pregadas, uma observação importante. As pontes em placas compostas de laminações longitudinais de madeira mutuamente pregadas podem ser idealizadas como placas articuladas somente durante os primeiros estágios de sua vida útil, quando a ponte for relativamente nova.

Após tais pontes estarem submetidas ao tráfego de veículos pesados por dois ou três anos, os furos que contêm os pregos alargam-se, permitindo a uma lâmina deslocar-se um pouco, independentemente, antes de influenciar as lâminas adjacentes. $E$ este movimento livre das laminações individuais que tornam impossivel a idealização da estrutura como um meio contínuo simples e portanto como uma placa ortotrópica.

A força cortante transversal estimada pelo método será maior que a real quando o aumento de uso e o alargamento dos furos de pregação aumentarem os deslocamentos livres das laminações longitudinais. 


\section{EXPERIMENTAÇÃO DE PLACAS EM LABORATÓRIO.}

A sistemática de cálculo das pontes em placa foi apresentada no Capítulo anterior, restando apresentar a avaliação realizada em testes de laboratório para dirimir as dúvidas relacionadas com os parâmetros elásticos que se devam empregar no cálculo quando se utiliza uma espécie de madeira local ou crescida no local, embora de origem exótica.

O programa cooperativo conjunto AUSTIM, descrito em 3.3 , já tem diretrizes para a utilização de madeiras importadas de Douglas fir nas pontes a serem construídas na Austrália, mas determina que, para o uso de outras espécies, ensaios especiais devam ser realizados, com as diretrizes de sua realização determinada pela equipe de consultores norte-americanos.

Na Austrália, o uso de madeiras de Dicotiledôneas comprovou perdas muito menores em um prazo de dois anos e meio - um terço das perdas anteriormente determinadas - favorecendo o comportamento de placa como um meio contínuo de resistência às ações externas com um desempenho ainda melhor do que já obtido anteriormente.

A metodologia destes ensaios propostos é a desenvolvida por OLIVA et al. (1990) no Forest Products Laboratory através do ensaio de torção de placa, para que fornecesse os parâmetros necessários ao cálculo das placas protendidas. Esta avaliação é apresentada no ANEXO C. 
Estes ensaios são os mesmos referidos no cálculo das pontes em placa usando-se Douglas Fir no programa cooperativo AUSTIM (RITTER e CREWS, 1991).

No Forest Products Laboratory, em Madison, está se realizando instrumentação de placas pequenas com dimensões reais das laminações, com nivel baixo de tensão residual nas barras de protensão, conforme as indicações de perdas que se descobriu existir nas pontes protendidas construídas com madeiras de coniferas.

Com vista à determinação do comportamento torcional do sistema laminado protendido, utilizando-se madeiras de reflorestamento e crescidas no Brasil, planejou-se o preparo de duas placas protendidas com as dimensões nominais das laminações de madeira de Eucalyptus citriodora de $5,0 \mathrm{~cm} X$ $22,0 \mathrm{~cm}, e$ os comprimentos determinados mantendo compatibilidade geométrica, combinando os dispositivos para ensaio e deformabilidade, com a metodologia proposta e instrumentados em pórticos de reação montados no Laboratório de Madeiras e de Estruturas de Madeira (LaMEM), na Escola de Engenharia de São Carlos, os comprimentos são:

.26 peças de $1,30 \mathrm{~m}$.

.14 peças de $0,50 \mathrm{~m}$.

.12 peças de $1,00 \mathrm{~m}$.

.08 peças de $1,70 \mathrm{~m}$.

.03 peças de $2,00 \mathrm{~m}$.

As duas placas previstas tinham a configuração apresentada nas Figuras 5.1 e 5.2 abaixo. 

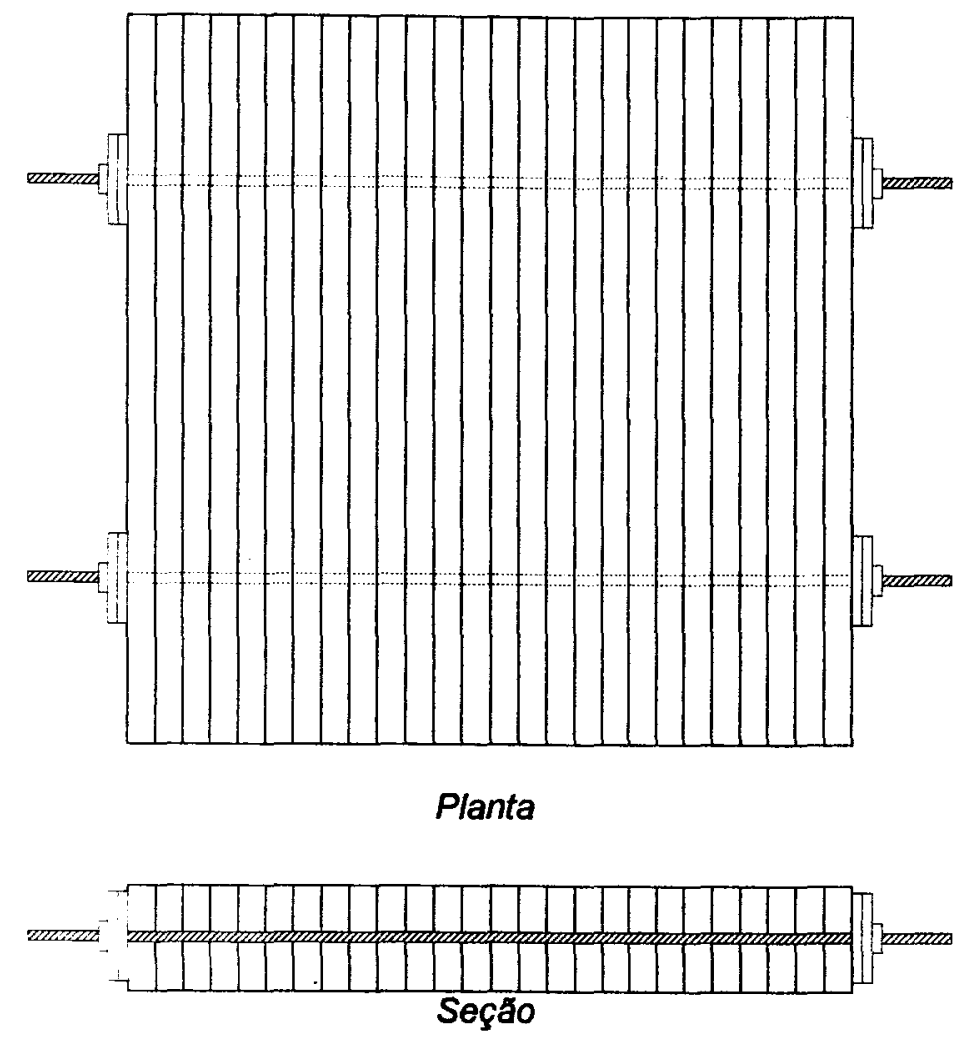

FIGURA 5.1 - Placa protendida para ensaio de torçăo.

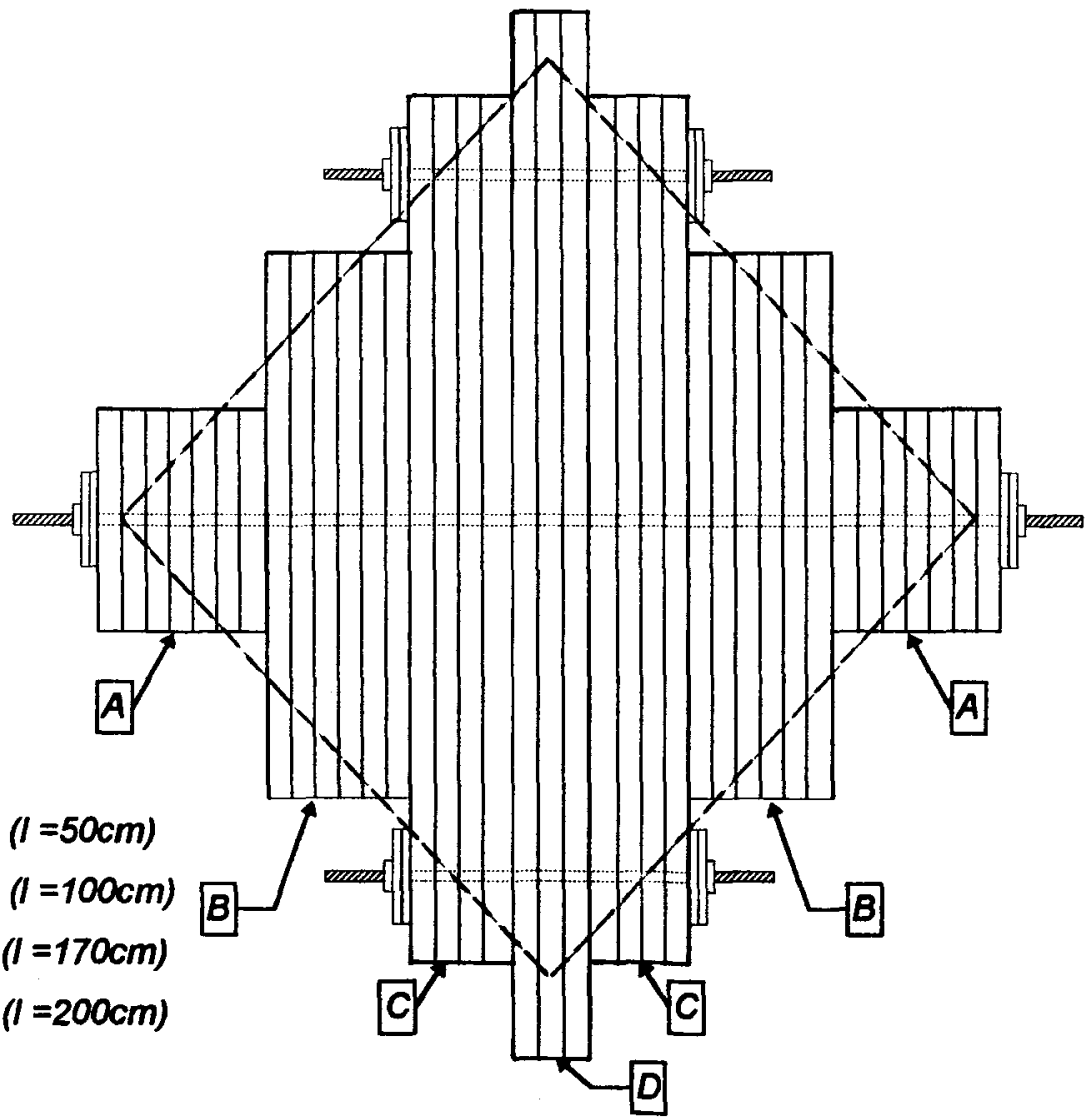

FIGURA 5.2 - Placa protendida para ensaio de torçăo. 


\subsection{INSTRUMENTAÇÃO PRELIMINAR}

Para a caracterização do comportamento do sistema de protensão nas peças de madeira, uma amostra de madeira de $5,0 \mathrm{~cm} \times 22,0 \mathrm{~cm} \times 22,0 \mathrm{~cm}$, com 60 unidades, de Eucalyptus citriodora, foi enviada ao LaMEM, para se detectar a flutuação da força de protensão com o tempo, estando o material confinado e apoiado no solo.

Todas as peças de madeira foram furadas com os furos centrados, de 22 $\mathrm{mm}$ de diâmetro, para que se ajustassem à passagem da barra de tensionamento.

Neste primeiro estágio, utilizou-se uma barra lisa de aço de fabricação mecânica, de $19 \mathrm{~mm}$ de diâmetro e 2,00m de comprimento, com $40 \mathrm{~cm}$ de rosca de passo fino em suas extremidades. Foi instalado o conjunto usandose um cilindro de reação para $50 \mathrm{kN}$, duas células de carga vazadas, uma em cada extremidade, e o aperto das porcas de extremidade foi dado manualmente, conforme o cilindro pressionava as placas de ancoragem, figura 5.3. As forças nas extremidades do conjunto foram lidas no Sistema Kyowa, do LaMEM.

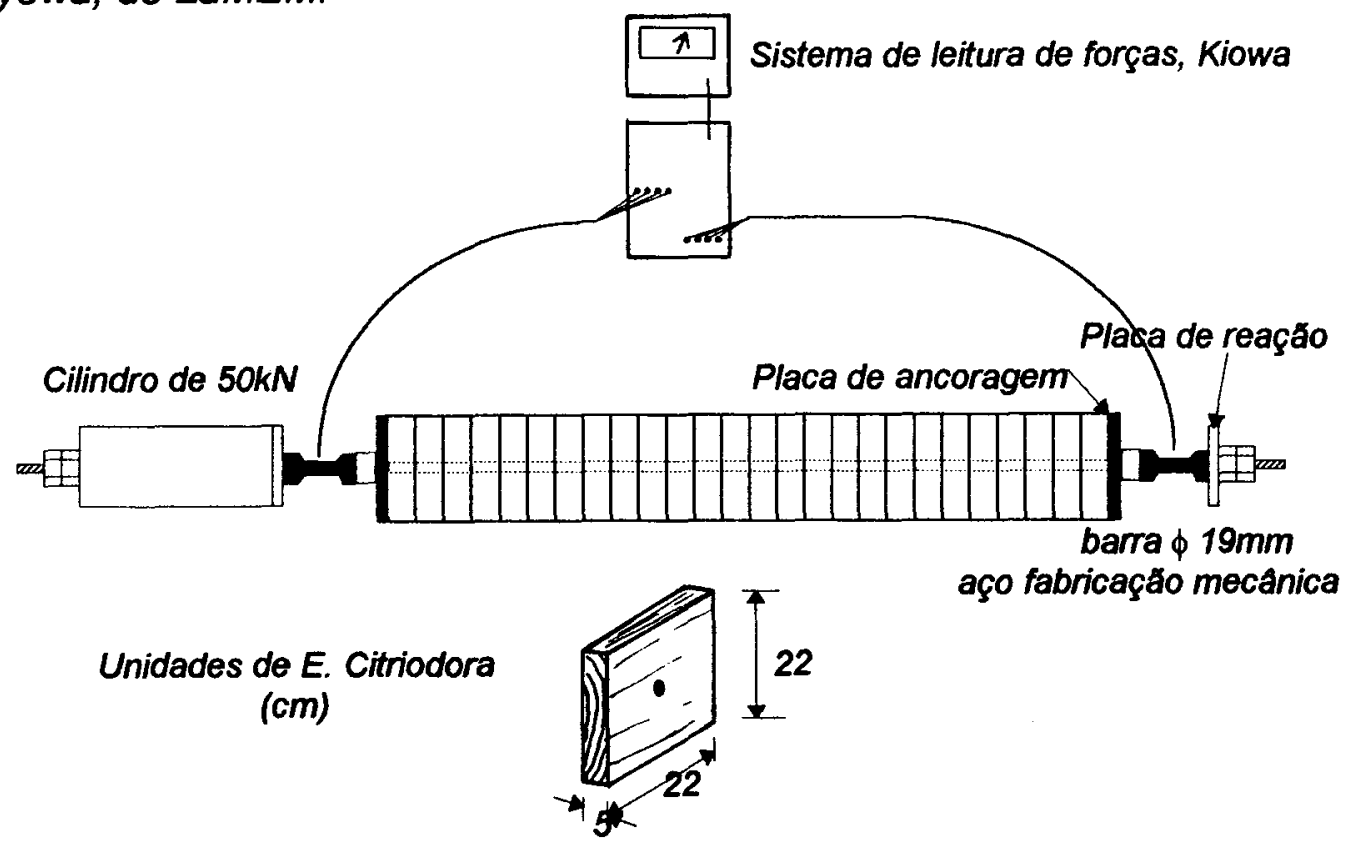

FIGURA 5.3 - Instrumentaçăo Preliminar, Primeira fase. 
Os resultados e os procedimentos de retensionamento estão mostrados na figura 5.4 .

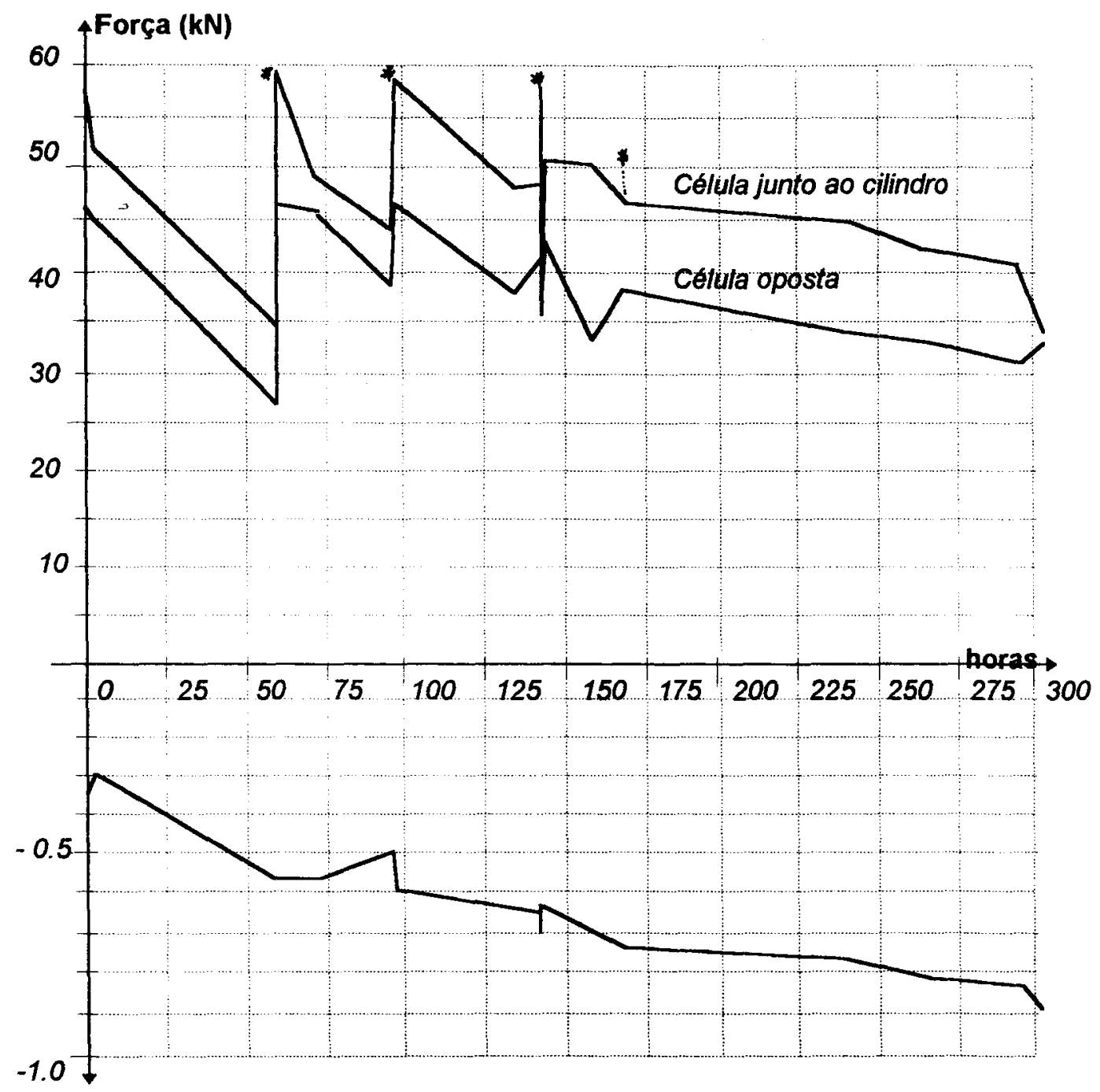

$\Delta(\%)$

FIGURA 5.4 - Primeiros resultados de laboratório.

As dificuldades operacionais, decorrentes do baixo nivel de tensionamento alcançado e do grande esforço braçal demandado, mais a recorrente plastificação da rosca dabarra de tensionamento e a grande fluência do sistema - a interação de fenômeno de fluência da madeira confinada com a rápida perda de umidade, encurtando o conjunto - fizeram com que se buscasse efetivamente as soluções de projeto, visando oferecer subsídios à construção de estruturas-protótipo em um futuro próximo. 
Como já se havia planejado construir as placas para ensaio em Laboratório, aproveitou-se uma das barras de protensão destinadas à placa $A B C D$ para a realização deste ensaio preliminar. Empregando o material já fornecido e já pré-furado, disponivel no Laboratório, repetiu-se a instrumentação, porém, com as proporções e o esforço total dado no equipamento de protensão igual ao previsto para a estrutura-protótipo.

É importante notar como medida restritiva à plena equivalência desta instrumentação, que as peças de madeira fornecidas não possuíam qualquer tratamento preservativo. O fornecedor contactado pelo LaMEM, mediante Convênio, foi a empresa Prema S.A., de Rio Claro.

Os resultados obtidos são mostrados na Figura 5.5.

PROTENSÃO TRANSVERSAL - PERDAS

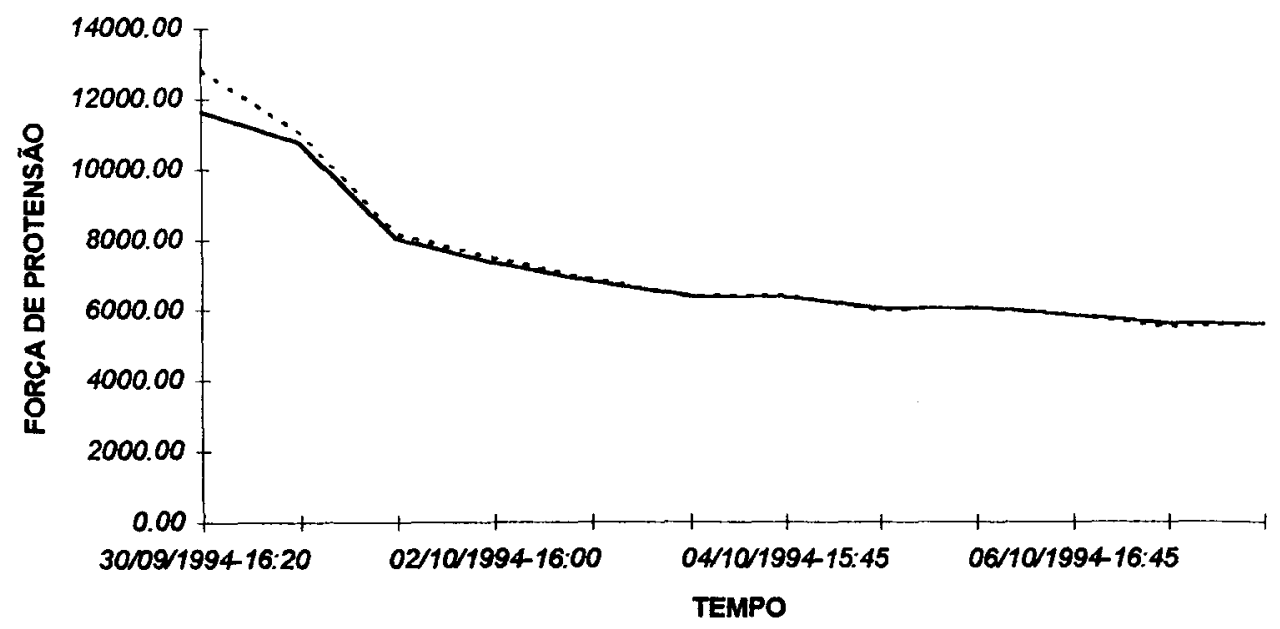

FIGURA 5.5 - Resultados experimentais; protensăo de 150 kN. 


\subsection{ENSAIO DAS PLACAS}

Para este ensaio foram utilizados as seguintes quantidades de peças :

.+. 18 unidades de $4,91 \mathrm{~cm} \times 21,77 \mathrm{~cm} \times 51,08 \mathrm{~cm}$, designadas pela letra A.

.+. 12 unidades de $5,58 \mathrm{~cm} \times 21,40 \mathrm{~cm} \times 101,48 \mathrm{~cm}$, designadas pela letra $B$.

.+08 unidades de $5,96 \mathrm{~cm} \times 21,71 \mathrm{~cm} \times 171,39 \mathrm{~cm}$, designadas pela letra $\mathrm{C}$.

.+. 03 unidades de $6,03 \mathrm{~cm} \times 21,63 \mathrm{~cm} \times 201,87 \mathrm{~cm}$, designadas pela letra $D$.

.+. 26 unidades de $5,36 \mathrm{~cm} \times 21,65 \mathrm{~cm} \times 131,28 \mathrm{~cm}$, designadas pela letra E.

As placas foram montadas conforme mostrado nas figuras 5.6 e 5.7 .
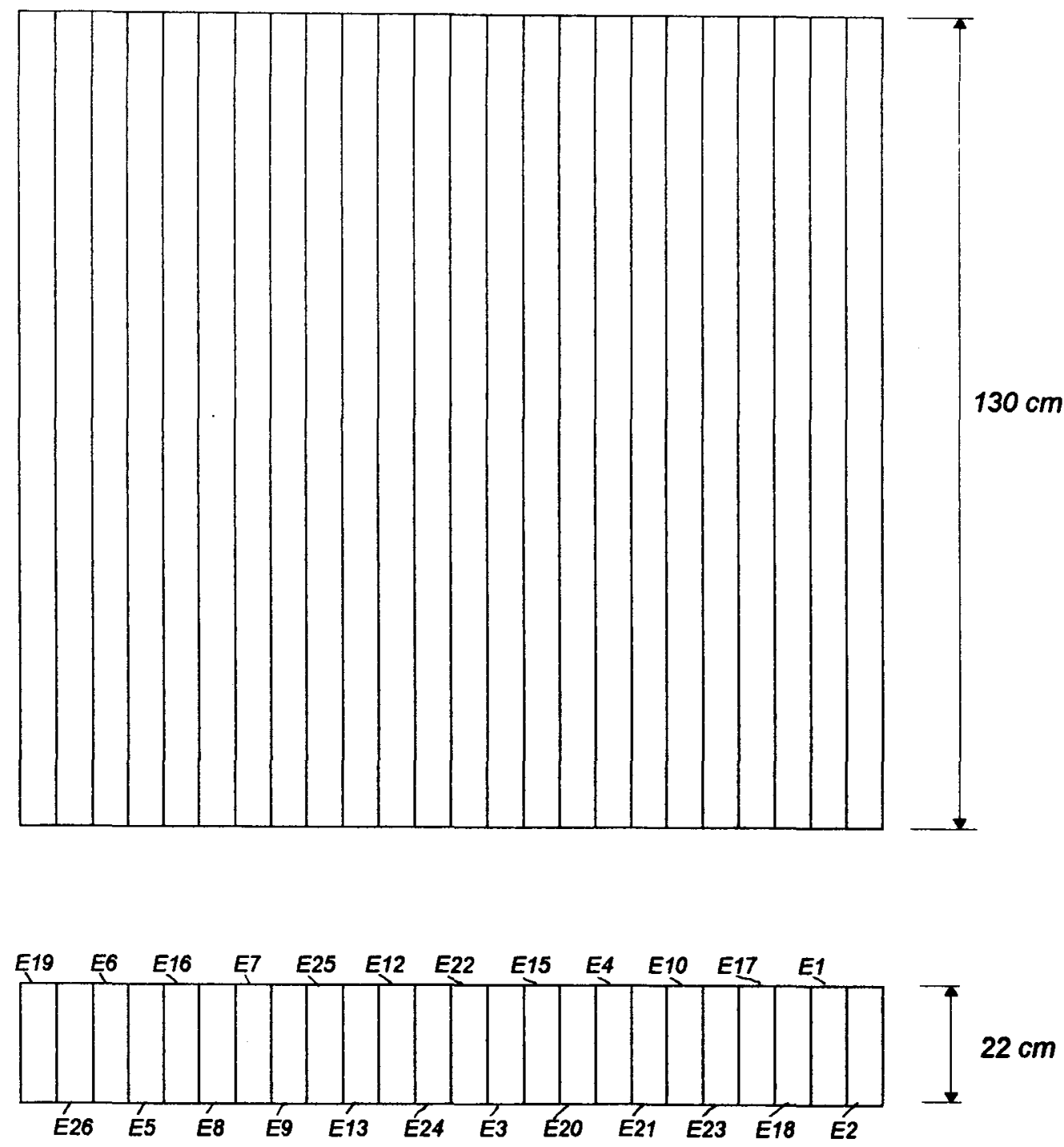


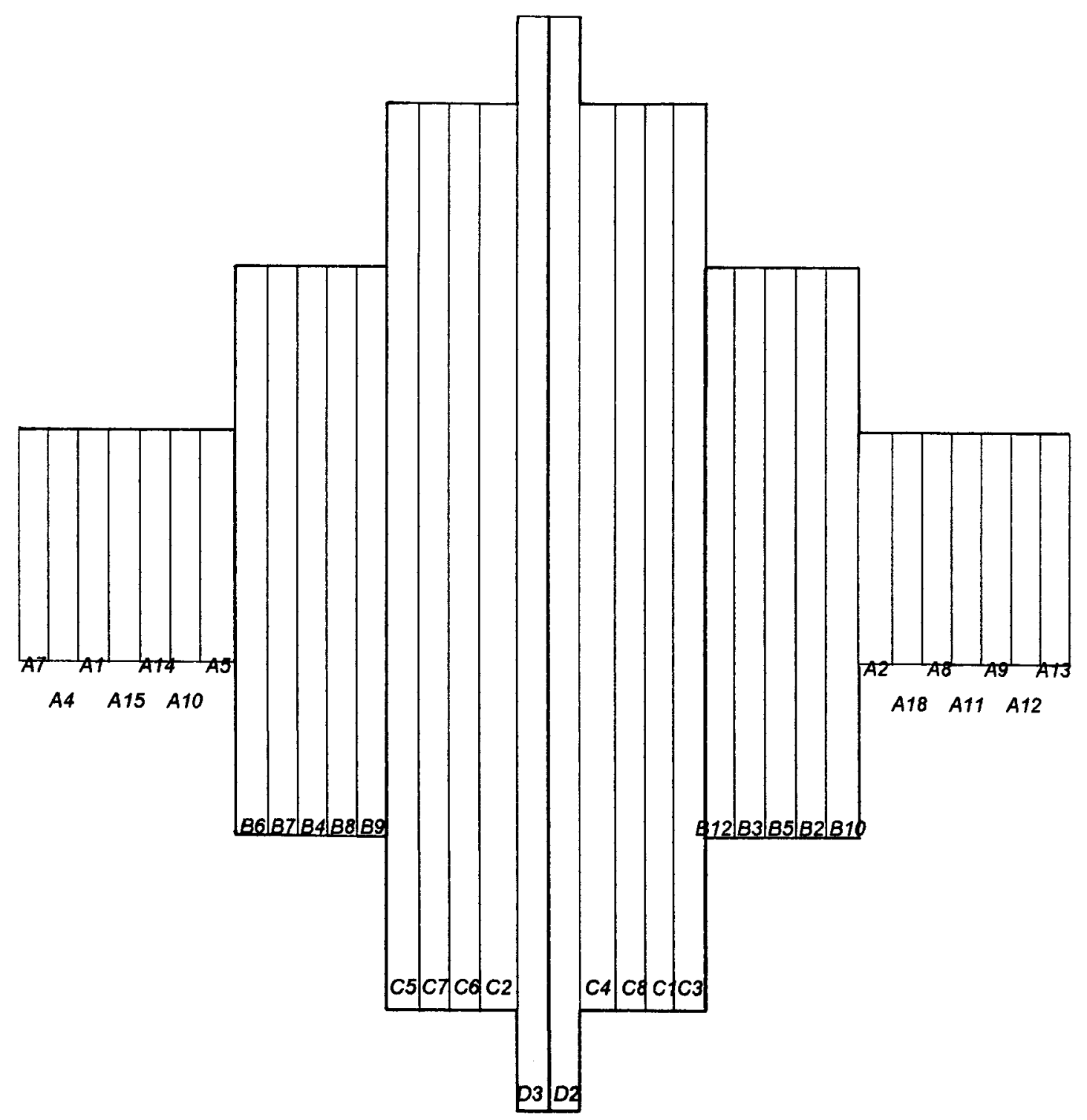

FIGURA 5.7 - Placa ABCD montada. 
As barras de protensão foram enviadas ao LaMEM pela Protendidos Dywidag do Brasil Ltda., juntamente com um cilindro hidráulico para protensão, porcas e placas especiais de ancoragem, luva de extensão e chave de catraca e aperto para trabalho local da protensão. Uma bomba manual, para até $600 \mathrm{kgf} / \mathrm{cm} 2$, foi cedida ao LaMEM pelo SET, Laboratório de Estruturas de Concreto, para a experimentação.

Todas as peças requisitadas para a montagem das placas a ensaiar foram classificadas, através de um ensaio de flexão simples, com a maior dimensão da seção transversal disposta na horizontal e o vão de ensaio da peça simplesmente apoiada igual ao seu comprimento menos dez centímetros. Os resultados desta classificação estão apresentados na Tabela 5.1.

TABELA 5.1 - RESULTADOS DA CLASSIFICAÇÃO POR FLEXÃO.

\begin{tabular}{ccccc}
\hline GRUPO & $N$ & $\begin{array}{c}E_{M} \\
\mathrm{kN} / \mathrm{cm}^{2}\end{array}$ & $\begin{array}{c}\mathrm{s} \\
\mathrm{kN} / \mathrm{cm}^{2}\end{array}$ & $\begin{array}{c}\text { Coef. Variação }\left(\mathrm{s} / \mathrm{E}_{M}\right) \\
\%\end{array}$ \\
\hline$A$ & 14 & 1020 & 205 & 20,1 \\
\hline$B$ & 12 & 1785 & 142 & 7,9 \\
\hline$C$ & 8 & 1961 & 306 & 15,6 \\
\hline$D$ & 2 & 2012 & 79 & 3,9 \\
\hline$E$ & 24 & 1713 & 320 & 18,7 \\
\hline$A B C D$ & 36 & 1539 & 470 & 30,5 \\
\hline
\end{tabular}

"OBS: As peças foram classificadas e os módulos comigidos săo apresentados.

Deve-se ressaltar que todas as peças classificadas já estavam com as furações feitas, levando os resultados obtidos diretamente à sua aplicação final e sua posição na placa. As laminaçőes não foram aparelhadas em nenhuma das medidas fornecidas, para que se tivesse reprodução das condiçōes definitivas de implantação e das dificuldades construtivas decorrentes, por um lado; para que se pudesse verificar um atrito lateral maior, tendo as superfícies maior rugosidade e imbricaçס̃es, por outro lado. 


\subsubsection{O ensaio de Torção de placas}

Uma placa ortotrópica, quadrada, sujeita à vinculação em apoios unitários (puntuais) em uma diagonal e submetida ao carregamento na extremidade da outra diagonal (Figura 5.8a) tem a relação tensorial:

$$
\left[\begin{array}{l}
\varepsilon_{x} \\
\varepsilon_{y} \\
\gamma_{x y}
\end{array}\right]=\left[\begin{array}{ccc}
S_{11} & S_{12} & 0 \\
S_{21} & S_{22} & 0 \\
0 & 0 & S_{66}
\end{array}\right] \cdot\left[\begin{array}{l}
\sigma_{x} \\
\sigma_{y} \\
\tau_{x y}
\end{array}\right]
$$

Se a direção dos eixos centrais da placa diferir de um ângulo a dos eixos de anisotropia do material, pode-se colocar os parâmetros tensoriais em função da relação [5.1], segundo RIBEIRO (1986):

$$
\begin{aligned}
& S_{11}^{\prime}=S_{11} m^{4}+\left(2 S_{12}+S_{66}\right) m^{2} n^{2}+S_{22} n^{4} \\
& S_{22}^{\prime}=S_{11} n^{4}+\left(2 S_{12}+S_{66}\right) m^{2} n^{2}+S_{22} m^{4} \\
& S_{12}^{\prime}=\left(S_{11}+S_{22}-S_{66}\right) m^{2} n^{2}+S_{12}\left(m^{4}+n^{4}\right) \\
& S_{16}^{\prime}=m n\left[2 S_{22} n^{2}-2 S_{11} m^{2}+\left(2 S_{12}+S_{66}\right)\left(m^{2}+n^{2}\right)\right] \\
& S_{26}^{\prime}=m n\left[2 S_{22} m^{2}-2 S_{11} n^{2}-\left(2 S_{12}+S_{66}\right)\left(m^{2}-n^{2}\right)\right] \\
& S_{66}^{\prime}=4\left(S_{11}+S_{22}-2 S_{12}\right) m^{2} n^{2}+S_{66}\left(m^{4}-n^{4}\right)^{2} \\
& m=\cos (\alpha) \quad ; \quad n=\operatorname{sen}(\alpha) ;
\end{aligned}
$$

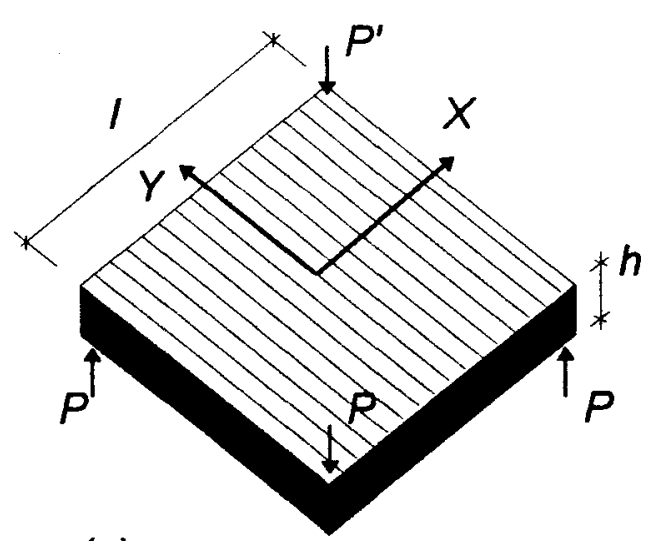

(a)

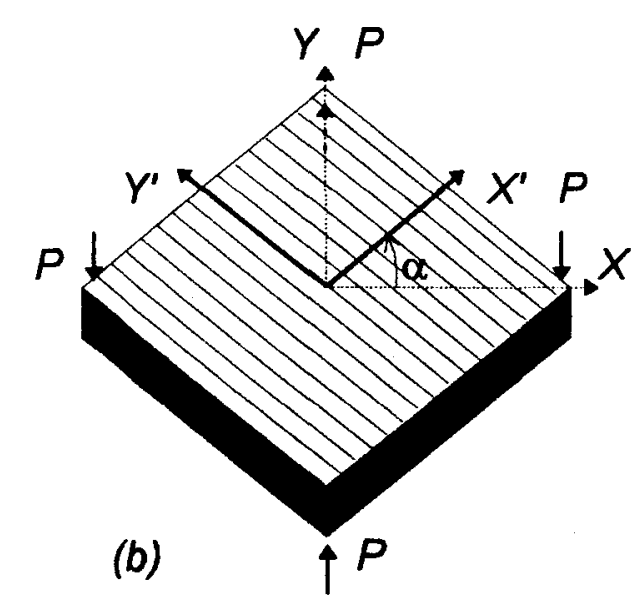

(b)

FIGURA 5.8 - Placa ortotrópica, quadrada, ensaio de torçăo:
(a) Placa $0^{\circ}$
(b) Placa $+45^{\circ}$ 
A equação que relaciona a elástica da placa, $w\left(x^{\prime}, y^{\prime}\right)$, com os parâmetros relacionados em [5.2]; carregamento indicado na figura 5.8b, é:

$W=-\frac{1}{h^{3}}\left[3 \cdot P\left(S_{16}^{\prime} \cdot x^{\prime 2}+S_{26}^{\prime} \cdot y^{\prime 2}+S_{66}^{\prime} \cdot x^{\prime} \cdot y^{\prime}\right)+a \cdot x^{\prime}+b \cdot y^{\prime}+c\right]$

As condições necessárias para se determinar $a, b, c$ são:

$x^{\prime}=-1 / 2 ; \quad y^{\prime}=-1 / 2 ; \quad w\left(x^{\prime}, y^{\prime}\right)=0$

$x^{\prime}=+1 / 2 ; \quad y^{\prime}=+1 / 2 ; \quad w\left(x^{\prime}, y^{\prime}\right)=0$

Compatibilidade: $a=-b$

Resolvendo [5.3] nas condições [5.4] se tem:

$$
\begin{array}{ll}
a=-\frac{3 \cdot P \cdot 1 \cdot S_{66}^{\prime}}{2} & b=\frac{3 \cdot P \cdot 1 \cdot S_{66}^{\prime}}{2} \\
c=-\frac{3}{4} P \cdot l^{2} \cdot\left(S_{16}^{\prime}+S_{26}^{\prime}+S_{66}^{\prime}\right) &
\end{array}
$$

Assim a equação [5.3] é reescrita:

$$
\begin{aligned}
W=-\frac{1}{h^{3}} & \mid 3 \cdot P\left(S_{16}^{\prime} \cdot x^{\prime 2}+S_{26}^{\prime} \cdot y^{\prime 2}+S_{66}^{\prime} \cdot x^{\prime} \cdot y^{\prime}\right)+\frac{3 \cdot P \cdot I \cdot S_{66}^{\prime}}{2}\left(y^{\prime}-x^{\prime}\right)- \\
& \frac{3 \cdot P \cdot l^{2}}{4}\left(S_{16}^{\prime}+S_{26}^{\prime}+S_{66}^{\prime}\right) \mid
\end{aligned}
$$

No centro da placa:

$w=\frac{3 \cdot P \cdot l^{2}}{4 h^{3}}\left(S_{16}^{\prime}+S_{26}^{\prime}+S_{66}^{\prime}\right)=w_{0}$

Reunindo os termos, $\quad S_{t}=S_{16}^{\prime}+S_{26}^{\prime}+S_{66}^{\prime}$ 
$E: \quad S_{t}=\frac{4 \cdot h^{3} \cdot W_{0}}{3 \cdot P \cdot l^{2}}$

Utilizando [5.8] nos termos de [5.2]:

$S_{16}^{\prime}+S_{26}^{\prime}+S_{66}^{\prime}=m n\left[2 S_{22}^{\prime}\left(m^{2}+n^{2}\right)-2 S_{11}^{\prime}\left(m^{2}+n^{2}\right)+\left(2 S_{12}^{\prime}+S_{66}^{\prime}\right) 2 n^{2}\right]+$ $+\left(4 S^{\prime}{ }_{11}+4 S^{\prime}{ }_{22}-8 S^{\prime}{ }_{12}\right) m^{2} n^{2}+S_{66}^{\prime}\left(m^{2}-n^{2}\right)^{2}$

$S_{t}=2 m n(m-n)^{2} S_{11}^{\prime}-8 m^{2} n^{2} S_{12}^{\prime}+2 m n(m+n)^{2} S_{22}^{\prime}+\left(m^{2}-n^{2}\right)^{2} S_{66}^{\prime}$

Para $\alpha=0^{\circ}, \quad m=\cos \left(0^{\circ}\right)=1$ e $n=\operatorname{sen}\left(0^{\circ}\right)=0$. Então:

$S_{t, 0}=S_{66}=\frac{1}{G_{x y}}$

Para $\alpha=+45^{\circ}, \quad m=\cos \left(45^{\circ}\right)=\sqrt{2} / 2$ e $n=\operatorname{sen}\left(45^{\circ}\right)=\sqrt{2} / 2$. Então:

$S_{t, 45}=2\left(S_{22}-S_{12}\right)$

Para $\alpha=-45^{\circ}, \quad m=\cos \left(-45^{\circ}\right)=\sqrt{2} / 2$ e $n=\operatorname{sen}\left(-45^{\circ}\right)=-\sqrt{2} / 2$. Então:

$S_{t,-45}=2\left(S_{11}-S_{12}\right)$

Então, usando-se os valores de $S_{t}$, pode-se medir a flecha no canto carregado, onde $x^{\prime}=1 / 2$ e $y^{\prime}=-1 / 2$, $\left(\right.$ se $\left.\alpha= \pm 45^{\circ}\right)$, ou $x=1 / 2\left(\alpha=0^{\circ}\right)$. Neste caso, $w=\frac{3 \cdot P \cdot l^{2} \cdot S_{t}}{h^{3}}$

ou:

$$
S_{t}=\frac{h^{3} \cdot w}{3 \cdot P \cdot l^{2}}
$$


$\frac{h^{3} \cdot W}{3 \cdot P \cdot l^{2}}=S_{66} \quad, \alpha=0^{\circ}$

$\frac{h^{3} \cdot W}{3 \cdot P \cdot l^{2}}=2\left(S_{22}-S_{12}\right) \quad, \alpha=+45^{\circ}$

$\frac{h^{3} \cdot W}{3 \cdot P \cdot l^{2}}=2\left(S_{11}-S_{12}\right) \quad, \alpha=-45^{\circ}$

As equações [5.13] mostram as relações que se devem utilizar na obtenção dos parâmentros procurados através do ensaio de torção de placas, de onde se poderá obter:
$S_{11}=\frac{1}{E_{x}}$
$S_{22}=\frac{1}{E_{y}}$
$S_{12}=-\frac{\nu_{x y}}{E_{x}}$
$S_{21}=-\frac{\nu_{y x}}{E_{y}}$
$S_{12}=S_{21}$
$S_{66}=\frac{1}{G_{x y}}$

\subsubsection{Ensaio da placa $0^{\circ}$}

A placa ortotrópica analisada (Figura 5.5) foi montada peça a peça com barras de tensionamento funcionando como guias. As peças foram tomadas ao acaso para a montagem, como arranjo geral que se faz em canteiro de obra. As larguras medidas estão na Tabela 5.2.

TABELA 5.2 - LARGURAS MEDIDAS DA PLACA $0^{\circ}$

\begin{tabular}{lll}
\hline Montagem: & $130.5 \mathrm{~cm}$ & Variação \\
\hline $1^{\circ}$ Tensionamento: & $129.3 \mathrm{~cm}$ & $-0.97 \%$ \\
\hline Após Acomodação: & $128.9 \mathrm{~cm}$ & $-1.28 \%$ \\
\hline $2^{\circ}$ Tensionamento: & $128.8 \mathrm{~cm}$ & $-1.30 \%$ \\
\hline Teor de Umidade: & $20.41 \%$ & \\
\hline
\end{tabular}


Os arranjos de carga e leitura dos deslocamentos, disposição dos apoios são conforme ilustrados na Figura 5.8a e nas Figuras 5.9 e 5.10.

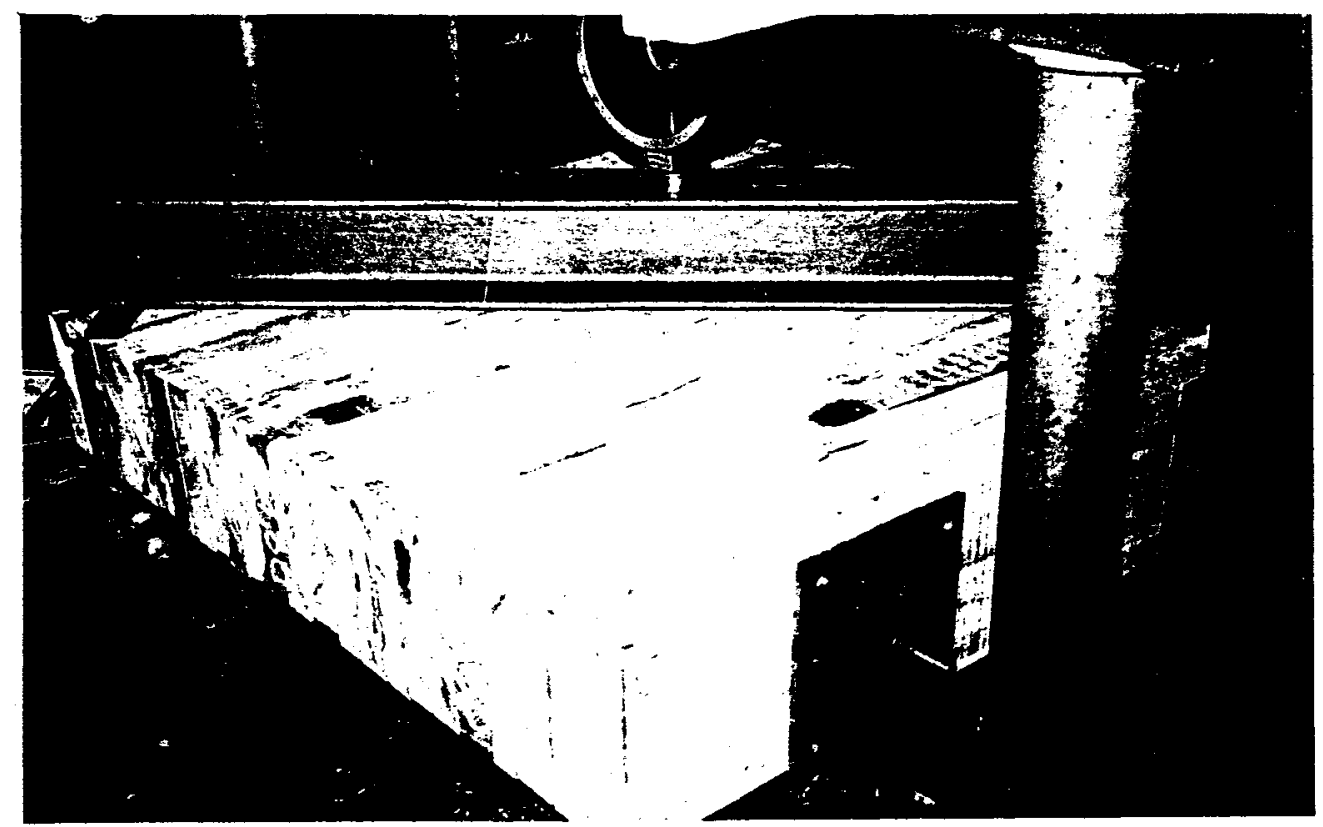

FIGURA 5.9 - Disposiçăo de Carregamento na Placa $0^{\circ}$. 


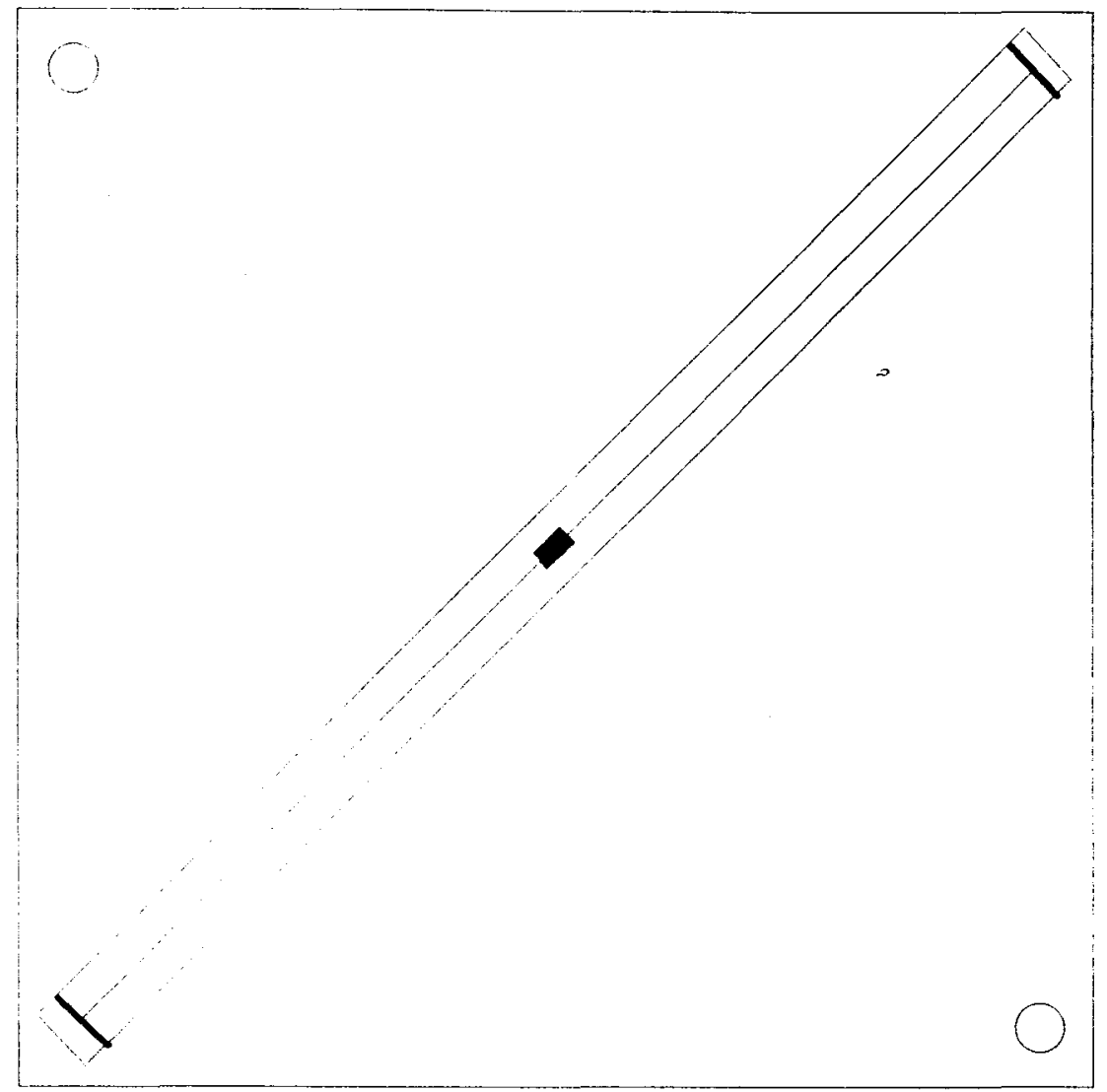

Planta

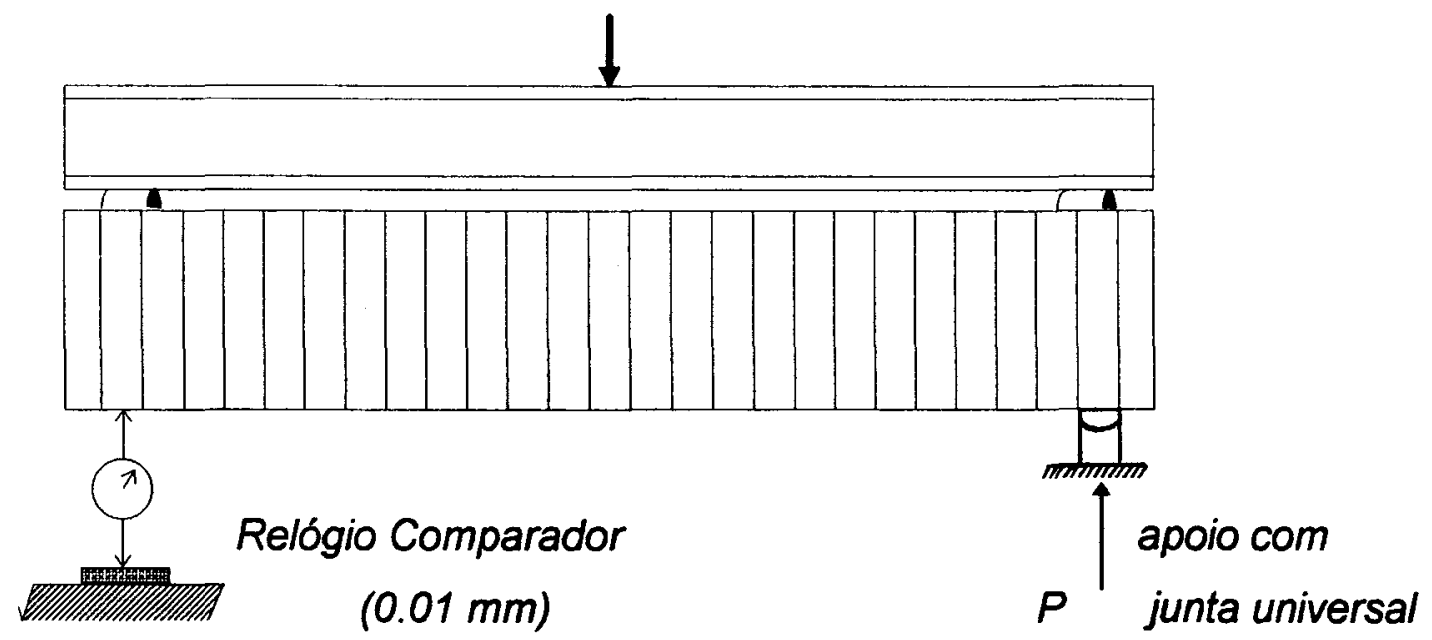

Elevação 


\subsubsection{Ensaio da placa $+/-45^{\circ}$}

Com critério semelhante, a montagem da placa $+/ 45^{\circ}$ foi realizada rapidamente (cerca de 40 minutos), içada e ensaiada (Figuras 5.11 e 5.12).

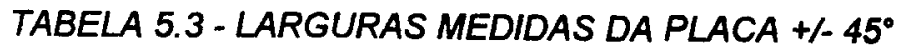

\begin{tabular}{lll}
\hline Montagem: & $187.1 \mathrm{~cm}$ & Vabiação \\
\hline $1^{\circ}$ Tensionamento: & $186.0 \mathrm{~cm}$ & $-0.59 \%$ \\
\hline $2^{\circ}$ Tensionamento: & $184.2 \mathrm{~cm}$ & $-1.55 \%$ \\
\hline Teor de umidade: & $20.67 \%$ & \\
\hline
\end{tabular}

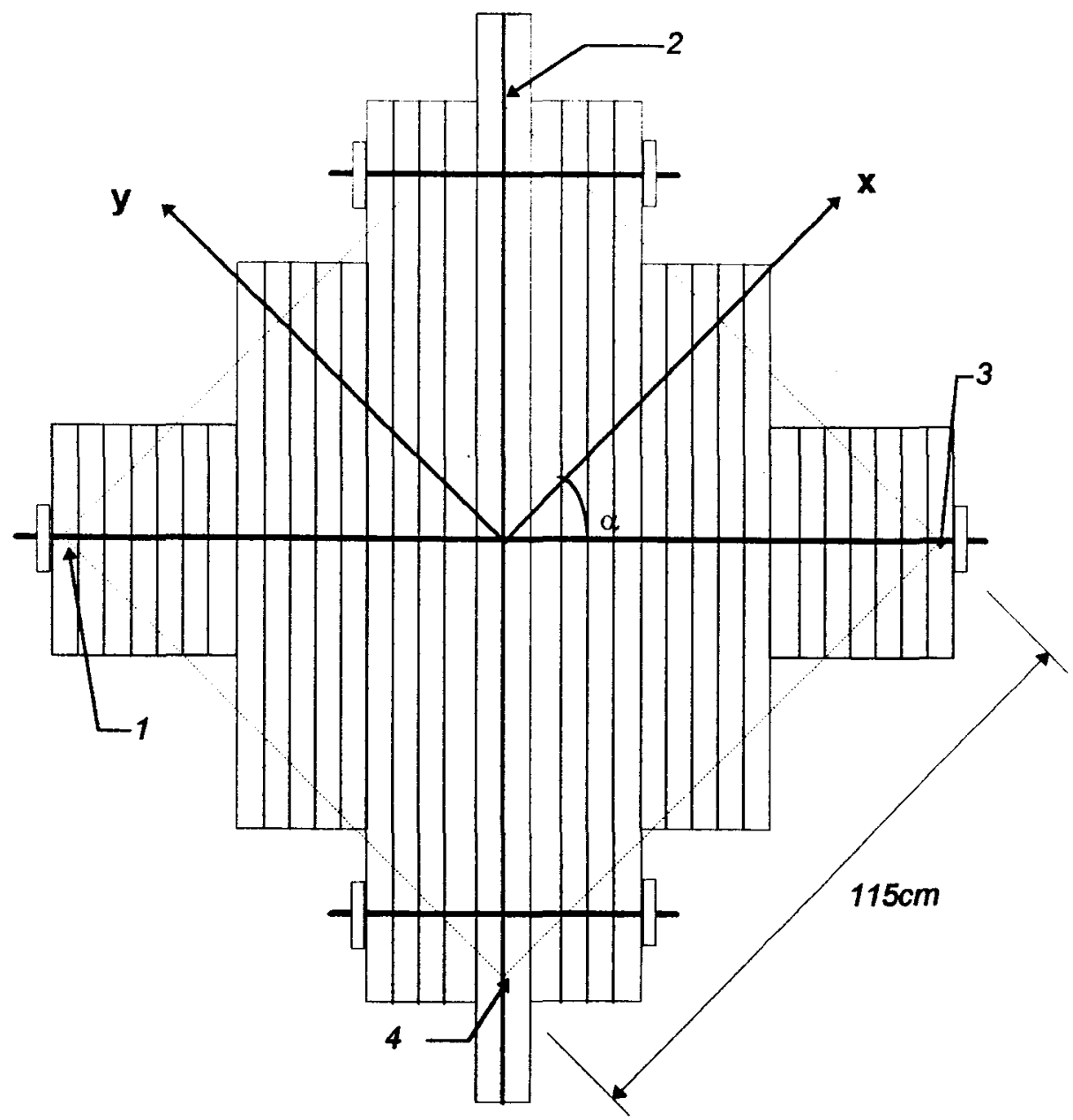

Carregamento em 1 e 3, apoio em 2 e 4: Placa $-45^{\circ}$ Carregamento em 2 e 4, apoio em 1 e 3: Placa $-45^{\circ}$ 


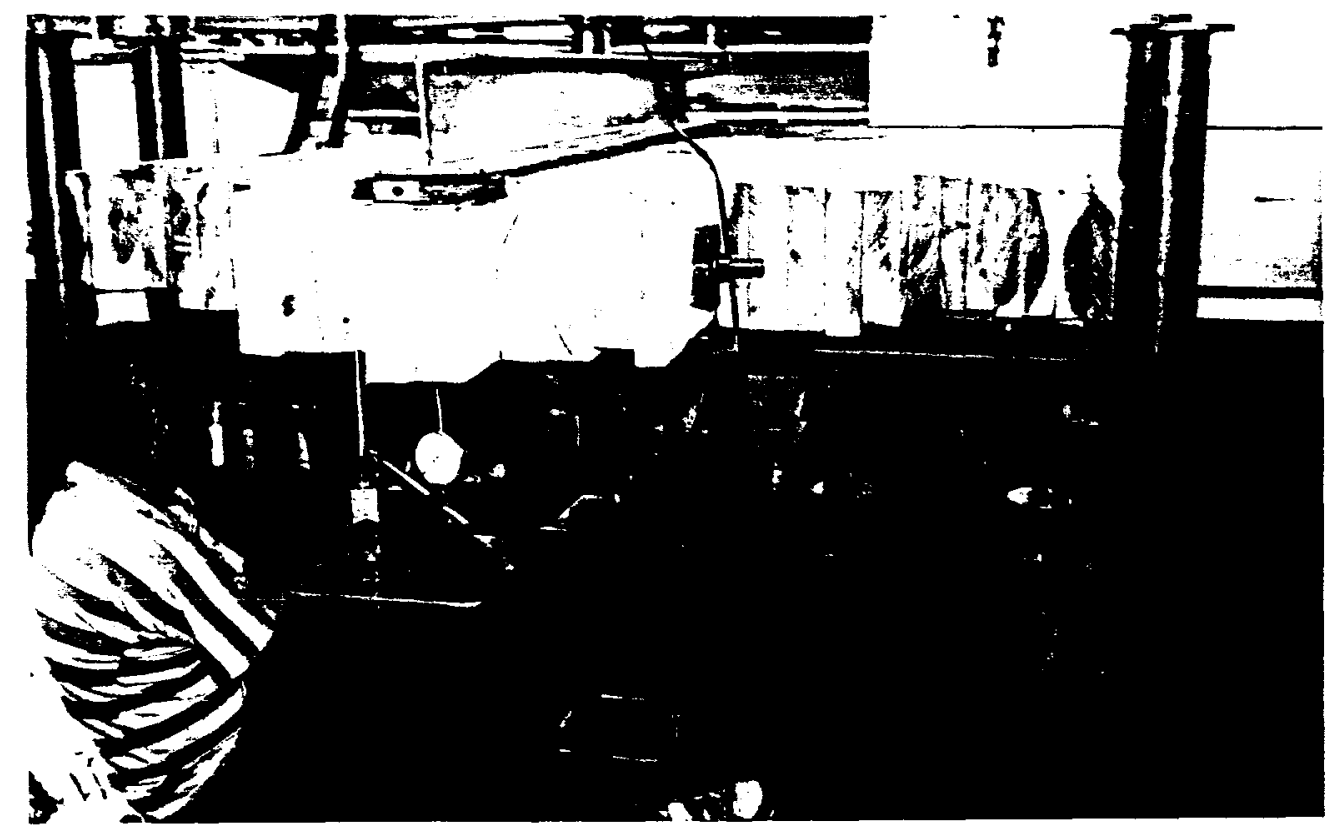

FIGURA 5.12 - Arranjo das peças, placa + 45․

\subsection{RESULTADOS DOS ENSAIOS.}

TABELA 5.4 - Resultados de Ensaios - Placa $0^{\circ}$.

\begin{tabular}{cccccc}
\hline ENSAIO & $\begin{array}{c}P_{\max } \\
(\mathrm{kN})\end{array}$ & $\begin{array}{c}w_{\operatorname{máx}} \\
(\mathrm{cm})\end{array}$ & Correlação & $\begin{array}{c}\text { Coef. Angular } \\
m\end{array}$ & $\begin{array}{c}S_{t} \\
\left(\mathrm{~cm}^{2} / \mathrm{kN}\right)\end{array}$ \\
\hline $0-1$ & 19.39 & 1.065 & 0.99594 & 17.00725 & 0.01428 \\
\hline $0-2$ & 17.77 & 0.925 & 0.99719 & 17.67236 & 0.01375 \\
\hline $0-3$ & 17.77 & 0.765 & 0.99771 & 19.89316 & 0.01221 \\
\hline $0-4$ & 19.39 & 0.968 & 0.99365 & 18.98953 & 0.01279 \\
\hline Média & & & & & 0.01326 \\
\hline
\end{tabular}

TABELA 5.5 - Resultados de Ensaios - Placa $-45^{\circ}$.

\begin{tabular}{cccccc}
\hline ENSAIO & $\begin{array}{c}P_{\max } \\
(\mathrm{kN})\end{array}$ & $\begin{array}{c}W_{\max } \\
(\mathrm{cm})\end{array}$ & Correlação & $\begin{array}{c}\text { Coef. Angular } \\
\mathrm{m}\end{array}$ & $\begin{array}{c}\mathrm{S}_{\mathrm{t}} \\
\left(\mathrm{cm}^{2} / \mathrm{kN}\right)\end{array}$ \\
\hline $1-1$ & 15.595 & 1.025 & 0.9553 & 15.7073 & 0.01627 \\
\hline $1-2$ & 15.595 & 0.833 & 0.9832 & 12.8427 & 0.01990 \\
\hline $1-3$ & 18.714 & 1.005 & 0.9907 & 13.5238 & 0.01890 \\
\hline $1-4$ & 18.714 & 0.925 & 0.9707 & 17.3625 & 0.01472 \\
\hline Média & & & & & 0.01745 \\
\hline
\end{tabular}


TABELA 5. 6 - Resultados de Ensaios - Placa +45

\begin{tabular}{cccccc}
\hline ENSAIO & $\begin{array}{c}P_{\max } \\
(\mathrm{kN})\end{array}$ & $\begin{array}{c}w_{\operatorname{máx}} \\
(\mathrm{cm})\end{array}$ & Correlação & $\begin{array}{c}\text { Coef. Angular } \\
\mathrm{m}\end{array}$ & $\begin{array}{c}\mathrm{S}_{t} \\
\left(\mathrm{~cm}^{2} / \mathrm{kN}\right)\end{array}$ \\
\hline$I I-1$ & 14.0355 & 0.841 & 0.9934 & 16.2724 & 0.01571 \\
\hline$I I-2$ & 18.714 & 1.284 & 0.9972 & 14.3858 & 0.01777 \\
\hline$I I-3$ & 18.314 & 1.255 & 0.9976 & 14.0403 & 0.01820 \\
\hline$I I-4$ & 18.714 & 1.225 & 0.9958 & 13.8967 & 0.01839 \\
\hline Média & & & & & 0.01752 \\
\hline
\end{tabular}

Usando as Equações [5.13], tem-se:
$\alpha=0^{\circ}$
$S_{t}=S_{66}=\frac{1}{G_{x y}}$
$\alpha=-45^{\circ}$
$S_{t}=2 \cdot\left(S_{11}-S_{21}\right)=2 \cdot\left[\frac{1}{E_{x}}-\frac{\nu_{y x}}{E_{y}}\right]$
$\alpha=+45^{\circ}$
$S_{t}=2 \cdot\left(S_{22}-S_{12}\right)=2 \cdot\left[\frac{1}{E_{y}}-\frac{\nu_{x y}}{E_{x}}\right]$

Da tabela 5.4,

$$
\begin{aligned}
& S_{t}=0.01326=\frac{1}{G_{x y}} \\
& G_{x y}=75.415 \mathrm{kN} / \mathrm{cm}^{2}
\end{aligned}
$$

Da tabela 5.5,

$$
S_{t}=0.01745=2 \cdot\left[\frac{1}{E_{x}}-\frac{\nu_{y x}}{E_{y}}\right]
$$

Da tabela 5.1,

$$
\begin{aligned}
& E_{X}=E_{M}(A B C D)=1539 \mathrm{kN} / \mathrm{cm}^{2} \\
& \frac{0.01745}{2}=\left[\frac{1}{1539}-\frac{\nu_{\mathrm{yx}}}{\mathrm{E}_{\mathrm{y}}}\right] \\
& \frac{\nu_{\mathrm{yx}}}{\mathrm{E}_{\mathrm{y}}}=0.009375
\end{aligned}
$$


Lembrando que:

$$
\frac{\nu_{y x}}{E_{y}}=\frac{\nu_{x y}}{E_{x}} \quad\left(\text { de } S_{21}=S_{12}\right)
$$

e, da tabela 5.6,

$$
\begin{aligned}
& S_{t}=0.01752=2 \cdot\left[\frac{1}{E_{y}}-\frac{\nu_{x y}}{E_{x}}\right] \\
& \frac{0.01752}{2}=\frac{1}{E_{y}}-0.009375 \\
& E_{y}=55,143 \mathrm{kN} / \mathrm{cm}^{2} \\
& v_{x y}=-0,516
\end{aligned}
$$

Os parâmetros determinados equivalem a:

$$
\begin{aligned}
& G_{L T}=0,049 E_{L} \\
& E_{T}=0,036 E_{L} \\
& v=-0,516
\end{aligned}
$$

No Forest Products Laboratory determinou-se, para níveis baixos de protensão:

$$
\begin{aligned}
& G_{L T}=0,012 E_{L} \\
& E_{T}=0,011 E_{L}
\end{aligned}
$$

Na Queen's University:

$$
\begin{aligned}
& G_{L T}=0,03 E_{L} \\
& E_{T}=0,02 E_{L}
\end{aligned}
$$

Ambos os estudos usaram Douglas Fir nas suas determinações. O nivel de tensão de confinamento foi de $50 \mathrm{lb} / \mathrm{in}^{2}\left(351,5 \mathrm{kN} / \mathrm{m}^{2}\right)$, quatro vezes menor que o utilizado aqui para o Eucalyptus citriodora. 


\section{6. - CONCLUSÕES.}

O extraordinário desenvolvimento das aplicações da madeira em pontes nos anos recentes deveu-se ao estabelecimento de estruturas-protótipo, instrumentação sistemática em laboratório e em campo, incentivo governamental em apoio a Instituições de Pesquisa e Desenvolvimento, e recuperação dos sistemas viários. As estruturas de madeira laminada transversalmente protendidas, desenvolvidas em Ontário, Canadá, têm sido construídas apenas em países do porte do Brasil, com grande demanda de pontes confiáveis em sistemas viários muito extensos, como os eixos rodoviários do Canadá (na Trans-Canada Highway) e da Austrália (EastWestern Roadway).

O aproveitamento tecnológico das madeiras disponiveis demanda o conhecimento do comportamento estrutural para os sistemas propostos. Neste aspecto, os ensaios de placa em Laboratório oferecem subsidios importantes para a confecção, fabricação e instalação das placas protendidas. $O$ uso dos parâmetros de ensaio no projeto e na avaliação de desempenho está intimamente relacionado com a instrumentação contínua e a longo prazo de estruturas-protótipo.

A grande capacidade resistente da placa de madeira laminada protendida faz com que o conjunto seja viável economicamente, para sua implantação em sistemas viários que têm cargas elevadas. A título de comparação, uma ponte de postes de Eucalipto citriodora, com $8 \mathrm{~m}$ de våo e $10 \mathrm{~m}$ de largura e tabuleiro de postes roliços, sistema Hellmeister, utiliza $31,36 \mathrm{~m}^{3}$ de madeira para vigas e tabuleiro, classe 36. [LOGSDON, 1982]. 
Para o mesmo vão, o sistema laminado protendido usa $20,4 \mathrm{~m}^{3}$ de madeira, classe 45 , e tem apenas o tabuleiro, sendo de construção muito mais simples conforme indicado nas pranchas do ANEXO A, propiciando maior rapidez de construção.

Os parâmetros necessários para o cálculo com a espécie Eucalyptus citriodora já foram determinados no Capitulo 5. A metodologia de cálculo (O.H.B.D.C.) foi apresentada no Capitulo 4. Assim, até que se desenvolva uma Norma Técnica nacional, este procedimento é o recomendado. Além disso, recomenda-se obedecer os procedimentos de protensão e retensionamento indicados pela Especificação TB 622 (ANEXO A) até que se levante experimentalmente (em campo) o comportamento estrutural em serviço das pontes de Eucalipto citriodora laminadas protendidas.

Na continuação desta pesquisa, devem ser investigados:

1. Pisos para as pontes de madeira - compatibilidade entre os revestimentos, tratamentos e a madeira utilizada, no Brasil.

2. Padronização e industrialização - produção industrializada, desde o corte de origem, beneficiamento, tratamento preservativo, estabilização química, montagem, instalação.

3. Critérios de projeto, visando a aplicação de espécies já conhecidamente promissoras, acabamentos, tratamentos, com durabilidade desejada.

4. Critérios de cálculo, facilitando a disseminação de conhecimento através da edição de Normas Técnicas e Manuais de Produto, desenvolvendo o setor produtivo dentro das filosofias de qualidade total (ISO 9000), atendendo a legislação ambiental e a demanda por pontes no País. 
5. Compatibilizar estruturas pré-montadas com vãos e classes de via, para um atendimento sistemático d̀ construção de pontes de madeira.

6. Diversificar os sistemas construtivos, anexando à sistemática de trabalho em pontes de madeira, o uso de madeira laminada colada, muito incipiente no Brasil. Esta medida vai incorporar 0 uso de chapas e painéis industrializados e propiciar a construção das pontes de madeira em vãos médios e grandes.

7. Coleta de dados sobre cargas reais, estáticas e dinâmicas, das estruturas, através de instrumentação, em campo, de estruturas construídas.

8. Avaliação do desempenho estrutural com os três tipos de tratamentos preservativos existentes no Brasil (CCB, CCA, Creosoto).

9. Construção de um protótipo, em local a ser definido, para avaliação do desempenho em serviço destas estruturas. 